NUREG/CR-6135

SAND93-2371

\title{
Uncertainty and Sensitivity Analysis of Early Exposure Results with the MACCS Reactor Accident Consequence Model
}

Manuscript Completed: November 1994

Date Published: January 1995

Prepared by

J. C. Helton, ${ }^{1}$ J. D. Johnson, ${ }^{2}$ M. D. McKay, ${ }^{3}$ A. W. Shiver, J. L. Sprung

Sandia National Laboratories

Albuquerque, NM 87185

Prepared for

Division of Systems Technology

Office of Nuclear Regulatory Research

U.S. Nuclear Regulatory Commission

Washington, DC 20555-0001

NRC Job Code L2294

${ }^{1}$ Arizona State University, Tempe, AZ 85287

${ }^{2}$ GRAM, Inc., Albuquerque, NM 87112

${ }^{3}$ Los Alamos National Laboratory, Los Alamos, NM 87545 
.

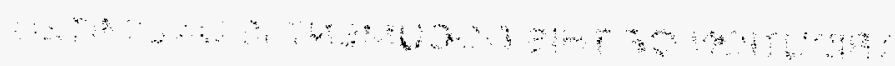
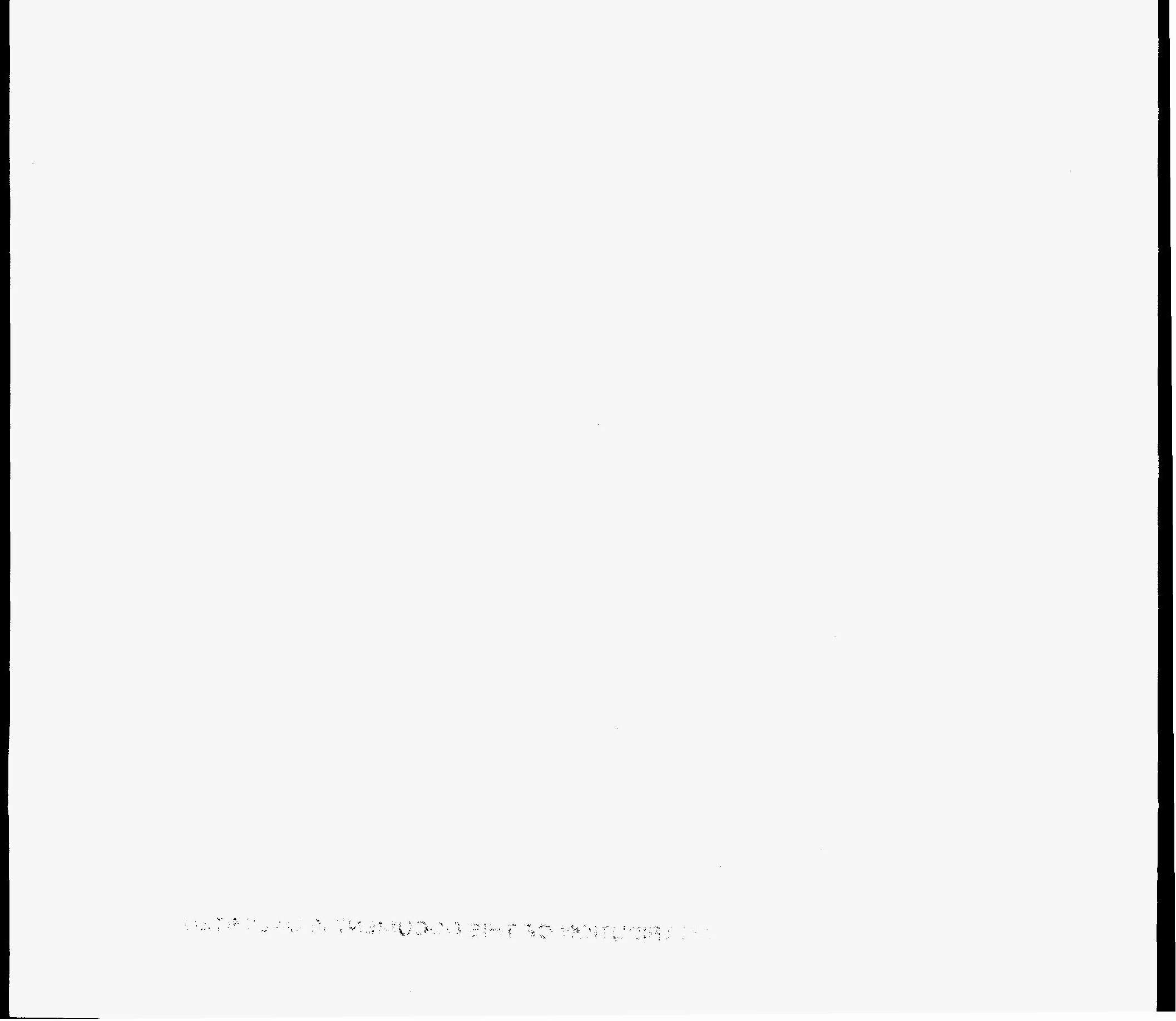


\section{DISCLAIMER}

This report was prepared as an account of work sponsored by an agency of the United States Government. Neither the United States Government nor any agency thereof, nor any of their employees, make any warranty, express or implied, or assumes any legal liability or responsibility for the accuracy, completeness, or usefulness of any information, apparatus, product, or process disclosed, or represents that its use would not infringe privately owned rights. Reference herein to any specific commercial product, process, or service by trade name, trademark, manufacturer, or otherwise does not necessarily constitute or imply its endorsement, recommendation, or favoring by the United States Government or any agency thereof. The views and opinions of authors expressed herein do not necessarily state or reflect those of the United States Government or any agency thereof. 


\section{DISCLAIMER}

Portions of this document may be illegible in electronic image products. Images are produced from the best available original document. 


\begin{abstract}
Uncertainty and sensitivity analysis techniques based on Latin hypercube sampling, partial correlation analysis and stepwise regression analysis are used in an investigation with the MACCS model of the early health effects associated with a severe accident at a nuclear power station. The primary purpose of this study is to provide guidance on the variables to be considered in future review work to reduce the uncertainty in the important variables used in the calculation of reactor accident consequences. The effects of 34 imprecisely known input variables on the following reactor accident consequences are studied: number of early fatalities, number of cases of prodromal vomiting, population dose within 10 $\mathrm{mi}$ of the reactor, population dose within $1000 \mathrm{mi}$ of the reactor, individual early fatality probability within $1 \mathrm{mi}$ of the reactor, and maximum early fatality distance. When the predicted variables are considered collectively, the following input variables were found to be the dominant contributors to uncertainty: scaling factor for horizontal dispersion, dry deposition velocity, inhalation protection factor for nonevacuees, groundshine shielding factor for nonevacuees, early fatality hazard function alpha value for bone marrow exposure, and scaling factor for vertical dispersion. The following results were obtained in tests to check the robustness of the analysis techniques that produced the preceding set of variables: two independent Latin hypercube samples produced similar uncertainty and sensitivity analysis results; setting important variables to best-estimate values produced substantial reductions in uncertainty, while setting the less important variables to best-estimate values had little effect on uncertainty; similar sensitivity analysis results were obtained when the original uniform and loguniform distributions assigned to the 34 imprecisely known input variables were changed to left-triangular distributions and then to righttriangular distributions; and analyses with rank-transformed and logarithmically transformed data produced similar results and substantially outperformed analyses with raw (i.e., untransformed) data.
\end{abstract}




\section{Contents}

$\underline{\text { Section }} \quad$ Page

Abstract $\ldots \ldots \ldots \ldots \ldots \ldots \ldots \ldots \ldots \ldots \ldots \ldots \ldots \ldots \ldots \ldots \ldots \ldots \ldots \ldots$

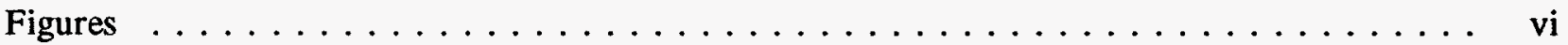

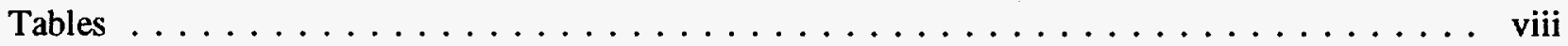

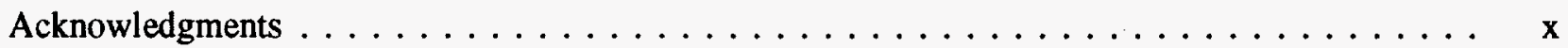

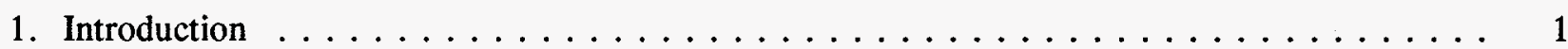

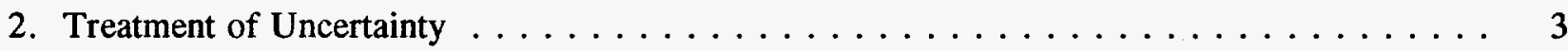

3. Overview of MACCS $\ldots \ldots \ldots \ldots \ldots \ldots \ldots \ldots \ldots \ldots$

3.1 Treatment of Stochastic Uncertainty . . . . . . . . . . . . . . 10

3.2 Calculation of Consequences $\ldots \ldots \ldots \ldots \ldots \ldots \ldots \ldots$

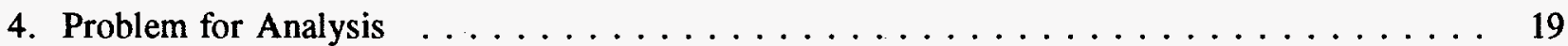

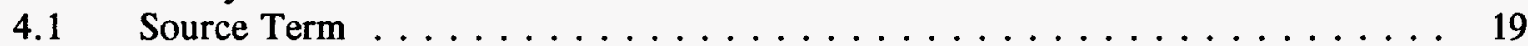

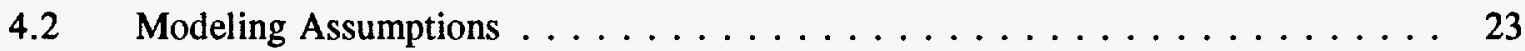

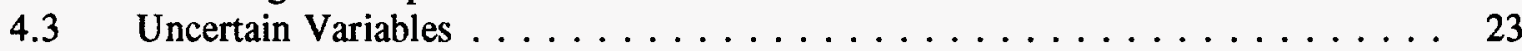

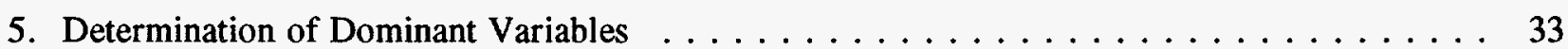

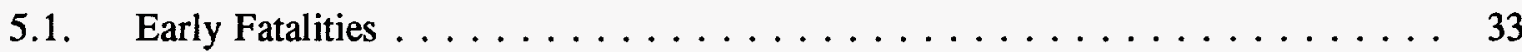

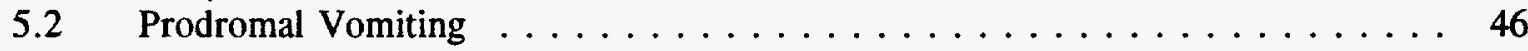

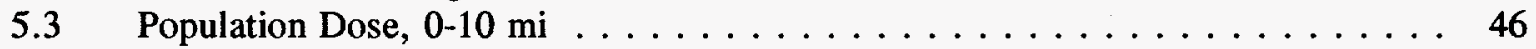

5.4 Population Dose, $0-1000 \mathrm{mi} \ldots \ldots \ldots \ldots \ldots \ldots$

5.5 Individual Early Fatality Probability, $0-1 \mathrm{mi} \ldots \ldots \ldots \ldots$

5.6 Maximum Early Fatality Distance $\ldots \ldots \ldots \ldots \ldots \ldots$

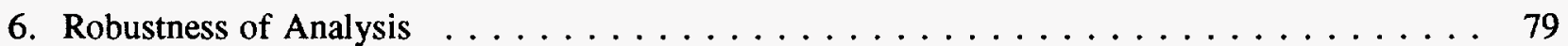

$6.1 \quad$ Results Obtained with Second Independent Sample . . . . . . . . . . . . . . 79

6.2 Important Variables Fixed at Best-Estimate Values . . . . . . . . . . . . . . 82

6.3 Important Variables Fixed at Different Best-Estimate Values . . . . . . . . . . 96

6.4 Effect of Different Distributions on Sensitivity Analysis Results _ . . . . . . . 97

6.5 Effect of Logarithmic Transformations . . . . . . . . . . . . . . 112

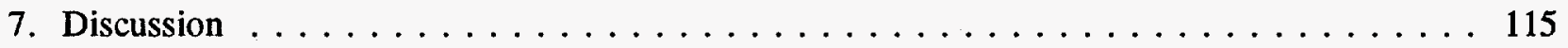

References $\ldots \ldots \ldots \ldots \ldots \ldots \ldots \ldots \ldots \ldots \ldots \ldots \ldots \ldots \ldots \ldots \ldots$ 


\section{Figures}

Figure

1. Estimated CCDF for Consequence Result $c S \ldots \ldots \ldots \ldots \ldots \ldots \ldots$

2. Example of Distribution of CCDFs as a Result of Subjective Uncertainty . . . . . . . . . 6

3. Construction of Scenarios for Consequence Calculations $\ldots \ldots \ldots \ldots \ldots \ldots \ldots$

4. Distribution of Nonzero Early and Chronic Health Effect Weights for Internally Initiated

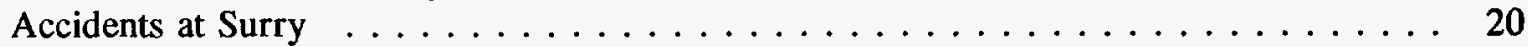

5. Distribution of Source Terms with Nonzero Early Health Effect and Chronic Health Effect Weights for Internally Initiated Accidents at Surry $\ldots \ldots \ldots \ldots \ldots \ldots \ldots \ldots$

6. Distribution of Source Terms with Nonzero Early Health Effect and Chronic Health Weights for Internally Initiated Accidents at Surry after Partitioning $\ldots \ldots \ldots \ldots \ldots \ldots$

7. Mean and Percentile Curves for Number of Early Fatalities . . . . . . . . . . . . 34

8. Partial Rank Correlation Coefficients for Probability that Specified Numbers of Early



9. Distribution of Mean Number of Early Fatalities . . . . . . . . . . . . . . 40

10. Mean and Percentile Curves for Number of Cases of Prodromal Vomiting . . . . . . . . . 47

11. Partial Rank Correlation Coefficients for Probability that Specified Numbers of Prodromal Vomiting Cases Will Be Exceeded . . . . . . . . . . . . . . . . . 48

12. Distribution of Mean Number of Cases of Prodromal Vomiting . . . . . . . . . . . . . 49

13. Mean and Percentile Curves for Population Dose (Sv) for Individuals Initially within $10 \mathrm{mi}$

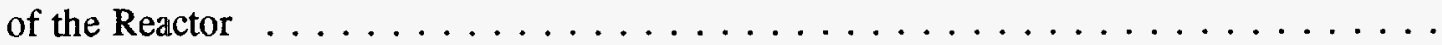

14. Partial Rank Correlation Coefficients for Probability that Specified Doses (Sv) to the Population Initially within $10 \mathrm{mi}$ of the Reactor Will Be Exceeded . . . . . . . . . .

15. Distribution of Mean Population Dose (Sv) for Individuals Initially Within $10 \mathrm{mi}$ of the

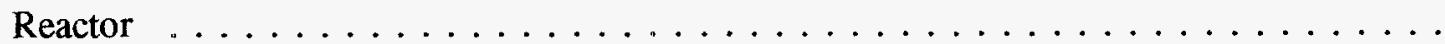

16. Mean and Percentile Curves for Population Dose (Sv) for Individuals Within $1000 \mathrm{mi}$ of the

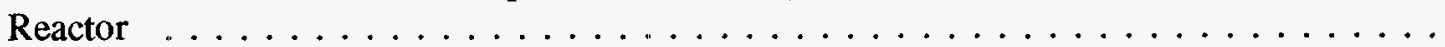

17. Partial Rank Correlation Coefficients for Probability that Specified Doses (Sv) to the Population Within $1000 \mathrm{mi}$ of the Reactor Will Be Exceeded . . . . . . . . . . . . .

18. Distribution of Mean Population Dose (Sv) for Individuals Within $1000 \mathrm{mi}$ of the Reactor . .

19. Mean and Percentile Curves for Probability that an Individual Within $1 \mathrm{mi}$ of the Reactor Will Become an Early Fatality . . . . . . . . . . . . . . . . .

20. Partial Rank Correlation Coefficients for Probability that Specified Individual Risk Values (i.e., probability that an individual within $1 \mathrm{mi}$ of the reactor will be an early fatality)



21. Distribution of Mean Individual Early Fatality Probability for Individuals Living Within 1

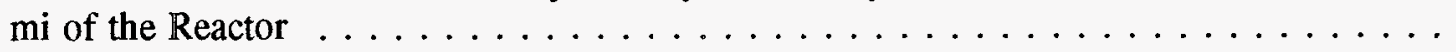

22. Mean and Percentile Curves for Maximum Early Fatality Distance $(\mathrm{km})$ with No

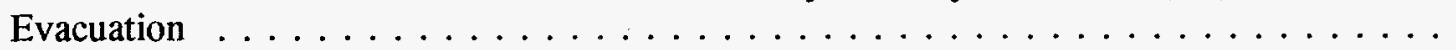

23. Partial Rank Correlation Coefficients for Probability that Specified Maximum Early Fatality Distances (km) with No Evacuation Will Be Exceeded . . . . . . . . . . . .

24. Distribution of Mean Value for Maximum Early Fatality Distance $(\mathrm{km})$ with No

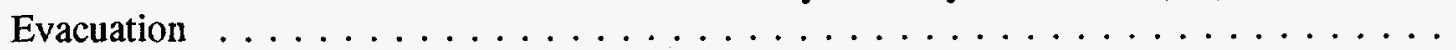

25. Comparison of Mean and Percentile Curves for Early Fatalities Obtained with Two Independent Latin Hypercube Samples $\ldots \ldots \ldots \ldots \ldots \ldots \ldots$

26. Comparison of PRCCs Obtained with Two Independent Latin Hypercube Samples . . . . . 81 
27. Comparison of Cumulative Distribution Functions and Mean Values for Early Fatalities Obtained with Two Independent Latin Hypercube Samples . . . . . . . . . . . . . .

28. Mean and Percentile Curves for Number of Early Fatalities with Variables Listed in Table 21 Fixed at Best-Estimate Values . . . . . . . . . . . . . . . . .

29. Distribution of Mean Number of Early Fatalities with Variables Listed in Table 21 Fixed

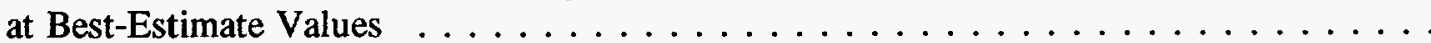

30. Partial Rank Correlation Coefficients for Probability that a Specified Number of Early Fatalities Will Be Exceeded with the Variables in Table 21 Fixed at Best Estimate Values . . . . . . . . . . . . . . . . . . . . . . . . .

31. Three Sets of CCDFs for Number of Early Fatalities with Variable Evacuation with Variables in Table 21 Set to Different Best-Estimate Values . . . . . . . . . . . . . .

32. Median CCDFs for Number of Early Fatalities with Variable Evacuation for 20 Sets of CCDFs with Variables in Table 21 Set to Different Best-Estimate Values . . . . . . .

33. Mean and Percentile Curves for Number of Early Fatalities with Variable Evacuation for Variables Not Contained in Table 21 Set to Five Different Sets of Best-Estimate Values . . . . . . . . . . . . . . . . . . . . . .

34. Mean and Percentile Curves for Number of Early Fatalities with Variable Evacuation for Left-Triangular Distributions (left frame) and Right-Triangular Distributions (right frame) Assigned to the Variables in Table $5 \ldots \ldots \ldots \ldots \ldots \ldots \ldots$

35. Box Plots for Mean Number of Early Fatalities for Left-Triangular Distributions, Original Distributions and Right-Triangular Distributions Assigned to the Variables in Table 5 


\section{Tables}

Table

1. Weather Bin Descriptions $\ldots \ldots \ldots \ldots \ldots \ldots \ldots \ldots \ldots \ldots \ldots \ldots$

2. Mean Source Terms Associated with Source Term Group SUR-11 for Internally Initiated

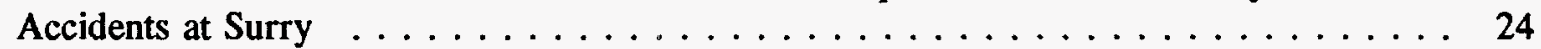

3. Overview of Modeling Assumptions $\ldots \ldots \ldots \ldots \ldots \ldots \ldots \ldots \ldots \ldots \ldots \ldots$

4. Imprecisely Known Variables Selected for Inclusion in Uncertainty/Sensitivity Study for

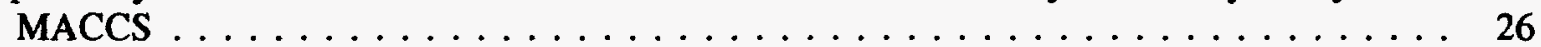

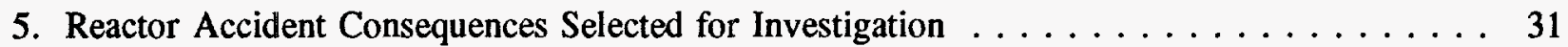

6. Stepwise Regression Analysis with Raw (i.e., untransformed) Data for Mean Number of Early Fatalities . . . . . . . . . . . . . . . . . . . 41

7. Stepwise Regression Analysis with Rank-Transformed Data for Mean Number of Early



8. Comparison of Variable Selection for Number of Early Fatalities in Partial Correlation Analysis in Figure 8 and Stepwise Regression Analysis in Table $7 \ldots \ldots \ldots . . .45$

9. Stepwise Regression Analyses with Rank-Transformed Data for Mean Number of Cases of

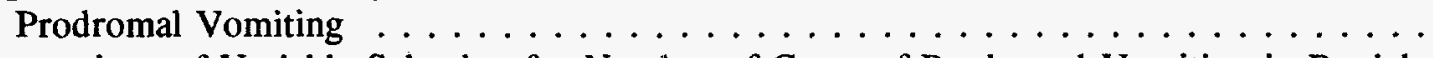

10. Comparison of Variable Selection for Number of Cases of Prodromal Vomiting in Partial Correlation Analysis in Figure 11 and Stepwise Regression Analysis in Table 9 . . . . 51

11. Stepwise Regression Analyses with Rank-Transformed Data for Mean Population Dose (Sv),



12. Comparison of Variable Selection for Population Dose (Sv) to Individuals Initially Within $10 \mathrm{mi}$ of the Reactor in Partial Correlation Analysis in Figure 14 and Stepwise Regression Analysis in Table $11 \ldots \ldots \ldots \ldots \ldots \ldots \ldots$

13. Stepwise Regression Analyses with Rank-Transformed Data for Mean Population Dose (Sv),

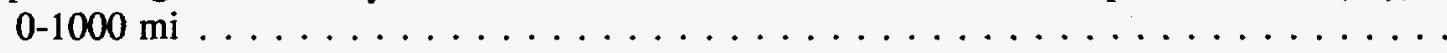

14. Comparison of Variable Selection for Population Dose (Sv) to Individuals Within $1000 \mathrm{mi}$ of the Reactor in Partial Correlation Analysis in Figure 17 and Stepwise Regression Analysis in Table $13 \ldots \ldots \ldots \ldots \ldots \ldots \ldots \ldots \ldots$

15. Stepwise Regression Analyses with Rank-Transformed Data for Mean Individual Early Fatality Probability, $0-1 \mathrm{mi} \ldots \ldots \ldots \ldots \ldots \ldots \ldots$

16. Comparison of Variable Selection for Individual Early Fatality Probability, 0-1 mi, in Partial Correlation Analysis in Figure 20 and Stepwise Regression Analysis in Table $15 \ldots .$.

17. Stepwise Regression Analysis with Rank-Transformed Data for Mean Value of Maximum Early Fatality Distance $(\mathrm{km})$ With No Evacuation $\ldots \ldots \ldots \ldots \ldots \ldots$

18. Comparison of Variable Selection for Maximum Early Fatality Distance $(\mathrm{km})$ with No Evacuation in Partial Correlation Analysis in Figure 23 and Stepwise Regression Analysis

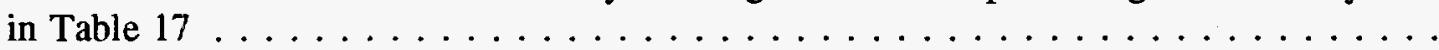

19. Comparison of Mean Values and Standard Deviations Obtained with Two Independent Latin Hypercube Samples . . . . . . . . . . . . . . . . . .

20. Comparison of Stepwise Regression Analyses with Rank-Transformed Data for Two Independent Latin Hypercube Samples for Mean Number of Early Fatalities . . . . . . . .

21. Important Input Variables Identified in Sensitivity Analyses for Early Fatalities . . . . . . .

22. Stepwise Regression Analysis with Rank-Transformed Data for Mean Number of Early Fatalities with Variables in Table 21 Set to Best-Estimate Values . . . . . . . . . .

23. Summary of Sensitivity Analysis Results Based on PRCCs and Stepwise Regression Analysis with the Variables in Table 21 Fixed at Best-Estimate Values . . . . . . . . . . . 
24. Comparison of Sensitivity Analysis Results Obtained with PRCCs for Left-Triangular Distributions, Original Distributions as Defined in Table 4 and Right-Triangular Distributions . . . . . . . . . . . . . . . . . . . . . 104

25. Comparison of Sets of Variables Identified in Sensitivity Analyses with PRCCs for LeftTriangular Distributions, Original Distributions as Defined in Table 4 and RightTriangular Distributions $\ldots \ldots \ldots \ldots \ldots \ldots$

26. Comparison of Sensitivity Analysis Results Obtained by Stepwise Regression Analysis with Rank-Transformed Data for Left-Triangular Distributions, Original Distributions as Defined in Table 4 and Right-Triangular Distributions . . . . . . . . . . . 108

27. Comparison of Sets of Variables Identified in Sensitivity Analyses Based on Stepwise Regression Analysis with Rank-Transformed Data for Left-Triangular Distributions, Original Distributions as Defined in Table 4 and Right-Triangular Distributions . . . . 110

28. Comparison of Stepwise Regression Analysis Results with Rank-Transformed Data and Logarithmically Transformed Data for Mean Number of Early Fatalities 


\section{Acknowledgments}

Recognition is extended to David Chanin of Technadyne, Inc. for his role in the development of the MACCS program and for many useful discussions involving MACCS and reactor accident consequence analysis. Review of the report was provided by Sarah Higgins and Leann Miller of Sandia National Laboratories. The support and encouragement of Jim Glynn and Christiana Lui of the U.S. Nuclear Regulatory Commission is greatly appreciated. Finally, thanks are extended to Fred Harper of Sandia National Laboratories for providing a productive environment in which to perform this analysis. 


\section{INTRODUCTION}

The U.S. Nuclear Regulatory Commission (NRC) has recently completed an assessment of the risks from five commercial nuclear power plants (NUREG-1150) in the United States: ${ }^{1}$ Surry, ${ }^{2-5}$ Peach Bottom, ${ }^{6-9}$ Sequoyah, ${ }^{10-12}$ Grand Gulf, ${ }^{13-15}$ and Zion. ${ }^{16,17}$ In response to a criticism of the Reactor Safety Study, ${ }^{18,19}$ the NUREG-1150 analysis project made an extensive effort to incorporate and present the effects of uncertainty in the analyses performed for these plants. The NUREG-1150 probabilistic risk assessments consisted of four analysis components: systems analysis, accident progression analysis, source term analysis and consequence analysis. ${ }^{20-23}$ The effect of uncertainties on the first three analysis components was assessed and incorporated into the final risk results. This assessment made extensive use of expert review ${ }^{24,25}$ and is documented in a sequence of reports. ${ }^{26-32}$

The NUREG-1150 probabilistic risk assessments used the MACCS computer model ${ }^{33-35}$ to calculate the off-site consequences of reactor accidents. Although a tentative attempt to assess the uncertainties in the input required by MACCS was made, ${ }^{36}$ these uncertainties were not incorporated into the NUREG-1150 analyses. This has led to questions involving the extent to which the results obtained in NUREG-1150 might be altered by the incorporation of the uncertainty associated with consequence modeling. ${ }^{37-39}$ However, considerable interest in the United States in uncertainty in consequence modeling predates the NUREG-1150 analyses. ${ }^{40-44}$ There has long been a similar interest in Europe. For example, both England ${ }^{45-47}$ and Germany ${ }^{48-54}$ have had active programs in this area. Much of this European effort has centered on the MARC ${ }^{55}$ and UFOMOD ${ }^{56,57}$ models for assessing the consequences of reactor accidents. In turn, MARC and UFOMOD are the precursors of the new European model for reactor accident consequences, COSYMA. ${ }^{58,59}$

This extensive interest in assessing the uncertainties in predictions made by reactor accident consequence models has led to a joint project involving the Commission of European Communities (CEC) and the NRC which has the following objectives: (1) to formulate a generic, state-of-the-art methodology for uncertainty estimation that will find broad acceptance, (2) to use the methodology to estimate the uncertainties associated with the predictions of reactor accident consequence models, and (3) to better quantify and obtain more valid estimates of the uncertainties associated with reactor accident consequence models, thus enabling more informed and better judgments to be made in the areas of risk comparison and acceptability. ${ }^{6}$

An important part of this project will be the use of an expert review process to assess the uncertainties in variables used as input to reactor accident consequence models. Such reviews involve the participation of many individuals, require extensive organization, and as a result, are expensive. ${ }^{24,25,61}$ For the preceding reasons, the number of variables that can be subjected to a formal expert review process is limited and is certainly substantially less than the several hundred variables that comprise the complete input to a reactor accident consequence model. As a result, the variables selected for a formal review must be carefully chosen so that limited resources (i.e., time, people, money) can be directed at the largest contributions to the uncertainty in the predictions made by a reactor accident consequence model.

In preparation for its participation in this project, the NRC is supporting a sequence of uncertainty/sensitivity studies with the MACCS reactor accident consequence model (Version 1.5.11.1) to identify the input variables that have the greatest impact on uncertainty in predicted consequences. These variables will then be candidates for formal review in the joint $\mathrm{CEC} / \mathrm{NRC}$ project. This report describes an uncertainty/sensitivity study conducted for early exposure results (i.e., for fatalities, injuries, and doses caused by radiation exposure incurred within 7 days of a reactor accident) performed for the NRC with the MACCS model as part of this preparation. 
Introduction

THIS PAGE INTENTIONALLY LEFT BLANK 


\section{TREATMENT OF UNCERTAINTY}

An uncertainty/sensitivity study for a reactor accident consequence model such as MACCS actually involves two types of uncertainty: stochastic uncertainty and subjective uncertainty. Stochastic uncertainty results when the system under study can behave in many different ways (e.g., many different types of weather are possible at the time of a reactor accident). Subjective uncertainty results from the existing state of knowledge with respect to the correctness of the assumptions used in an analysis (e.g., what is the appropriate dry deposition velocity to use for a particular combination of release characteristics and weather). Thus, stochastic uncertainty is a property of the system under study, and subjective uncertainty is a property of the analysts performing the study. The importance of maintaining a distinction between these two types of uncertainty has been emphasized by several authors. ${ }^{62-68}$

The ordered triple representation for risk proposed by Kaplan and Garrick ${ }^{68}$ provides a useful conceptual model for maintaining this distinction. In this representation, risk is expressed as a set $\mathbf{R}$ of ordered triples of the form

$$
\mathbf{R}=\left\{\left(\mathbf{S}_{i}, p S_{i}, c S_{i}\right) i=1,2, \ldots, n S\right\}
$$

where

$$
\begin{aligned}
\mathbf{S}_{i} & =\text { a set of similar occurrences (i.e., a scenario) } \\
p S_{i} & =\text { probability (or frequency, as appropriate) for } \mathbf{S}_{i} \\
c S_{i} & =\text { vector of consequences associated with } \mathbf{S}_{i} \\
n S & =\text { number of sets selected for consideration, }
\end{aligned}
$$

and the sets $\mathbf{S}_{i}$ have no occurrences in common (i.e., the $\mathbf{S}_{i}$ are disjoint). This representation formally decomposes risk into what can happen (the $S_{i}$ ), how likely things are to happen (the $p S_{i}$ ), and the consequences of what can happen (the $c S_{i}$ ).

Unless $n S$ is small, the set $\mathbf{R}$ is difficult to examine. As a result, the information contained in the $p S_{i}$ and $c S_{i}$ is usually summarized as complementary cumulative distribution functions (CCDFs). With the assumption that a particular consequence result $c S$ in the vector $c S$ has been ordered so $c S_{i} \leq c S_{i+1}$ for $i=1,2, \ldots, n S-1$, the associated CCDF is defined as shown in Figure 1 and presents the probability of exceeding individual consequence values. Thus, a CCDF answers the question "How likely is it to be this bad or worse?" Technically, a CCDF of the form shown in Figure 1 displays the probability of exceeding a quantity rather than the probability of equaling or exceeding a quantity. However, in the limit as the vertical and horizontal stepsizes go to zero, a CCDF does indeed answer the indicated question.

The sets $\mathbf{S}_{i}$ and their associated probabilities $p S_{i}$ in Eq. (1) are summarizing stochastic uncertainty. In a properly constructed analysis, the set $\cup_{i} \mathbf{S}_{i}$ should contain all possible occurrences of interest. For an analysis with a reactor accident consequence model such as MACCS, $\cup_{i} \mathbf{S}_{i}$ might contain all possible weather sequences that could be associated with a reactor accident at the particular site under consideration. If the information needed to determine the $S_{i}, p S_{i}$, and $c S_{i}$ appearing in Eq. (1) were known with complete certainty, there would be no subjective uncertainty and the expression in Eq. (1) would provide a complete representation for the possible states of the system under consideration (subject, of course, to the inevitable aggregation error that results when an infinite number of possible conditions must be divided into a finite number of sets $S_{1}, S_{2}, \ldots, S_{n s}$ ). 


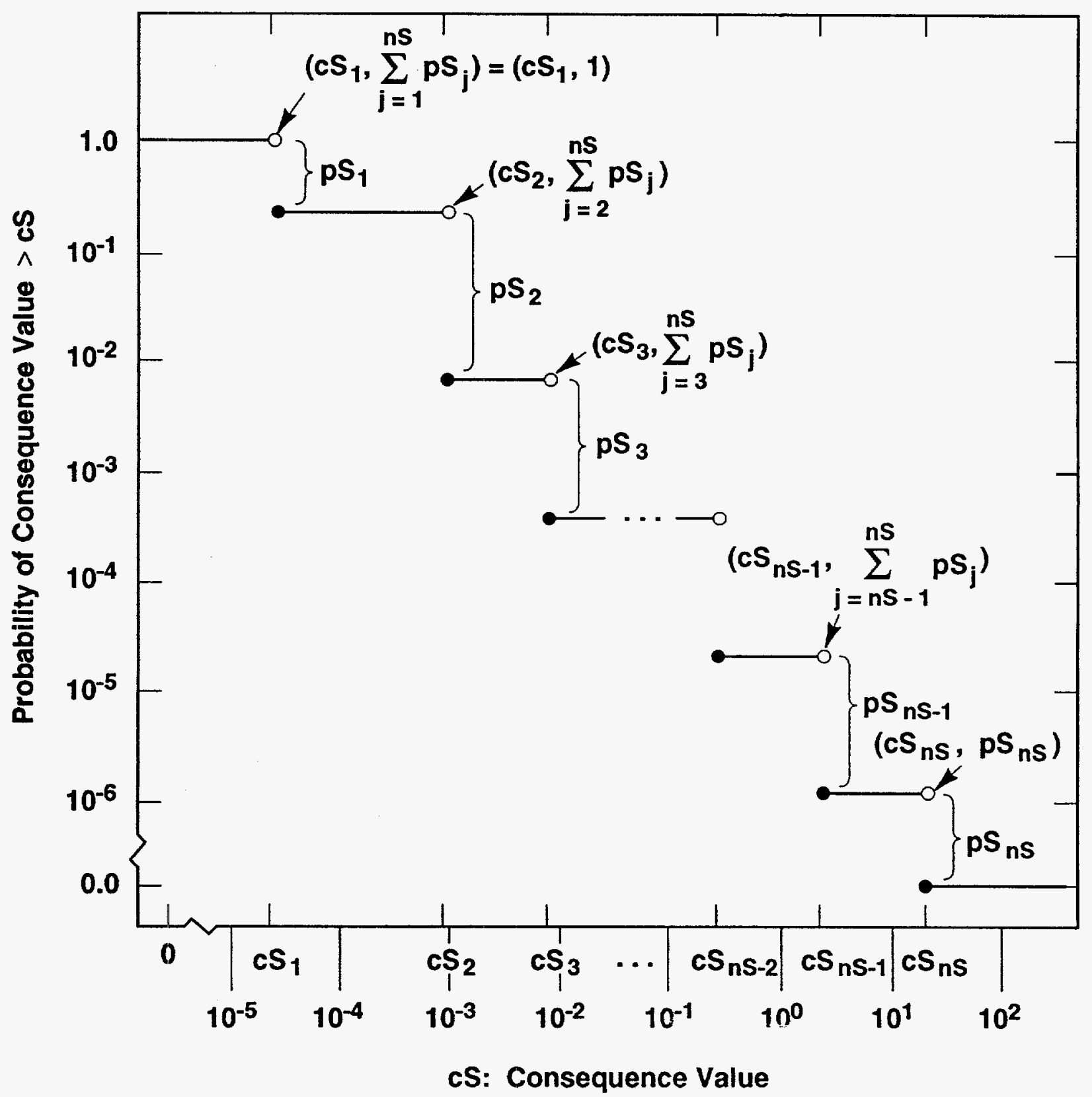

Figure 1. Estimated CCDF for Consequence Result aS (Ref. 71, Figure V1-1). 
Subjective uncertainty enters when the computational reality of evaluating the risk representation in Eq. (1) must be addressed. In practice, evaluation of the expression in Eq. (1) requires extensive computation and, in turn, this computation requires many inputs. If these inputs are represented by a vector

$$
\boldsymbol{x}=\left[x_{1}, x_{2}, \ldots, x_{n v}\right]
$$

where $n V$ is the number of such inputs, the representation in Eq. (1) becomes

$$
\mathbf{R}(\boldsymbol{x})=\left\{\left[\mathbf{S}_{i}(\boldsymbol{x}), p S_{i}(\boldsymbol{x}), c S_{i}(\boldsymbol{x})\right], i=1,2, \ldots, n S(x)\right\}
$$

If the vector $x$ was known with complete certainty, then the expression in Eq. (3) could be evaluated and presented as the unambiguous outcome of the analysis. However, $\boldsymbol{x}$ is not known with certainty in most analyses.

The uncertainty in $\boldsymbol{x}$ is characterized by developing a distribution

$$
D_{j}, j=1,2, \ldots, n V
$$

for each variable $x_{j}$ in $x$. These distributions describe a degree of belief as to where the appropriate value for $x_{j}$ is located given that the analysis has been structured so that only a single value of each variable $x_{j}$ is required in the determination of the set $\mathbf{R}(x)$. Correlations and other restrictions between the $x_{j}$ are also possible, which is equivalent to the specification of a joint probability distribution for the variables contained in $\boldsymbol{x}$. The distributions developed for the $x_{j}$ are characterizing subjective uncertainty as they indicate the possible locations of fixed, but unknown, quantities.

Uncertainty in $x$ results in uncertainty in the set $\mathbf{R}(\boldsymbol{x})$ shown in Eq. (3). Ultimately, this leads to a distribution of CCDFs for each consequence result of interest as illustrated in Figure 2 rather than a single CCDF as shown in Figure 1. In a suitably designed analysis, the individual CCDFs in Figure 2 show the effects of stochastic uncertainty, and the distribution of CCDFs shows the effects of subjective uncertainty.

The analyses contained in this presentation attempt to maintain a separation between stochastic and subjective uncertainty. As discussed in Section 3, stochastic uncertainty enters into the analysis through the different weather conditions that could exist at the time of an accident. The risk representation shown in Eq. (1) is actually implemented within MACCS. There, logic based on a simple event tree is used to divide all possible 5-day weather sequences that could occur over the course of one year into the sets $S_{i}$ and to determine the probabilities $p S_{i}$ for these sets. Then, a vector of consequences $c S_{i}$ is calculated for each set $S_{i}$. The analysis results for the individual consequence measures contained in $c S$ can be summarized with CCDFs of the form shown in Figure 1. Conceptually, this is equivalent to the development and implementation of an importance-sampling procedure (i.e., experimental design) to ensure the inclusion of different types of weather in the calculation [Ref. 69, Section 5.4]. In this and other similar analyses, importance sampling is often used to ensure the inclusion of low-probability, highconsequence conditions. 


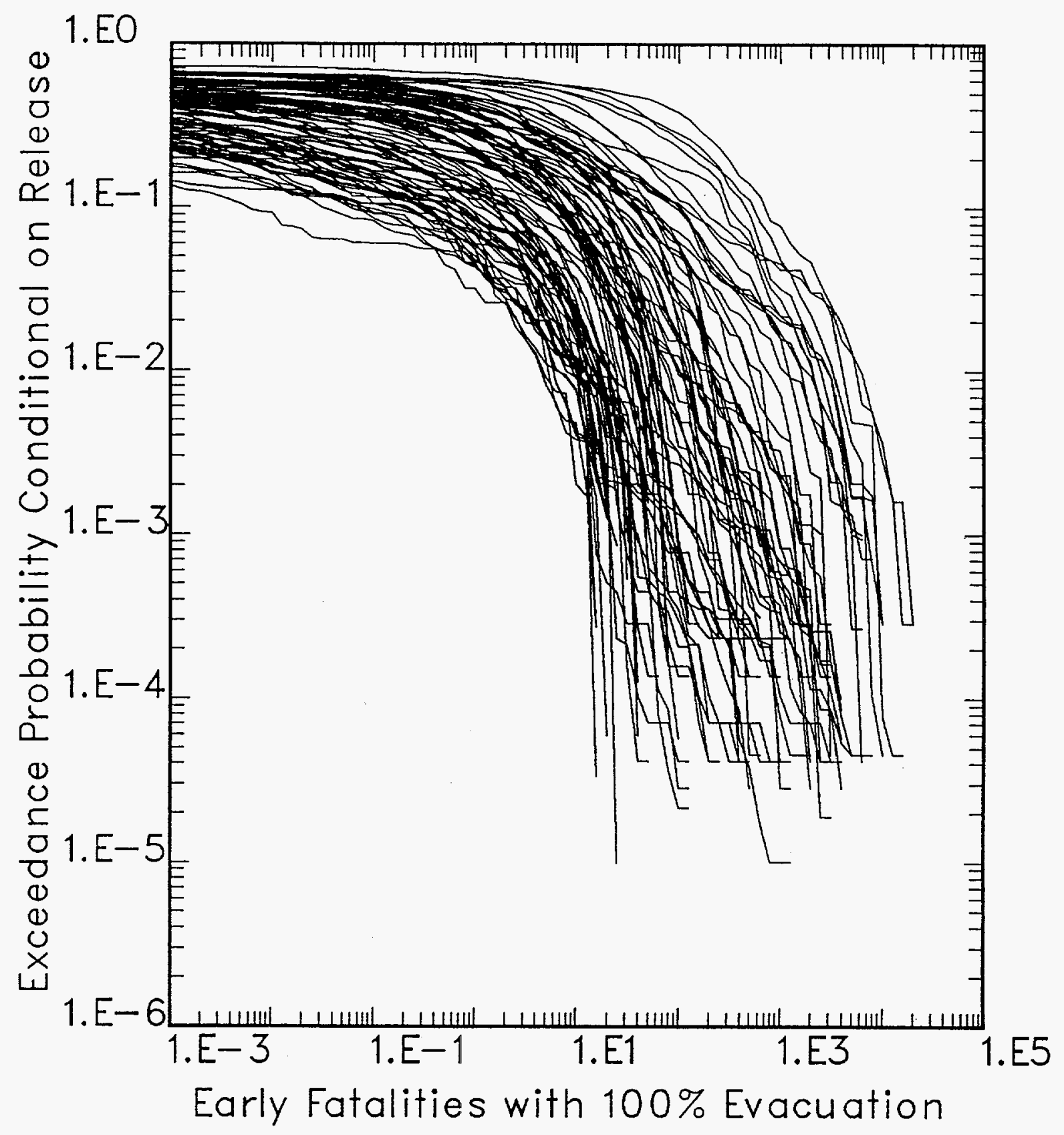

Figure 2. Example of Distribution of CCDFs as a Result of Subjective Uncertainty. Each CCDF shown in this figure results from one of the sets $R\left(x_{j}\right)$ shown in Eq. (3). 
Subjective uncertainty enters into the analysis through the uncertainty in the appropriate values for various inputs required by MACCS. As discussed in Section 4, distributions were developed for a number of the input variables required by MACCS. These distributions characterize subjective uncertainty. As already discussed and illustrated in Figure 2, the uncertainty characterized by these distributions will ultimately lead to distributions of CCDFs. The development of distributions of CCDFs of the form shown in Figure 2 will also require a sampling procedure. However, unlike the importancesampling procedure used for coverage of stochastic uncertainty, a random or Monte Carlo sampling procedure will be used. More specifically, Latin hypercube sampling ${ }^{70}$ will be used because of the efficient manner in which it stratifies across the range of each imprecisely known variable.

The investigation of the effects of subjective uncertainty will proceed with the selection of a Latin hypercube sample

$$
x_{k}=\left[x_{1 k}, x_{2 k}, \ldots, x_{n v, k}\right], k=1,2, \ldots, n L H S,
$$

according to the distributions characterizing the subjective uncertainty in the individual elements $x_{j}$ of $x$, where $n L H S$ is the sample size. In turn, this will produce the risk results

$$
\mathbf{R}\left(\boldsymbol{x}_{k}\right)=\left\{\left[\mathbf{S}_{i}, p S_{i}, c S_{i}\left(\boldsymbol{x}_{k}\right)\right], i=1,2, \ldots, n S\right\},
$$

for $k=1,2, \ldots, n L H S$, and hence, distributions of CCDFs of the form shown in Figure 2, with a single CCDF resulting for each sample element. Although the general representation for $\mathbf{R}(x)$ in Eq. (3) shows $S_{i}, p S_{i}, c S_{i}$ and $n S$ as all being functions of $x$, in this particular study only $c S_{i}$ will be a function of $x$.

The primary purpose of the analyses contained in this presentation is to assess the impact of subjective uncertainty in individual variables on predictions made by the MACCS model. This assessment will be made by using techniques based on regression analysis and partial correlation analysis $^{71,72}$ to determine which variables dominate the uncertainty in the MACCS outcomes $\mathbf{R}\left(x_{k}\right)$ shown in Eq. (6) and associated CCDFs of the form shown in Figure 2. 
THIS PAGE INTENTIONALLY LEFT BLANK 


\section{OVERVIEW OF MACCS ${ }^{a}$}

The MACCS program ${ }^{33-35}$ estimates the following quantities for a severe reactor accident that releases a plume of radioactive materials to the atmosphere: (1) the downwind transport, dispersion, and deposition of the radioactive materials released to the atmosphere from the failed reactor containment; (2) the short- and long-term radiation doses received by exposed populations via direct (cloudshine, plume inhalation, groundshine and resuspension inhalation) and indirect (ingestion) pathways; (3) the mitigation of those doses by protective actions (evacuation, sheltering, and postaccident relocation of people; disposal of milk, meat, and crops; and decontamination, temporary interdiction or condemnation of land and buildings); (4) the early fatalities and injuries expected to occur within 1 year of the accident (early health effects) and the delayed cancer fatalities and injuries (latent health effects) expected to occur over the lifetime of the exposed individuals; and (5) the off-site costs of short-term emergency response actions (evacuation, sheltering, relocation); crop and milk disposal, and the decontamination, temporary interdiction, or condemnation of land and buildings.

To calculate the preceding quantities, MACCS requires the following information as input: (1) the inventory at accident initiation (e.g., reactor scram) of the radionuclides important for the calculation of ex-plant consequences; (2) the atmospheric source term produced by the accident (number of plume segments, sensible heat content, timing, duration and height of each plume segment, time at which off-site officials are warned that an emergency response should be initiated; and for each important radionuclide, the fraction of that radionuclide's inventory released with each plume segment); (3) meteorological data characteristic of the site region (usually 1 year of hourly wind speed, atmospheric stability and rainfall data recorded at the site or at a nearby National Weather Service station); (4) the population distribution around the reactor site (distributions are constructed from census data on a polar coordinate grid having 16 angular sectors aligned with the 16 compass directions and a number of radial intervals that extend outward to 500 miles or more); (5) emergency response assumptions for evacuation (delay time before evacuation, area evacuated, average evacuation speed and travel distance), sheltering (delay time before sheltering and area in which people take shelter), and postaccident relocation (dose criteria and relocation time), (6) long-term protective measures, such as decontamination, temporary relocation, condemnation of contaminated crops and milk, and prohibition of farming; and (7) land use (habitable land fractions, farmland fractions) and economic data (worth of crops, land, and buildings) for the region around the reactor site.

The models in MACCS are implemented in three modules: ATMOS, EARLY, and CHRONC. The ATMOS module models the atmospheric dispersion and transport of material and its deposition onto the ground. The EARLY module provides direct exposure pathways, dosimetry, mitigative actions, and health effects during the emergency phase of an accident. The CHRONC module models direct and indirect exposure pathways, dosimetry, mitigative actions, and health effects during the period that follows the emergency phase: the intermediate and long-term phases of an accident. The CHRONC module also models the economic costs associated with mitigative actions performed during the emergency, intermediate, and long-term phases. The uncertainty/sensitivity results given in this presentation involve early exposure and thus were calculated with the ATMOS and EARLY modules of MACCS.

\footnotetext{
${ }^{\mathrm{a}}$ The material presented in this section is adapted in part from Sections 1.2 and 1.3 of Ref. 34.
} 


\subsection{Treatment of Stochastic Uncertainty}

As indicated in Section 2, MACCS explicitly incorporates the stochastic uncertainty present in reactor accident consequences that derives from weather variability. For notational convenience, let $\mathbf{S}$ denote the set

$$
\begin{aligned}
& \mathbf{S}=\{x: x \text { a weather sequence that could occur at the site of the nuclear power plant under } \\
& \text { consideration }\}
\end{aligned}
$$

where a weather sequence is a possible sequence of meteorological conditions, including time of occurrence, that contains all the information needed to calculate a reactor accident consequence. The set $\mathbf{S}$ is infinite. Thus, $\mathbf{S}$ must be broken into a finite collection of subsets to facilitate the actual performance of consequence calculations.

As indicated in Figure 3, the division of $\mathbf{S}$ into subsets by MACCS, and also by its precursor CRAC2, ${ }^{73}$ is based on type of weather (i.e., weather bin), wind direction and time of year (i.e., time interval). In general, $n W B$ weather bins, $n W D$ wind directions and $n T I$ time intervals are possible. Both the NUREG-1150 analyses and the analyses contained in this presentation use the $n W B=40$ weather bins listed in Table 1. Each weather bin $\mathbf{W B} \mathbf{B}_{j}, j=1,2, \ldots, 40$, defined in Table 1 is a subset of $\mathbf{S}$, and the weather bins collectively are all inclusive in the sense that

$$
\mathbf{S}=\cup_{j} \mathbf{W B}_{j}
$$

In turn, each weather bin $\mathbf{W B}_{j}$ is further subdivided on the basis of wind direction and time interval. Wind direction and time of year are handled in MACCS by the use of $n W D=16$ wind directions of equal angular spacing (i.e.,22.5 ) and $n T T_{j}$ time intervals $\left[t_{j},{ }_{l-1}, t_{j l}\right), l=1,2, \ldots, n T I_{j}$, of equal probability for each weather bin $\mathbf{W B}_{j}$. The time intervals $\left[t_{j}, t_{-1}, t_{j l}\right)$ are defined by the relationship

$$
\operatorname{prob}\left(t_{j, 1-1} \leq t_{x}<t_{j l} \mid x \in \mathbf{W B}_{j}\right)=1 / n T_{j},
$$

where

$$
t_{x}=\text { time (measured from beginning of year) at which weather sequence } x \text { starts. }
$$

The number of wind directions (i.e., $n W D$ ) is fixed in MACCS at 16. The NUREG-1150 analyses and the analyses contained in this report used $n T I_{j}=4$ for most weather bins.

The following subsets of $\mathbf{S}$ can now be defined:

$$
\begin{gathered}
\mathbf{W D}_{k}=\left\{x: x \in \mathbf{S} \text { and the wind at the start of the sequence (i.e., at time } t_{x}\right. \text { ) } \\
\text { blows in direction } k\}
\end{gathered}
$$

and

$$
\begin{gathered}
\mathbf{T I}_{j l}=\left\{x: x \in \mathbf{S} \text { and the start of the sequence (i.e., at time } t_{x}\right) \text { is contained in the } \\
\text { time interval } \left.\left[t_{j, l-1}, t_{j l}\right)\right\} .
\end{gathered}
$$




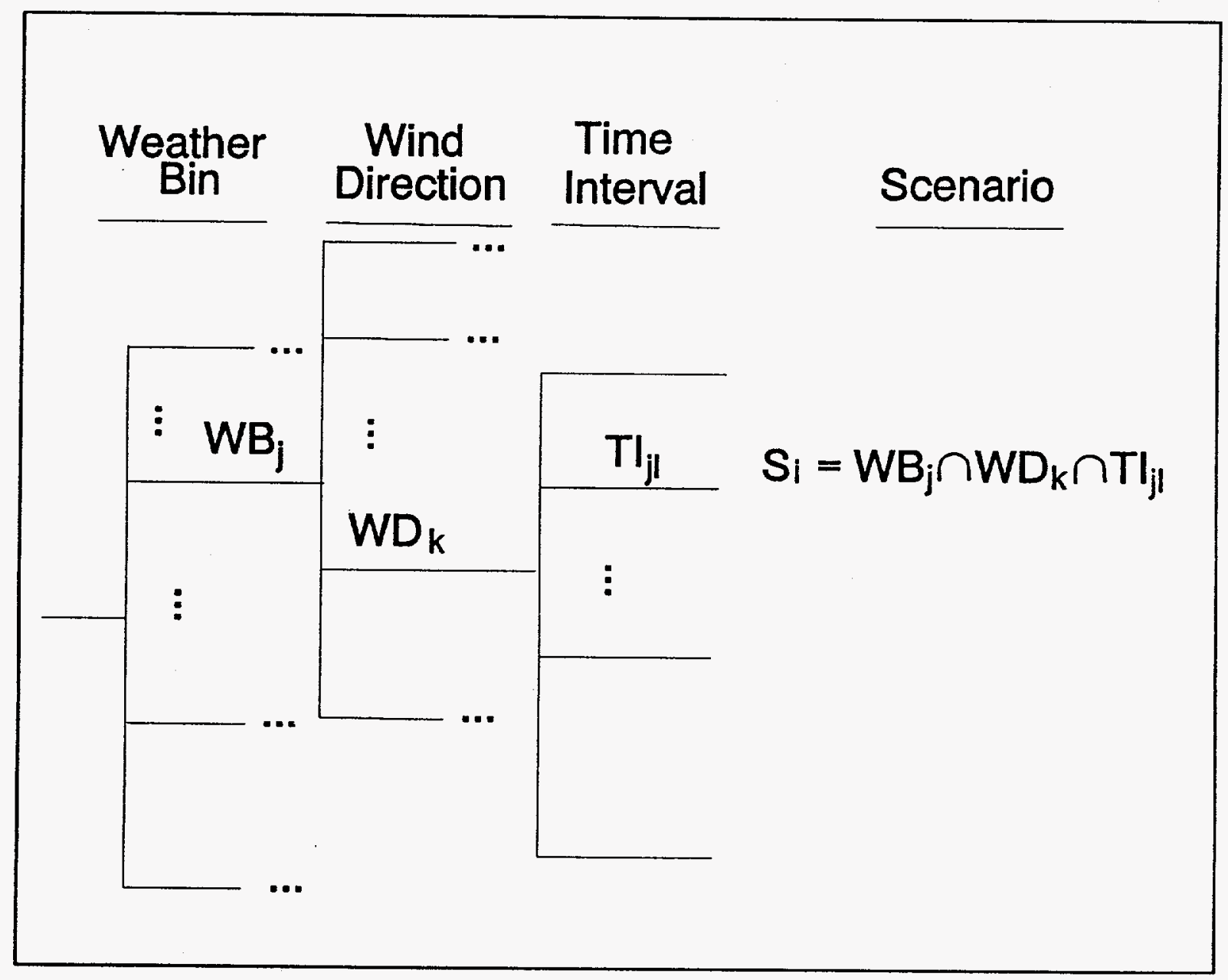

Figure 3. Construction of Scenarios for Consequence Calculations. 
Table 1. Weather Bin Descriptions

\begin{tabular}{|c|c|}
\hline BIN & DESCRIPTION OF WEATHER SEQUENCES IN BIN \\
\hline 1 & Rainfall: None. ${ }^{2}$ Initial stability class: A or B. Initial windspeed: $[0,3 \mathrm{~m} / \mathrm{s}]$. \\
\hline 2 & Rainfall: None. Initial stability class: A or B. Initial windspeed: $(3, \infty \mathrm{m} / \mathrm{s})$. \\
\hline 3 & Rainfall: None. Initial stability class: C or D. Initial windspeed: $[0,1 \mathrm{~m} / \mathrm{s}]$. \\
\hline 4 & Rainfall: None. Initial stability class: C or D. Initial windspeed: $(1,2 \mathrm{~m} / \mathrm{s}]$ \\
\hline 5 & Rainfall: None. Initial stability class: C or D. Initial windspeed: $(2,3 \mathrm{~m} / \mathrm{s}]$. \\
\hline 6 & Rainfall: None. Initial stability class: $C$ or D. Initial windspeed: $(3,5 \mathrm{~m} / \mathrm{s}]$. \\
\hline 7 & Rainfall: None. Initial stability class: C or D. Initial windspeed: $(5,7 \mathrm{~m} / \mathrm{s}]$ \\
\hline 8 & Rainfall: None. Initial stability class: C or D. Initial windspeed: $(7, \infty \mathrm{m} / \mathrm{s})$. \\
\hline 9 & Rainfall: None. Initial stability class: $E$. Initial windspeed: $[0,1 \mathrm{~m} / \mathrm{s}]$ \\
\hline 10 & Rainfall: None. Initial stability class: E. Initial windspeed: $(1,2 \mathrm{~m} / \mathrm{s}]$. \\
\hline 11 & Rainfall: None. Initial stability class: E. Initial windspeed: $(2,3 \mathrm{~m} / \mathrm{s}]$. \\
\hline 12 & Rainfall: None. Initial stability class: E. Initial windspeed: $(3, \infty \mathrm{m} / \mathrm{s})$. \\
\hline 13 & Rainfall: None. Initial stability class: F. Initial windspeed: $[0,1 \mathrm{~m} / \mathrm{s}]$. \\
\hline 14 & Rainfall: None. Initial stability class: F. Initial windspeed: $(1,2 \mathrm{~m} / \mathrm{s}]$. \\
\hline 15 & Rainfall: None. Initial stability class: $F$. Initial windspeed: $(2,3 \mathrm{~m} / \mathrm{s}]$. \\
\hline 16 & Rainfall: None. Initial stability class: F. Initial windspeed: $(3, \infty \mathrm{m} / \mathrm{s})$. \\
\hline 17 & Rainfall: $[0,3 \mathrm{~km}]^{b}$ Rainfall intensity: $(0,1 \mathrm{~mm} / \mathrm{h}] .^{{ }^{*}}$ \\
\hline 18 & Rainfall: $(3,6 \mathrm{~km}]$. Rainfall intensity: $(0,1 \mathrm{~mm} / \mathrm{h}]$. \\
\hline 19 & Rainfall: $(6,11 \mathrm{~km}]$. Rainfall intensity: $(0,1 \mathrm{~mm} / \mathrm{h}]$. \\
\hline 20 & Rainfall: $(11,21 \mathrm{~km}]$. Rainfall intensity: $(0,1 \mathrm{~mm} / \mathrm{h}]$. \\
\hline 21 & Rainfall: $[21,40 \mathrm{~km}]$. Rainfall intensity: $(0,1 \mathrm{~mm} / \mathrm{h}]$. \\
\hline 22 & Rainfall: $(40,80 \mathrm{~km}]$. Rainfall intensity: $(0,1 \mathrm{~mm} / \mathrm{h}]$. \\
\hline 23 & Rainfall: $(0,3 \mathrm{~km}]$. Rainfall intensity: $(1,2 \mathrm{~mm} / \mathrm{h})$ \\
\hline 24 & Rainfall: $(3,6 \mathrm{~km}]$. Rainfall intensity: $(1,2 \mathrm{~mm} / \mathrm{h}]$. \\
\hline 25 & Rainfall: $[6,11 \mathrm{~km}]$. Rainfall intensity: $(1,2 \mathrm{~mm} / \mathrm{h}]$. \\
\hline 26 & Rainfall: $(11,21 \mathrm{~km}]$. Rainfall intensity: $(1,2 \mathrm{~mm} / \mathrm{h}]$. \\
\hline 27 & Rainfall: $(21,40 \mathrm{~km}]$. Rainfall intensity: $(1,2 \mathrm{~mm} / \mathrm{h}]$. \\
\hline 28 & Rainfall: $(40,80 \mathrm{~km}]$. Rainfall intensity: $(1,2 \mathrm{~mm} / \mathrm{h}]$. \\
\hline 29 & Rainfall: $[0,3 \mathrm{~km}]$. Rainfall intensity: $(2,3 \mathrm{~mm} / \mathrm{h}]$ \\
\hline 30 & Rainfall: $(3,6 \mathrm{~km}]$. Rainfall intensity: $(2,3 \mathrm{~mm} / \mathrm{h}]$. \\
\hline 31 & Rainfall: $(6,11 \mathrm{~km}]$. Rainfall intensity: $(2,3 \mathrm{~mm} / \mathrm{h}]$ \\
\hline 32 & Rainfall: $(11,21 \mathrm{~km}]$. Rainfall intensity: $(2,3 \mathrm{~mm} / \mathrm{h}]$. \\
\hline 33 & Rainfall: $(21,40 \mathrm{~km}$. Rainfall intensity: $(2,3 \mathrm{~mm} / \mathrm{h}]$. \\
\hline 34 & Rainfall: $(40,80 \mathrm{~km}]$. Rainfall intensity: $(2,3 \mathrm{~mm} / \mathrm{h}]$. \\
\hline 35 & Rainfall: $(0,3 \mathrm{~km}]$. Rainfall intensity: $(3, \infty \mathrm{mm} / \mathrm{h})$. \\
\hline 36 & Rainfall: $[3,6 \mathrm{~km}]$. Rainfall intensity: $(3, \infty \mathrm{mm} / \mathrm{h})$ \\
\hline 37 & Rainfall: $(6,11 \mathrm{~km}]$. Rainfall intensity: $(3, \infty \mathrm{mm} / \mathrm{h})$ \\
\hline 38 & Rainfall: $(11,21 \mathrm{~km}]$. Rainfall intensity: $(3, \infty \mathrm{mm} / \mathrm{h})$. \\
\hline 39 & Rainfall: $(21,40 \mathrm{~km}]$. Rainfall intensity: $(3, \infty \mathrm{mm} / \mathrm{h})$. \\
\hline 40 & Rainfall: $(40,80 \mathrm{~km}]$. Rainfall intensity: $(3, \infty \mathrm{mm} / \mathrm{h})$. \\
\hline
\end{tabular}

aWile leading edge of plume is within $80 \mathrm{~km}$ of reactor.

'Distance interval measured from reactor in which leading edge of plume first encounters rainfall.

'Intensity of rainfall first encountered by leading edge of plume. 
Memberships in these sets are the basis for the last two questions on the event tree in Figure 3. A single path through the tree in Figure 3 defines a set $\mathbf{S}_{i}$ of the form

$$
\mathbf{S}_{i}=\mathbf{W B}_{j} \cap \mathbf{W D}_{k} \cap \mathbf{T I}_{j l}
$$

For $n W B=40, n W D=16$ and $n T I_{j}=4$, there are

$$
\mathrm{nS}=(40)(16)(4)=2560
$$

such sets. Further, the probabilities for these sets are given by

$$
p S_{i}=\operatorname{prob}\left(\mathbf{W B}_{j}\right) \operatorname{prob}\left(\mathbf{W D}_{k} \mid \mathbf{W B}_{j}\right) \operatorname{prob}\left(\mathbf{T I}_{j l} \mid \mathbf{W B}_{j} \cap \mathbf{W D}_{k}\right)
$$

As noted earlier, the representation of stochastic uncertainty due to weather variability by MACCS is consistent with the ordered triple representation for risk shown in Eq. (1). In particular, the sets $\mathbf{S}_{i}$ and probabilities $p S_{i}$ in Eqs. (13) and (15) correspond to the $S_{i}$ and $p S_{i}$ appearing in Eq. (1).

Estimates for the probabilities $p S_{i}$ appearing in Eq. (15) are obtained by MACCS from 1 year of hourly weather data obtained at or close to the reactor site under consideration. These data are used to define 8760 5-day weather sequences (i.e., one weather sequence for each hour in a year). The probability $\operatorname{prob}\left(\mathbf{W B}_{j}\right)$ for weather bin $\mathbf{W B}_{j}$ is approximated by

$$
\operatorname{prob}(W B j)=n W B j|\phi n W B w=n W B j| 8760,
$$

where

$$
\begin{aligned}
n W B_{w}= & \text { number of weather sequences (out of the } 8760 \text { ) belonging to } \\
\text { weather bin } \mathbf{W B}_{w} & \text {. }
\end{aligned}
$$

The probability $\operatorname{prob}\left(\mathbf{W D}_{k} \mid \mathbf{W B}_{j}\right)$ that wind blows in direction $k$ at the beginning of a weather sequence given the occurrence of weather bin $\mathbf{W B}_{j}$ is approximated by

$$
\operatorname{prob}\left(\mathbf{W D}_{k} \mid \mathbf{W B}_{j}\right)=n W D_{j k} / n W B_{j},
$$

where

$$
\begin{aligned}
& n W D_{j k}= \text { number of weather sequences (out of the 8760) } \\
& \text { that belong to both } \mathbf{W B}_{j} \text { and } \mathbf{W D}_{k}
\end{aligned}
$$

The probability prob $\left(\mathbf{T I}_{j l} \mid \mathbf{W B}_{j} \cap \mathbf{W D}_{k}\right)$ is approximated with the assumption that

$$
\operatorname{prob}\left(\mathbf{T I}_{j l} \mid \mathbf{W B}_{j} \cap \mathbf{W D}_{k}\right)=\operatorname{prob}\left(\mathbf{T I}_{j l} \mid \mathbf{W B}_{j}\right),
$$

with the result that

$$
\operatorname{prob}\left(\mathbf{T I}_{j l} \mid \mathbf{W B}_{j} \cap \mathbf{W D}_{k}\right)=1 / n T_{j}
$$


owing to the original definition of $\mathbf{T I}_{j l}$ given in Eq. (12). The number of time intervals $n T_{j}$ associated with weather bin $\mathbf{W B}_{j}$ is defined by

$$
n T T_{j}=\min \left\{n T=4, n W B_{j}\right\} .
$$

Further, the time intervals $\left[t_{j, l-1}, t_{j l}\right], l=1,2, \ldots, n T I_{j}$, are determined so that the equality in Eq. (21) is satisfied.

The relations in Eqs. (16), (18), and (21) lead to the approximation

$$
p S_{i}=n W D_{j k} /\left(8760 n T T_{j}\right)
$$

for the set $S_{i}$ in $E q$. (13).

As described in this section, MACCS uses the risk representation in Eq. (1) to represent the stochastic uncertainty associated with weather variability. The sets $\mathbf{S}_{i}$ and probabilities $p S_{i}$ are formally defined as shown in Eqs. (13) and (15). Further, MACCS calculates an approximation to $p S_{i}$ with the relationship shown in Eq. (23). The third element of the risk representation in Eq. (1) is the vector $c S_{i}$ of consequences (e.g., early fatalities, latent cancer fatalities, population doses, economic costs, ...) associated with each set $\mathbf{S}_{i}$. As shown in Figure 1, it is the probabilities $p S_{i}$ and the individual consequence results in $c S_{i}$ that are used to produce the CCDFs that are typically used to display the results of a reactor accident consequence analysis. The remainder of Section 3 provides an overview of the procedures used in MACCS to produce the vector $\boldsymbol{c} \boldsymbol{S}_{i}$ for each set $\boldsymbol{S}_{i}$ of weather sequences; more detailed information is available in the program documentation. ${ }^{33-35}$

\subsection{Calculation of Consequences}

The MACCS program allows a release of radioactive materials to the atmosphere to be divided into successive plume segments, which can have different compositions, release times, durations, and release heights and energies (amounts of sensible heat). Plume segment lengths are determined by the product of release duration and average wind speed during release. The initial vertical and horizontal dimensions of each plume segment are user specified. If release into a building wake occurs, then wake dimensions can be used to set the initial crosswind dimensions of the plume. If not, a point source can be specified.

A lift-off criterion (a critical wind speed that increases as plume buoyancy increases ${ }^{74}$ ) determines whether buoyant plumes are subject to plume rise. When the wind speed at release equals or exceeds the critical wind speed, plume rise is prevented. When the wind speed at release is less than the critical wind speed, plume rise is allowed, and the height to which a buoyant plume rises is determined by using equations recommended by Briggs. ${ }^{75,76}$ After release, wind speed determines the rates at which plume segments transport in the downwind direction, and wind direction at the time of release determines the direction of travel. As is done in many consequence codes, ${ }^{77,78}$ MACCS neglects wind trajectories.

During transport, dispersion of the plume in the vertical and horizontal (crosswind) directions is estimated by using an empirical straight-line Gaussian plume model. ${ }^{79}$ Dispersion rates depend on wind 
speed and atmospheric stability. Although horizontal dispersion of plume segments is unconstrained, vertical dispersion is bounded by the ground and the top of the mixing layer (as specified by seasonal mixing layer heights ${ }^{80}$ ), which are modeled as totally reflecting layers using mirror image sources. ${ }^{79}$ Since the number of reflections increases as travel times lengthen, the vertical distribution of each plume segment eventually becomes uniform and is so modeled thereafter. ${ }^{81}$

In MACCS, aerosols are removed from the plume by washout, which varies with rainfall rate, ${ }^{82}$ and by diffusion to, impaction on, and gravitational settling onto surfaces. The combined removal rate from diffusion, impaction, and settling is modeled using an empirical dry-deposition velocity. ${ }^{83}$ If the aerosol size distribution is divided into ranges, a dry deposition velocity can be specified for each range. Radioactive decay during transport is determined for the individual radionuclides but is limited to twomember decay chains. Weathering, resuspension, washoff, and radioactive decay decrease surface concentrations of radioactive materials deposited on the ground. Weathering is modeled using Gale's equation. ${ }^{84}$ Resuspension is modeled using resuspension factors ${ }^{83}$ that attempt to represent the average effect of resuspension by many processes throughout a large region.

Water bodies (rivers, the Great Lakes, oceans) are contaminated by direct deposition of radioactive materials onto their surfaces by dry and wet (washout) deposition, and by washoff of contamination previously deposited on land. Washoff is modeled as a first-order removal process that is integrated over all time after the initial deposition. ${ }^{85}$

The MACCS program divides time after accident initiation into three phases: an emergency phase, an optional intermediate phase, and a long-term phase. During the emergency phase, which can last up to 7 days, doses are reduced by evacuation, sheltering, and temporary relocation of people. During the intermediate phase, doses may be avoided by temporary relocation of people, and ground contamination can be surveyed to prepare for decontamination actions. During the long-term phase, doses are reduced by decontamination of property that is not habitable, by temporary interdiction of property that cannot be restored to habitability by decontamination alone, by condemnation of property that cannot be restored to habitability at a cost that does not exceed the worth of the property, by disposal of contaminated crops, and by banning farming on contaminated farmland.

In MACCS, people are relocated if their projected doses exceed a user-specified dose criterion (e.g., if projected 7 day exposures will exceed $0.25 \mathrm{~Sv}$, people are relocated 1 day after their exposures begin). In contrast to temporary relocation, evacuation and sheltering automatically take place within some specified region without regard to projected exposures. After a delay period that follows warning, evacuation proceeds radially at an average speed chosen to reflect site conditions. At a specified distance outside the evacuation zone, evacuees are assumed to be directed out of the path of the plume, so that further exposures are avoided. The MACCS sheltering model also assumes that there is a delay period between the time when warning is given and the time when shelter is taken. Once shelter is taken, people remain sheltered for a user-specified time, after which no additional exposure is accumulated.

At the beginning of the long-term phase, MACCS projects the doses that people would receive if no recovery actions are taken and compares these doses with the user-specified long-term protective action guides (e.g., the proposed EPA habitability criteria of no more than $0.02 \mathrm{~Sv}$ in the first year following an accident and no more than $0.005 \mathrm{~Sv}$ in any subsequent year). If the long-term dose criterion is not met, MACCS attempts to meet the criterion, first by decontamination alone and, if that is insufficient, by decontamination followed by a period of temporary interdiction to allow radionuclide 
removal by weathering and radioactive decay. However, these actions are taken only if they are costeffective (i.e., the worth of the recovered property is greater than the sum of the following recovery costs: decontamination costs, earnings from investments that are lost by temporary interdiction of property, and the cost of any repairs necessitated by lack of maintenance of property during the temporary interdiction period).

During the long-term phase, exposure is also avoided by controlling the consumption and production of contaminated foodstuffs. When the accident occurs during the growing season and thus contaminates crops and pasture by direct deposition on plant surfaces, disposal of crops and milk occurs if ground concentrations of food pathway radionuclides exceed user-specified maximum allowable ground concentrations for those nuclides or if the habitability dose criterion is exceeded for the area where the foodstuffs are grown. Farming is prohibited in subsequent years until farmland is habitable (i.e., can be worked without violating habitability criteria), and then crops are grown only if the ground concentrations of food pathway radionuclides do not exceed user-specified maximum allowable concentrations. Because deep ploughing, the most likely decontamination method for farmland, may not remove significant amounts of radioactivity from the root zone, MACCS assumes that decontamination of farmland will reduce doses to farmers from groundshine and from inhalation of resuspended radioactive materials, but will not decrease uptake of radioactivity by root systems. Thus, decontamination of farmland does not affect doses injested through food. Accordingly, root uptake of radioactivity can be decreased only by temporary interdiction of farmland to allow radioactivity to be removed by weathering and decay. Temporary interdiction is assumed to take place provided (1) the value of the interdicted crops is less than the value of the land; (2) the interdiction period does not exceed 8 years, otherwise, the land is assumed to be condemned and permanently removed from agricultural use.

The MACCS program models seven exposure pathways: exposure to the passing plume (cloudshine), exposure to materials deposited on the ground (groundshine), exposure to materials deposited on skin (skin deposition), inhalation of materials directly from the passing plume (cloud inhalation), inhalation of materials resuspended from the ground by natural and mechanical processes (resuspension inhalation), ingestion of contaminated foodstuffs (food ingestion), and ingestion of contaminated water (water ingestion). Ingestion doses do not contribute to the doses calculated for the emergency phase of the accident. Only groundshine and inhalation of resuspended materials produce doses during the optional intermediate phase of the accident. Long-term doses are caused by groundshine, inhalation of resuspended materials, and ingestion of contaminated foodstuffs and water. Ingestion of contaminated food or water exposes to people who reside at unknown locations (i.e., societal doses) both on and off of the computational grid.

Cloudshine doses are calculated by applying a correction factor for finite cloud size to the dose that would be produced by a cloud of infinite extent. ${ }^{86}$ Skin dose is modeled under the assumptions that skin is contaminated only by dry deposition and that skin dose is caused only by $\beta$ particles.

Ingestion doses result from the consumption of contaminated water or contaminated foods. The drinking water pathway is modeled by assuming that a fixed fraction of all contaminated fresh water is consumed by man. Ingestion doses are also produced by consumption of contaminated milk, meat or crops. Crops are divided into categories (the MACCS default input file uses seven crop categories: pasture, stored forage, grains, green leafy vegetables, legumes and seeds, roots and tubers, and other crops). Transfer of radioactivity through root systems or from plant surfaces to edible portions of plants, losses during harvesting, incorporation into meat and milk, and retention in meat, milk, or edible portions of plants during processing, shelf storage, and cooking are all modeled using transfer factors. 
The MACCS program assigns people to three groups: evacuees, people actively taking shelter, and people who continue normal activities indoors, outdoors and riding in vehicles. Doses to evacuees are calculated using vehicle shielding factors. Shielding factors for people who actively take shelter are smaller (i.e., they are better shielded) than the factors for people who continue normal activities indoors and/or outdoors because people who actively take shelter are assumed to close doors and windows, turn off air circulation systems, and move to interior rooms or basements. Shielding factors for people must be calculated outside of the code and specified by the user.

Health effects are calculated from doses to specific organs. ${ }^{87}$ Doses to specific organs are calculated using dose conversion factors. ${ }^{88}$ Early injuries and fatalities (i.e., those that occur within one year of the accident) are estimated using nonlinear dose-response models. As recommended in a recent review of radiation induced health effects, ${ }^{89}$ MACCS uses hazard functions $\left(H_{i}\right)$ for the calculation of early injuries or fatalities due to damage to organ $i$. Specifically, the probability or risk $(r)$ that an individual will experience a given early health effect is given by

$$
r=1-\exp \left\{-\sum_{i} H_{i}\right\},
$$

where

$$
H_{i}=(\ln 2)\left[\frac{D_{i}}{D_{50, i}}\right]^{\beta}, \text { if } D_{i}>D_{t h, i} \text {, }
$$

and

$$
H_{i}=0, \text { if } D_{i} \leq D_{t h j} .
$$

Here, $D_{i}$ is the dose received by organ $i, D_{t h, i}$ is the damage threshold, $\mathrm{D}_{\mathrm{SO}, i}$ is the dose that induces the specified health effect in half of the exposed population (e.g., the $L D_{s 0}$ value for deaths), and the exponent $\beta$ is a parameter that determines the shape of the dose-response curve. Hazards $\left(H_{i}\right)$ are summed (1) over time periods to model any health effect that has $D_{s 0}$ values that vary significantly with exposure period and (2) over organs to model early fatalities in which fatality may be caused by the impaired functioning of several organs. With regard to early fatalities and injuries, the lessened effectiveness of dose delivered at low dose rates over long time periods (dose protraction) is modeled using "effective" acute dose conversion factors. ${ }^{87}$

As recommended by several reviews, ${ }^{90-93}$ MACCS calculates mortality and injuries resulting from radiation-induced cancers using a linear, zero-threshold dose-response model. Accordingly, MACCS cancer fatality predictions are linear with dose. However, the predictions are not always linear with the magnitude of the source term because dose is avoided by crop disposal and by decontamination, temporary interdiction and condemnation of land and buildings. 
Economic consequences ${ }^{94}$ are estimated by summing the following costs: evacuation costs, temporary relocation costs (food, lodging, lost income); costs of decontaminating land and buildings; lost return on investment from properties that are temporarily interdicted to allow contamination to be decreased by weathering and radioactive decay; costs of repairing temporarily interdicted property; value of crops destroyed or not grown because they were contaminated by direct deposition or would be contaminated by root uptake; and value of farmland and of individual, public, and nonfarm commercial property that is condemned. Costs associated with damage to the reactor, the purchase of replacement power, medical care, life-shortening, and litigation are not calculated by MACCS. 


\section{PROBLEM FOR ANALYSIS}

\subsection{Source Term}

The structure of the NUREG-1150 risk assessments produced a large number of individual source terms. As a result, it was not possible to perform a consequence calculation for each source term. To control the overall computational cost of the NUREG-1150 risk assessments, source terms were partitioned into source term groups at the interface between the source term analysis and the consequence analysis. Representative source terms were calculated for the individual source term groups and then consequence calculations were performed for these representative source terms. ${ }^{95,96}$ The consequence results obtained for these representative source terms were then used in the calculation of the consequence risks presented in NUREG-1150. The uncertainty/sensitivity analysis results in this presentation are based on one of the source terms developed in the partitioning process for internally initiated accidents at Surry. ${ }^{6,7}$

The partitioning process was based on the definition of an early health effect weight and a chronic health effect weight for each source term, where the early health effect weight provides a measure of the potential of a source term to cause early fatalities in the absence of any mitigative actions, and the chronic health effect weight provides a similar measure for latent cancer fatalities. The analysis for internally initiated accidents at Surry produced a total of 18,591 source terms, of which 6820 had early and chronic health effect weights that were both nonzero. The distribution of nonzero early and chronic health effects weights for internally initiated accidents at Surry is shown in Figure 4.

The partitioning process begins by placing a user-defined grid on the plot of early and chronic health effect weights shown in Figure 4 . Then, in an interactive mode, lightly populated grid cells can be combined with other cells. For illustration, Figure 5 shows the number of source terms and percent of total frequency in each cell before partitioning for the source terms in Figure 4, and Figure 6 shows the same information after partitioning. The populated cells in Figure 6 correspond to the source term groups used in the NUREG-1150 analyses. Once the source term groups are defined, the source terms are further divided into three subgroups on the basis of evacuation timing:

Subgroup 1: Evacuation starts at least 30 minutes before the radioactive release begins, Subgroup 2: Evacuation starts between 30 minutes before and 1 hour after the release begins, Subgroup 3: Evacuation starts more than 1 hour after the release begins.

A frequency-weighted mean source term is calculated for each subgroup in the final step of the partitioning process. The resultant mean source terms are the source terms that are actually used as input to the consequence analysis.

The partitioning process is performed in a similar manner for the source terms in which the early health effect weight is zero and the chronic health effect weight is nonzero except that the cells are onedimensional.

As already indicated, this presentation uses a source term associated with internally initiated accidents at Surry. A NUREG-1150 source term was selected due to the wide interest in the NUREG- 
Problem for Analysis

SURRY INTERNAL EVENTS SOURCE TERMS

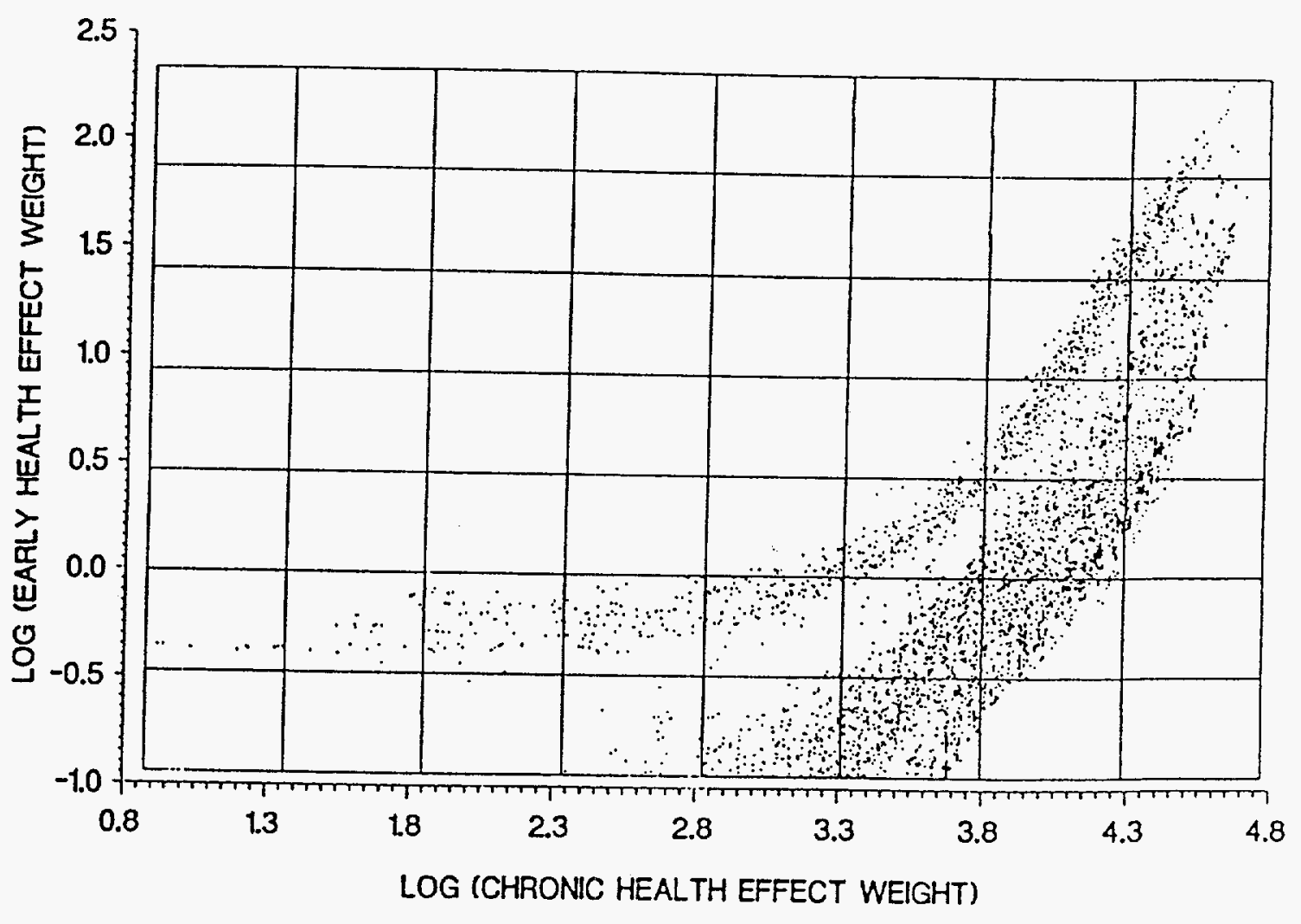

Figure 4. Distribution of Nonzero Early and Chronic Health Effect Weights for Internally Initiated Accidents at Surry (Figure 3.4-1, Ref. 6). 
CEII COUNTS UITHIN THE GRID FOR A TOTAL COUNT OF 6B20:

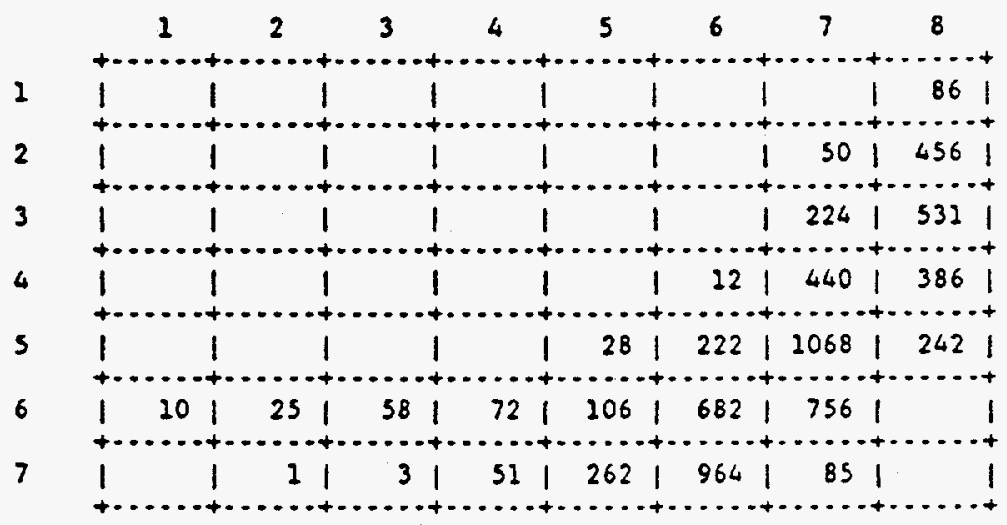

PERCENI OE FREQUENCY CONTAINED IN EACH CELL:

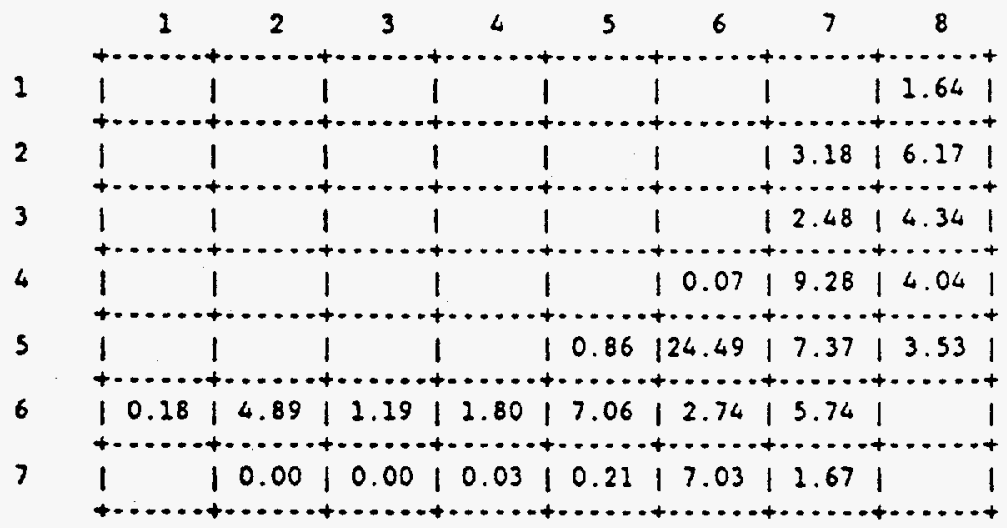

Figure 5. Distribution of Source Terms with Nonzero Early Health Effect and Chronic Health Effect Weights for Internally Initiated Accidents at Surry (adapted from Table 3.4-2 of Ref. 0). 
Problem for Analysis

CELL COUSTS UITHIN THE GRID FOR A TOTAL COUNT OF 6820:

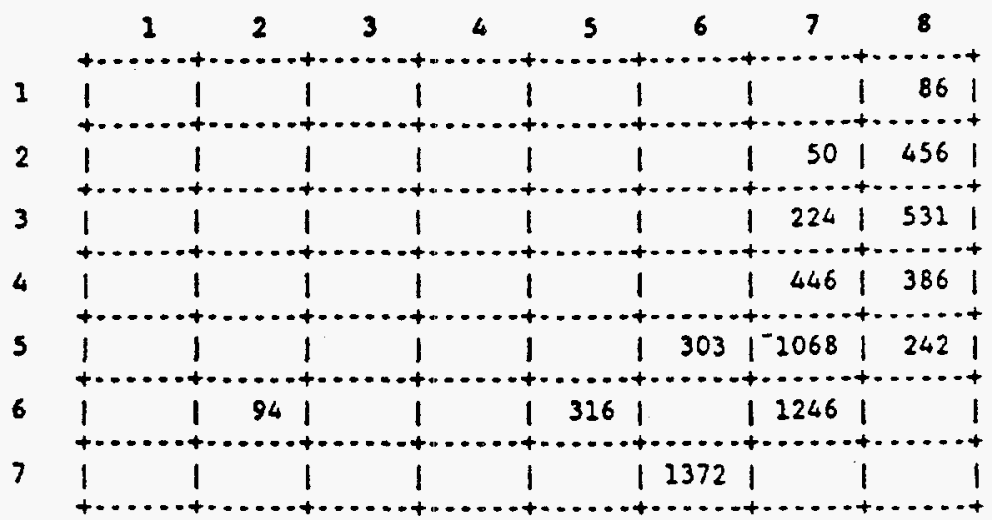

PERCENT OF FREQUENCY CONTAINED IN EACH CELL:

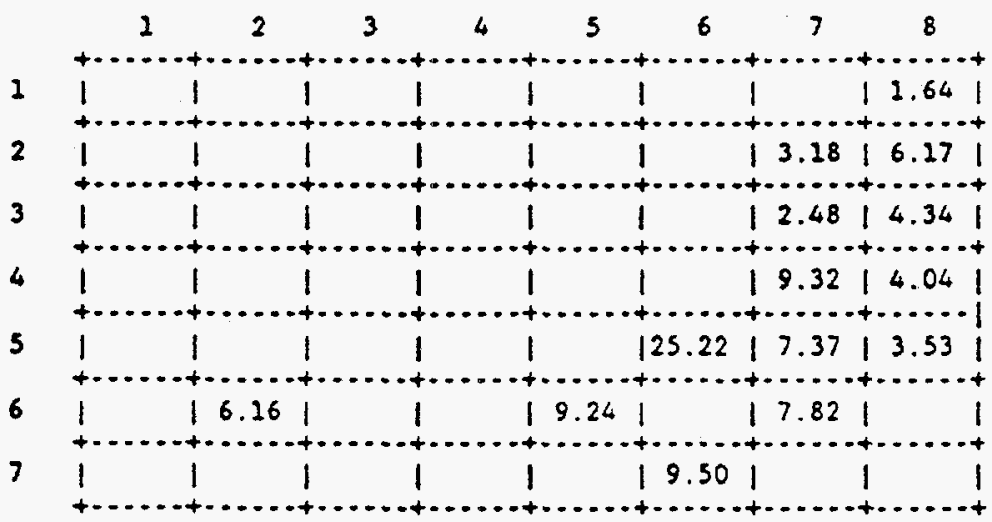

LABEIING AFIER PARIIIIONING:

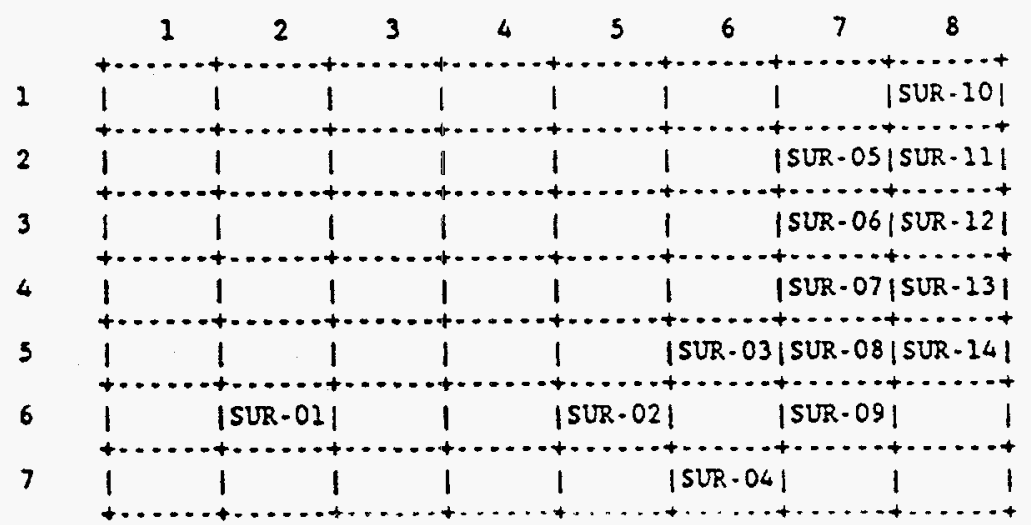

Figure 6. Distribution of Source Terms with Nonzero Early Health Effect and Chronic Health Weights for Internally Initiated Accidents at Surry after Partitioning (adapted from Table 3.4-2 of Ref. 6 ). 
1150 analyses, a desire to use a source term from a published probabilistic risk assessment rather than one "invented" specifically for this uncertainty/sensitivity study, and recognition of the fact that this study is part of a process intended to lead ultimately to an assessment of the impact of consequence modeling uncertainty on NUREG-1150 results. A source term for internally initiated accidents at Surry was selected because that probabilistic risk assessment is often used to illustrate properties of the NUREG1150 analyses. ${ }^{22,23,95,97,98}$ As this study addresses early health effects (e.g., fatalities occurring within a year of an accident), a relatively large release must be considered; otherwise, there will be no early health effects. For this reason, a source term associated with Surry source term group 11 (i.e., SUR-11) as shown in Figure 6 was selected. The mean source terms associated with this source term group are summarized in Table 2. The source term actually used in the analysis is labeled SUR-11-3 in Table 2 (i.e., the mean source term for Subgroup 3 of Source Term Group 11, which is the subgroup for which evacuation starts more than 1 hour after the release begins). A late evacuating source term was chosen so that the effects of uncertain variables on the doses and early health effects experienced by evacuees could be observed. Although evacuation preceding a release is the typical situation in the NUREG-1150 analyses, this is not very interesting in a sensitivity analysis because the evacuees avoid exposure, and as a result, the effects of the uncertain variables cannot be observed.

\subsection{Modeling Assumptions}

As indicated in Section 3, performance of a MACCS calculation for the source term SUR-11-3 shown in Table 2 requires a large amount of input. The development of this input for use in the NUREG-1150 analyses is documented in Sprung et al. ${ }^{36}$ with the actual MACCS input files used in the NUREG-1150 analyses for Surry appearing in Appendix A of the indicated report. The MACCS input for Surry described in Sprung et al. ${ }^{36}$ is taken as the base line description for the analysis problem considered in this study. Taken collectively, this input corresponds to the vector $x$ shown in Eqs. (2) and (3). An overview of the analysis assumptions used in MACCS for the analyses contained in this presentation is given in Table 3.

\subsection{Uncertain Variables}

If there was no uncertainty in the input supplied to MACCS, then there would also be no uncertainty in the predictions made by MACCS [i.e., in the analysis outcome indicated in Eq. (1)]. Here, uncertainty refers to subjective uncertainty. As a reminder, stochastic uncertainty is already incorporated into MACCS results by the probabilities $p S_{i}$ shown in Eq. (1) and approximated in Eq. (23). As discussed in both Sprung et al ${ }^{36}$ and Helton et al. ${ }^{37}$ there is significant subjective uncertainty in the input that must be used with MACCS. This uncertainty is conditional on (1) the level of detail associated with the subdivision of the set $\mathbf{S}$ indicated in Eq. (7) into the sets $\mathbf{S}_{i}$ appearing in Eq. (1); (2) the manner in which the individual variables are used by MACCS; and (3) the available experimental, observational, and theoretical results that pertain to the possible values for the individual input variables and the relationships that may exist between them.

After a review of the results in Sprung et al.$^{36}$ and Helton et al. ${ }^{37}$ the 34 variables listed in Table 4 were selected for consideration in this study. The distributions associated with the individual variables characterize subjective uncertainty and thus correspond to the distributions shown in Eq. (4). When done carefully, the development of such distributions is a very demanding task and requires detailed knowledge of the operation of the model under consideration, extensive literature review, and interaction with many individual investigators who are knowledgeable about the individual variables. The distributions in Table 
Table 2. Mean Source Terms Associated with Source Term Group SUR-11

for Internally Initiated Accidents at Surry (Ref. 6, Table 3.4-4)

\begin{tabular}{|c|c|c|c|c|c|c|c|c|c|c|c|c|c|c|c|c|c|}
\hline \multirow[t]{2}{*}{$\begin{array}{l}\text { Source } \\
\text { Term }\end{array}$} & \multirow[t]{2}{*}{$\begin{array}{l}\text { Freq" } \\
(1 / y r)\end{array}$} & \multirow[t]{2}{*}{$\begin{array}{l}\text { Cond } \\
\text { Prob. }\end{array}$} & \multirow[t]{2}{*}{$\begin{array}{l}\text { Warne } \\
\text { (s) }\end{array}$} & \multirow[t]{2}{*}{ 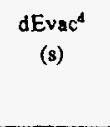 } & \multirow[t]{2}{*}{$\begin{array}{l}\text { Elev } \\
\text { (m) }\end{array}$} & \multirow[t]{2}{*}{$\begin{array}{l}\text { Energy' } \\
\text { (W) }\end{array}$} & \multirow[t]{2}{*}{$\begin{array}{l}\text { Start' } \\
(s)\end{array}$} & \multirow[t]{2}{*}{$\begin{array}{c}\text { Dur } \\
(s)\end{array}$} & \multicolumn{9}{|c|}{ Release Fractions' } \\
\hline & & & & & & & & & NG & 1 & $\mathrm{Cs}$ & $\mathrm{Te}$ & St & $\mathbf{R u}$ & La & $\mathrm{Ce}$ & $\mathrm{Ba}$ \\
\hline \multirow[t]{2}{*}{ SUR-11 } & $1.8 \mathrm{E}-07$ & & $8.8 E+03$ & $-2.3 E+03$ & 3. & $3.4 E+07$ & $1.4 E+04$ & $1.9 E+03$ & $9.7 \mathrm{E}-01$ & $5.0 \mathrm{E}-01$ & $4.9 \mathrm{E}-01$ & $1.9 \mathrm{E}-01$ & $6.8 \mathrm{E}-02$ & $1.4 \mathrm{E}-02$ & $5.1 \mathrm{E}-03$ & 2.5E-02 & $7.2 \mathrm{E}-02$ \\
\hline & & & & & & $1.6 \mathrm{E}+05$ & $1.1 E+05$ & 1.1. $\mathrm{E}+05$ & $8.6 \mathrm{E}-03$ & $2.8 \mathrm{E}-02$ & $5.3 \mathrm{E}-03$ & 1.3E-01 & 4.8E-02 & $2.8 \mathrm{E}-04$ & 4.2E-03 & 4.9E-03 & 3.7E-02 \\
\hline \multirow[t]{2}{*}{ SUR-11-1 } & & 0.147 & $3.6 E+04$ & $7.8 E+03$ & 10. & $1.0 E+06$ & $5.1 \mathrm{E}+04$ & $2.4 E+03$ & $9.8 \mathrm{E}-01$ & 6.1E-01 & $5.9 \mathrm{E}-01$ & 4.2E-01 & $3.3 \mathrm{E}-01$ & $6.1 \mathrm{E}-02$ & $2.7 \mathrm{E}-02$ & $1.4 \mathrm{E}-01$ & 3.4E-01 \\
\hline & & & & & & $0.0 E+\infty$ & $5.5 E+04$ & $1.0 E+04$ & $2.4 \mathrm{E}-02$ & $2.9 \mathrm{E}-02$ & $2.1 \mathrm{E}-02$ & $5.3 \mathrm{E}-02$ & $2.8 \mathrm{E}-02$ & 1.5E-03 & $3.1 \mathrm{E}-03$ & $6.0 \mathrm{E}-03$ & 2.5E-02 \\
\hline \multirow[t]{2}{*}{ SUR-11-2 } & & 0.164 & $1.6 \mathrm{E}+04$ & $-5.3 E+02$ & 10. & $2.0 E+08$ & $2.3 E+04$ & $2.1 \mathrm{E}+03$ & 8.6E-01 & $6.7 \mathrm{E}-01$ & $6.3 \mathrm{E}-01$ & 4.8E-01 & $7.8 \mathrm{E}-02$ & $2.3 \mathrm{E}-02$ & $4.6 \mathrm{E}-03$ & $1.5 \mathrm{E}-02$ & 8.8E-02 \\
\hline & & & & & & $2.6 \mathrm{E}+05$ & $5.6 E+05$ & S.SE+05 & 1.1E-02 & $7.5 \mathrm{E}-03$ & $6.1 \mathrm{E}-03$ & 1.4E-02 & $1.7 \mathrm{E}-03$ & 3.1E-04 & 8.8E-05 & 2.8E-04 & $1.9 \mathrm{E}-03^{\circ}$ \\
\hline \multirow[t]{2}{*}{ SUR-11-3 } & & 0.689 & $1.3 E+03$ & $-4.8 \mathrm{E}+3$ & 0. & $2.7 \mathrm{E}+06$ & $3.7 E+03$ & $1.8 \mathrm{E}+03$ & $1.0 \mathrm{E}+\infty$ & 4.4E-01 & 4.3E-01 & $7.8 \mathrm{E}-02$ & $9.2 \mathrm{E}_{-03}$ & 2.3E-03 & S.AE-04 & $2.3 \mathrm{E}-03$ & 1.tE-02 \\
\hline & & & & & & $1.7 \mathrm{E}+05$ & $1.0 E+04$ & $2.2 \mathrm{E}+04$ & 4.7E- 03 & 3.2E-02 & $1.8 E_{-03}$ & $1.7 \mathrm{E}-01$ & $6.4 \mathrm{E}-02$ & 2.2E-05 & S.4E-03 & $5.7 \mathrm{E}-03$ & $4.8 \mathrm{E}-02$ \\
\hline
\end{tabular}

- Frequency (yr-1) of source term group.

- Conditional probability of source term subgroup given source term group.

- Time (s) at which warning is given.

- Difference between time evacuation starts and time release starts for an assumed evacuation delay time of $7200 \mathrm{~s}$

- Elevation (m) of release.

'Energy (W) in release, with one value for each release segment.

- Time (s) at which release starts, with one value for each release segment.

"Duration (s) of release, with one value for each release segment.

i Release fractions (dimensionless) for individual radionuclide release classes, with one value for each release segment. 
Table 3. Overview of Modeling Assumptions

\begin{tabular}{|c|c|}
\hline Variable & Data \\
\hline Population Distribution & $\begin{array}{l}\text { Based on } 1980 \text { census data, corrected for estimated average daily } \\
\text { transient populations, for the region surrounding Surry; updated } 0-10 \\
\text { mi population data supplied by the NRC. Population distribution } \\
\text { described on a polar coordinate grid with } 16 \text { angular } 22.5^{\circ} \text { sectors and } \\
26 \text { radial intervals with outer radii of } 0.1,0.32,0.75,1,1.5,2,2.5 \text {, } \\
3,3.5,5,7,10,13,16,20,25,30,40,50,70,100,150,200,350 \text {, } \\
500 \text { and } 1000 \text { miles. }\end{array}$ \\
\hline Weather data & $\begin{array}{l}\text { Used weather data measured at the Surry reactor site. The data } \\
\text { consisted of } 1 \text { year of hourly observations of wind speed, atmospheric } \\
\text { stability, and precipitation. The } 8760 \text { ( } 365 \text { days } \times 24 \text { hours) weather } \\
\text { sequences in this data set were sorted into } 40 \text { weather bins. } \\
\text { Inspection of the bins showed that (1) stable atmospheric conditions } \\
\text { (i.e. stability classes E and F) occurred for } 41 \% \text { of the sequences; }(2) \\
\text { precipitation occurred within } 21 \text { miles of the reactor site for } 9.2 \% \text { of } \\
\text { the sequences; and (3) all weather bins indicated in Table } 1 \text { contained } \\
\text { at least one sequence. For the reported analyses, four sequences were } \\
\text { selected from each weather bin; when a bin contained fewer than four } \\
\text { sequences, all sequences were used. }\end{array}$ \\
\hline Core inventory & $\begin{array}{l}\text { Used an end-of-cycle } 3412-\mathrm{MW} \text { Westinghouse pressurized water } \\
\text { reactor core inventory calculated with the SANDIA-ORIGEN code } \\
\text { and scaled to } 2441 \mathrm{MW} \text {, which is the power of the Surry reactor. } \\
\text { Sixty radionuclides were used in the consequence calculations. }\end{array}$ \\
\hline $\begin{array}{l}\text { Emergency response } \\
\text { assumptions }\end{array}$ & $\begin{array}{l}\text { Evacuation occurs radially, and evacuees receive no additional dose } \\
\text { beyond } 20 \text { miles from the reactor. Inhalation shielding factor for } \\
\text { evacuees is } 1 \text {. Nonevacuees continue normal activities. Most } \\
\text { emergency response parameters are variables in the sensitivity study. }\end{array}$ \\
\hline $\begin{array}{l}\text { Source term release } \\
\text { form }\end{array}$ & $\begin{array}{l}\text { All radionuclides released from the reactor except for the noble gases } \\
\text { were assumed to be incorporated into aerosols with a mass median } \\
\text { aerodynamic diameter of about } 10^{-6} \mathrm{~m} \text {. }\end{array}$ \\
\hline
\end{tabular}


Table 4. Imprecisely Known Variables Selected for Inclusion in Uncertainty/Sensitivity Study for MACCS

\begin{tabular}{|c|c|}
\hline Variable & Description \\
\hline BUILDH & $\begin{array}{l}\text { Reactor building height }(\mathrm{m}) \text {. Defines initial vertical height of plume. Range: } 15 \text { - } \\
35 \mathrm{~m} \text {. Distribution: uniform. Correlation: } 0.9 \text { rank correlation with BUILDW. } \\
\text { Best estimate value: } 25 \mathrm{~m} \text {. Correlation results from belief that weather and } \\
\text { accident conditions that increase initial vertical plume extent will also increase } \\
\text { initial horizontal plume extent }\end{array}$ \\
\hline BUILDW & $\begin{array}{l}\text { Reactor building width }(\mathrm{m}) \text {. Defines initial horizontal width of plume. Range: } \\
15-100 \mathrm{~m} \text {. Distribution: uniform. Correlation: } 0.9 \text { rank correlation with } \\
\text { BUILDH. Best estimate value: } 60 \mathrm{~m} \text {. }\end{array}$ \\
\hline CSFACTE & $\begin{array}{l}\text { Cloudshine shielding factor for evacuees. Defines element of MACCS input array } \\
\text { CSFACT. Range: } 0.9-1 \text {. Distribution: uniform. Correlation: } 0.5 \text { rank } \\
\text { correlation with GSHFACE. Best estimate value: } 0.95 \text {. Correlation results from } \\
\text { belief that increasing surface "roughness" will increase both CSFACTE and } \\
\text { GSHFACE. }\end{array}$ \\
\hline CSFACTN & $\begin{array}{l}\text { Cloudshine shielding factor for nonevacuees. Defines element of MACCS input } \\
\text { array CSFACT. Range: } 0.6-0.95 \text {. Distribution: uniform. Correlation: } 0.5 \\
\text { rank correlation with GSHFACN. Best estimate value: } 0.75 \text {. Correlation results } \\
\text { from belief that increasing surface "roughness" will increase both CSFACTN and } \\
\text { GSHFACN. Additional background: Ref. } 36 \text {. }\end{array}$ \\
\hline CSFACTS & $\begin{array}{l}\text { Cloudshine shielding factor for individuals who shelter. Defines element of } \\
\text { MACCS input array CSFACT. Range: } 0.5-0.7 \text {. Distribution: uniform. } \\
\text { Correlation: } 0.5 \text { rank correlation with GSHFACS. Best estimate value: } 0.6 \text {. } \\
\text { Correlation results from belief that increasing surface "roughness" will increase } \\
\text { both CSFACTS and GSHFACS. Additional background: Ref. } 36 \text {. }\end{array}$ \\
\hline CWASH 1 & $\begin{array}{l}\text { Linear term in wet deposition model }(\mathrm{h} / \mathrm{mm} \mathrm{s}) \text {. Range: } 3.1 \times 10^{-5}-3.1 \times 10^{-4} \\
\text { h/mm s. Distribution: Loguniform. Best estimate value: } 1.0 \times 10^{-4} \mathrm{~h} / \mathrm{mm} \mathrm{s} \text {. } \\
\text { Additional background: Refs. } 36,82,102 \text {. }\end{array}$ \\
\hline CWASH2 & $\begin{array}{l}\text { Exponent in wet deposition model. Range: } 0.7-0.9 \text {. Distribution: uniform. } \\
\text { Best estimate value: } 0.8 \text {. Additional background: Refs. } 36,82,102 \text {. }\end{array}$ \\
\hline DOSHOT & $\begin{array}{l}\text { Projected dose used to initiate hot-spot relocation (Sv). At time TIMHOT } \\
\text { individuals are relocated if their projected dose for the entire emergency phase of } \\
\text { the accident (i.e., } 0-7 \text { days) exceeds DOSHOT. Range: } 0.25-1.0 \mathrm{~Sv} \text {. } \\
\text { Distribution: uniform. Correlation: } 0.75 \text { rank correlation with P2DOS1. Best } \\
\text { estimate value: } 0.5 \mathrm{~Sv} \text {. Correlation reflects belief that the dose criteria used for } \\
\text { hot-spot (i.e., DOSHOT) and normal (i.e., P2DOS1) relocation tend to increase } \\
\text { and decrease together. }\end{array}$ \\
\hline
\end{tabular}


Table 4 (continued)

\begin{tabular}{|c|c|}
\hline Variable & Description \\
\hline EFFACA1 & $\begin{array}{l}\text { Early fatality hazard function alpha value for bone marrow exposure (Gy). } \\
\text { Corresponds to exposure level at which } 50 \% \text { of exposed individuals die (i.e., the } \\
\text { LD }_{50} \text { value). Defines element of MACCS input array EFFACA. Range: } 2.5 \text { - } \\
5.5 \mathrm{~Gy} \text {. Distribution: uniform. Correlation: } 0.75 \text { rank correlation with } \\
\text { EFFACB1 and EFFTHR1. Correlation with EFFACB1 results from belief that the } \\
\text { probability of becoming an early fatality would tend to increase more rapidly } \\
\text { above large } \mathrm{LD}_{50} \text { values, and correlation with EFFTHR1 results from belief that } \\
\text { threshold doses will tend to increase as the LD } \mathrm{L}_{50} \text { increases. Best estimate value: } 4 \\
\text { Gy. Additional background: Ref. } 89 \text {. }\end{array}$ \\
\hline EFFACA2 & $\begin{array}{l}\text { Early fatality hazard function alpha value for lung exposure (Gy). Defines element } \\
\text { of MACCS input array EFFACA. Range: } 8-12 \mathrm{~Gy} \text {. Distribution: uniform. } \\
\text { Correlation: } 0.75 \text { rank correlations with EFFACB2 and EFFTHR2. Best estimate } \\
\text { value: } 10 \mathrm{~Gy} \text {. See EFFACA1 for rationale for assumed correlations. Additional } \\
\text { background: Ref. } 89 \text {. }\end{array}$ \\
\hline EFFACA3 & $\begin{array}{l}\text { Early fatality hazard function alpha value for gastrointestinal exposure (Gy). } \\
\text { Defines element of MACCS input array EFFACA. Range: } 10-20 \mathrm{~Gy} \text {. } \\
\text { Distribution: uniform. Correlation: } 0.75 \text { rank correlation with EFFACB3. Best } \\
\text { estimate value: } 15 \mathrm{~Gy} \text {. See EFFACA1 for rationale for assumed correlations. } \\
\text { Additional background: Ref. } 89 \text {. }\end{array}$ \\
\hline EFFACB1 & $\begin{array}{l}\text { Early fatality hazard function beta value for bone marrow exposure. Defines } \\
\text { element of MACCS input array EFFACB. Range: } 4-8 \text {. Distribution: uniform. } \\
\text { Correlation: } 0.75 \text { rank correlation with EFFACA1 and EFFTHR1. Best estimate } \\
\text { value: } 6 \text {. Additional background: Ref. } 89 \text {. }\end{array}$ \\
\hline EFFACB2 & $\begin{array}{l}\text { Early fatality hazard function beta value for lung exposure (Gy). Defines element } \\
\text { of MACCS input array EFFACB. Range: } 9-14 \text {. Distribution: uniform. } \\
\text { Correlation: } 0.75 \text { rank correlation with EFFACA2 and EFFTHR2. Best estimate } \\
\text { value: } 11.5 \text {. Additional background: Ref. } 89 \text {. }\end{array}$ \\
\hline EFFTHR1 & $\begin{array}{l}\text { Early fatality threshold dose for bone marrow exposure (Gy). Defines element of } \\
\text { MACCS input array EFFTHR. Range: } 1-2 \mathrm{~Gy} \text {. Distribution: uniform. } \\
\text { Correlation: } 0.75 \text { rank correlation with EFFACA1 and EFFACB1. Best estimate } \\
\text { value: } 1.5 \mathrm{~Gy} \text {. Additional background: Ref. } 89 \text {. }\end{array}$ \\
\hline EFFTHR2 & $\begin{array}{l}\text { Early fatality threshold dose for lung exposure (Gy). Defines element of MACCS } \\
\text { input array EFFTHR. Range: } 4-6 \text { Gy. Distribution: uniform. Correlation: } \\
0.75 \text { rank correlation with EFFACA2 and EFFACB2. Best estimate value: } 5 \text { Gy. } \\
\text { Additional background: Ref. } 89 \text {. }\end{array}$ \\
\hline EIFACA1 & $\begin{array}{l}\text { Early injury hazard function alpha value for prodromal vomiting (Gy). } \\
\text { Corresponds to exposure level at which } 50 \% \text { of exposed individuals will } \\
\text { experience prodromal vomiting. Defines element of MACCS input array } \\
\text { EIFACA. Range: } 1.5-2.5 \text { Gy. Distribution: uniform. Best estimate value: } 2 \\
\text { Gy. Additional background: Ref. } 89 \text {. }\end{array}$ \\
\hline
\end{tabular}


Table 4 (continued)

\begin{tabular}{|c|c|}
\hline Variable & Description \\
\hline ESPEED & $\begin{array}{l}\text { Evacuation speed }(\mathrm{m} / \mathrm{s}) \text {. Range: } 0.9-3.6 \mathrm{~m} / \mathrm{s} \text {. Distribution: uniform. Best } \\
\text { estimate value: } 2.2 \mathrm{~m} / \mathrm{s} \text {. Additional background: Ref. } 36 \text {. }\end{array}$ \\
\hline EVFRAC & $\begin{array}{l}\text { Fraction of population in emergency response zone (i.e., within } 10 \text { miles of } \\
\text { reactor) that does not evacuate. MACCS input variable WTFRAC equals } 1 \text { - } \\
\text { EVFRAC. Range: } 0.005-0.05 \text {. Distribution: uniform. Best estimate value: } \\
0.027 \text {. Additional background: Ref. } 36 \text {. }\end{array}$ \\
\hline GSHFACE & $\begin{array}{l}\text { Groundshine shielding factor for evacuees. Defines element of MACCS input } \\
\text { array GSHFAC. Range: } 0.3-0.7 \text {. Distribution: uniform. Correlation: } 0.5 \\
\text { rank correlation with CSFACTE. Best estimate value: } 0.5 \text {. Additional } \\
\text { background: Refs. } 36,86 \text {. }\end{array}$ \\
\hline GSHFACN & $\begin{array}{l}\text { Groundshine shielding factor for nonevacuees. Defines element of MACCS input } \\
\text { array GSHFAC. Range: } 0.2-0.75 \text {. Distribution: uniform. Correlation: } 0.5 \\
\text { rank correlation with CSFACTN. Best estimate value: } 0.33 \text {. Additional } \\
\text { background: Refs. } 36,86 \text {. }\end{array}$ \\
\hline GSHFACS & $\begin{array}{l}\text { Groundshine shielding factor for individuals who shelter. Defines element of } \\
\text { MACCS input array GSHFAC. Range: } 0.1-0.3 \text {. Distribution: uniform. } \\
\text { Correlation: } 0.5 \text { rank correlation with CSFACTS. Best estimate value: } 0.2 \text {. } \\
\text { Additional background: Refs. } 36,86 \text {. }\end{array}$ \\
\hline PHS2T2 & $\begin{array}{l}\text { Time after plume arrival at which individuals are relocated if their projected dose } \\
\text { exceeds P2DOS1 (days). Defines MACCS input variable TIMNRM. Range: } 0.5 \\
-2 \text { days. Distribution: uniform. Correlation: } 0.75 \text { rank correlation with } \\
\text { TIMHOT. Best estimate value: } 1.2 \text { days. Correlation reflects belief that the } \\
\text { times used for hotspot (i.e., TIMHOT) and normal (i.e., PHS2T2) relocation tend } \\
\text { to increase and decrease together. }\end{array}$ \\
\hline P2DOS1 & $\begin{array}{l}\text { Projected dose used to initiate normal relocation (Sv). At time PHS2T2, } \\
\text { individuals are relocated if their projected dose for the entire emergency phase of } \\
\text { the accident (i.e., } 0-7 \text { days) exceeds P2DOS1. Defines MACCS input variable } \\
\text { DOSNRM. Range: } 0.05-0.5 \mathrm{~Sv} \text {. Distribution: uniform. Correlation: } 0.75 \\
\text { rank correlation with DOSHOT. Best estimate value: } 0.28 \text {. }\end{array}$ \\
\hline TIMHOT & $\begin{array}{l}\text { Time after plume arrival at which individuals are relocated if their projected dose } \\
\text { exceeds DOSHOT (days). Range: } 0.25-1 \text { day. Distribution: uniform. } \\
\text { Correlation: } 0.75 \text { rank correlation with PHS2T2. Best estimate value: } 0.5 \text { day. }\end{array}$ \\
\hline PROTINN & $\begin{array}{l}\text { Inhalation protection factor for nonevacuees. Defines element of MACCS input } \\
\text { array PROTIN. Range: } 0.2-0.8 \text {. Distribution: uniform. Best estimate value: } \\
0.5 \text {. Additional background: Refs. } 36,86 \text {. }\end{array}$ \\
\hline
\end{tabular}


Table 4 (concluded)

\begin{tabular}{|c|c|}
\hline Variable & Description \\
\hline PROTINS & $\begin{array}{l}\text { Inhalation protection factor for individuals who shelter. Defines element of } \\
\text { MACCS input array PROTIN. Range: } 0.1-0.4 \text {. Distribution: uniform. Best } \\
\text { estimate value: } 0.25 \text {. Additional background: Refs. } 36,86 \text {. }\end{array}$ \\
\hline SCLADP & $\begin{array}{l}\text { Plume rise scaling factor for stability classes A through D. Range: } 0.5-1.5 \text {. } \\
\text { Distribution: uniform. Correlation: } 0.5 \text { rank correlation with SCLEFP. Best } \\
\text { estimate value: } 1 \text {. Additional background: Ref. } 103 \text {. }\end{array}$ \\
\hline SCLCRW & $\begin{array}{l}\text { Critical wind speed scaling factor. Range: } 0.5-2 \text {. Distribution: uniform. Best } \\
\text { estimate value: } 1 \text {. Additional background: Ref. } 103 \text {. }\end{array}$ \\
\hline SCLEFP & $\begin{array}{l}\text { Plume rise scaling factor for stability classes E through F. Range: } 0.5-1.5 \text {. } \\
\text { Distribution: uniform. Correlation: } 0.5 \text { rank correlation with SCLADP. Best } \\
\text { estimate value: } 1 \text {. Additional background: Ref. } 103 \text {. }\end{array}$ \\
\hline TDELAY & $\begin{array}{l}\text { Time from accident warning to start of evacuation }(\mathrm{hr}) \text {. Defines element of } \\
\text { MACCS input array EDELAY. Range: } 1.25-3.25 \mathrm{hr} \text {. Distribution: uniform. } \\
\text { Best estimate value: } 2.3 \mathrm{hr} \text {. }\end{array}$ \\
\hline TTOSH2 & $\begin{array}{l}\text { Time from accident warning to start of sheltering (hr). Range: } 0.25-0.75 \mathrm{hr} \text {. } \\
\text { Distribution: uniform. Best estimate value: } 0.5 \mathrm{hr} \text {. }\end{array}$ \\
\hline VDEPOS & $\begin{array}{l}\text { Dry deposition velocity }(\mathrm{m} / \mathrm{s}) \text {. Defines element of MACCS input array of same } \\
\text { name. Range: } 0.003-0.03 \mathrm{~m} / \mathrm{s} \text {. Distribution: loguniform. Best estimate value: } \\
0.01 \mathrm{~m} / \mathrm{s} \text {. Additional background: Ref. } 83 \text {. }\end{array}$ \\
\hline YSCALE & $\begin{array}{l}\text { Scaling factor for sigma-y (i.e., horizontal dispersion). Range: } 0.33-3 \text {. } \\
\text { Distribution: loguniform. Correlation: } 0.5 \text { rank correlation with ZSCALE. Best } \\
\text { estimate value: 1. Correlation reflects belief that environmental "roughness" } \\
\text { produces tendency for YSCALE and ZSCALE to increase together. Additional } \\
\text { background: Refs. } 104,105 \text {. }\end{array}$ \\
\hline ZSCALE & $\begin{array}{l}\text { Scaling factor for sigma-z (i.e., vertical dispersion). Range: } 0.423-3.81 \text {. } \\
\text { Distribution: loguniform. Correlation: } 0.5 \text { rank correlation with YSCALE. Best } \\
\text { estimate value: } 1.27 \text {. Range a factor of } 3 \text { on value to correct for a surface- } \\
\text { roughness length of } 10 \mathrm{~cm} \text {. Additional background: Refs. } 104,105 \text {. }\end{array}$ \\
\hline
\end{tabular}


4 were developed by the investigators in this study and are not the result of a comprehensive review process. It is hoped that this preliminary assessment of subjective uncertainty will help to identify the most important contributors to the (subjective) uncertainty in MACCS results. Then, efforts can be focused on better characterizing the uncertainty in the inputs that have significant impacts on the uncertainty in predictions made by MACCS.

The correlations indicated in Table 4 are rank correlations, which provide a measure of the extent to which variables tend to move up and down together..$^{100,101}$ Rank correlations also have the desirable property that they are independent of the distributions assigned to the individual variables.

The reactor accident consequences selected for investigation in this study are listed in Table 5 . The predicted values for these consequences correspond to the elements of the vector $c S_{i}$ appearing in Eq. (1).

All of the variables in Table 4 are used in the calculation of the consequence vector $c S_{i}$ appearing in Eq. (1). Thus, when the uncertainty in the variables in Table 4 is propagated in the analysis, the outcome will be of the form shown in Eq. (6). However, this does not have to be the case. For example, the probabilities $p S_{i}$ are approximated by 1 year of weather data, as shown in Eq. (23), with the result that there is subjective uncertainty as to the appropriate values for these probabilities. This analysis does not include the uncertainty in the $p S_{i}$, although there is no conceptual problem in the inclusion of such uncertainty. The analysis also does not include a measure of the uncertainty in how to divide the set $S$ in Eq. (7) into the sets $S_{i}$ in Eq. (1), which would involve making the sets $S_{i}$ and the number of sets $n S$ functions of one or more imprecisely known variables. Again, although this analysis does not include uncertainty in $n S$ and the $S_{i}$, there is no conceptual reason why this uncertainty could not be included. 
Table 5. Reactor Accident Consequences Selected for Investigation.

\begin{tabular}{|c|c|}
\hline CONSEQUENCE & DEFINITION \\
\hline Early Fatalities & $\begin{array}{l}\text { Number of fatalities occurring within } 1 \text { year of the accident. Cases: } \\
100 \% \text { evacuation, no evacuation, } 100 \% \text { sheltering, variable } \\
\text { evacuation. }\end{array}$ \\
\hline Prodromal Vomiting & $\begin{array}{l}\text { Number of individuals experiencing prodromal vomiting. Cases: } \\
\text { Same as for early fatalities. }\end{array}$ \\
\hline $\begin{array}{l}\text { Population Dose } \\
0-10 \mathrm{mi}\end{array}$ & $\begin{array}{l}\text { Population dose (Sv) resulting from to exposure received by } \\
\text { individuals within } 10 \mathrm{mi} \text { of the reactor at accident initiation. Cases: } \\
\text { Same as for early fatalities. }\end{array}$ \\
\hline $\begin{array}{l}\text { Population Dose } \\
0-1000 \mathrm{mi}\end{array}$ & $\begin{array}{l}\text { Population dose (Sv) resulting from exposure received by individuals } \\
\text { within } 1000 \mathrm{mi} \text { of the reactor at accident initiation. Cases: Same as } \\
\text { for early fatalities. }\end{array}$ \\
\hline $\begin{array}{l}\text { Early Fatality } \\
\text { Probability } 0-1 \mathrm{mi}\end{array}$ & $\begin{array}{l}\text { Probability that an individual within } 1 \mathrm{mi} \text { of the reactor at accident } \\
\text { initiation will become an early fatality. Cases: Same as for early } \\
\text { fatalities. }\end{array}$ \\
\hline $\begin{array}{l}\text { Maximum Early } \\
\text { Fatality Distance }\end{array}$ & $\begin{array}{l}\text { Maximum distance }(\mathrm{km}) \text { from reactor at which an individual has a } \\
\text { probability of becoming an early fatality that exceeds } 0.005 \text {. Case: } \\
\text { No evacuation. }\end{array}$ \\
\hline
\end{tabular}

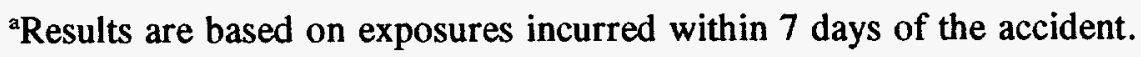


THIS PAGE INTENTIONALLY LEFT BLANK

NUREG/CR-6135 


\section{DETERMINATION OF DOMINANT VARIABLES}

The purpose of the analyses presented in this section is to determine the effects of uncertainty in the MACCS input variables listed in Table 4 on the consequence results indicated in Table 5. To accomplish this, the LHS program ${ }^{100}$ was used to generate a Latin hypercube sample of size 100 from the 34 variables in Table 4, with the Iman/Conover restricted pairing technique ${ }^{100}$ being used to induce the indicated rank correlations. This produced a sample of the form shown in Eq. (5) with $n V=34$ and $n L H S=100$, which was then propagated through MACCS to produce the results shown in Eq. (6). As a reminder, the vector $c S_{i}\left(x_{k}\right)$ in Eq. (6) contains the values for the consequence results in Table 5 obtained for scenario $\mathbf{S}_{i}$, where $\mathbf{S}_{i}$ is the set of similar weather conditions defined in Eq. (13). The analyses for the individual consequence results follow.

\subsection{Early Fatalities}

The number of early fatalities was estimated for four emergency response assumptions: (1) $100 \%$ evacuation, (2) no evacuation, (3) $100 \%$ sheltering, and (4) variable evacuation (i.e., the fraction EVFRAC of the population continues normal activities and the remaining fraction 1-EVFRAC of the population evacuates). Each sample element produces a CCDF of the form shown in Figure 1 for each of the preceding emergency response assumptions. When taken collectively, the CCDFs for each emergency response assumption produce a distribution of CCDFs of the form shown in Figure 2. Specifically, the distribution of CCDFs obtained in this analysis for number of early fatalities with $100 \%$ evacuation is shown in Figure 2.

Plots similar to the one appearing in Figure 2 can also be produced for each of the other analysis cases under consideration (i.e., no evacuation, $100 \%$ sheltering, and variable evacuation). Although these plots contain all $100 \mathrm{CCDFs}$ generated in this analysis, they are difficult to examine and compare. A less congested summary of these distributions is provided by the mean and percentile curves shown in Figure 7. The summary results presented in the individual frames of Figure 7 are derived from results of the form shown in Figure 2. Specifically, at each point on the abscissa in Figure 2, a vertical line is drawn through the $100 \mathrm{CCDFs}$ above this point. As a reminder, there is one CCDF for each sample element, which results in a total of 100 CCDFs. Further, the individual CCDFs do not really end at points in space as shown in Figure 2, but rather drop vertically from their last point to an exceedance probability of zero and then continue along the abscissa to the right. The points at which the indicated vertical line crosses the CCDFs yield 100 exceedance probabilities, from which the mean and various percentiles (e.g., 5\%, 50\%, 95\%) can be determined. The curves in Figure 7 result from connecting the mean and percentile values obtained for individual early fatality numbers. The mean and percentile curves in the upper left frame of Figure 7 for early fatalities with $100 \%$ evacuation are constructed from the results shown in Figure 2; the curves in the other frames of Figure 7 are constructed from similar distributions of CCDFs for number of early fatalities with no evacuation, $100 \%$ sheltering, and variable evacuation, respectively.

As examination of the results in Figure 7 shows, there is considerable uncertainty associated with the probability that a specified number of early fatalities will be exceeded. This uncertainty comes from the ranges and distributions assigned to the variables in Table 4. The percentile curves in Figure 7 can be used to provide a measure of confidence (i.e., degree of belief) as to where the exceedance probabilities are located for each number of early fatalities. However, these results are conditional on the distributions specified in Table 4 for the characterization of subjective uncertainty and also on the other modeling assumptions used in this analysis. 

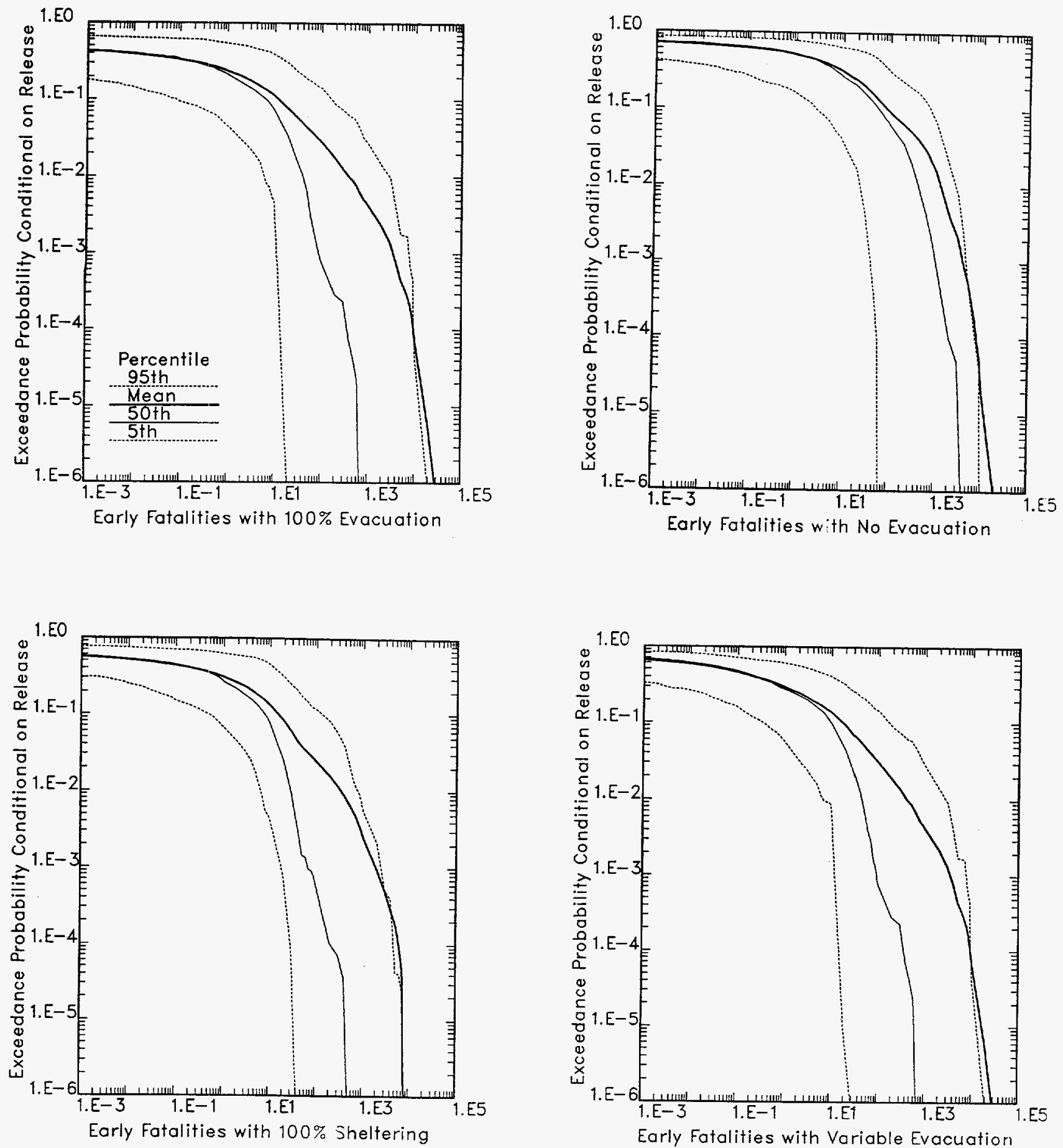

Figure 7. Mean and Percentile Curves for Number of Early Fatalities for the Following Cases: $100 \%$ Evacuation, No Evacuation, $100 \%$ Sheltering and Variable Evacuation. 
An assessment of the subjective uncertainty in reactor accident consequence modeling parameters that appropriately incorporates the diverse body of information potentially available is a very large endeavor. Indeed, the present sensitivity study is being performed to help focus the resources of such an endeavor on the most important inputs used in modeling the consequences of reactor accidents. The ranges and distributions given in Table 4 were developed only to support this sensitivity study; the level of effort was not adequate to obtain and evaluate all information potentially available to the reactor safety community. Therefore, excessive emphasis should not be placed on the numeric values associated with uncertainty analysis results in this report. However, it is useful to present uncertainty results such as shown in Figures 2 and 7 because this information both provides the input to the sensitivity studies that are the primary focus of this presentation and forms a basis for assessing the effectiveness of the techniques in use. Further, the results in Figures 2 and 7 and other similar figures are conditional on the occurrence of the accident under consideration (i.e., SUR-11-3 as defined in Table 2), which was estimated in the NUREG-1150 analysis for internally initiated accidents at Surry to have a frequency of approximately $1.2 \times 10^{-7} \mathrm{yr}^{-1}$. Thus, the conditional probabilities appearing on the ordinates of Figures 2 and 7 and other similar figures must be multiplied by $1.2 \times 10^{-7} \mathrm{yr}^{-1}$ to obtain annual exceedance frequencies that incorporate the likelihood of the accident under consideration.

The identification of the variables in Table 4 that dominate the uncertainty displayed in Figures 2 and 7 is now addressed. Specifically, the PCCSRC program ${ }^{107}$ is used to calculate partial rank correlation coefficients (PRCCs) for the probability that specified numbers of early fatalities will be exceeded. As a reminder, PRCCs provide a measure for the tendency of two variables to increase and/or decrease together after a correction has been made for the effects of the other variables in the analysis. Specifically, PRCCs are defined the same as ordinary partial correlation coefficients (PCCs) except that the independent and dependent variables are rank-transformed before the calculation of PRCCs. The use of the rank transform helps remove the effects of nonlinear relationships between variables that reduce the effectiveness of ordinary PCCs. For this presentation, all variables that have a PRCC above 0.5 in absolute value were identified. Typically, 4 to 9 variables satisfy this selection criterion.

As shown in Figure 8, a relatively compact display of this information can be achieved by plotting the PRCCs for the 4 variables that have the largest PRCCs in absolute value and simply listing the remaining variables whose PRCCs exceeded 0.5 in absolute value together with a + or - after the variable to indicate whether the coefficient is positive or negative when its absolute value exceeds 0.5 . In a few instances, a variable will have both positive and negative partial correlations that exceed 0.5 in absolute value. In this case, the variable will be followed by,+- if the coefficient is positive and then negative and by,-+ if the coefficient is negative and then positive.

The analysis for number of early fatalities with $100 \%$ evacuation shown in the upper left frame of Figure 8 can be used to illustrate the presentation of the partial correlation results. The four variables with the largest PRCCs in absolute value are YSCALE (scaling factor for horizontal dispersion), ZSCALE (scaling factor for vertical dispersion), TDELAY (time from warning to start of evacuation) and ESPEED (evacuation speed); there is a partial correlation plot for each of these variables. For example, a vertical line drawn through one early fatality intersects the curves for YSCALE, ZSCALE, TDELAY, and ESPEED at $-0.95,-0.85,0.67$, and -0.67 respectively. The numbers $-0.95,-0.85,0.67$, and -0.67 are the PRCCs between YSCALE, ZSCALE, TDELAY, and ESPEED and the probability that one or more early fatalities will occur given the occurrence of the source term SUR-11-3. In addition to YSCALE, ZSCALE, TDELAY, and ESPEED, the variables SCLCRW (critical wind speed scaling factor), EFFACA1 (early fatality hazard function alpha value for bone marrow exposure), VDEPOS (dry deposition velocity) and CSFACTN (cloudshine shielding factor for nonevacuees) were found to have 
Determination of Dominant Variables
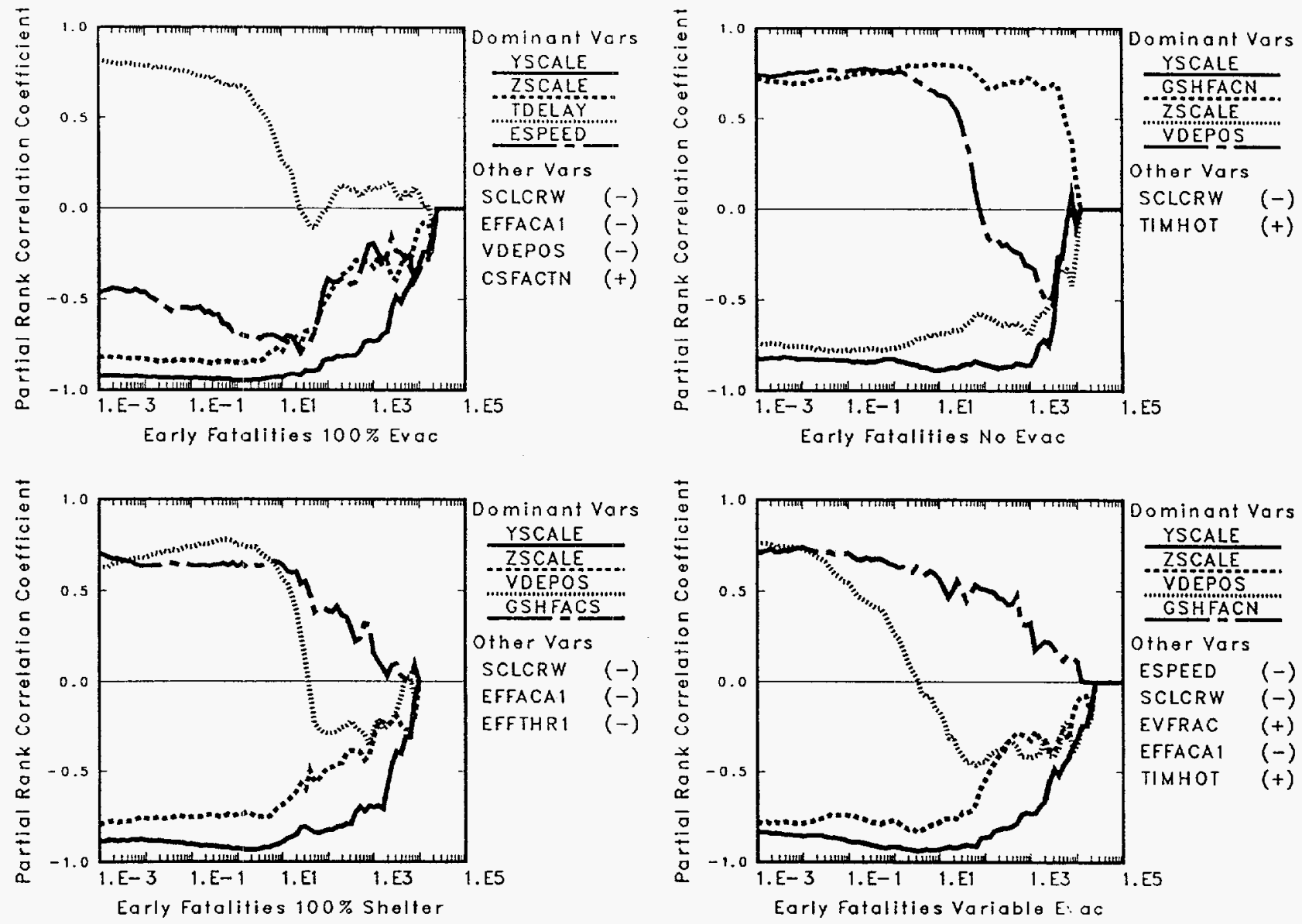

Figure 8. Partial Rank Correlation Coefficients for Probability that Specified Numbers of Early Fatalities Will Be Exceeded for the Following Cases: 100\% Evacuation, No Evacuation, $100 \%$ Sheltering and Variable Evacuation. 
PRCCs that exceeded 0.5 in absolute value. As indicated by the + and - symbols following these variables, SCLCRW, EFFACA1, and VDEPOS have PRCCs that are less than -0.5 and CSFACTN has PRCCs that exceed 0.5; however, this summary does not contain enough information to identify the numbers of early fatalities for which these variables have PRCCs that exceed 0.5 in absolute value.

The sensitivity analysis results contained in Figure 8 for number of early fatalities with $100 \%$ evacuation are now discussed. As measured by the size of the PRCCs, the two most important variables are YSCALE (scaling factor for horizontal dispersion) and ZSCALE (scaling factor for vertical dispersion). Both of these variables have negative PRCCs, which indicates that increasing each of these variables tends to decrease the probability of exceeding a specified number of early fatalities. This effect occurs because increasing YSCALE and ZSCALE tends to spread the plume out and thus reduce the number of individuals receiving large radiation exposures. The variables YSCALE and ZSCALE consistently appear as important variables in the analyses presented in Figure 8.

The variable with the next largest PRCCs for number of early fatalities with $100 \%$ evacuation is TDELAY (time from warning to start of evacuation). The positive correlation indicated for TDELAY results because increasing TDELAY tends to increase the amount of radiation exposure that individuals receive before they begin evacuation. The partial correlation coefficients for TDELAY drop to approximately zero by 10 early fatalities. Thus, although increasing TDELAY tends to increase the probability of having a small number of early fatalities in this analysis, it does not appear to have an effect on the occurrence of a large number of early fatalities. However, it is important to recognize that all of the partial correlation plots will tend to zero as more and more of the individual CCDFs shown in Figure 7 drop to zero. The variable with the fourth largest PRCCs is ESPEED (evacuation speed). The negative correlation coefficients shown for ESPEED result because increasing ESPEED reduces the total time required for evacuation and thus reduces radiation exposure.

In addition to YSCALE, ZSCALE, TDELAY, and ESPEED, the following four variables were found to have PRCCs that exceeded 0.5 in absolute value for number of early fatalities with $100 \%$ evacuation: (1) SCLCRW (critical wind speed scaling factor) with negative PRCCs because increasing SCLCRW tends to increase plume rise and thus reduce the number of individuals receiving large radiation exposures, (2) EFFACA1 (early fatality hazard function alpha value for bone marrow exposure) with negative PRCCs because increasing EFFACA1 increases the dose that an individual must receive in order to have a probability of 0.5 of becoming an early fatality, (3) VDEPOS (dry deposition velocity) with negative PRCCs because increasing VDEPOS tends to increase the amount of radiation deposited near the reactor and thus decrease the amount of radiation deposited at greater distances from the reactor where more individuals are located, and (4) CSFACTN (cloudshine shielding factor for nonevacuees) with positive PRCCs because increasing CSFACTN tends to increase the radiation exposure received by individuals before they initiate evacuation.

The sensitivity analysis results in Figure 8 for number of early fatalities without evacuation are similar to those obtained for $100 \%$ evacuation. Increasing YSCALE (scaling factor for horizontal dispersion), ZSCALE (scaling factor for vertical dispersion), and SCLCRW (critical wind speed scaling factor) tends to decrease the probability of exceeding specified numbers of early fatalities while the opposite effect is indicated for GSHFACN (groundshine shielding factor for nonevacuees) and VDEPOS (dry deposition velocity). The analysis for $100 \%$ evacuation selected the cloudshine shielding factor for nonevacuees (CSFACTN) rather than the groundshine shielding factor for nonevacuees (GSHFACN). This difference results because cloudshine is more important when people are exposed to the plume but ultimately evacuate, while groundshine is more important when people do not evacuate at all. The 
variable VDEPOS shows an interesting pattern, going from positive correlation values for small numbers of early fatalities to negative correlation values for larger numbers of early fatalities. This pattern probably derives from the fact that large values for VDEPOS result in more deposition close to the reactor and hence in less deposition at greater distances from the reactor where more individuals are located, with the result that the probability of a small number of early fatalities goes up and the probability of a large number of early fatalities goes down. The variable TIMHOT (time at which individuals are relocated if their projected dose exceeds DOSHOT) was also identified in the analysis as having positive PRCCs that exceed 0.5 , with this positive correlation resulting because increasing TIMHOT tends to increase the amount of radiation exposure that individuals receive before they are relocated.

Overall, the sensitivity analysis results in Figure 8 for number of early fatalities with $100 \%$ sheltering are similar to those obtained with and without evacuation. Increasing YSCALE (scaling factor for horizontal dispersion), ZSCALE (scaling factor for vertical dispersion), SCLCRW (critical wind speed scaling factor), EFFACA1 (early fatality hazard function alpha value for bone marrow exposure) and EFFTHR1 (early fatality threshold dose for bone marrow exposure) tends to decrease the probability of exceeding a specified number of early fatalities while the opposite effect is indicated for VDEPOS (dry deposition velocity) and GSHFACS (groundshine shielding factor for individuals who shelter). Of the preceding variables, only GSHFACS and EFFTHR1 were not identified in the analyses with and without evacuation. The variable GSHFACS has exactly the same role in the analysis with sheltering as the variable GSHFACN (groundshine shielding factor for nonevacuees) in the analysis for no evacuation. The variable EFFTHR1 defines the dose below which early fatalities due to bone marrow exposure will not occur. Thus, increasing EFFTHR1 tends to decrease the number of early fatalities. The variable EFFTHR1 also affects the number of early fatalities with and without evacuation; however, owing to the concurrent effects of other variables, it does not result in correlation coefficients with absolute values that exceed the selection criterion (i.e., 0.5 ) for these two cases.

The last sensitivity analysis results in Figure 8 are for the number of early fatalities that result when a fraction EVFRAC of the population within $10 \mathrm{mi}$ of the reactor (i.e., within the emergency response zone) does not evacuate and the remaining fraction (i.e., 1-EVFRAC) of the population does evacuate. Increasing YSCALE (scaling factor for horizontal dispersion), ZSCALE (scaling factor for vertical dispersion), ESPEED (evacuation speed), SCLCRW (critical wind speed scaling facto), and EFFACA1 (early fatality hazard function alpha value for bone marrow exposure) tends to decrease the probability of exceeding a specified number of early fatalities while increasing VDEPOS (dry deposition velocity), GSHFACN (groundshine shielding factor for nonevacuees), EVFRAC (fraction of population in emergency response zone that does not evacuate) and TIMHOT (time at which individuals are relocated if their projected dose exceeds DOSHOT) tends to increase the probability of exceeding a specified number of early fatalities. With the exception of EVFRAC, all of the preceding variables were previously identified as having the same effects in either the analysis with or the analysis without evacuation. Increasing EVFRAC tends to increase the number of early fatalities by increasing the number of individuals who do not evacuate.

As discussed in conjunction with Figure 1, CCDFs are the basic summary display for analyses involving stochastic uncertainty. However, another more condensed summary is provided by the summation 


$$
\overline{c S}=\sum_{i=1}^{n S} p S_{i} c S_{i}
$$

where $c S$ is a particular consequence value (e.g., number of early fatalities) in the vector $c S$ appearing in Eq. (1). Here, $\overline{c S}$ is the expected value for the particular consequence value under consideration, where the expectation is being taken over stochastic uncertainty, and is the result of reducing the information in the CCDF in Figure 1 to a single number. In the presence of subjective uncertainty, the expression in Eq. (27) becomes

$$
\overline{c S(x)}=\sum_{i=1}^{n S(x)} p S_{i}(x) c S_{i}(x),
$$

where $\boldsymbol{x}$ is a vector of imprecisely known quantities required in the determination of the expression in Eq. (3).

Although the results of reactor accident consequence assessments are usually presented as CCDFs to maintain a separation between scenario probability and consequence magnitude, mean consequence results of the form shown in Eq. (27) are also used as summary measures. In the present study, the expression in Eq. (27) provides a way to reduce an entire CCDF to a single number (i.e., the expected number of consequences due to weather variability) to facilitate sensitivity analysis. Due to the imprecisely known variables listed in Table 4, this expected number of consequences is actually of the form shown in Eq. (28). For the present study, Eq. (28) can be evaluated for each CCDF in distributions of the form shown in Figure 2, where $x$ takes on the values $x_{k}, k=1, \ldots, n L H S=100$, of the elements of the Latin hypercube sample generated for the variables summarized in Table 4. The resultant mean consequence values for early fatalities are summarized in Figure 9. While each mean consequence value summarized in the distributions in Figure 9 results from stochastic uncertainty, the distributions themselves are displaying subjective uncertainty. Further, the single mean associated with each distribution in Figure 9, designated by a large dot, is a mean over subjective uncertainty.

Stepwise regression analysis provides a convenient tool with which to determine the importance of individual variables in influencing the uncertainty in mean number of early fatalities displayed in Figure 9. With stepwise regression analysis, the importance of a variable is indicated by the order in which variables enter the regression model, the changes in $\mathrm{R}^{2}$ values with the entry of successive variables into the regression model, and the standardized regression coefficients in the final regression model constructed in the stepwise process. The regression analyses contained in this presentation were performed with the STEP program. ${ }^{108}$ Alpha values of 0.01 and 0.02 were required for variables to enter and remain in the regression models, respectively. Further, the PRESS criterion ${ }^{109}$ was used to check for overfitting the data.

As illustrated in Tables 6 and 7, the analyses were initially tried with both raw (i.e., untransformed) data and rank-transformed data. ${ }^{110}$ The analyses with rank-transformed data consistently performed as well as or better than the analyses with raw data. For example, the regression analysis with raw data in Table 6 for mean number of early fatalities with $100 \%$ evacuation selected only the variable YSCALE (scaling factor for horizontal dispersion), which could account for $16 \%$ (i.e., $R^{2}=0.16$ ) of the observed variability. In contrast, the corresponding analysis in Table 7 with rank-transformed data selected 8 variables and the final regression model could account for $92 \%$ (i.e., $R^{2}=0.92$ ) of the 
Determination of Dominant Variables
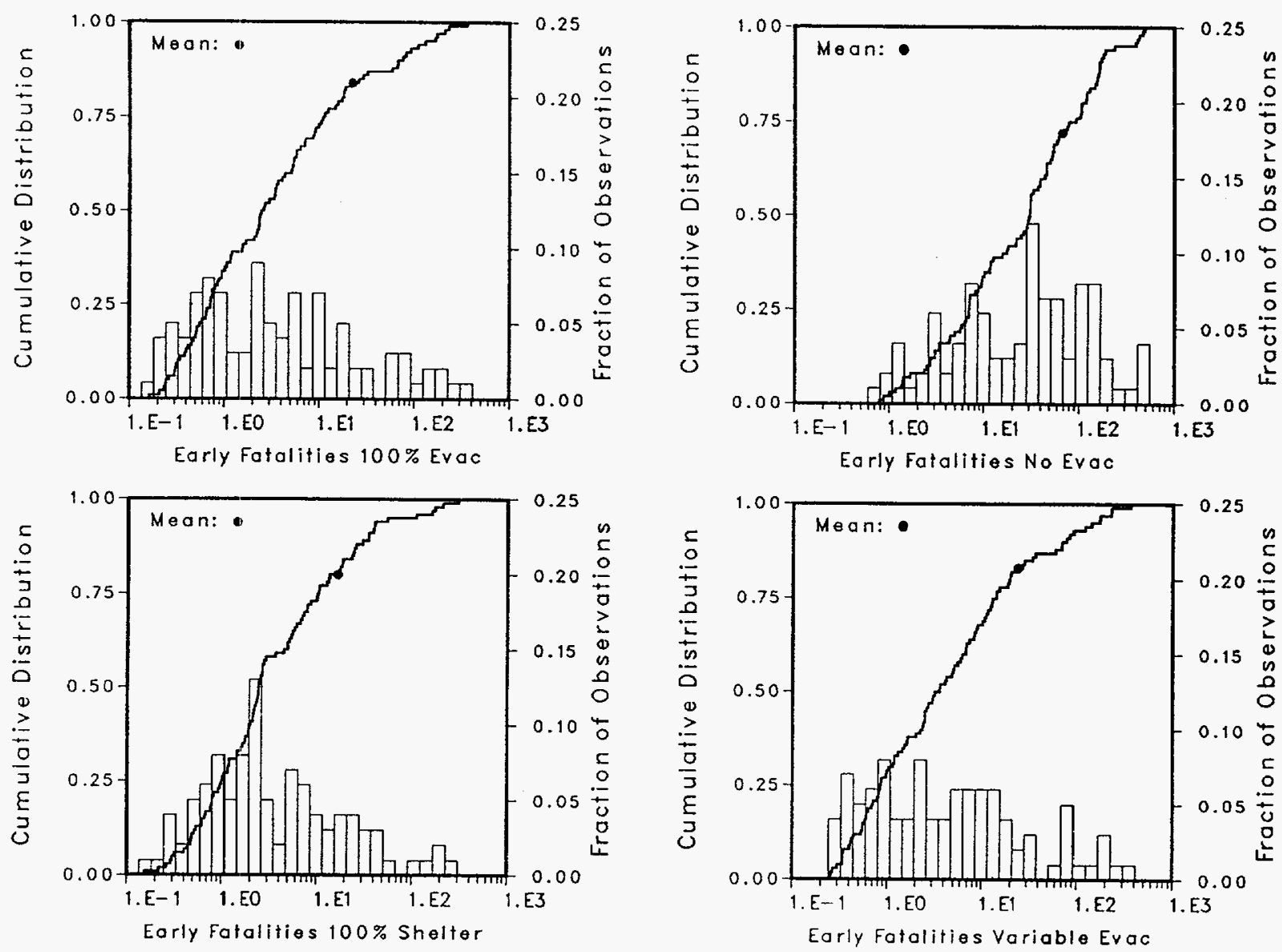

Figure 9. Distribution of Mean Number of Early Fatalities for the Following Cases: $100 \%$ Evacuation, No Evacuation, $100 \%$ Sheltering, and Variable Evacuation. 
Table 6. Stepwise Regression Analysis with Raw (i.e., untransformed) Data for Mean Number of Early Fatalities for the Following Cases: $100 \%$ Evacuation, No Evacuation, $100 \%$ Sheltering, and Variable Evacuation

\begin{tabular}{||c|c|c|c|c|c|c||}
\cline { 2 - 7 } \multicolumn{1}{c|}{} & \multicolumn{3}{c|}{$100 \%$ Evacuation } & \multicolumn{3}{c|}{ No Evacuation } \\
\hline Step $^{\mathrm{a}}$ & Variable $^{\mathrm{b}}$ & SRC $^{\mathrm{c}}$ & $\mathbf{R}^{2 \mathrm{~d}}$ & Variable $^{\mathrm{b}}$ & SRC $^{\mathrm{c}}$ & $\mathbf{R}^{2 \mathrm{~d}}$ \\
\hline 1 & YSCALE & -0.39 & 0.16 & YSCALE & -0.59 & 0.50 \\
2 & & & & GSHFACN & 0.37 & 0.37 \\
3 & & & & EFFACA1 & -0.32 & 0.47 \\
4 & & & & ZSCALE & -0.33 & 0.54 \\
5 & & & & TIMHOT & 0.25 & 0.60 \\
\hline
\end{tabular}

\begin{tabular}{|c|c|c|c|c|c|c||}
\cline { 2 - 7 } \multicolumn{1}{c|}{} & \multicolumn{3}{c|}{$100 \%$ Shelter } & \multicolumn{3}{c|}{ Variable Evacuation } \\
\hline Step $^{\mathbf{2}}$ & Variable $^{\mathrm{b}}$ & SRC $^{\mathrm{c}}$ & $\mathbf{R}^{\mathbf{2}}$ & Variable $^{\mathrm{b}}$ & SRC $^{\mathbf{c}}$ & $\mathbf{R}^{\mathbf{2 d}}$ \\
\hline 1 & YSCALE & -0.36 & 0.12 & YSCALE & -0.40 & 0.16 \\
2 & EFFACA1 & -0.31 & 0.22 & & & \\
\hline
\end{tabular}

aSteps in stepwise regression analysis.

'Variables listed in order of selection in regression analysis.

'Standardized regression coefficients in final regression model.

${ }^{d}$ Cumulative $R^{2}$ value with entry of each variable into regression model 
Determination of Dominant Variables

Table 7. Stepwise Regression Analysis with Rank-Transformed Data for Mean Number of Early Fatalities for the Following Cases: 100\% Evacuation, No Evacuation, 100\%

Sheltering, and Variable Evacuation

\begin{tabular}{||c|l|c|c|l|l|l||}
\cline { 2 - 7 } \multicolumn{1}{c|}{} & \multicolumn{3}{c|}{$100 \%$ Evacuation } & \multicolumn{3}{c||}{ No Evacuation } \\
\hline Step $^{\mathbf{a}}$ & Variable $^{\mathbf{b}}$ & SRC $^{\mathbf{c}}$ & $\mathbf{R}^{\mathbf{2} \mathbf{d}}$ & Variable $^{\mathbf{b}}$ & SRC $^{\mathbf{c}}$ & $\mathbf{R}^{\mathbf{2}}$ \\
\hline 1 & YSCALE & -0.68 & 0.65 & YSCALE & -0.59 & 0.50 \\
2 & ESPEED & -0.28 & 0.72 & GSHFACN & 0.39 & 0.66 \\
3 & ZSCALE & -0.29 & 0.79 & EFFACA1 & -0.33 & 0.76 \\
4 & EFFACA1 & -0.23 & 0.85 & TIMHOT & 0.27 & 0.83 \\
5 & GSHFACN & 0.14 & 0.88 & ZSCALE & -0.28 & 0.89 \\
6 & VDEPOS & -0.12 & 0.90 & & & \\
7 & CSFACTN & $\mathbf{0 . 1 0}$ & $\mathbf{0 . 9 1}$ & & & \\
8 & TDELAY & 0.08 & 0.92 & & & \\
\hline
\end{tabular}

\begin{tabular}{||c|l|c|c|l|l|l||}
\cline { 2 - 7 } \multicolumn{1}{c|}{} & \multicolumn{3}{c|}{$100 \%$ Shelter } & \multicolumn{3}{c|}{ Variable Evacuation } \\
\hline Step $^{\mathbf{a}}$ & Variable $^{\mathbf{b}}$ & SRC $^{\mathbf{c}}$ & $\mathbf{R}^{\mathbf{2} \mathbf{d}}$ & Variable $^{\mathbf{b}}$ & SRC $^{\mathbf{c}}$ & $\mathbf{R}^{\mathbf{2} \mathbf{d}}$ \\
\hline 1 & YSCALE & -0.64 & 0.57 & YSCALE & -0.68 & 0.63 \\
2 & EFFACA1 & -0.39 & 0.72 & ZSCALE & -0.29 & 0.70 \\
3 & ZSCALE & -0.29 & 0.79 & EFFACA1 & -0.24 & 0.76 \\
4 & GSHFACS & 0.22 & 0.84 & ESPEED & -0.25 & 0.81 \\
5 & VDEPOS & 0.12 & 0.85 & GSHFACN & 0.20 & 0.87 \\
6 & PROTINS & 0.11 & 0.86 & EVFRAC & 0.14 & 0.89 \\
7 & & & & TIMHOT & 0.11 & 0.90 \\
8 & & & & CSFACTN & 0.09 & 0.91 \\
9 & & & & SCLCRW & -0.08 & 0.92 \\
10 & & & & VDEPOS & -0.08 & 0.92 \\
\hline
\end{tabular}

${ }^{\mathrm{a} S t e p s}$ in stepwise regression analysis.

bVariables listed in order of selection in regression analysis.

'Standardized regression coefficients in final regression model.

${ }^{\mathrm{d}}$ Cumulative $\mathrm{R}^{2}$ value with entry of each variable into regression model. 
observed variability. Further, the indicated effects for the variables in the regression model in Table 7 are consistent with their use in MACCS. Similarly unfavorable comparisons between regressions with raw and rank-transformed data also exist for the other three variables in Tables 6 and 7 . As a result, the sensitivity analyses based on stepwise regression analysis contained in this report use rank-transformed data.

The individual analyses in Table 7 are now discussed. For mean number of early fatalities with $100 \%$ evacuation, the first variable selected in the regression analysis is YSCALE (scaling factor for horizontal dispersion), which can account for $65 \%$ of the observed variability. The variable YSCALE has a negative regression coefficient; thus, increasing YSCALE tends to decrease the mean number of early fatalities. This negative effect results because increasing YSCALE tends to spread the plume out and thus reduce the number of individuals receiving large radiation exposures. The next three variables selected in the analysis are ESPEED (evacuation speed), ZSCALE (scaling factor for vertical dispersion), and EFFACA1 (early fatality hazard function alpha value for bone marrow exposure), with each of these variables having a negative regression coefficient and accounting for approximately $7 \%$ of the observed variability. Increasing ESPEED and ZSCALE tends to decrease the number of the fatalities by decreasing individual exposure; in contrast, increasing EFFACA1 tends to decrease the number of fatalities by decreasing the probability that a specified radiation exposure will cause an early fatality. The last four variables selected in the analysis are GSHFACN (groundshine shielding factor for nonevacuees), VDEPOS (dry deposition velocity), CSFACTN (cloudshine shielding factor for nonevacuees) and TDELAY (time from warning to start of evacuation), with each of these variables accounting for 1 to $3 \%$ of the observed variability. The variables GSHFACN, CSFACTN, and TDELAY have positive regression coefficients; thus increasing each of these variables tends to increase the mean number of early fatalities. This positive effect results because increasing GSHFACN, CSFACTN, and TDELAY each increases the amount of radiation exposure that individuals receive before they begin to evacuate. The variable VDEPOS has a negative regression coefficient; thus, increasing VDEPOS tends to decrease the mean number of early fatalities. Large values for VDEPOS result in more of the release being deposited close to the reactor and hence in a reduction in the number of individuals receiving large radiation exposures. The final regression model containing all eight variables can account for $92 \%$ of the observed variability.

The analysis in Table 7 for mean number of early fatalities without evacuation is considered next. The first variable selected in the regression analysis is YSCALE (scaling factor for horizontal dispersion), which can account for $50 \%$ of the observed variability. As for the $100 \%$ evacuation case, increasing YSCALE decreases the mean number of fatalities by decreasing the number of individuals receiving large radiation exposures. After YSCALE, the regression analysis selects GSHFACN (groundshine shielding factor for nonevacuees) and EFFACA1 (early fatality hazard function alpha value for bone marrow exposure), which can account for $16 \%$ and $10 \%$, respectively, of the observed variability. As for the $100 \%$ evacuation case, GSHFACN has a positive regression coefficient because increasing GSHFACN increases the dose that individuals receive, and EFFACA1 has a negative regression coefficient because increasing EFFACA1 decreases the probability that a given radiation exposure will cause a fatality. The last two variables selected in the regression analysis are TIMHOT (time at which individuals are relocated if their projected dose exceeds DOSHOT) and ZSCALE (scaling factor for vertical dispersion), which can account for $7 \%$ and $6 \%$, respectively, of the variability. The positive regression coefficient for TIMHOT results because increasing TIMHOT increases the radiation exposure that individuals receive before they are relocated, and the negative regression coefficient for ZSCALE results because increasing ZSCALE tends to reduce the number of individuals receiving large radiation exposures. The final regression model containing all five variables can account for $89 \%$ of the observed variability. 
The next regression analysis in Table 7 is for mean number of early fatalities with $100 \%$ sheltering. This analysis is generally similar to the analyses with and without evacuation, with YSCALE (scaling factor for horizontal dispersion) identified as the most important variable and EFFACA1 (early fatality hazard function alpha value for bone marrow exposure) and ZSCALE (scaling factor for vertical dispersion) identified as the next two most important variables. Further, small effects are indicated for GSHFACS (groundshine shielding factor for individuals who shelter), VDEPOS (dry deposition velocity) and PROTINS (inhalation protection factor for individuals who shelter). The variable YSCALE was able to account for $57 \%$ of the variability, and all six variables together could account for $86 \%$. As might be expected, this analysis selected the shielding factors GSHFACS and PROTINS for individuals who shelter rather than shielding factors for nonevacuees. The variable VDEPOS was selected with a positive regression coefficient, while it appears in the analysis for $100 \%$ evacuation with a negative regression coefficient. As examination of Figure 8 shows, VDEPOS plays a complex role in MACCS calculations by increasing the probability of a small number of early fatalities and decreasing the probability of a large number of early fatalities; it is probably a slight difference in the balance between these two roles that is causing VDEPOS to have a positive regression coefficient in one analysis and a negative regression coefficient in the other analysis.

The last regression analysis in Table 7 is for the variable evacuation case in which a fraction EVFRAC of the population does not evacuate and the remaining fraction 1-EVFRAC does evacuate. The number of early fatalities for this case is obtained by a combination of the results that underlie the cases with and without evacuation. The first five variables selected in the regression analysis are YSCALE (scaling factor for horizontal dispersion), ZSCALE (scaling factor for vertical dispersion), EFFACA1 (early fatality hazard function alpha value for bone marrow exposure), ESPEED (evacuation speed), and GSHFACN (groundshine shielding factor for nonevacuees), which are also the first five variables selected in the regression analysis for $100 \%$ evacuation. Although their order of selection varies somewhat, these five variables have identically signed regression coefficients in both analyses; further, they account for $88 \%$ and $87 \%$ of the variability in the $100 \%$ evacuation and variable evacuation cases, respectively. The next variable selected in the regression analysis is EVFRAC (fraction of population in emergency response zone that does not evacuate), which can account for approximately $2 \%$ of the variability. Thus, for this analysis problem, the fraction of the population not participating in evacuation does not have a large effect on the uncertainty in the mean number of early fatalities. After EVFRAC, four additional variables having small effects are identified. Collectively, the ten variables selected in the regression analysis can account for $92 \%$ of the variability, with $63 \%$ of the variability accounted for by YSCALE.

As shown in Table 8, the partial correlation analyses for exceedance probabilities in Figure 8 and the stepwise regression analysis for mean number of early fatalities in Table 7 produce similar, but not identical, sets of important variables and rankings of variable importance. Some differences between the two analyses should be expected as neither the dependent variables nor the analysis techniques are the same, although they are closely related. However, all analyses are consistent in the selection of YSCALE (scaling factor for horizontal dispersion) as the most important variable. Further, with the exception of VDEPOS (dry deposition velocity) in the analysis for variable evacuation, the analyses are consistent in indicating the same effect for variables identified in both analyses. As shown in Figure 8, VDEPOS can have both a positive and negative effect on the probability of exceeding specified numbers of early fatalities. If desired, the top-down correlation technique ${ }^{109}$ could be used to provide a numerical measure of the similarity of the two variable rankings, although such a comparison is not needed in the present study. 
Table 8. Comparison of Variable Selection for Number of Early

Fatalities in Partial Correlation Analysis in Figure 8 and

Stepwise Regression Analysis in Table 7

\begin{tabular}{|c|c|c|c|}
\hline & $\begin{array}{l}\text { Variables Selected in } \\
\text { Both Analyses }\end{array}$ & $\begin{array}{c}\text { Additional } \\
\text { Variables Selected } \\
\text { in Partial } \\
\text { Correlation } \\
\text { Analysis }\end{array}$ & $\begin{array}{c}\text { Additional } \\
\text { Variables Selected } \\
\text { in Stepwise } \\
\text { Regression Analysis }\end{array}$ \\
\hline $\begin{array}{l}\text { Early Fatalities } \\
\text { with } 100 \% \\
\text { Evacuation }\end{array}$ & $\begin{array}{l}\text { YSCALE }(1-, 1-)^{2} \\
\text { ZSCALE }(2-, 3-) \\
\text { TDELAY }(3+, 8+) \\
\text { ESPEED }(4-, 2-) \\
\text { EFFACA1 }(6-, 4-) \\
\text { VDEPOS }(7-, 6-) \\
\text { CSFACTN }(8+, 7+)\end{array}$ & SCLCRW (5-) & $\operatorname{GSHFACN}(5+)^{c}$ \\
\hline $\begin{array}{c}\text { Early Fatalities } \\
\text { with No } \\
\text { Evacuation }\end{array}$ & $\begin{array}{l}\text { YSCALE }(1-, 1-) \\
\text { GSHFACN }(2+, 2+) \\
\text { ZSCALE }(3-, 5-) \\
\text { TIMHOT }(6+, 4+)\end{array}$ & $\begin{array}{l}\text { VDEPOS }(4+-) \\
\text { SCLCRW (5-) }\end{array}$ & EFFACA1 (3-) \\
\hline $\begin{array}{l}\text { Early Fatalities } \\
\text { with } 100 \% \\
\text { Sheltering }\end{array}$ & $\begin{array}{l}\text { YSCALE }(1-, 1-) \\
\text { ZSCALE }(2-, 3-) \\
\text { VDEPOS }(3+, 5+) \\
\text { GSHFACS }(4+, 4+) \\
\text { EFFACA1 }(5-, 2-)\end{array}$ & $\begin{array}{l}\text { SCLCRW (5-) } \\
\text { EFFTHR1 (7-) }\end{array}$ & PROTINS (6+) \\
\hline $\begin{array}{c}\text { Early Fatalities } \\
\text { with Variable } \\
\text { Evacuation }\end{array}$ & $\begin{array}{l}\text { YSCALE }(1-, 1-) \\
\text { ZSCALE }(2-, 2-) \\
\text { VDEPOS }(3+, 10-) \\
\text { GSHFACN }(4+, 5+) \\
\text { ESPEED }(5-, 4-) \\
\text { SCLCRW }(6-, 9-) \\
\text { EVFRAC }(7+, 6+) \\
\text { EFFACA1 }(8-, 3-) \\
\text { TIMHOT }(9+, 7+)\end{array}$ & & CSFACTN $(8+)$ \\
\hline
\end{tabular}

${ }^{2}(i+/-, j+/-)$ indicates that the associated variable had $i^{\text {th }}$ largest PRCC, in absolute value, in Figure 8, with this coefficient being positive $(+)$ or negative $(-)$ when its absolute value exceeds 0.5 and was also the $j^{\text {th }}$ variable selected in the stepwise regression analysis in Table 7 , with the regression coefficient being positive $(+)$ or negative $(-)$.

b $(i+/-)$ indicates that the associated variable had $i^{\text {th }}$ largest PRCC, in absolute value, in Figure 8 , with this coefficient being positive $(+)$ or negative $(-)$ when its absolute value exceeds 0.5 .

c $(j+/-)$ indicates that the associated variable was the $j^{\text {th }}$ variable selected in the stepwise regression analysis in Table 7 , with the regression coefficient being positive $(+)$ or negative $(-)$. 


\subsection{Prodromal Vomiting}

Prodromal vomiting and early fatalities are estimated in the same manner within MACCS. The only difference is in the values used in the expressions in Eqs. (25) and (26) for the threshold dose, hazard function alpha value (i.e, $L_{\mathrm{s}_{0}}$ ), and the hazard function beta value (i.e., shape factor). For prodromal vomiting, the hazard function alpha value is the variable EIFACA1 in Table 4, and the threshold dose and hazard function beta value are fixed at EITHRE1 $=0.5 \mathrm{~Gy}$ and EIFACB1 $=3.75$, respectively. As a result, the analyses for prodromal vomiting are quite similar to the already presented analyses for early fatalities, with EIFACA1 (early injury hazard function alpha value for prodromal vomiting) playing the same role in the analyses for prodromal vomiting as EFFACA1 (early fatality hazard function alpha value for bone marrow exposure) in the analyses for early fatalities. Because of this similarity, Figures 10,11, and 12 and Tables 9 and 10 are presented without discussion. The discussions of the corresponding results in Section 5.1 for early fatalities can be consulted for additional information. The similarity of the results for early fatalities and prodromal vomiting can be seen by comparing the variable rankings summarized in Tables 8 and 10.

\subsection{Population Dose, 0-10 mi}

The distributions of CCDFs for population dose received by individuals initially within $10 \mathrm{mi}$ of the reactor are summarized by the mean and percentile curves presented in Figure 13. As examination of these curves shows, the analyses with evacuation actually yield higher doses than the analyses without evacuation. This pattern results because evacuees have larger shielding factors (i.e., less shielding) than nonevacuees and may also be under the plume for part of the time that they are evacuating.

The PRCC analyses for the probability of exceeding specified dose levels are given in Figure 14. For $100 \%$ evacuation, the most important variable, as measured by the absolute value of the PRCC, for the population dose to individuals initially within $10 \mathrm{mi}$ of the reactor is TDELAY (time from warning to start of evacuation), with the exceedance probabilities for population doses tending to increase as TDELAY increases. As examination of the PRCC plot for TDELAY shows, a strong positive correlation exists between TDELAY and exceedance probability for small population doses, with this correlation decreasing as the population dose increases. This pattern may occur because, although increasing TDELAY tends to increase the dose to individuals before they begin to evacuate, large values for TDELAY also reduce the amount of time that evacuees might spend evacuating under the plume and thus reduce their doses while evacuating. The next variable identified in the analysis is YSCALE (scaling factor for horizontal dispersion), which has a negative correlation, with the probability of exceeding doses between approximately $1 \times 10^{3}$ and $1 \times 10^{5} \mathrm{~Sv}$. This effect does not appear in the analyses for no evacuation and $100 \%$ sheltering and thus must be related to the doses received by individuals who undergo evacuation. In particular, individuals within $10 \mathrm{mi}$ of the reactor are evacuating radially and are assumed to receive no additional dose after they are 20 - $\mathrm{mi}$ from the reactor. The reduced exposure from increasing YSCALE results from a combination of shifting part of the plume to regions within $20 \mathrm{mi}$ of the reactor from which evacuees have already departed and decreasing the distance from the reactor at which the plume edges start to move outside of the boundary of the 20-mi zone within which radiation exposures to evacuees are calculated. After YSCALE, negative effects are indicated for ESPEED (evacuation speed), VDEPOS (dry deposition velocity), and ZSCALE (scaling factor for vertical dispersion). Increasing ESPEED reduces the exposure to evacuees by reducing the transit time in evacuation; increasing VDEPOS results in more deposition close to the reactor and hence in less total exposure, and increasing ZSCALE tends to move the plume higher and hence reduce exposure to both radioactivity in the plume and radioactivity deposited on the ground. Finally, a positive effect is indicated 

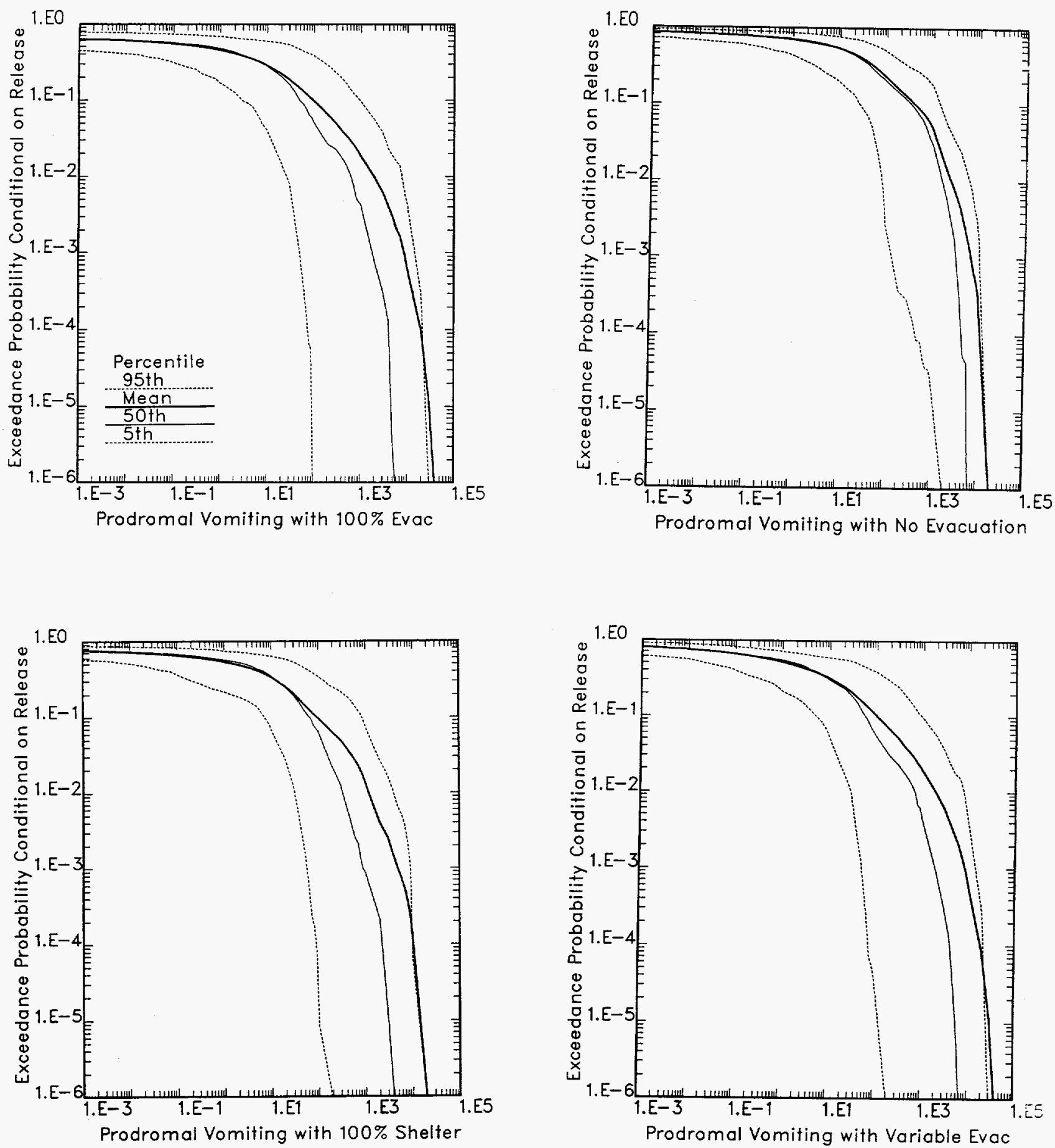

Figure 10. Mean and Percentile Curves for Number of Cases of Prodromal Vomiting for the Following Analysis Cases: 100\% Evacuation, No Evacuation, $100 \%$ Sheltering, and Variable Evacuation. 
Determination of Dominant Variables
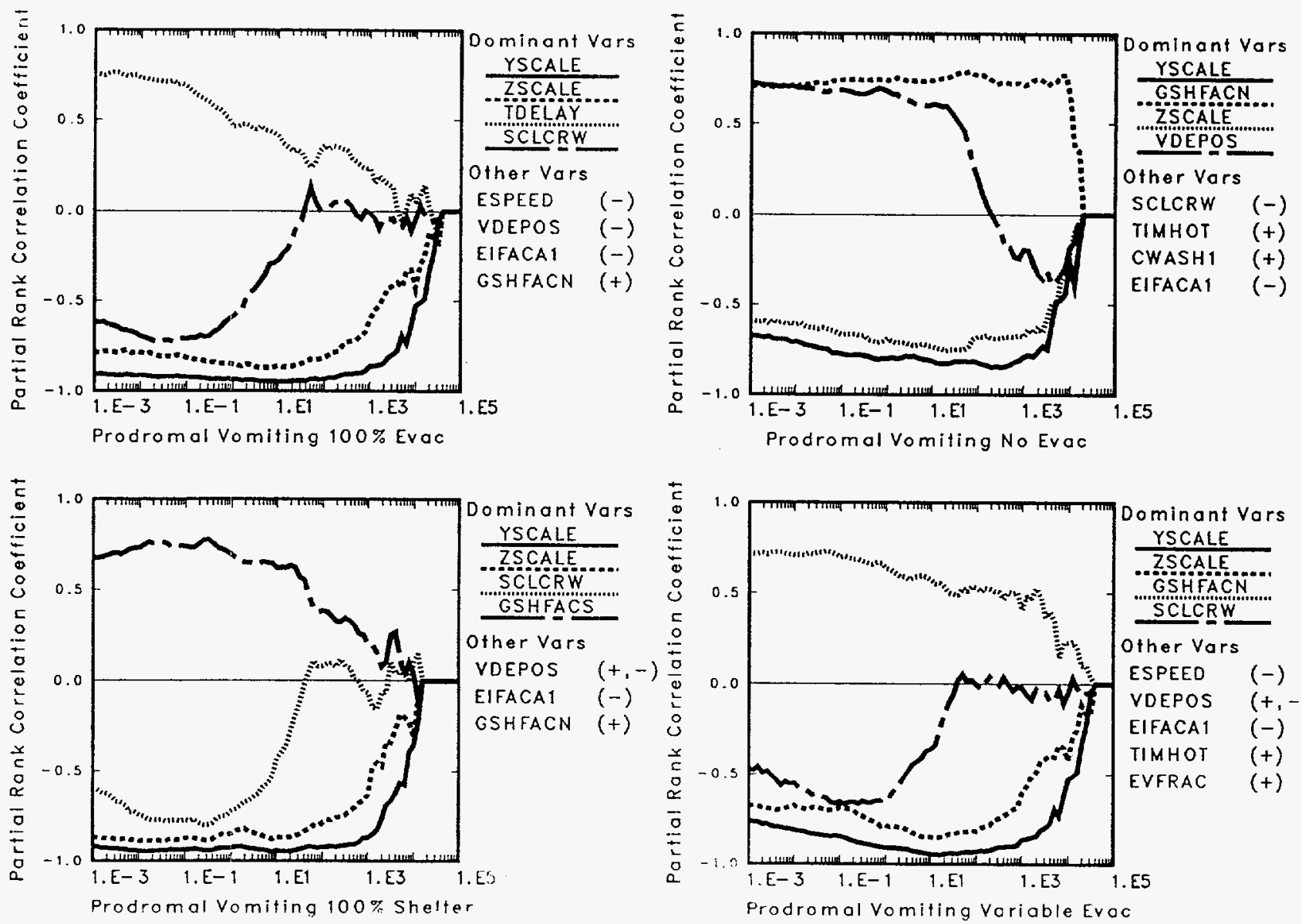

Figure 11. Partial Rank Correlation Coefficients for Probability that Specified Numbers of Prodromal Vomiting Cases Will Be Exceeded for the Following Analysis Cases: $100 \%$ Evacuation, No Evacuation, $1100 \%$ Sheltering, and Variable Evacuation. 

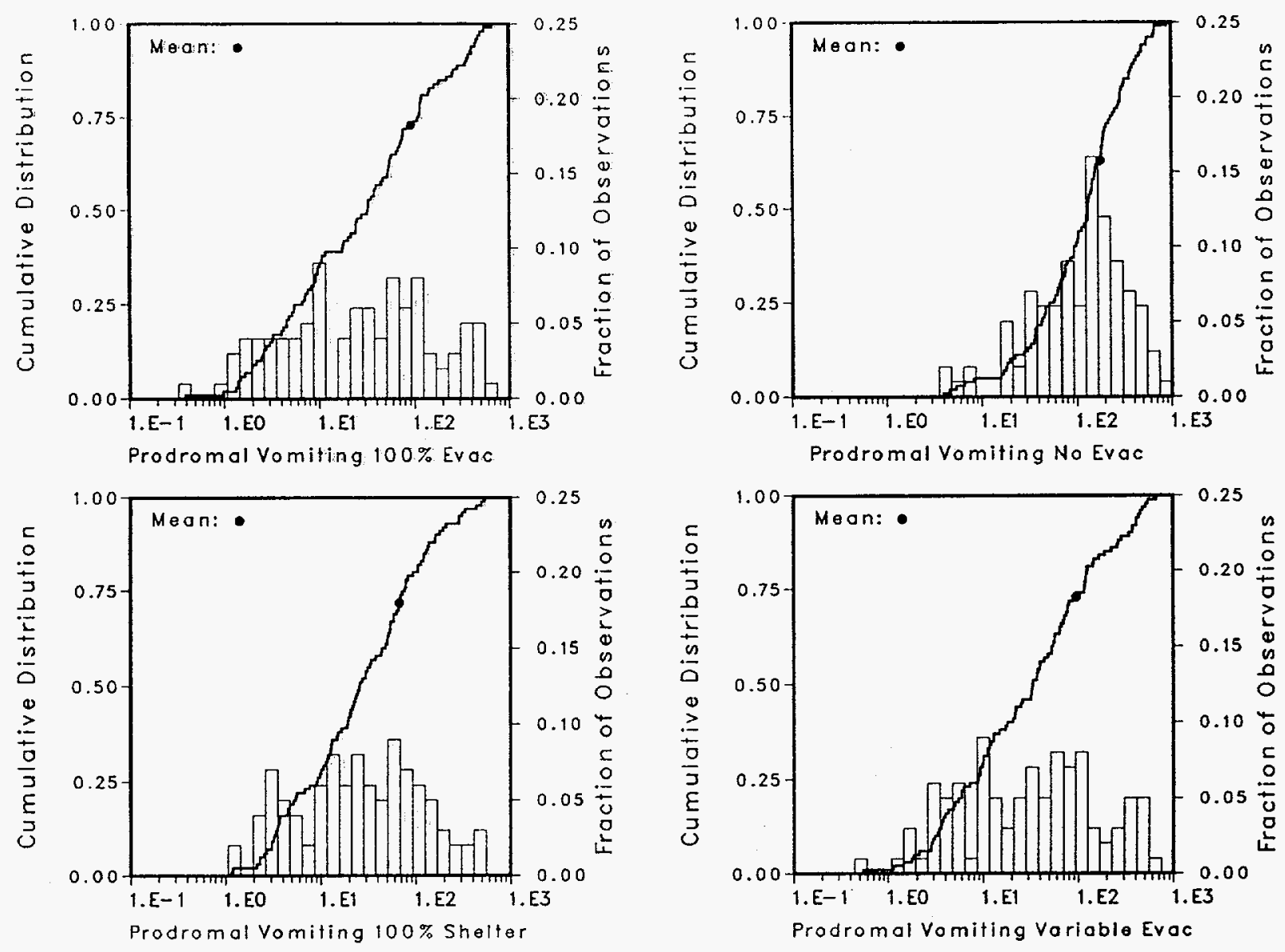

Figure 12. Distribution of Mean Number of Cases of Prodromal Vomiting for the Following Analysis Cases: 100\% Evacuation, No Evacuation, $100 \%$ Sheltering, and Variable Evacuation. 
Determination of Dominant Variables

Table 9. Stepwise Regression Analyses with Rank-Transformed Data for Mean Number of Cases of Prodromal Vomiting for the Following Cases: $100 \%$ Evacuation, No Evacuation, $100 \%$ Sheltering, and Variable Evacuation

\begin{tabular}{||c|l|c|c|l|l|l||}
\cline { 2 - 7 } \multicolumn{1}{c|}{} & \multicolumn{3}{c|}{$100 \%$ Evacuation } & \multicolumn{3}{c||}{ No Evacuation } \\
\hline Step $^{\mathbf{a}}$ & Variable $^{\mathbf{b}}$ & SRC $^{\mathbf{c}}$ & $\mathbf{R}^{2 \mathrm{~d}}$ & Variable $^{\mathbf{b}}$ & SRC $^{\mathbf{c}}$ & $\mathbf{R}^{\mathbf{2} \mathbf{d}}$ \\
\hline 1 & YSCALE & -0.66 & 0.67 & YSCALE & -0.50 & 0.45 \\
2 & ZSCALE & -0.36 & 0.78 & GSHFACN & 0.44 & 0.65 \\
3 & ESPEED & -0.24 & 0.83 & ZSCALE & -0.36 & 0.74 \\
4 & VDEPOS & -0.19 & 0.87 & TIMHOT & 0.31 & 0.84 \\
5 & GSHFACN & 0.15 & 0.89 & EIFACA1 & -0.17 & 0.87 \\
6 & EIFACA1 & -0.16 & 0.92 & & & \\
7 & TDELAY & 0.12 & 0.93 & & & \\
8 & TIMHOT & 0.08 & 0.94 & & & \\
9 & CSFACTE & 0.07 & 0.94 & & & \\
\hline
\end{tabular}

\begin{tabular}{|c|c|c|c|c|c|c|}
\hline \multirow[b]{2}{*}{ Step ${ }^{a}$} & \multicolumn{3}{|c|}{$100 \%$ Shelter } & \multicolumn{3}{|c|}{ Variable Evacuation } \\
\hline & Variable $^{\mathrm{b}}$ & SRC $^{c}$ & $R^{2 d}$ & Variable $^{b}$ & $S_{R C}^{c}$ & $\mathbf{R}^{\mathbf{2 d}}$ \\
\hline 1 & YSCALE & -0.68 & 0.73 & YSCALE & -0.66 & 0.67 \\
\hline 2 & ZSCALE & -0.38 & 0.84 & ZSCALE & -0.35 & 0.77 \\
\hline 3 & EIFACA1 & -0.18 & 0.87 & ESPEED & -0.23 & 0.82 \\
\hline 4 & GSHFACS & 0.15 & 0.90 & GSHFACN & 0.17 & 0.86 \\
\hline 5 & GSHFACN & 0.11 & 0.91 & VDEPOS & -0.17 & 0.89 \\
\hline 6 & VDEPOS & -0.11 & 0.92 & EIFACA1 & -0.16 & 0.91 \\
\hline 7 & TIMHOT & 0.10 & 0.93 & TIMHOT & 0.11 & 0.92 \\
\hline 8 & PROTINS & 0.08 & 0.93 & TDELAY & 0.09 & 0.93 \\
\hline
\end{tabular}

"Steps in stepwise regression analysis.

bVariables listed in order of selection in regression analysis.

'Standardized regression coefficients in final regression model.

${ }^{d}$ Cumulative $R^{2}$ value with entry of each variable into regression model. 
Table 10. Comparison of Variable Selection for Number of Cases of Prodromal Vomiting in Partial Correlation Analysis in Figure 11 and Stepwise Regression Analysis in Table 9

\begin{tabular}{|c|c|c|c|}
\hline & $\begin{array}{l}\text { Variables Selected in } \\
\text { Both Analyses }\end{array}$ & $\begin{array}{l}\text { Additional } \\
\text { Variables Selected } \\
\text { in Partial } \\
\text { Correlation } \\
\text { Analysis }\end{array}$ & $\begin{array}{c}\text { Additional } \\
\text { Variables Selected } \\
\text { in Stepwise } \\
\text { Regression Analysis }\end{array}$ \\
\hline $\begin{array}{l}\text { Prodromal Vomiting } \\
\text { with } 100 \% \\
\text { Evacuation }\end{array}$ & $\begin{array}{l}\text { YSCALE }(1-, 1-)^{\mathrm{a}} \\
\text { ZSCALE }(2-, 2-) \\
\text { TDELAY }(3+, 7+) \\
\text { ESPEED }(5-, 3-) \\
\text { VDEPOS }(6-, 4-) \\
\text { EIFACA1 }(7-, 6-) \\
\text { GSHFACN }(8+, 5+)\end{array}$ & SCLCRW (4- $)^{b}$ & $\begin{array}{l}\text { TIMHOT }(+)^{c} \\
\text { CSFACTE }(+)\end{array}$ \\
\hline $\begin{array}{l}\text { Prodromal Vomiting } \\
\text { with No Evacuation }\end{array}$ & $\begin{array}{l}\text { YSCALE }(1-, 1-) \\
\text { GSHFACN }(2+, 2+) \\
\text { ZSCALE }(3-, 3-) \\
\text { TIMHOT }(5+, 4+) \\
\text { EIFACA1 }(8-, 5-)\end{array}$ & $\begin{array}{ll}\text { VDEPOS } & (4+) \\
\text { SCLCRW } & (5-) \\
\text { CWASH1 } & (7+)\end{array}$ & \\
\hline $\begin{array}{l}\text { Prodromal Vomiting } \\
\text { with } 100 \% \text { Sheltering }\end{array}$ & $\begin{array}{l}\text { YSCALE }(1-, 1-) \\
\text { ZSCALE }(2-, 2-) \\
\text { GSHFACN }(4+, 4+) \\
\text { VDEPOS }(5+-, 6-) \\
\text { EFFACA1 }(6-, 3-) \\
\text { GSHFACN }(7+, 5+)\end{array}$ & SCLCRW (3-) & $\begin{array}{l}\text { TIMHOT }(7+) \\
\text { PROTINS }(8+)\end{array}$ \\
\hline $\begin{array}{l}\text { Prodromal Vomiting } \\
\text { with Variable } \\
\text { Evacuation }\end{array}$ & $\begin{array}{l}\text { YSCALE }(1-, 1-) \\
\text { ZSCALE }(2-, 2-) \\
\text { GSHFACN }(3+, 4+) \\
\text { ESPEED }(5-, 3-) \\
\text { VDEPOS }(6+-, 5-) \\
\text { EIFACA1 }(7-, 6-) \\
\text { TIMHOT }(8+, 7+) \\
\text { EFFACA1 }(8-, 3-) \\
\text { TIMHOT }(9+, 7+)\end{array}$ & $\begin{array}{l}\text { SCLCRW (4-) } \\
\text { EVFRAC }(9+)\end{array}$ & TDELAY $(+)$ \\
\hline
\end{tabular}

" $(i+/-, j+/-)$ indicates that the associated variable had $i^{\text {th }}$ largest PRCC, in absolute value, in Figure 11, with this coefficient being positive $(+)$ or negative $(-)$ when its absolute value exceeds 0.5 and was also the $j^{\text {th }}$ variable selected in the stepwise regression analysis in Table 9 , with the regression coefficient being positive $(+)$ or negative $(-)$.

b $(i+/-)$ indicates that the associated variable had $i^{\text {th }}$ largest $\mathrm{PRCC}$, in absolute value, in Figure 11 , with this coefficient being positive $(+)$ or negative $(-)$ when its absolute value exceeds 0.5 .

${ }^{c}(j+/-)$ indicates that the associated variable was the $j^{\text {th }}$ variable selected in the stepwise regression analysis in Table 9 , with the regression coefficient being positive $(+)$ or negative $(-)$. 
Determination of Dominant Variables
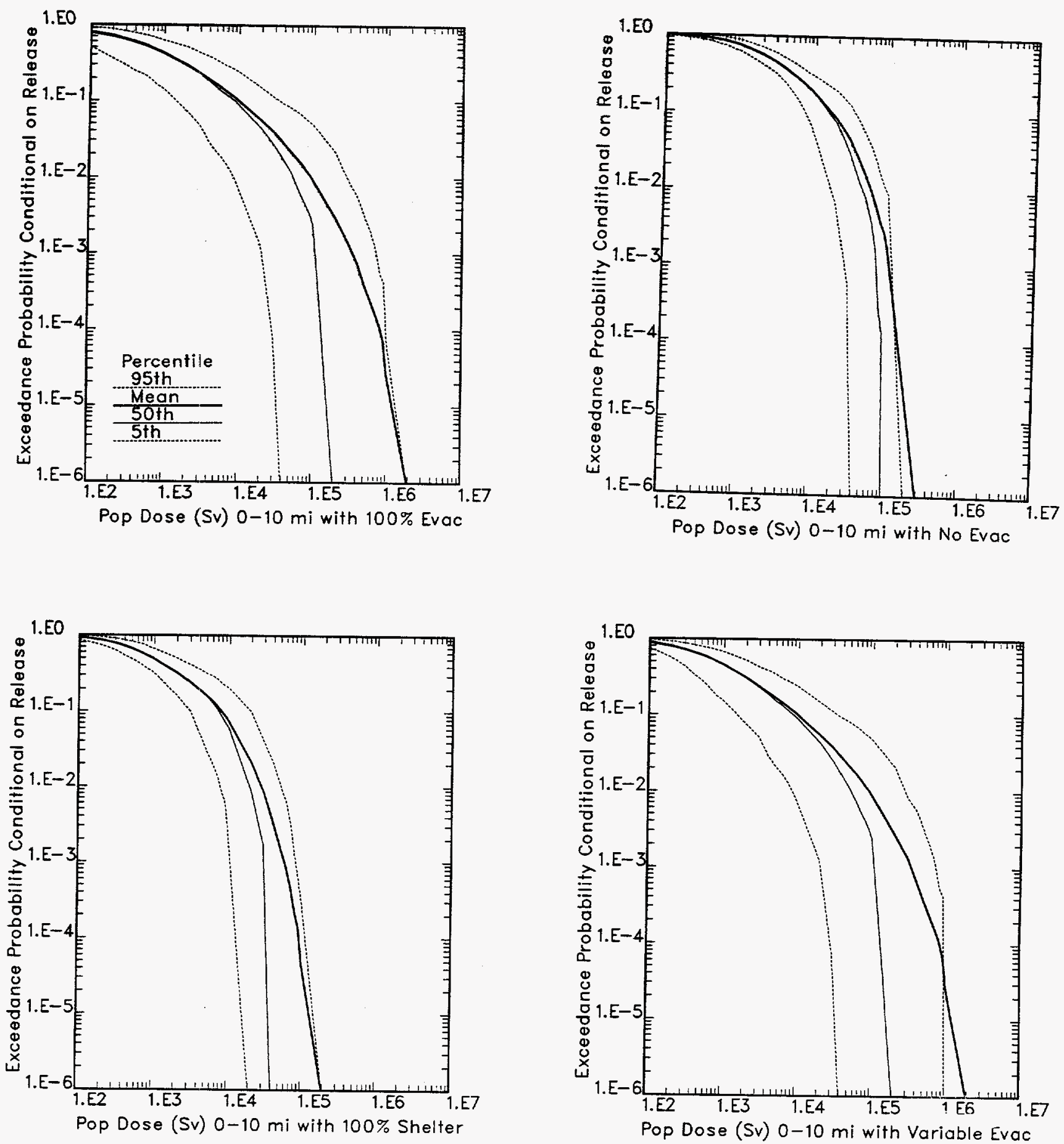

Figure 13. Mean and Percentile Curves for Population Dose (Sv) for Individuals Initially within $10 \mathrm{mi}$ of the Reactor for the Following Cases: $100 \%$ Evacuation, No Evacuation, $100 \%$ Sheltering, and Variable Evacuation. 
Determination of Dominant Variables
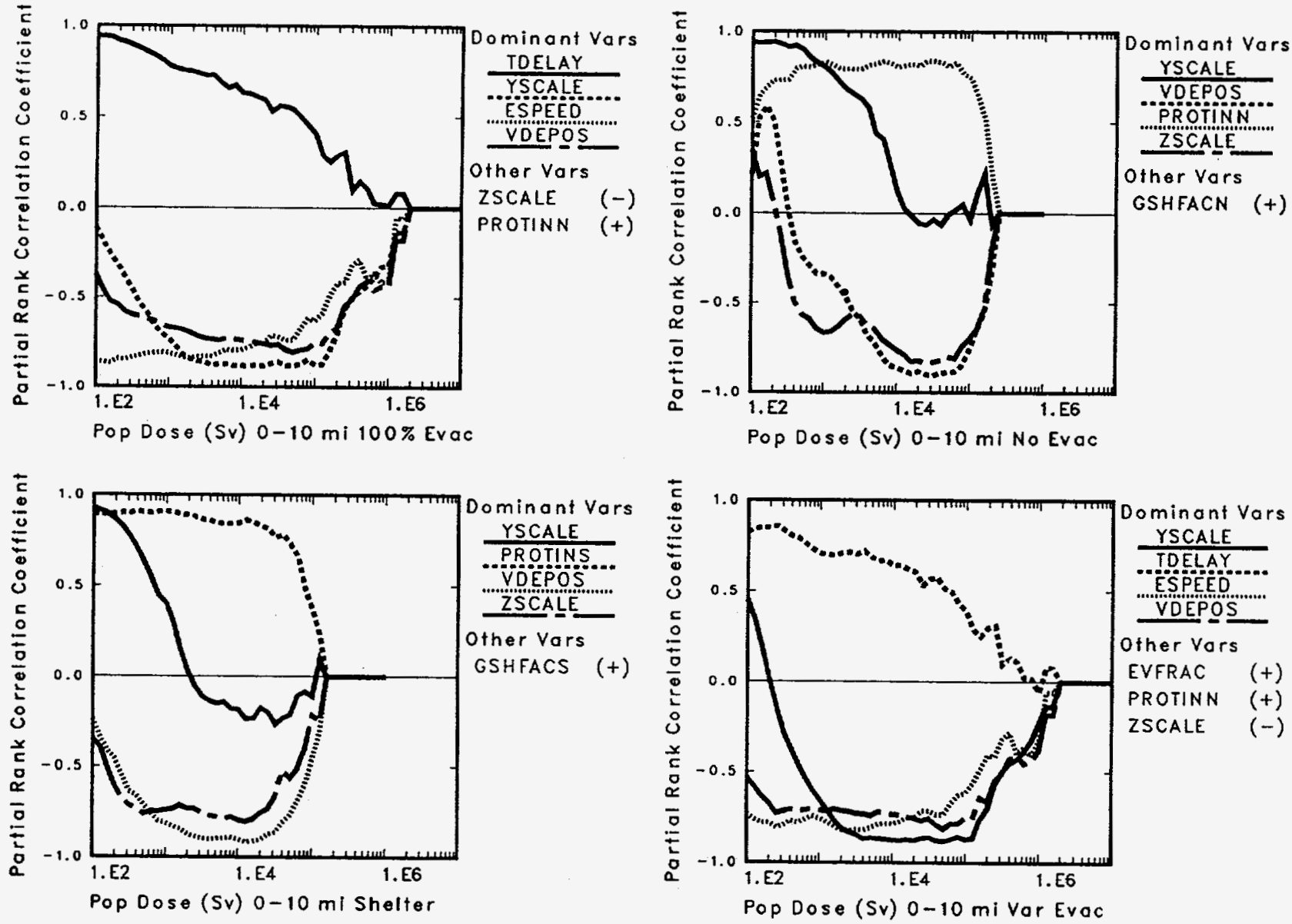

Figure 14. Partial Rank Correlation Coefficients for Probability that Specified Doses (Sv) to the Population Initially within $\mathbf{1 0}$ mi of the Reactor Will Be Exceeded for the Following Cases: $100 \%$ Evacuation, No Evacuation, $100 \%$ Sheltering, and Variable Evacuation. 
for PROTINN (inhalation protection factor for nonevacuees), which results because increasing PROTINN increases the radiation exposure that individuals receive before they begin to evacuate.

For no evacuation, YSCALE (scaling factor for horizontal dispersion) has the largest PRCC in absolute value, with the probability of exceeding small population doses tending to increase as YSCALE increases. However, the impact of YSCALE decreases as dose increases, with YSCALE having essentially no impact on the probabilities of exceeding large doses. This is quite different from the effects indicated for YSCALE in the analysis for $100 \%$ evacuation, where increasing YSCALE tended to reduce the probability of exceeding large doses. In addition, positive effects are indicated for PROTINN (inhalation protection factor for nonevacuees) and GSHFACN (groundshine protection factor for nonevacuees), and negative effects are indicated for VDEPOS (dry deposition velocity) and ZSCALE (scaling factor for vertical dispersion). An interesting pattern is shown by VDEPOS, with this variable having a positive effect on the probability of exceeding small doses and a negative effect on the probability of exceeding large doses. This pattern probably results because large values of VDEPOS result in large doses to a small number of individuals while small values of VDEPOS result in small doses to a large number of individuals. The effect of VDEPOS is further complicated by the fact that both hotspot and normal relocation are based on projected individual dose, with the result that large values of VDEPOS may lead to more dose avoidance by relocation than small values of VDEPOS.

For $100 \%$ sheltering, the patterns of variable importance shown in Figure 14 are very similar to those shown for no evacuation with the exception that the shielding factors PROTINS (inhalation protection factor for individuals who shelter) and GSHFACS (groundshine shielding factor for individuals who shelter) are selected in the PRCC analysis rather than the corresponding shielding factors for nonevacuees. This similarity results because the shielding factors in use are the primary differences between these two analyses, although there are also differences related to the times at which sheltering and relocation take place.

For variable evacuation, the patterns of variable importance shown in Figure 14 are essentially the same as those shown for $100 \%$ evacuation. The positive effect indicated for EVFRAC (fraction of population in emergency response zone that does not evacuate) only occurs for small doses, where the variability is coming primarily from the evacuees, as shown in the upper two frames of Figure 13.

The distributions of CCDFs summarized in Figure 13 can be reduced to the distributions of expected dose shown in Figure 15. Then, as summarized in Table 11, stepwise regression analysis can be used to investigate the variability in these expected doses.

For $100 \%$ evacuation, the stepwise regression analysis in Table 11 indicates that YSCALE (scaling factor for horizontal dispersion) is the most important variable affecting expected population dose to individuals initially within $10 \mathrm{mi}$ of the reactor, with expected dose tending to decrease as YSCALE increases. This is consistent with the negative influence on the probability of exceeding large doses indicated for YSCALE in Figure 14. Also in consistency with the results shown in Figure 14, negative effects are indicated for ESPEED (evacuation speed), VDEPOS (dry deposition velocity) and ZSCALE (scaling factor for vertical dispersion), and a positive effect is indicated for TDELAY (time from warning to start of evacuation). The variables YSCALE, ESPEED, and VDEPOS are the first three variables selected in the regression analysis and can account for $77 \%$ of the variability in mean dose; adding TDELAY and ZSCALE results in regression models that can account for an additional 7\% and 3\%, respectively, of the variability. On the basis of absolute value of the $\mathrm{PRCC}$, the analysis shown in Figure 14 would rank TDELAY as the most important variable; however, TDELAY is less important in affecting 
Determination of Dominant Variables
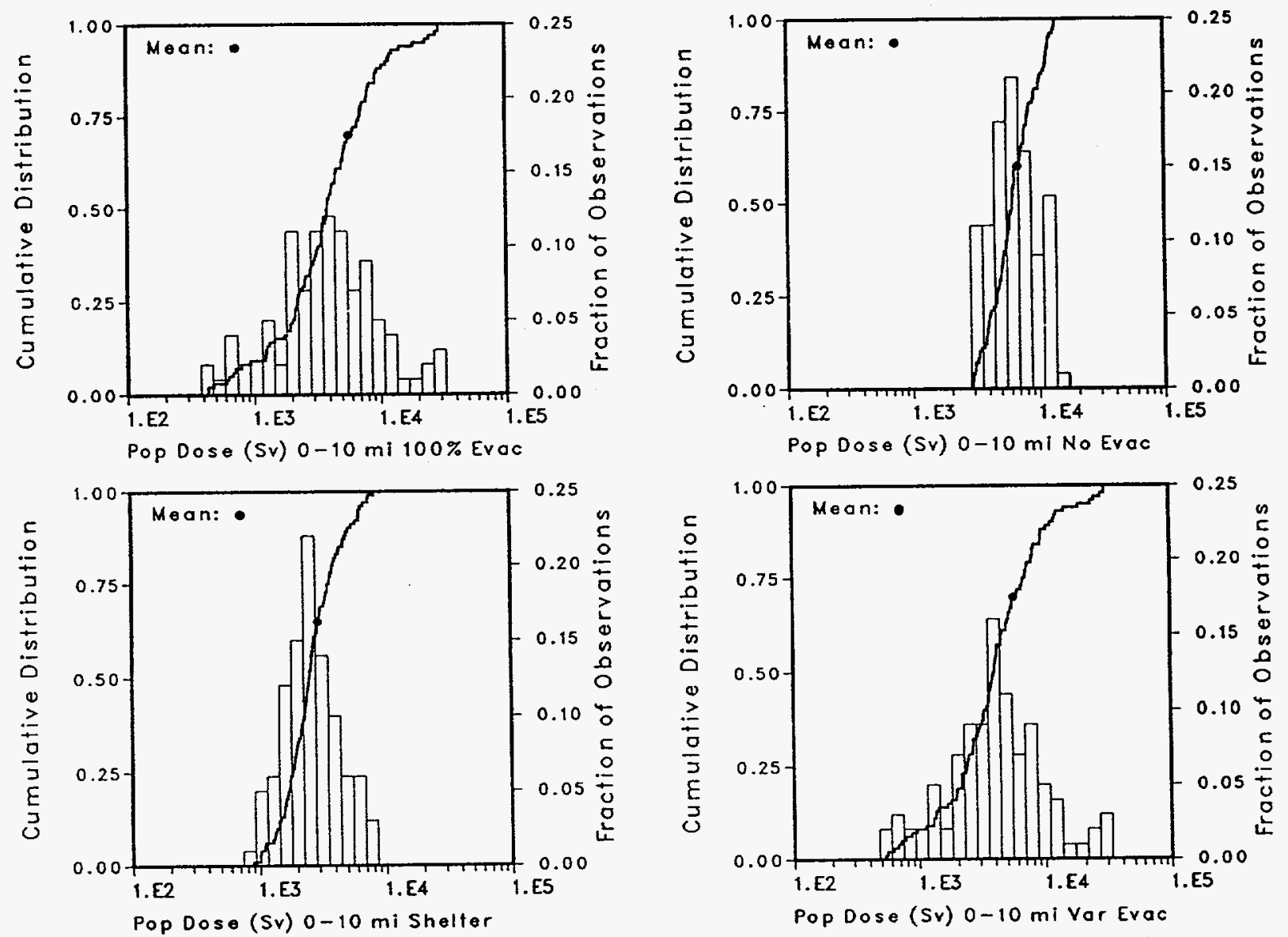

Figure 15. Distribution of Mean Population Dose (Sv) for Individuals Initially Within 10 mi of the Reactor for the Following Cases: $100 \%$ Evacuation, No Evacuation, $100 \%$ Sheltering, and Variable Evacuation. 
Determination of Dominant Variables

Table 11. Stepwise Regression Analyses with Rank-Transformed Data for Mean Population Dose (Sv), 0-10 mi, for the Following Cases: $100 \%$ Evacuation, No Evacuation, $100 \%$ Sheltering, and Variable Evacuation

\begin{tabular}{||c|l|c|c|l|c|c||}
\cline { 2 - 7 } \multicolumn{1}{c|}{} & \multicolumn{3}{c|}{$100 \%$ Evacuation } & \multicolumn{3}{c|}{ No Evacuation } \\
\hline Step $^{\mathbf{2}}$ & Variable $^{\mathrm{b}}$ & SRC $^{\mathrm{c}}$ & $\mathbf{R}^{\mathbf{2} \mathrm{d}}$ & Variable $^{\mathrm{b}}$ & SRC $^{\mathrm{c}}$ & $\mathbf{R}^{\mathbf{2 d}}$ \\
\hline 1 & YSCALE & -0.60 & 0.48 & VDEPOS & -0.55 & 0.34 \\
2 & ESPEED & -0.37 & 0.64 & PROTINN & 0.50 & 0.56 \\
3 & VDEPOS & -0.37 & 0.77 & ZSCALE & -0.44 & 0.74 \\
4 & TDELAY & 0.26 & 0.84 & GSHFACN & 0.25 & 0.80 \\
5 & ZSCALE & -0.21 & 0.87 & TIMHOT & 0.21 & 0.85 \\
6 & & & & SCLEFP & 0.11 & 0.86 \\
\hline
\end{tabular}

\begin{tabular}{|c|c|c|c|c|c|c|}
\hline & \multicolumn{3}{|c|}{$100 \%$ Shelter } & \multicolumn{3}{|c|}{ Variable Evacuation } \\
\hline Step $^{\mathrm{a}}$ & Variable $^{b}$ & $\mathrm{SRC}^{\mathrm{c}}$ & $\mathbf{R}^{2 \mathrm{~d}}$ & Variable $^{b}$ & $S_{R C}$ & $\mathbf{R}^{\mathbf{2 d}}$ \\
\hline 1 & VDEPOS & -0.61 & 0.37 & YSCALE & -0.59 & 0.46 \\
\hline 2 & PROTINS & 0.55 & 0.67 & VDEPOS & -0.37 & 0.63 \\
\hline 3 & ZSCALE & -0.43 & 0.85 & ESPEED & -0.36 & 0.76 \\
\hline 4 & & & & TDELAY & 0.25 & 0.82 \\
\hline 5 & & & & ZSCALE & -0.23 & 0.86 \\
\hline
\end{tabular}

Steps in stepwise regression analysis.

${ }^{b}$ Variables listed in order of selection in regression analysis.

'Standardized regression coefficients in final regression model.

${ }^{d}$ Cumulative $R^{2}$ value with entry of each variable into regression model. 
mean dose than YSCALE, ESPEED, and VDEPOS because TDELAY primarily affects small doses while the other three variables primarily affect large doses.

For no evacuation, the first three variables selected in the regression analysis for mean population dose presented in Table 11 are VDEPOS (dry deposition velocity), PROTINN (inhalation protection factor for nonevacuees) and ZSCALE (scaling factor for vertical dispersion), which can account for 34\%, $22 \%$ and $18 \%$ of the uncertainty in mean dose, respectively. In addition, GSHFACN (groundshine shielding factor for nonevacuees), TIMHOT (time at which individuals are relocated if their projected dose exceeds DOSHOT) and SCLEFP (plume rise scaling factor for stability classes $E$ through F) account for $6 \%, 5 \%$ and $1 \%$ of the uncertainty in mean dose. Increasing VDEPOS results in more concentrated deposits of radioactivity and hence in more effective dose avoidance by relocation; increasing PROTINN and GSHFACN increases dose by reducing shielding; increasing TIMHOT increases dose by increasing the exposure that individuals receive before they are relocated, and increasing SCLEFP increases dose by reducing plume rise and thus increasing the amount of radioactivity that will be deposited within 10 $\mathrm{mi}$ of the reactor.

For $100 \%$ sheltering, the regression analysis in Table 11 selects VDEPOS (dry deposition velocity), PROTINS (inhalation protection factor for individuals who shelter) and ZSCALE (scaling factor for vertical dispersion), which can account for $37 \%, 30 \%$ and $18 \%$, respectively, of the observed uncertainty in dose to individuals initially within 10 miles of the reactor. This selection is the same as the first three variables identified in the analysis for no evacuation, with the exception that PROTINS rather than PROTINN (inhalation protection factor for nonevacuees) appears in the regression model.

The regression analysis in Table 11 for variable evacuation is similar to the analysis for $100 \%$ evacuation, with the exception that the order of importance indicated for ESPEED (evacuation speed) and VDEPOS (dry deposition velocity) is reversed. This reversal probably occurs because VDEPOS is the third most important variable, accounting for $13 \%$ of the uncertainty for $100 \%$ evacuation and the most important variable, accounting for $34 \%$ of the uncertainty for no evacuation. For variable evacuation, VDEPOS is the second most important variable, accounting for $17 \%$ of the uncertainty. The variable ESPEED is of reduced importance for the variable evacuation case relative to $100 \%$ evacuation because although ESPEED affects the doses received by evacuees, it has no effect on the doses received by nonevacuees.

A comparison of the sensitivity analysis results for population dose to individuals initially within $10 \mathrm{mi}$ of the reactor obtained with PRCCs and stepwise regression is presented in Table 12. Overall, the rankings of variable importance obtained with the two approaches are quite similar. The notable exception to this is the designation of YSCALE (scaling factor for horizontal dispersion) as being the most important variable in the PRCC analyses for population dose to individuals initially within $10 \mathrm{mi}$ of the reactor under the assumptions of no evacuation and $100 \%$ sheltering, while YSCALE is not even selected in the corresponding regression analyses. However, as examination of the PRCC plots in Figure 15 shows, YSCALE has a large effect on the exceedance probabilities for small doses. Thus, because as the mean is dominated by the large doses, the absence of YSCALE from the regression analyses for mean dose is consistent with the effects indicated for YSCALE in the PRCC analysis. 
Table 12. Comparison of Variable Selection for Population Dose (Sv) to Individuals Initially Within $\mathbf{1 0}$ mi of the Reactor in Partial Correlation Analysis in Figure 14 and Stepwise Regression Analysis in Table 11

\begin{tabular}{|c|c|c|c|}
\hline & $\begin{array}{l}\text { Variables Selected in } \\
\text { Both Analyses }\end{array}$ & $\begin{array}{l}\text { Additional Variables } \\
\text { Selected in Partial } \\
\text { Correlation Analysis }\end{array}$ & $\begin{array}{l}\text { Additional Variables } \\
\text { Selected in Stepwise } \\
\text { Regression Analysis }\end{array}$ \\
\hline $\begin{array}{c}\text { Population Dose, 0-10 } \\
\text { mi, with } 100 \% \\
\text { Evacuation }\end{array}$ & $\begin{array}{l}\text { TDELAY }(1+, 4+)^{a} \\
\text { YSCALE }(2-, 1-) \\
\text { ESPEED }(3-, 2-) \\
\text { VDEPOS }(4-, 3-) \\
\text { ZSCALE }(5-, 5-)\end{array}$ & PROTINN $(6+)^{b}$ & \\
\hline $\begin{array}{c}\text { Population Dose, 0-10 } \\
\text { mi, with No } \\
\text { Evacuation }\end{array}$ & $\begin{array}{l}\text { VDEPOS }(2+-, 1-) \\
\text { PROTINN }(3+, 2+) \\
\text { ZSCALE }(4-, 3-) \\
\text { GSHFACN }(5+, 4+)\end{array}$ & YSCALE $(1+)$ & $\begin{array}{l}\text { TIMHOT }(5+)^{c} \\
\text { SCLEFP }(6+)\end{array}$ \\
\hline $\begin{array}{c}\text { Population Dose, 0-10 } \\
\text { mi, with 100\% } \\
\text { Sheltering }\end{array}$ & $\begin{array}{l}\text { PROTINS }(2+, 2+) \\
\text { VDEPOS }(3-, 1-) \\
\text { ZSCALE }(4-, 3-) \\
\end{array}$ & $\begin{array}{l}\text { YSCALE }(1+) \\
\text { GSHFACS }(5+)\end{array}$ & \\
\hline $\begin{array}{c}\text { Population Dose, 0-10 } \\
\text { mi, with Variable } \\
\text { Evacuation }\end{array}$ & $\begin{array}{l}\text { YSCALE }(1-, 1-) \\
\text { TDELAY }(2+, 4+) \\
\text { ESPEED }(3-, 3-) \\
\text { VDEPOS }(4-, 2-) \\
\text { ZSCALE }(7-, 5-)\end{array}$ & $\begin{array}{l}\text { EVFRAC }(5+) \\
\text { PROTINN }(6+)\end{array}$ & \\
\hline
\end{tabular}

" $(i+/-, j+/-)$ indicates that the associated variable had $i^{\text {th }}$ largest PRCC, in absolute value, in Figure 14, with this coefficient being positive $(+)$ or negative $(-)$ when its absolute value exceeds 0.5 and was also the $j^{\text {th }}$ variable selected in the stepwise regression analysis in Table 11, with the regression coefficient being positive $(+)$ or negative $(-)$.

${ }^{b}(i+1-)$ indicates that the associated variable had $i^{\text {th }}$ largest PRCC, in absolute value, in Figure 14, with this coefficient being positive $(+)$ or negative $(-)$ when its absolute value exceeds 0.5 .

${ }^{c}(j+/-)$ indicates that the associated variable was the $j^{\text {th }}$ variable selected in the stepwise regression analysis in Table 11 , with the regression coefficient being positive $(+)$ or negative $(-)$. 


\subsection{Population Dose, 0-1000 mi}

The distributions of CCDFs for population dose received by individuals within $1000 \mathrm{mi}$ of the reactor are summarized in Figure 16. Because a substantial portion of this dose is received by individuals initially more than $10 \mathrm{mi}$ from the reactor, the summaries in Figure 16 for the four emergency response assumptions under consideration are similar. However, as comparison of the CCDFs for $100 \%$ evacuation and no evacuation shows, a poorly chosen evacuation strategy can substantially increase the 1000-mi population dose.

The PRCC analyses for the CCDF distributions summarized in Figure 16 are presented in Figure 17. Given the similarity of the CCDF distributions, it is not surprising that the PRCC analyses in Figure 17 for the four emergency response assumptions are also similar. In particular, positive effects are indicated for PROTINN (inhalation protection factor for nonevacuees), GSHFACN (groundshine shielding factor for nonevacuees) and YSCALE (scaling factor for horizontal dispersion), and a negative effect is indicated for VDEPOS (dry deposition velocity). The only real difference in the analyses in Figure 17 involves YSCALE, which has a positive effect on the exceedance probabilities for small doses (i.e., $10^{4}$ $\mathrm{Sv})$ for all emergency response assumptions but a negative effect on the exceedance probabilities for large doses only for $100 \%$ evacuation and variable evacuation. As shown in Figure 14, this pattern results from the tendency of large values of YSCALE to produce a reduction of large doses to evacuees.

The result of reducing the CCDFs summarized in Figure 16 to distributions of expected doses is shown in Figure 18. Owing to the importance of emergency response assumptions about the population dose to individuals initially within $10 \mathrm{mi}$ of the reactor, the distributions for expected dose, at $0-10 \mathrm{mi}$ in Figure 15 are considerably broader than the distributions for expected dose at 0-1000 mi in Figure 18.

The stepwise regression analyses for the mean population doses presented in Figure 18 are summarized in Table 13. Owing to the importance of doses received by individuals initially outside the emergency response zone (i.e., more than $10 \mathrm{mi}$ from the reactor), the four regression analyses summarized in Table 12 are quite similar. In particular, the first three variables selected in all four analyses are VDEPOS (dry deposition velocity), GSHFACN (groundshine shielding factor for nonevacuees), and PROTINN (inhalation protection factor for nonevacuees), with dose tending to decrease as VDEPOS increases and tending to increase as GSHFACN and PROTINN each increases. In each analysis, these three variables can account for $86 \%$ or $87 \%$ of the observed uncertainty. After VDEPOS, GSHFACN, and PROTINN, each of the regression analyses in Table 13 selects several additional variables that have small effects on the population dose.

A comparison of the sensitivity analysis results for population dose within $1000 \mathrm{mi}$ of the reactor obtained with PRCCs and stepwise regression analysis is presented in Table 14. As examination of this table shows, both sensitivity analyses select VDEPOS (dry deposition velocity), GSHFACN (groundshine shielding factor for nonevacuees), and PROTINN (inhalation protection factor for nonevacuees) as the three most important variables with respect to each of the four population doses under consideration. There is considerable variability in the variables selected by the two techniques after VDEPOS, GSHFACN, and PROTINN; however, these additional variables are making relatively small contributions to the uncertainty in population dose within $1000 \mathrm{mi}$ of the reactor. 
Determination of Dominant Variables


Figure 16. Mean and Percentile Curves for Population Dose (Sv) for Individuals within $1000 \mathrm{mi}$ of the Reactor for the Following Cases: $100 \%$ Evacuation, No Evacuation, $100 \%$ Sheltering, and Variable Evacuation. 

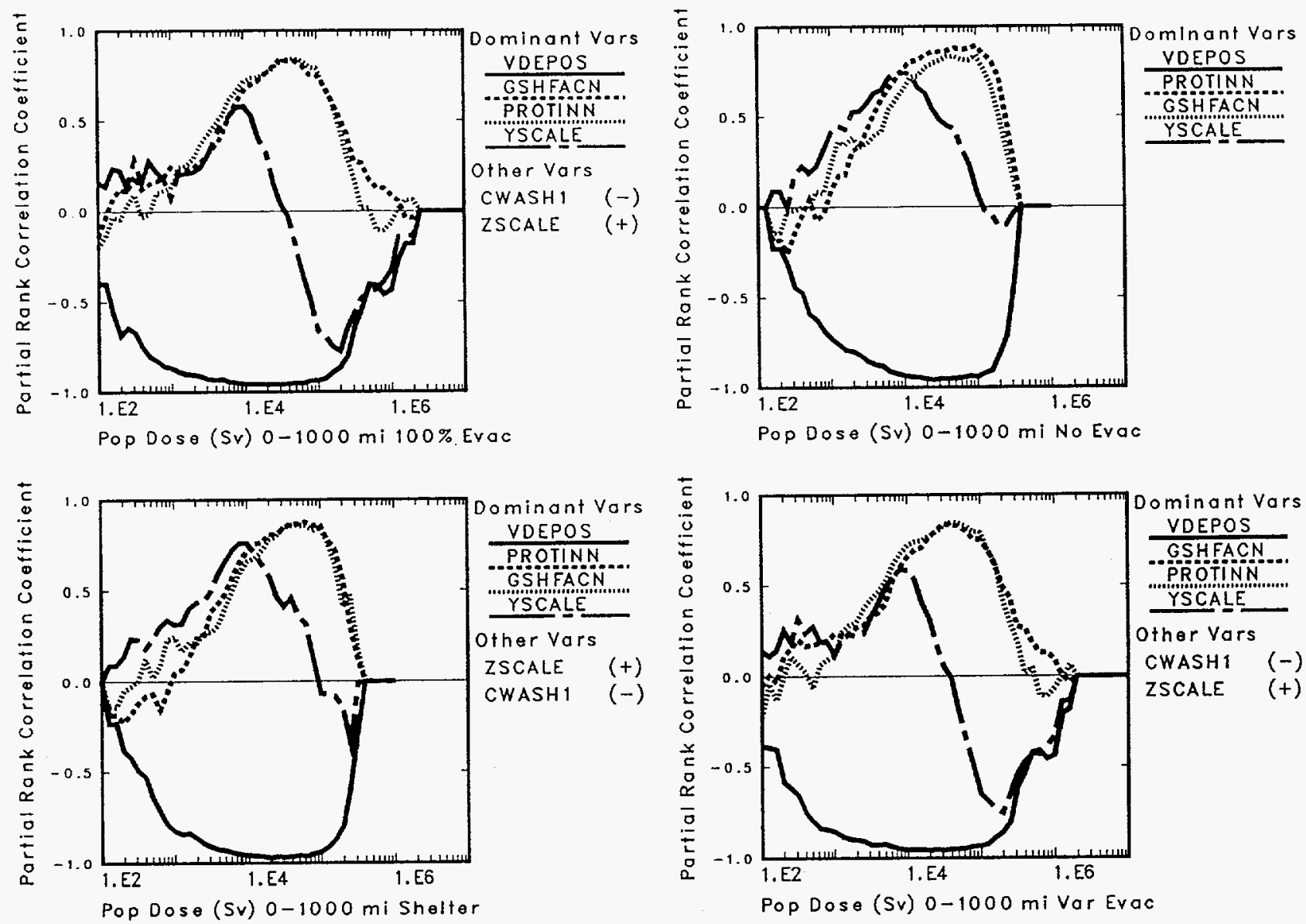

Figure 17. Partial Rank Correlation Coefficients for Probability that Specified Doses (Sv) to the Population within $1000 \mathrm{mi}$ of the Reactor Will Be Exceeded for the Following Cases: 100\% Evacuation, No Evacuation, $100 \%$ Sheltering, and Variable Evacuation. 
Determination of Dominant Variables
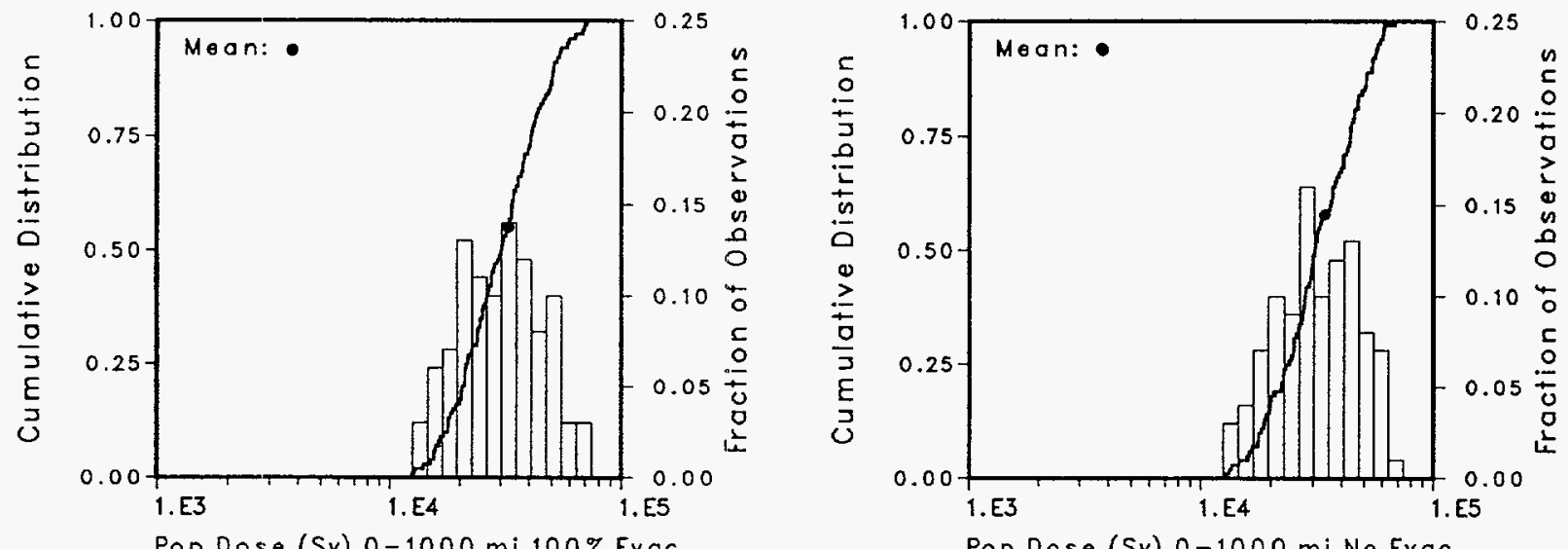

Pop Dose (Sv) 0-1000 mi $100 \%$ Evac
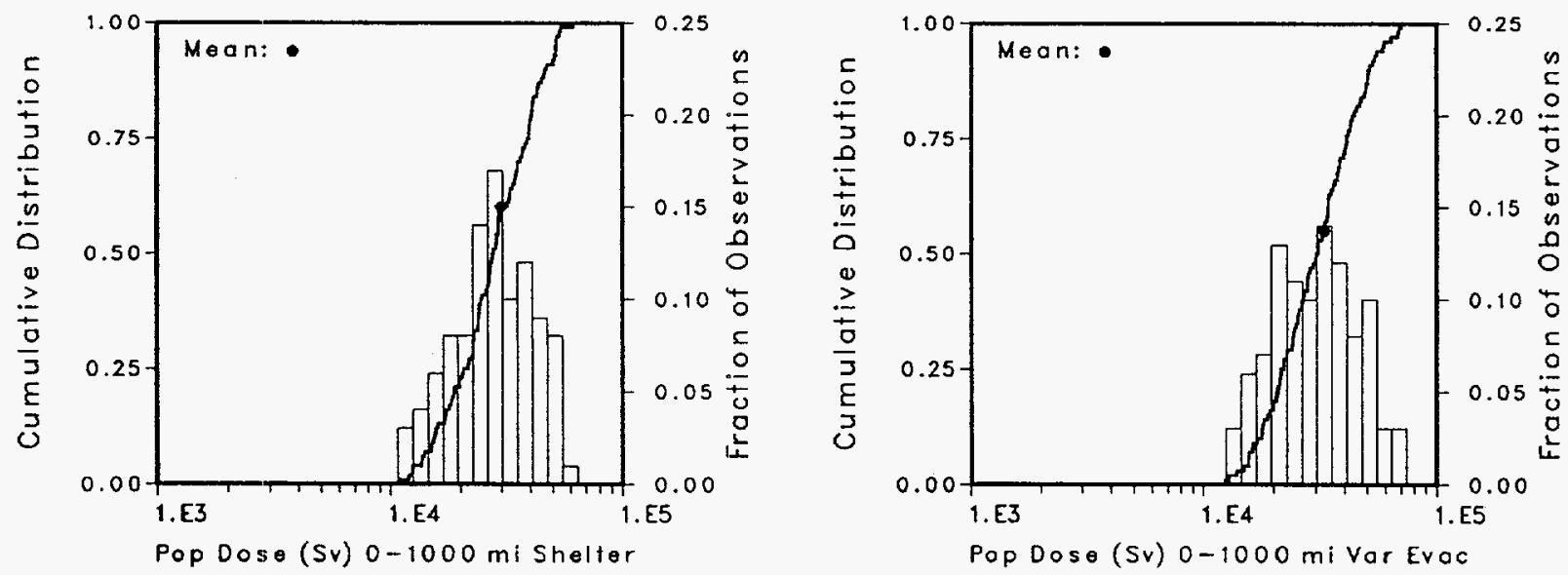

Figure 18. Distribution of Mean Population Dose (Sv) for Individuals within 1000 mi of the Reactor for the Following Cases: 100\% Evacuation, No Evacuation, $100 \%$ Sheltering, and Variable Evacuation. 
Table 13. Stepwise Regression Analyses with Rank-Transformed Data for Mean Population Dose (Sv), 0-1000 mi, for the Following Cases: 100\% Evacuation, No Evacuation, $100 \%$ Sheltering, and Variable Evacuation

\begin{tabular}{||c|l|c|c|l|l|l||}
\cline { 2 - 7 } \multicolumn{1}{c|}{} & \multicolumn{3}{c|}{$100 \%$ Evacuation } & \multicolumn{3}{c|}{ No Evacuation } \\
\hline Step $^{\mathrm{a}}$ & Variable $^{\mathrm{b}}$ & SRC $^{\mathrm{c}}$ & $\mathbf{R}^{2 \mathrm{~d}}$ & Variable $^{\mathrm{b}}$ & SRC $^{\mathrm{c}}$ & $\mathbf{R}^{\mathbf{2} \mathrm{d}}$ \\
\hline 1 & VDEPOS & -0.78 & 0.66 & VDEPOS & -0.74 & 0.59 \\
2 & GSHFACN & 0.37 & 0.78 & PROTINN & 0.39 & 0.73 \\
3 & PROTINN & 0.30 & 0.87 & GSHFACN & 0.38 & 0.87 \\
4 & P2DOS1 & 0.12 & 0.89 & ZSCALE & 0.16 & 0.90 \\
5 & ESPEED & -0.12 & 0.90 & P2DOS1 & 0.14 & 0.92 \\
\hline
\end{tabular}

\begin{tabular}{||c|l|c|c|l|l|l||}
\cline { 2 - 7 } \multicolumn{1}{c|}{} & \multicolumn{3}{c|}{$100 \%$ Shelter } & \multicolumn{3}{c||}{ Variable Evacuation } \\
\hline Step $^{\mathrm{a}}$ & Variable $^{\mathrm{b}}$ & SRC $^{\mathrm{c}}$ & $\mathbf{R}^{\mathbf{2} \mathrm{d}}$ & Variable $^{\mathrm{b}}$ & SRC $^{\mathbf{c}}$ & $\mathbf{R}^{\mathbf{2 ~ d}}$ \\
\hline 1 & VDEPOS & -0.78 & 0.64 & VDEPOS & -0.78 & 0.66 \\
2 & GSHFACN & 0.36 & 0.76 & GSHFACN & 0.38 & 0.78 \\
3 & PROTINN & 0.32 & 0.86 & PROTINN & 0.30 & 0.87 \\
4 & ZSCALE & 0.11 & 0.89 & P2DOS1 & 0.12 & 0.89 \\
5 & P2DOS1 & 0.14 & 0.91 & ESPEED & -0.12 & 0.90 \\
6 & PROTINS & 0.11 & 0.93 & & & \\
7 & YSCALE & 0.11 & 0.94 & & & \\
8 & SCLCRW & 0.07 & 0.94 & & & \\
\hline
\end{tabular}

aSteps in stepwise regression analysis.

'Variables listed in order of selection in regression analysis.

'Standardized regression coefficients in final regression model.

${ }^{\mathrm{d}}$ Cumulative $\mathrm{R}^{2}$ value with entry of each variable into regression model. 
Determination of Dominant Variables

Table 14. Comparison of Variable Selection for Population Dose (Sv) to Individuals Within 1000 mi of the Reactor in Partial Correlation Analysis in Figure 17 and Stepwise Regression Analysis in Table 13

\begin{tabular}{|c|c|c|c|}
\hline & $\begin{array}{c}\text { Variables Selected in } \\
\text { Both Analyses }\end{array}$ & $\begin{array}{c}\text { Additional } \\
\text { Variables Selected } \\
\text { in Partial } \\
\text { Correlation } \\
\text { Analysis }\end{array}$ & $\begin{array}{l}\text { Additional Variables } \\
\text { Selected in Stepwise } \\
\text { Regression Analysis }\end{array}$ \\
\hline $\begin{array}{c}\text { Population Dose, } 0- \\
1000 \mathrm{mi} \text {, with } 100 \% \\
\text { Evacuation }\end{array}$ & $\begin{array}{l}\text { VDEPOS }(1-, 1-)^{a} \\
\text { GSHFACN }(2+, 2+) \\
\text { PROTINN }(3+, 3+)\end{array}$ & $\begin{array}{l}\text { YSCALE }(4+-)^{\mathrm{b}} \\
\text { CWASH1 }(5-) \\
\text { ZSCALE }(6+)\end{array}$ & P2DOS1 $(4+)^{c}$ \\
\hline $\begin{array}{c}\text { Population Dose, 0- } \\
1000 \mathrm{mi} \text {, with No } \\
\text { Evacuation }\end{array}$ & $\begin{array}{l}\text { VDEPOS }(1-, 1-) \\
\text { PROTINN }(2+, 2+) \\
\text { GSHFACN }(3+, 3+) \\
\text { YSCALE }(4+, 4+)\end{array}$ & & P2DOS1 $(5+)$ \\
\hline $\begin{array}{l}\text { Population Dose, 0- } \\
1000 \mathrm{mi} \text {, with } 100 \% \\
\text { Sheltering }\end{array}$ & $\begin{array}{l}\text { VDEPOS }(1-, 1-) \\
\text { PROTINN }(2+, 3+) \\
\text { GSHFACN }(3+, 2+) \\
\text { YSCALE }(4+, 7+) \\
\text { ZSCALE }(5+, 4+)\end{array}$ & CWASH1 (6-) & $\begin{array}{l}\text { P2DOS1 }(5+) \\
\text { PROTINS }(6+) \\
\text { SCLCRW }(7+)\end{array}$ \\
\hline $\begin{array}{c}\text { Population Dose, 0- } \\
1000 \text { mi, with Variable } \\
\text { Evacuation }\end{array}$ & $\begin{array}{l}\text { VDEPOS }(1-, 1-) \\
\text { GSHFACN }(2+, 2+) \\
\text { PROTINN }(3+, 3+)\end{array}$ & $\begin{array}{ll}\text { YSCALE } & (4+-) \\
\text { CWASH1 } & (5-) \\
\text { ZSCALE } & (6+)\end{array}$ & $\begin{array}{l}\text { P2DOS1 }(4+) \\
\text { ESPEED }(5-)\end{array}$ \\
\hline
\end{tabular}

${ }^{\mathrm{a}}(i+/-, j+/-)$ indicates that the associated variable had $i^{\text {th }}$ largest $\mathrm{PRCC}$, in absolute value, in Figure 17, with this coefficient being positive $(+)$ or negative $(-)$ when its absolute value exceeds 0.5 and was also the $j^{\text {th }}$ variable selected in the stepwise regression analysis in Table 13, with the regression coefficient being positive $(+)$ or negative (-).

b $(i+/-)$ indicates that the associated variable had $i^{\text {th }}$ largest PRCC, in absolute value, in Figure 17, with this coefficient being positive $(+)$ or negative $(-)$ when its absolute value exceeds 0.5 .

${ }^{c}(j+/-)$ indicates that the associated variable was the $j^{\text {th }}$ variable selected in the stepwise regression analysis in Table 13 , with the regression coefficient being positive $(+)$ or negative $(-)$. 


\subsection{Individual Early Fatality Probability, 0-1 mi}

The distribution of CCDFs for the probability that an individual within $1 \mathrm{mi}$ of the reactor will become an early fatality is summarized in Figure 19. The general patterns displayed by the mean and percentile curves in Figure 19 for the four emergency response assumptions are similar, although the CCDFs for $100 \%$ evacuation indicate lower early fatality probabilities than the CCDFs for the other three emergency response assumptions. The stairstep pattern appearing in the CCDFs results from the nonuniform population distribution within $1 \mathrm{mi}$ of the reactor (i.e., 19 individuals live within $1 \mathrm{mi}$, with 17 individuals in one wind direction, 1 individual in each of two additional wind directions, and the remaining wind directions having no resident individuals).

The PRCCs for the CCDFs summarized in Figure 19 are presented in Figure 20. For 100\% evacuation, the two most important variables are SCLCRW (critical wind speed scaling factor) and YSCALE (scaling factor for horizontal dispersion), with the probability of exceeding a specified early fatality probability tending to decrease as SCLCRW and YSCALE each increases. These negative effects result because increasing SCLCRW increases the number of weather sequences for which plume liftoff will occur and increasing YSCALE causes more spreading out of the plume. Thus, increasing SCLCRW and YSCALE reduces individual radiation exposure. The next two variables in importance are TDELAY (time from warning to start of evacuation) and ESPEED (evacuation speed). The positive and negative effects indicated for TDELAY and ESPEED, respectively, result because increasing TDELAY causes individuals to receive more radiation exposure before they begin to evacuate while increasing ESPEED causes individuals to receive less radiation exposure during the time that they are actually evacuating. Smaller effects are indicated for ZSCALE (scaling factor for vertical dispersion), EFFTHR1 (early fatality threshold dose for bone marrow exposure), VDEPOS (dry deposition velocity) and EFFACA1 (early fatality hazard function alpha value for bone marrow exposure). Increasing ZSCALE tends to spread the plume vertically and thus reduce individual radiation exposure; increasing EFFTHR1 and EFFACA1 tends to reduce the probability that a specified radiation exposure will be fatal; and increasing VDEPOS tends to result in more radionuclide deposition close to the reactor and hence in higher individual radiation exposures. The sharp spikes in the PRCC plots between 0.01 and 0.1 in Figure 20 result from the nonuniform population distribution within $1 \mathrm{mi}$ of the reactor.

For no evacuation, the four most important variables are YSCALE (scaling factor for horizontal dispersion), VDEPOS (dry deposition velocity), SCLCRW (critical wind speed scaling factor) and ZSCALE (scaling factor for vertical dispersion). For 100\% evacuation, increasing YSCALE tended to decrease the probability of exceeding a specified individual early fatality probability; in contrast, the opposite effect is displayed for no evacuation, although the PRCCs for YSCALE show a sawtoothed pattern for both cases owing to the nonuniform population distribution within $1 \mathrm{mi}$ of the reactor. The positive effect for YSCALE in the absence of evacuation probably results because increasing YSCALE tends to move radiation from unpopulated to populated grid cells, which is more important for the no evacuation case than for the $100 \%$ evacuation case because individuals remain in place longer and thus receive more radiation exposure in the absence of evacuation. The variables VDEPOS, SCLCRW and ZSCALE appear in the analysis for no evacuation for the same reasons that they appear in the analysis for $100 \%$ evacuation, although the ordering of importance is not the same. In addition, smaller positive effects are indicated for GSHFACN (groundshine shielding factor for nonevacuees) and TIMHOT (time at which individuals are relocated if their projected dose exceeds DOSHOT).

The analyses for $100 \%$ sheltering are similar to those for no evacuation in the sense that VDEPOS (dry deposition velocity), YSCALE (scaling factor for horizontal dispersion), SCLCRW (critical 
Determination of Dominant Variables
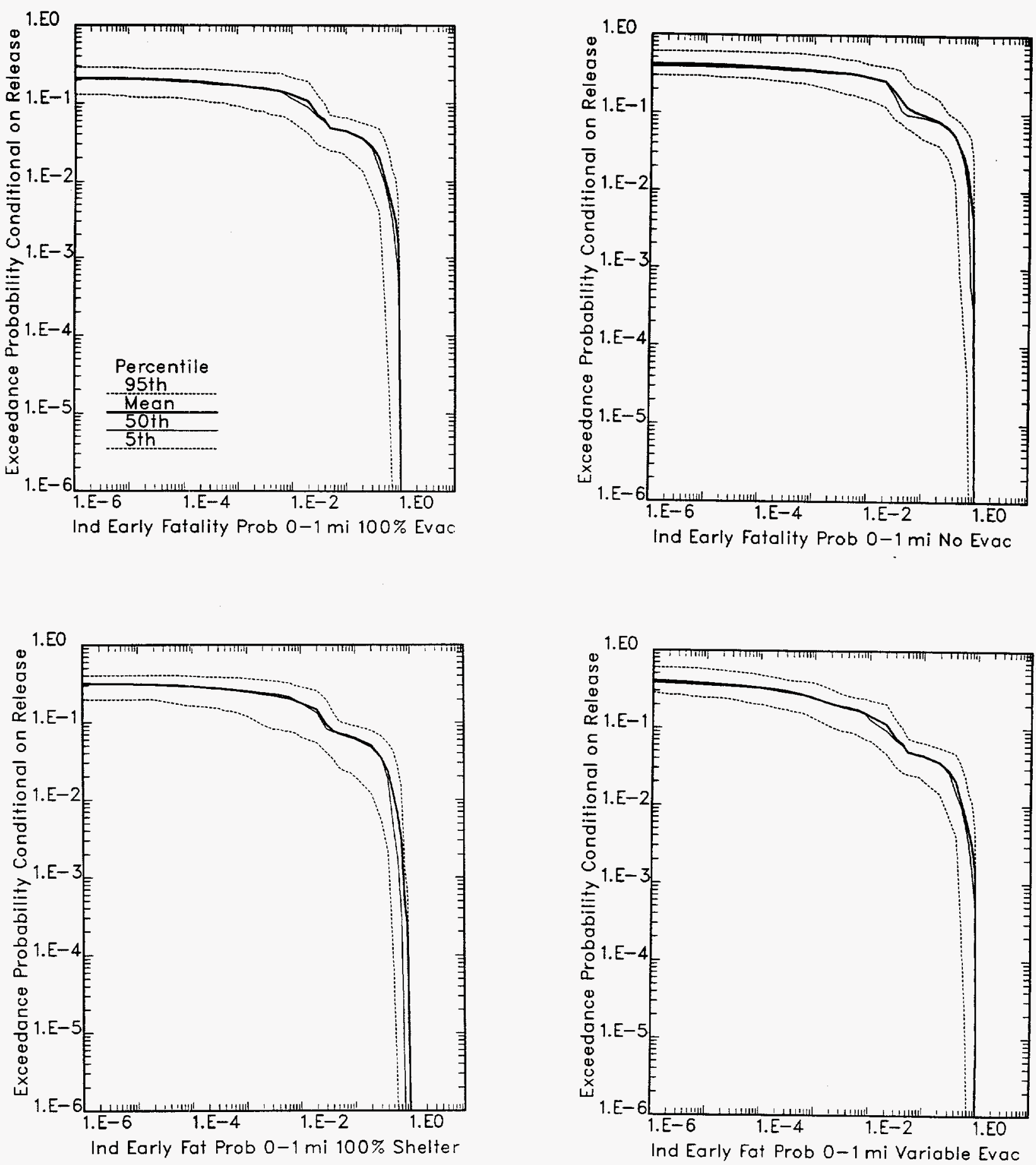

Figure 19. Mean and Percentile Curves for Probability that an Individual Within $1 \mathrm{mi}$ of the Reactor Will Become an Early Fatality for the Following Cases: $100 \%$ Evacuation, No Evacuation, 100\% Sheltering, and Variable Evacuation. 

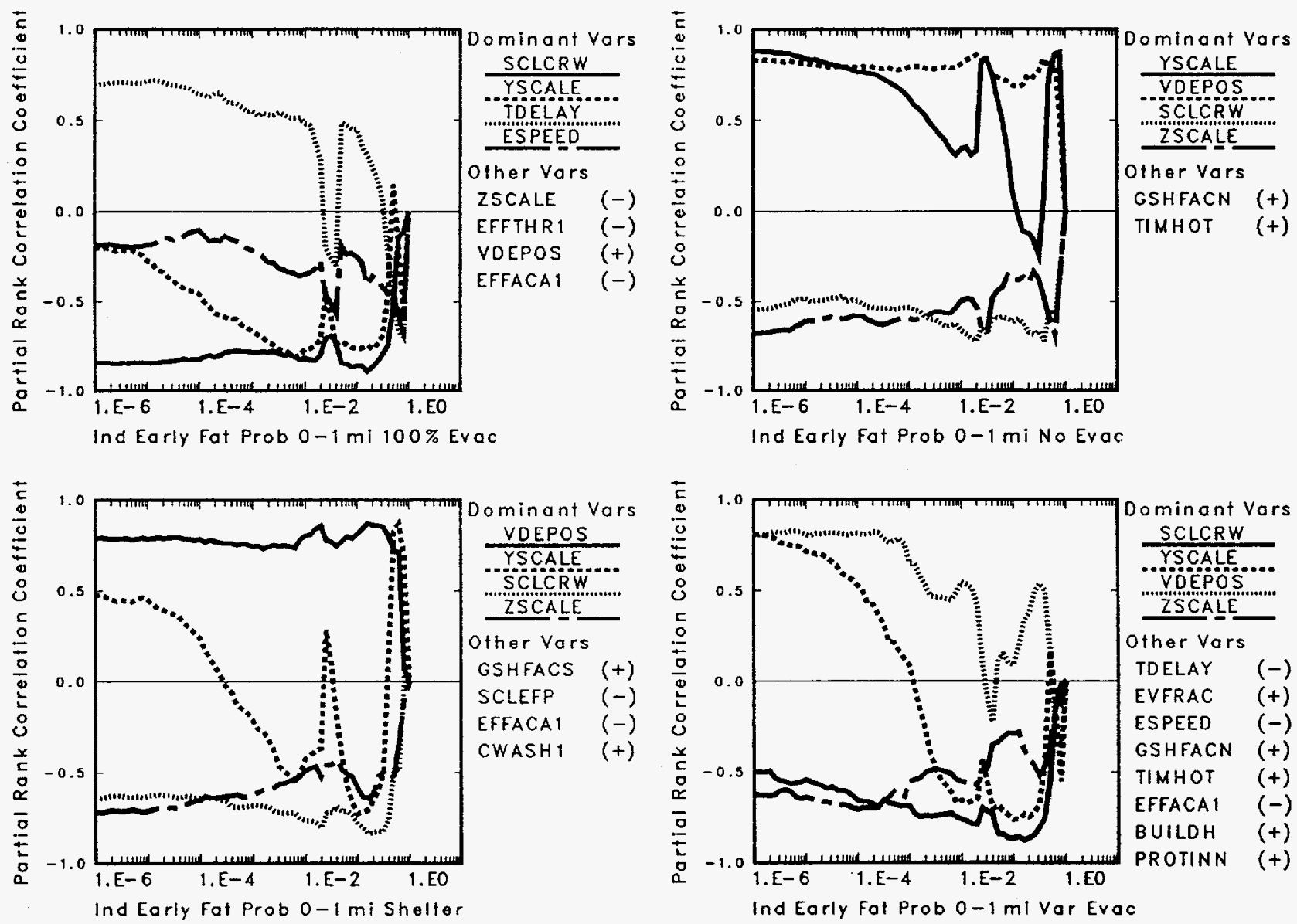

Figure 20. Partial Rank Correlation Coefficients for Probability that Specified Individual Risk Values (i.e., probability that an individual within $1 \mathrm{mi}$ of the reactor will be an early fatality) Will Be Exceeded for the Following Cases: 100\% Evacuation, No Evacuation, $100 \%$ Sheltering, and Variable Evacuation. 
wind speed scaling factor), and ZSCALE (scaling factor for vertical dispersion) are again the four most important variables, although the order of VDEPOS and YSCALE is reversed. Further, these variables have similar effects in both analyses. The PRCCs for YSCALE display a complex sawtoothed pattern owing to the nonuniform population distribution within $1 \mathrm{mi}$ of the reactor. In addition to VDEPOS, YSCALE, SCLCRW, and ZSCALE, the PRCC analysis for $100 \%$ sheltering also identifies positive effects for GSHFACS (groundshine shielding factor for individuals who shelter) and CWASH1 (linear term in wet deposition model) and negative effects for SCLEFP (plume rise scaling factor for stability classes E through F) and EFFACA1 (early fatality hazard function alpha value for bone marrow exposure). Increasing GSHFACS and CWASH1 tends to increase radiation exposure by reducing shielding to groundshine and increasing wet deposition, respectively, while increasing SCLEFP tends to reduce exposure by increasing plume rise. In contrast, increasing EFFACA1 reduces the probability that a specified radiation exposure will result in an early fatality.

For variable evacuation, the four most important variables are SCLCRW (critical wind speed scaling factor), YSCALE (scaling factor for horizontal dispersion), VDEPOS (dry deposition velocity), and ZSCALE (scaling factor for vertical dispersion), as was the case for no evacuation and $100 \%$ sheltering, although there is some shifting in order of importance. The variables SCLCRW, VDEPOS, and ZSCALE display the same effects, although to somewhat different degrees of importance, in all four PRCC analyses presented in Figure 20. In contrast, the indicated effects for YSCALE are less consistent. For variable evacuation, increasing YSCALE tends to increase the probability of exceeding a small individual early fatality probability and decrease the probability of exceeding a large individual early fatality probability, which is a pattern not displayed in any of the other analyses presented in Figure 20. Rather, this is a blending of the effects indicated for YSCALE in the analyses for $100 \%$ evacuation and no evacuation. After SCLCRW, YSCALE, VDEPOS, and ZSCALE, the PRCC analysis for variable evacuation identifies a number of additional variables that have small effects. With the exception of TDELAY (time from warning to start of evacuation), these variables have PRCCs that are consistent with their use in MACCS and what should be the resultant effects on individual early fatality probability with variable evacuation. The appearance of TDELAY with a negative PRCC does not make sense and is probably spurious.

The distributions of CCDFs summarized in Figure 19 can be reduced to the distributions of mean individual early fatality probability shown in Figure 21 . Often, the production of mean reactor accident consequence results, where the mean is taken over weather variability as shown in Eqs. (27) and (28), produces results that are not very useful owing to the combining of consequence magnitude and consequence probability. The results shown in Figure 21 are somewhat more natural because they are equal to the annual probability that an individual currently living within $1 \mathrm{mi}$ of the reactor will be killed given the occurrence of a reactor accident of the particular type under consideration (i.e., an accident producing the source term SUR-11-3 as defined in Table 2 for this analysis, which was estimated in the NUREG-1150 analysis for Surry to have a mean frequency of $1.2 \times 10^{-7} \mathrm{yr}^{-1}$ for internally initiated accidents).

The regression analyses for mean individual early fatality probability are presented in Table 15 . For $100 \%$ evacuation, the uncertainty is dominated by variables that tend to reduce radiation levels in the plume close to the ground surface. In particular, negative effects are indicated for SCLCRW (critical wind speed scaling factor), YSCALE (scaling factor for horizontal dispersion), SCLEFP (plume rise scaling factor for stability classes E through F), and ZSCALE (scaling factor for vertical dispersion). These variables constitute four out of the first five variables selected in the regression analysis and can account for $57 \%$ of the uncertainty in mean individual early fatality probability. The variable EFFACA1 (early fatality hazard function alpha value for bone marrow exposure) was also among the first five 
variables selected and can account for an additional $11 \%$ of the uncertainty. Increasing EFFACA1 reduces mean individual early fatality probability by reducing the probability that a specified radiation exposure will result in an early fatality. In addition to these variables, small positive effects are indicated for PROTINN (inhalation protection factor for nonevacuees), BUILDH (initial vertical height of plume) and CSFACTN (cloudshine shielding factor for nonevacuees), and small negative effects are indicated for ESPEED (evacuation speed) and EFFACA2 (early fatality hazard function alpha value for lung exposure).

For no evacuation, the uncertainty in mean individual early fatality probability is dominated by variables that affect groundshine dose. In particular, VDEPOS (dry deposition velocity), GSHFACN (groundshine shielding factor for nonevacuees), and TIMHOT (time at which individuals are relocated if their projected dose exceeds DOSHOT) account for $52 \%$ of the uncertainty in mean individual early fatality probability, with this probability tending to increase as each of these variables increases. The variables SCLCRW (critical wind speed scaling factor) and EFFACA1 (early fatality hazard function alpha value for bone marrow exposure) account for an additional $10 \%$ and $8 \%$, respectively, of the uncertainty, with mean probability tending to decrease as each of these variables increases. In addition to VDEPOS, GSHFACN, TIMHOT, SCLCRW and EFFACA1, small positive effects are indicated for BUILDH (initial vertical height of plume), YSCALE (scaling factor for horizontal dispersion) and PROTINN (inhalation protection factor for nonevacuees), and small negative effects are indicated for SCLEFP (plume rise scaling factor for stability classes E through F) and ZSCALE (scaling factor for vertical dispersion). The small positive effect indicated for YSCALE contrasts with relatively strong negative effect indicated for YSCALE in the regression analysis for mean individual early fatality probability with $100 \%$ evacuation. As examination of the corresponding PRCC plots in Figure 20 shows, YSCALE does indeed have a negative effect in the analysis for $100 \%$ evacuation and a complex, but positive, effect in the analysis for no evacuation.

The analysis in Table 15 for mean individual early fatality probability with $100 \%$ sheltering is similar to the analysis for no evacuation with the exceptions that TIMHOT (time at which individuals are relocated if their projected dose exceeds DOSHOT) is not a relevant variable and thus does not appear in the regression analysis and also that protection factors for individuals who shelter rather than for nonevacuees appear in the regression analysis. The analysis in Table 15 for mean individual early fatality probability with variable evacuation is almost identical to the analysis for $100 \%$ evacuation.

A comparison of the sensitivity analysis results for individual early fatality probability within 1 mi obtained with PRCCs and stepwise regression is presented in Table 16. The two approaches generally agree on the most important variables, although there was less consistency than in the analyses summarized in Tables $8,10,12$, and 14 . This reduced consistency is probably due to the effects that result from a nonuniform population distribution within $1 \mathrm{mi}$ of the reactor. In particular, YSCALE (scaling factor for horizontal dispersion) and TDELAY (time from warning to start of evacuation) show complex patterns of influence in Figure 20 that cannot be captured in the regression analyses for mean results presented in Table 15. Further, the large number of variables identified in the PRCC analyses in Figure 20 and the stepwise regression analyses in Table 15 indicates that the uncertainty in individual early fatality probability is influenced by many variables, with no single variable having a dominant effect. 
Determination of Dominant Variables
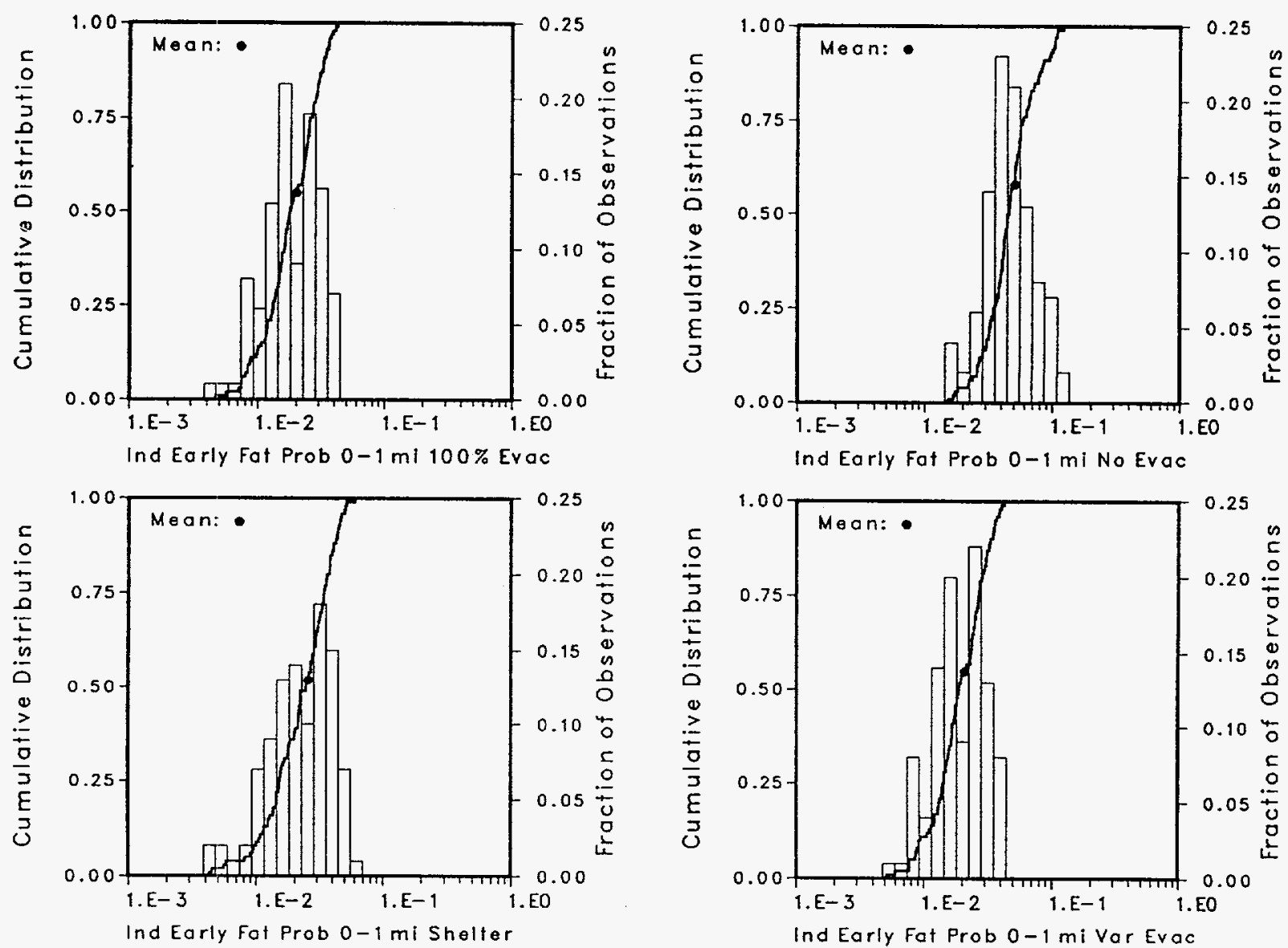

Figure 21. Distribution of Mean Individual Early Fatality Probability for Individuals Living Within $1 \mathrm{mi}$ of the Reactor for the Following Cases: 100\% Evacuation, No Evacuation, 100\% Sheltering and Variable Evacuation. 
Table 15. Stepwise Regression Analyses with Rank-Transformed Data for Mean

Individual Early Fatality Probability, 0-1 mi, for the Following Cases:

$100 \%$ Evacuation, No Evacuation, $100 \%$ Sheltering and Variable Evacuation

\begin{tabular}{|c|c|c|c|c|c|c|}
\hline & \multicolumn{3}{|c|}{$100 \%$ Evacuation } & \multicolumn{3}{|c|}{ No Evacuation } \\
\hline Step $^{\mathrm{a}}$ & Variable $^{\text {b }}$ & $\mathrm{SRC}^{\mathrm{c}}$ & $\mathbf{R}^{2 \mathbf{d}}$ & Variable $^{b}$ & $\mathbf{S R C}^{\mathrm{c}}$ & $\mathbf{R}^{2 \mathrm{~d}}$ \\
\hline 1 & SCLCRW & -0.51 & 0.23 & VDEPOS & 0.53 & 0.26 \\
\hline 2 & YSCALE & -0.36 & 0.45 & GSHFACN & 0.37 & 0.40 \\
\hline 3 & EFFACA1 & -0.34 & 0.56 & TIMHOT & 0.36 & 0.52 \\
\hline 4 & SCLEFP & -0.23 & 0.62 & SCLCRW & -0.33 & 0.62 \\
\hline 5 & ZSCALE & -0.26 & 0.68 & EFFACA1 & -0.28 & 0.70 \\
\hline 6 & PROTINN & 0.18 & 0.72 & BUILDH & 0.16 & 0.74 \\
\hline 7 & BUILDH & 0.17 & 0.75 & SCLEFP & -0.15 & 0.76 \\
\hline 8 & CSFACTN & 0.17 & 0.78 & YSCALE & 0.28 & 0.78 \\
\hline 9 & ESPEED & -0.16 & 0.80 & ZSCALE & -0.26 & 0.83 \\
\hline \multirow[t]{2}{*}{10} & EFFACA2 & -0.13 & 0.82 & PROTINN & 0.14 & 0.85 \\
\hline & \multicolumn{3}{|c|}{$100 \%$ Shelter } & \multicolumn{3}{|c|}{ Variable Evacuation } \\
\hline Step ${ }^{a}$ & Variable $^{b}$ & SRC $^{c}$ & $\mathbf{R}^{2 d}$ & Variable $^{\mathbf{b}}$ & SRC & $\mathbf{R}^{2 \mathbf{d}}$ \\
\hline 1 & VDEPOS & 0.55 & 0.29 & SCLCRW & -0.52 & 0.24 \\
\hline 2 & SCLCRW & -0.42 & 0.45 & YSCALE & -0.33 & 0.43 \\
\hline 3 & EFFACA1 & -0.35 & 0.57 & EFFACA1 & -0.35 & 0.55 \\
\hline 4 & GSHFACS & 0.32 & 0.67 & ZSCALE & -0.27 & 0.61 \\
\hline 5 & ZSCALE & -0.28 & 0.75 & SCLEFP & -0.23 & 0.67 \\
\hline 6 & SCLEFP & -0.21 & 0.80 & PROTINN & 0.19 & 0.72 \\
\hline 7 & BUILDH & 0.16 & 0.82 & CSFACTN & 0.17 & 0.74 \\
\hline 8 & PROTINS & 0.14 & 0.84 & ESPEED & -0.17 & 0.77 \\
\hline 9 & & & & BUILDH & 0.16 & 0.79 \\
\hline 10 & & & & EFFACA2 & -0.14 & 0.81 \\
\hline 11 & & & & VDEPOS & 0.13 & 0.83 \\
\hline
\end{tabular}

${ }^{\mathrm{a} S t e p s}$ in stepwise regression analysis.

bVariables listed in order of selection in regression analysis.

'Standardized regression coefficients in final regression model.

${ }^{\mathrm{d}}$ Cumulative $R^{2}$ value with entry of each variable into regression model. 
Table 16. Comparison of Variable Selection for Individual Early Fatality Probability, 0-1 mi, in Partial Correlation Analysis in Figure 20 and Stepwise Regression Analysis in Table 15

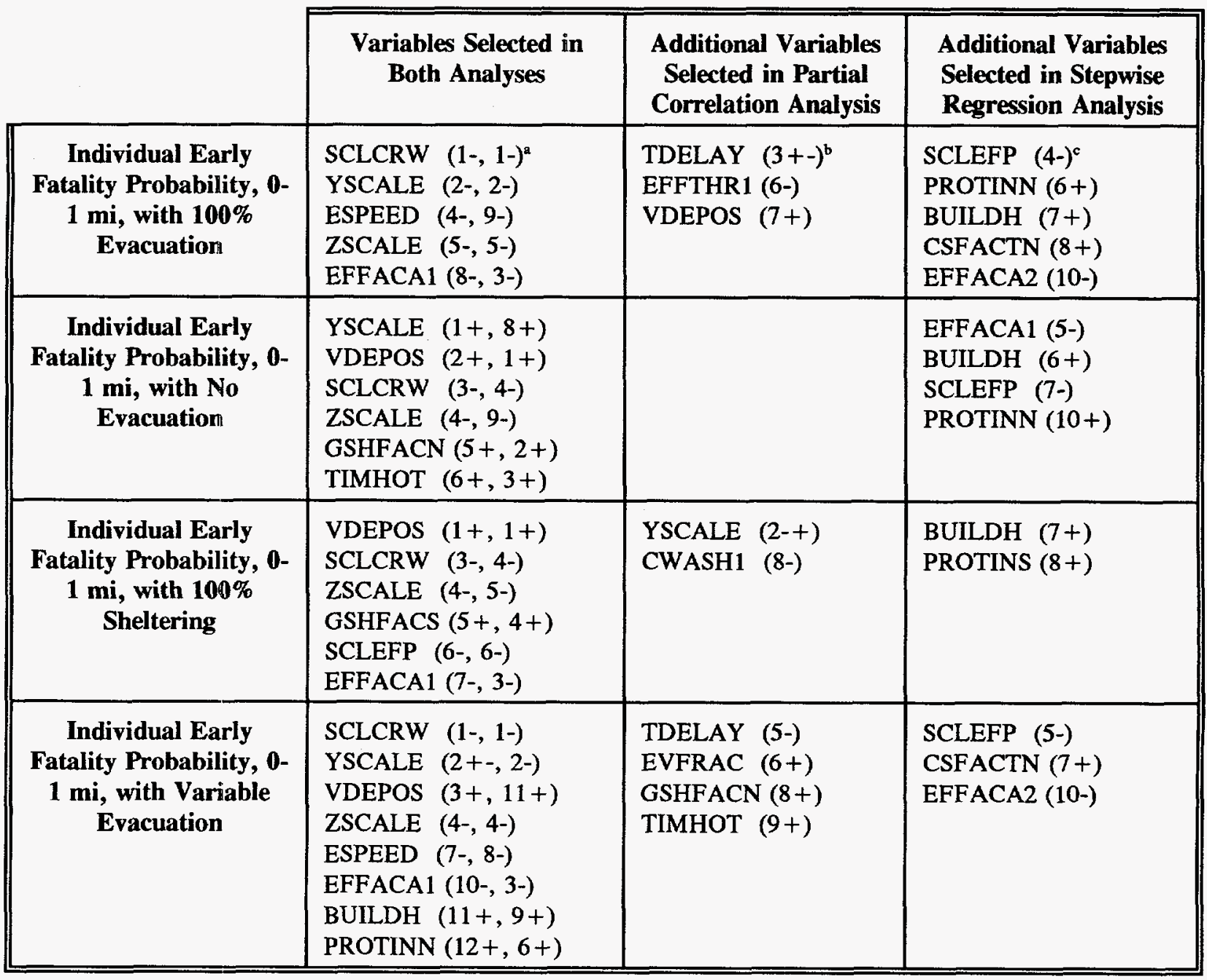

" $(i+/-, j+/-)$ indicates that the associated variable had $i^{\text {th }}$ largest PRCC, in absolute value, in Figure 20, with this coefficient being positive $(+)$ or negative $(-)$ when its absolute value exceeds 0.5 and was also the $j^{\text {th }}$ variable selected in the stepwise regression analysis in Table 15 , with the regression coefficient being positive $(+)$ or negative (-).

b $(i+/-)$ indicates that the associated variable had $i^{\text {th }}$ largest PRCC, in absolute value, in Figure 20, with this coefficient being positive $(+)$ or negative $(-)$ when its absolute value exceeds 0.5 .

c $(j+/-)$ indicates that the associated variable was the $j^{\text {th }}$ variable selected in the stepwise regression analysis in Table 15 , with the regression coefficient being positive $(+)$ or negative $(-)$. 


\subsection{Maximum Early Fatality Distance}

The distribution of CCDFs for maximum early fatality distance with no evacuation is summarized in Figure 22. As examination of this figure shows, there is considerable variability in maximum early fatality distance owing to both weather and the imprecisely known variables listed in Table 4.

As shown in Figure 23, PRCCs can be used to identify the variables that contribute to the distribution of CCDFs summarized in Figure 22. The four most important variables are YSCALE (scaling factor for horizontal dispersion), VDEPOS (dry deposition velocity), ZSCALE (scaling factor for vertical dispersion), and GSHFACN (groundshine shielding factor for nonevacuees). Increasing YSCALE and ZSCALE tends to reduce maximum early fatality distance by spreading out the plume and thus reducing individual exposure; increasing VDEPOS shows a complex pattern of effects by both increasing the probability of exceeding small values for maximum early fatality distance and decreasing the probability of exceeding large scales; increasing GSHFACN tends to increase maximum early fatality distance by increasing individual radiation exposure. Smaller effects are also indicated for SCLCRW (critical wind speed scaling factor), SCLADP (plume rise scaling factor for stability classes A through D) and TIMHOT (time at which individuals are relocated if their projected dose exceeds DOSHOT). Increasing SCLCRW and SCLADP tends to decrease maximum early fatality distance by reducing plume liftoff, while increasing DOSHOT tends to increase maximum early fatality distance by increasing the radiation exposure that individuals receive before they are relocated.

As shown in Figure 24, the CCDFs summarized in Figure 23 for maximum early fatality distance can be reduced to a distribution of mean early fatality distances, where the mean is taken over weather variability. Then, as shown in Table 17, stepwise regression analysis can be used to determine the variables that dominate the uncertainty in mean early fatality distance.

The variable YSCALE (scaling factor for horizontal dispersion) can account for $59 \%$ of the uncertainty in mean early fatality distance, with this distance tending to decrease as YSCALE increases due to spreading of the plume and a resultant reduction in individual radiation exposure. After YSCALE, similar effects (i.e., 6-10\% of the uncertainty) are indicated for GSHFACN (groundshine shielding factor for nonevacuees), EFFACA1 (early fatality hazard function alpha value for bone marrow exposure), ZSCALE (scaling factor for vertical dispersion) and TIMHOT (time at which individuals are relocated if their projected dose exceeds DOSHOT). Increasing GSHFACN reduces radiation shielding and thus increases individual radiation exposure; increasing EFFACA1 reduces the probability that a small dose (i.e., a dose close to the threshold value EFFTHR1) will result in an early fatality; increasing ZSCALE tends to spread the plume out and thus reduce individual radiation exposure, and increasing TIMHOT increases the radiation exposure that individuals receive before relocation. In addition, a small negative effect is indicated for EFFACB1 (early fatality hazard function beta value for bone marrow exposure), and a small positive effect is indicated for VDEPOS (dry deposition velocity). Increasing EFFACB1 reduces the probability that a small dose will result in an early fatality. As shown in Figure 23, VDEPOS has a complex pattern of effects on maximum early fatality distance.

A comparison of sensitivity analysis results obtained with PRCCs and stepwise regression for maximum early fatality distance is presented in Table 18. Both analyses identify YSCALE (scaling factor for horizontal dispersion) as the most important variable. The variables ZSCALE (scaling factor for vertical dispersion), GSHFACN (groundshine shielding factor for nonevacuees) and TIMHOT (time at which individuals are relocated if their projected dose exceeds DOSHOT) also have similar importance rankings. There is considerable difference in the importance rankings for VDEPOS (dry deposition 
Determination of Dominant Variables

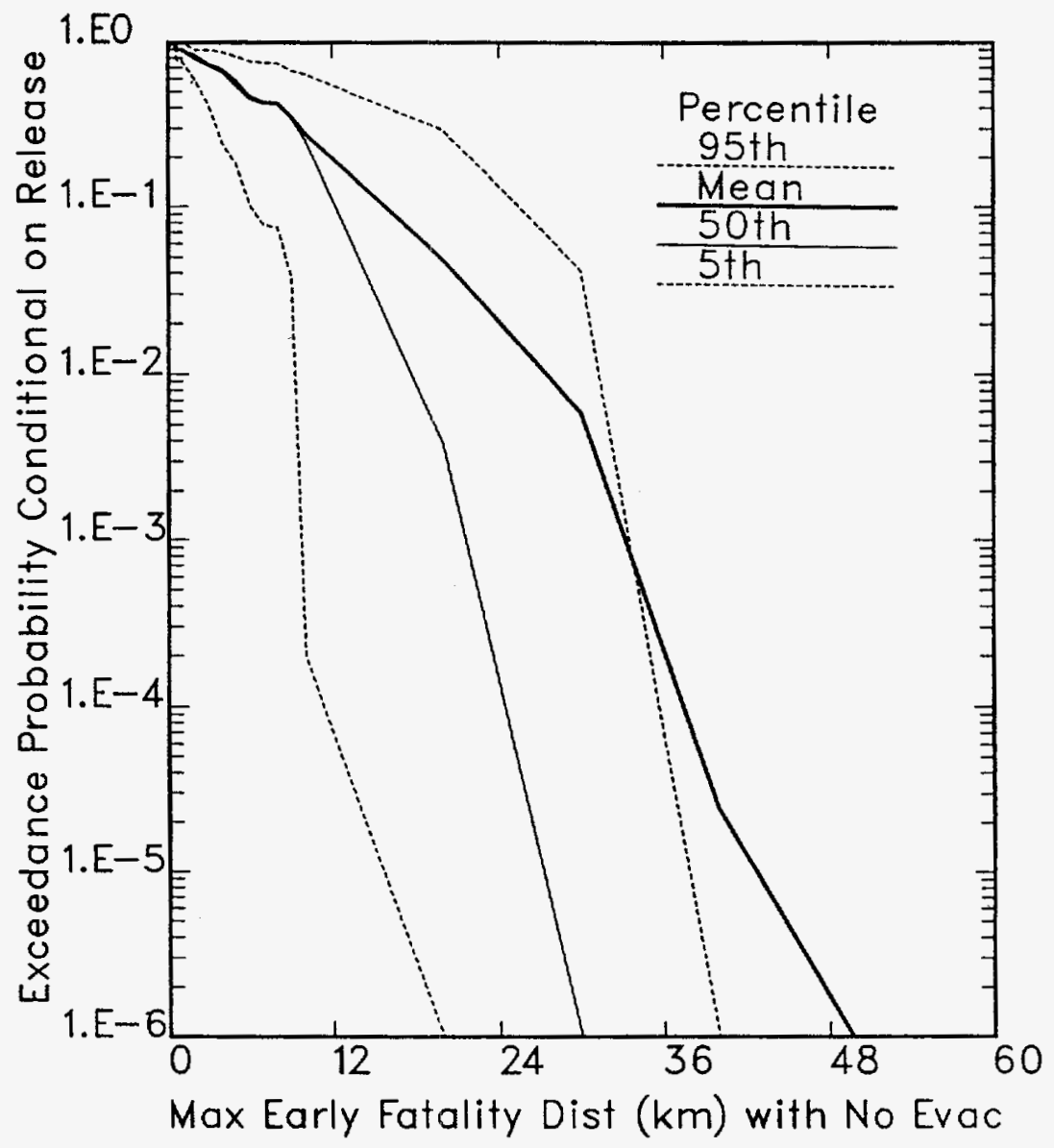

Figure 22. Mean and Percentile Curves for Maximum Early Fatality Distance $(\mathbf{k m})$ with No Evacuation. 


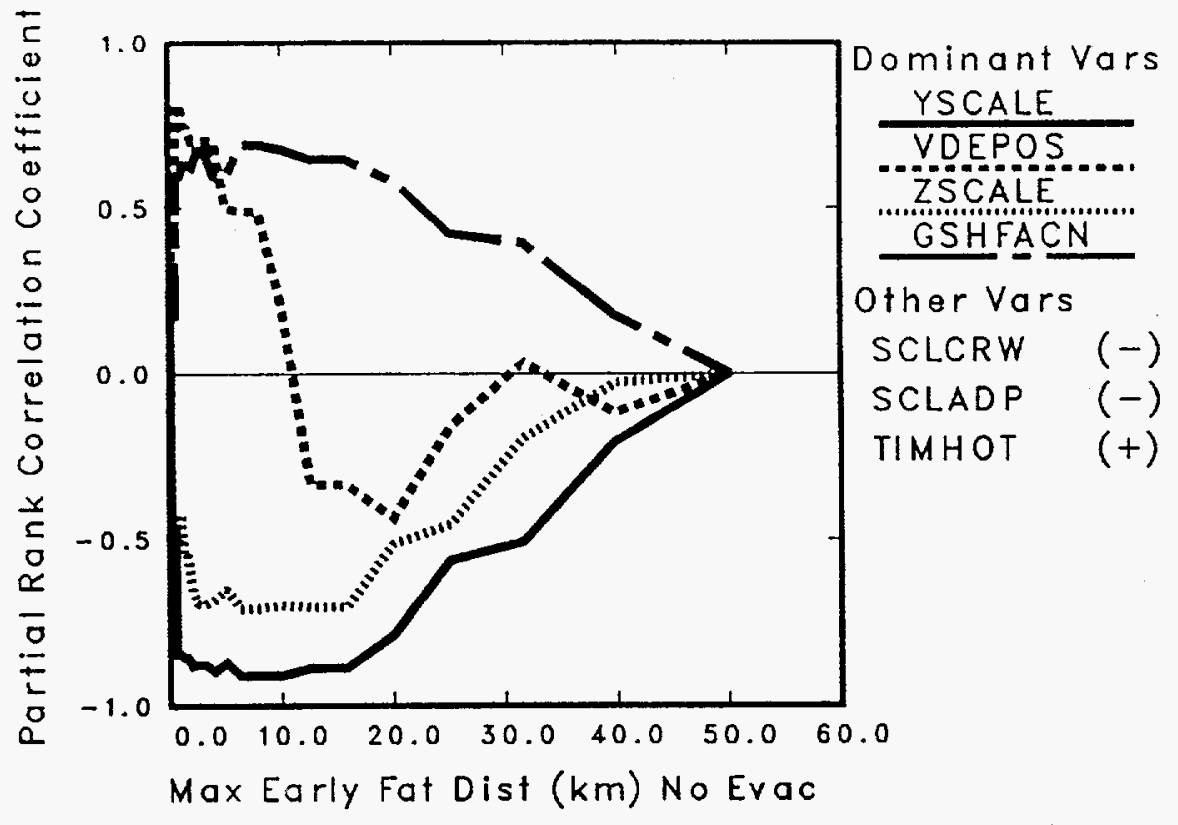

Figure 23. Partial Rank Correlation Coefficients for Probability that Specified Maximum Early Fatality Distances (km) with No Evacuation Will Be Exceeded. 
Determination of Dominant Variables



Figure 24. Distribution of Mean Value for Maximum Early Fatality Distance $(\mathrm{km})$ with No Evacuation. 
Table 17. Stepwise Regression Analysis with Rank-Transformed Data for Mean Value of Maximum Early Fatality Distance (km) with No Evacuation

\begin{tabular}{||c|l|c|c||}
\cline { 2 - 4 } \multicolumn{1}{c|}{} & \multicolumn{3}{c|}{ No Evacuation } \\
\hline Step $^{\mathrm{a}}$ & \multicolumn{1}{|c|}{ Variable $^{\mathrm{b}}$} & \multicolumn{1}{c|}{ SRC $^{\mathbf{c}}$} & $\mathbf{R}^{\mathbf{2} ~}$ \\
\hline 1 & YSCALE & -0.62 & 0.59 \\
2 & GSHFACN & 0.30 & 0.69 \\
3 & EFFACA1 & -0.19 & 0.78 \\
4 & ZSCALE & -0.33 & 0.85 \\
5 & TIMHOT & 0.22 & 0.91 \\
6 & EFFACB1 & -0.16 & 0.92 \\
7 & VDEPOS & 0.09 & 0.92 \\
\hline
\end{tabular}

"Steps in stepwise regression analysis.

${ }^{\text {b}}$ Variables listed in order of selection in regression analysis.

"Standardized regression coefficients in final regression model.

${ }^{d}$ Cumulative $R^{2}$ value with entry of each variable into regression model.

Table 18. Comparison of Variable Selection for Maximum Early Fatality

Distance (km) with No Evacuation in Partial Correlation Analysis in Figure 23 and Stepwise Regression Analysis in Table 17

\begin{tabular}{|c|l|l|l||}
\cline { 2 - 4 } \multicolumn{1}{c|}{} & \multicolumn{1}{c|}{$\begin{array}{c}\text { Variables Selected in } \\
\text { Both Analyses }\end{array}$} & $\begin{array}{l}\text { Additional Variables } \\
\text { Selected in Partial } \\
\text { Correlation Analysis }\end{array}$ & $\begin{array}{c}\text { Additional Variables } \\
\text { Selected in Stepwise } \\
\text { Regression Analysis }\end{array}$ \\
\hline $\begin{array}{c}\text { Matality Distance with } \\
\text { No Evacuation }\end{array}$ & $\begin{array}{l}\text { YSCALE }(1-, 1-)^{\mathrm{a}} \\
\text { VDEPOS }(2+, 7+) \\
\text { ZSCALE (3-, 4-) } \\
\text { GSHFACN }(4+, 2+) \\
\text { TIMHOT }(7+, 5+)\end{array}$ & $\begin{array}{l}\text { SCLCRW (5-) } \\
\text { SCLADP (6-) }\end{array}$ & $\begin{array}{l}\text { EFFACA1 (3-) } \\
\text { EFFACB1 (6-) }\end{array}$ \\
\hline
\end{tabular}

a $(i+/-, j+/-)$ indicates that the associated variable had $i^{\text {th }}$ largest PRCC, in absolute value, in Figure 23, with this coefficient being positive $(+)$ or negative $(-)$ when its absolute value exceeds 0.5 and was also the $j^{\text {th }}$ variable selected in the stepwise regression analysis in Table 17, with the regression coefficient being positive $(+)$ or negative (-).

b $(i+/)$ indicates that the associated variable had $i^{\text {th }}$ largest PRCC, in absolute value, in Figure 23, with this coefficient being positive $(+)$ or negative $(-)$ when its absolute value exceeds 0.5 .

${ }^{\mathrm{c}}(j+/-)$ indicates that the associated variable was the $j^{\text {th }}$ variable selected in the stepwise regression analysis in Table 17 , with the regression coefficient being positive $(+)$ or negative $(-)$. 
velocity) as a result of the bimodal effects indicated for VDEPOS in Figure 23. Finally, the PRCC analysis indicates negative effects for two variables related to plume liftoff, while the stepwise regression analysis indicates negative effects for two variables related to the shape of the early fatality hazard function in Eq. (25) for bone marrow exposure. 


\section{ROBUSTNESS OF ANALYSIS}

This section presents the results of several investigations intended to provide perspective on the quality of the uncertainty and sensitivity analyses described in Section 5. A natural question to ask is "Would the uncertainty and sensitivity analysis results change if a different Latin hypercube sample is used?" The results of repeating the analyses in Section 5 with a second Latin hypercube sample are discussed in Section 6.1. The use of a second independent Latin hypercube of size 100 was found to produce uncertainty and sensitivity analysis results that were essentially the same as those produced with the first sample. Another natural question is "Will reducing the uncertainty in the dominant variables identified in the sensitivity analyses significantly reduce the uncertainty in the associated predicted variables?" As shown in Sections 6.2 and 6.3, fixing the dominant variables at "best estimate" values leads to substantial reductions in the uncertainty in the corresponding predicted variables, while fixing the less important variables at best-estimate values had little effect on uncertainty. Further, fixing the values for the dominate variables allows the effects of the less important variables to be assessed more accurately. Another question is "What effects do the assumed variable distributions have on the outcomes of the uncertainty and sensitivity analysis?" As shown in Section 6.4, similar sensitivity analysis results were obtained when the original uniform and loguniform distributions assigned to the 34 imprecisely known variables in Table 4 changed to left-triangular and then to right-triangular distributions, although there were shifts in the uncertainty analysis results. The original analyses were performed with ranktransformed data, which leads to the question "Would other data transformations produce similar sensitivity analysis results?" As shown in Section 6.5, both rank-transformed and logarithmically transformed data lead to similar sensitivity analysis results.

\subsection{Results Obtained with Second Independent Sample}

No formal results are currently known that define an appropriate or optimum sample size to use in an uncertainty/sensitivity study based on Latin hypercube sampling, although the experience of the authors in a number of such studies ${ }^{98,112-117}$ suggests that a sample size that is approximately 1.5 to 3 times the number of variables is usually adequate. One way to test the stability of the results is to rerun the analysis with a second independently generated Latin hypercube sample and then compare the uncertainty and sensitivity analysis results obtained with the two samples. To this end, a second Latin hypercube sample of size 100 was generated from the variables in Table 4 and the analyses leading to the results in Section 5 were repeated with this sample. The uncertainty and sensitivity analysis results obtained with these two samples were very similar.

Owing to the large number of curves involved, it is difficult to directly compare distributions of CCDFs. However, the mean and percentile curves derived from such distributions can be readily compared. As an example, the mean and percentile curves for early fatalities obtained with the two samples are presented in Figure 25 and are essentially the same. Thus, the estimation of these curves is quite robust for the sample size in use (i.e., 100). Similarly close comparisons resulted for all predicted variables listed in Table 5.

The sensitivity analyses presented in Section 5 for the distributions of CCDFs are based on PRCCs. The sensitivity analyses obtained with the two samples are very similar. As an example, four selected partial rank correlation results are shown in Figure 26. Similarly close comparisons between PRCCs calculated with the two samples were obtained for all results presented in Section 5. 
Robustness of Analysis
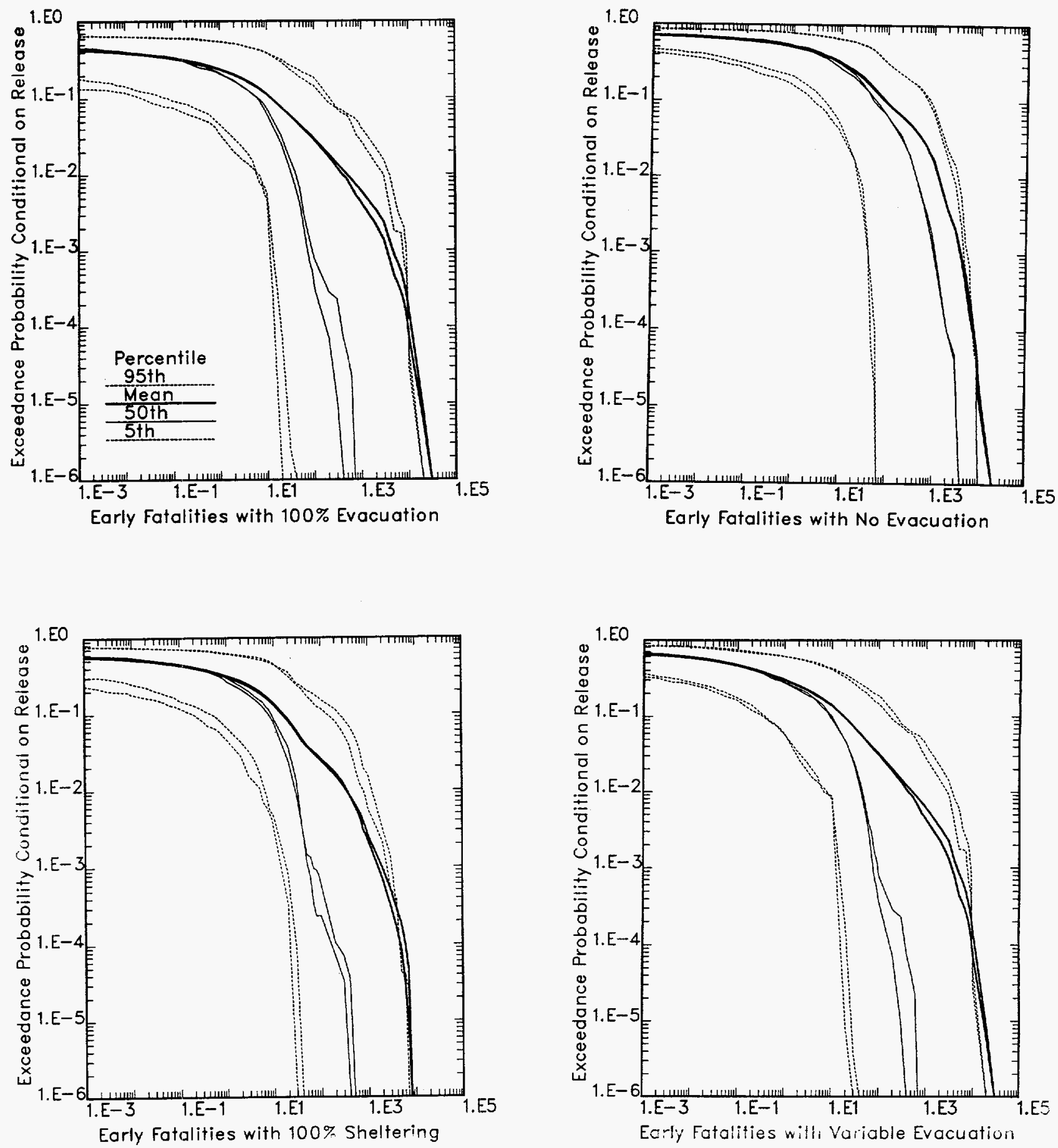

Figure 25. Comparison of Mean and Percentile Curves for Early Fatalities Obtained with Two Independent Latin Hypercube Samples for the Following Cases: $100 \%$ Evacuation, No Evacuation, $100 \%$ Sheltering, and Variable Evacuation. 
Robustness of Analysis
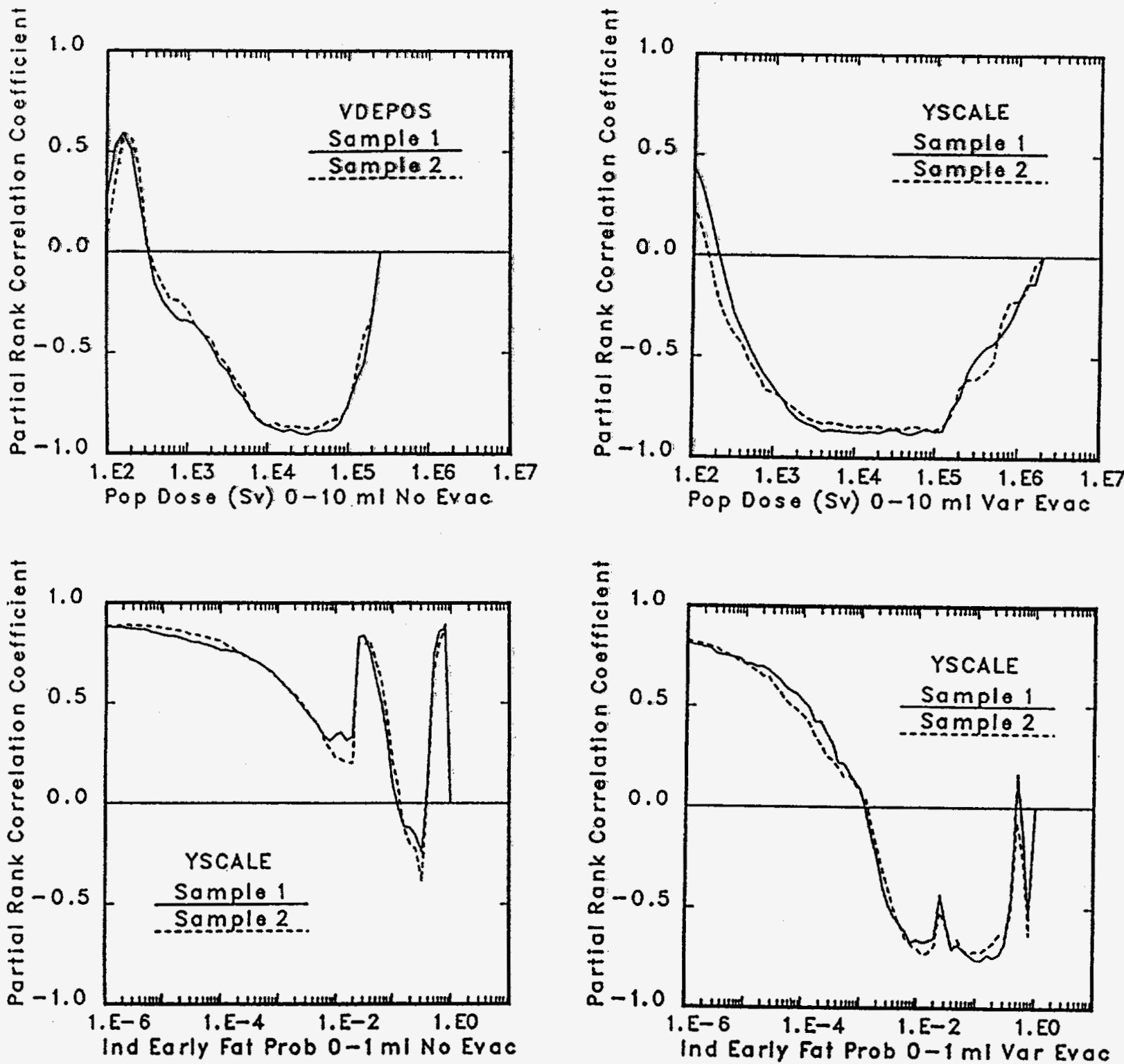

Figure 26. Comparison of PRCCs Obtained with Two Independent Latin Hypercube Samples. 
Robustness of Analysis

Each CCDF in Section 5 can be reduced to a single number by the calculation of an expected value as shown in Eq. (27). The result of the analysis for each variable in Table 5 can then be summarized with a cumulative distribution function for these expected values. A single mean value can also be calculated for each cumulative distribution function, which is equivalent to the reduction of a distribution of CCDFs to a single number. The results of these calculations for the two samples are illustrated in Figure 27 for early fatalities. As examination of this figure shows, the cumulative distribution functions and corresponding mean values obtained with the two samples are very close together. Similar results were obtained for all variables in Table 5.

As the comparisons in Table 19 show, the mean values and standard deviations obtained with the two samples are quite similar for all variables in Table 5. The biggest differences occur for early fatalities, with a $-\mathbf{2 3 . 4 \%}$ difference between the mean estimated with the first and second sample for $100 \%$ evacuation and a $31.8 \%$ difference between the standard deviation estimated with the first and second sample for $100 \%$ sheltering. As examination of Figure 27 shows, these differences are small compared with the almost four orders of magnitude uncertainty in the 100 expected values for each sample element that were used in the calculation of the means and standard deviations for early fatalities.

Stepsize regression analysis with rank-transformed variables was used in Section $\mathbf{5}$ to determine the dominant variables influencing the expected values for the variables in Table 5. Essentially the same results as presented in Section 5 were obtained when these analyses were repeated with the second Latin hypercube sample. As an example, summaries of the analyses for early health effects with the two samples are presented in Table 20. Although there are small variations in the order in which variables enter the analysis, the overall results are quite similar. For example, the analyses for each of the four cases in Table 20 select the same top four variables, and the analyses for three of the cases select the same top five variables. There is some variation in the variables selected near the end of the regression analysis; however, these variables tend to have small effects on the total uncertainty in the dependent variable under consideration (i.e., $<2 \%$ ).

\subsection{Important Variables Fixed at Best-Estimate Values}

After the analyses presented in Section 5 were completed, a test was run to determine if fixing the important variables identified in the sensitivity analysis at their "best-estimate" values would produce a substantial reduction in the uncertainty in the associated predicted results. ${ }^{118.119}$ In particular, the early fatality results discussed in Section 5.1 were used as the basis for this test. The input variables identified as being important with respect to early fatalities are summarized in Table 21 . In the test, the 14 variables listed at the bottom of Table 21 (i.e., EFFACA1, .., ZSCALE and CSFACTN, .., SCLCRW) were held fixed at their best-estimate values indicated in Table 4, and the remaining 20 variables were allowed to vary as before. In particular, the original Latin hypercube sample was modified by replacing the sampled values of the previously indicated 14 variables by their best-estimate values and leaving the sampled values for the remaining 20 variables unchanged. The resultant sample was then propagated through MACCS as before.

The resultant distributions of CCDFs for number of early fatalities are summarized in Figure 28. As comparison of Figures 7 and 28 shows, holding the important variables identified in the sensitivity analysis at their best-estimate values leads to a substantial reduction in the uncertainty in the CCDFs for number of early fatalities. 

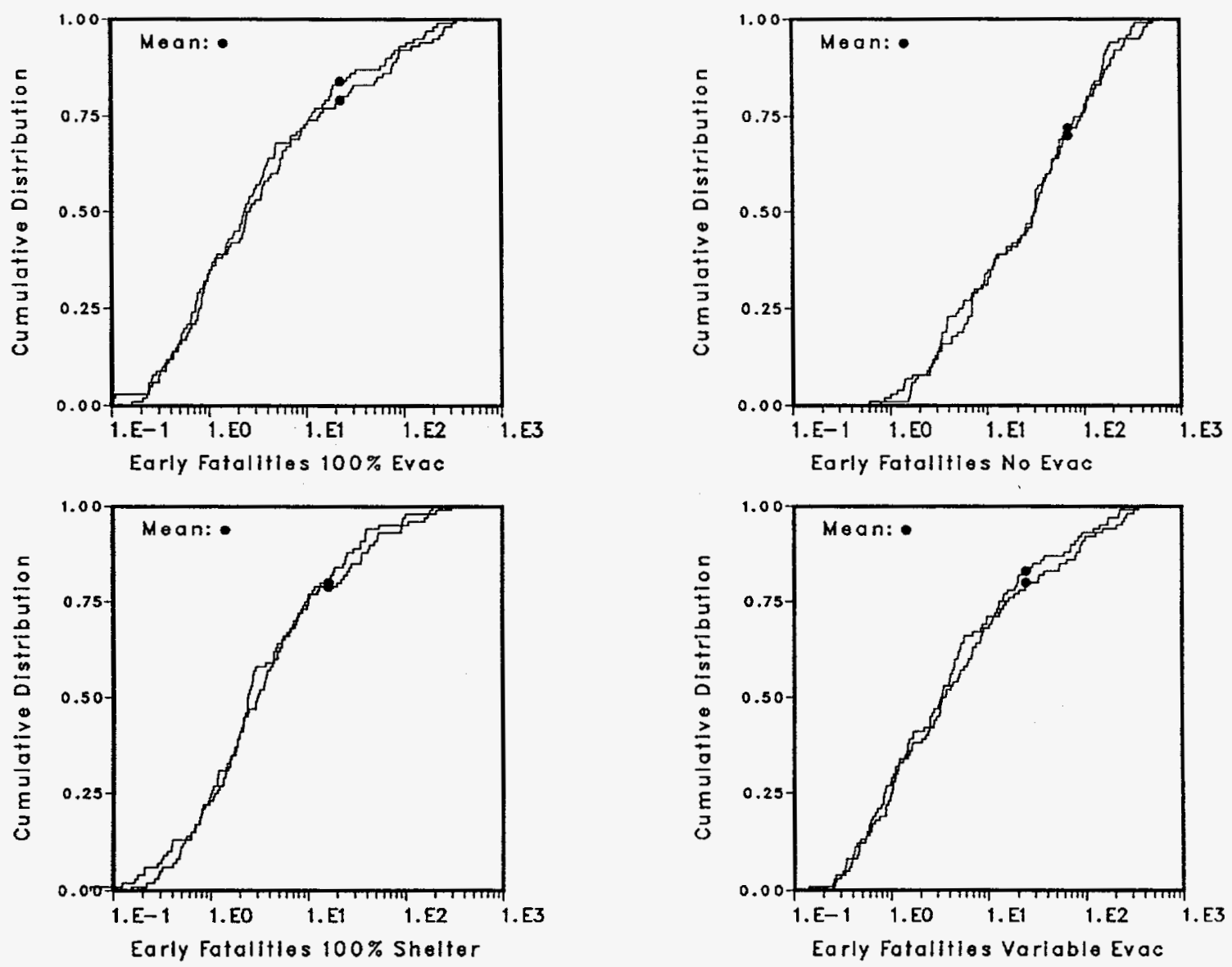

Figure 27. Comparison of Cumulative Distribution Functions and Mean Values for Early Fatalities Obtained with Two Independent Latin Hypercube Samples for the Following Cases: $100 \%$ Evacuation, No Evacuation, 100\% Sheltering, and Variable Evacuation. 
Robustness of Analysis

Table 19. Comparison of Mean Values and Standard Deviations Obtained with Two Independent Latin Hypercube Samples

\begin{tabular}{|c|c|c|c|c|c|c|}
\hline \multirow[b]{2}{*}{ Consequence } & \multicolumn{3}{|c|}{ Mean } & \multicolumn{3}{|c|}{ Standard Deviation } \\
\hline & Sample 1 & Sample 2 & $\%$ Dif & Sample 1 & Sample 2 & $\%$ Dif \\
\hline $\begin{array}{c}\text { Early Fatalities } \\
100 \% \text { Evacuation } \\
\text { No Evacuation } \\
100 \% \text { Shelter } \\
\text { Variable Evacuation } \\
\end{array}$ & $\begin{array}{l}2.25 \times 10^{1} \\
6.75 \times 10^{1} \\
1.64 \times 10^{1} \\
2.39 \times 10^{1} \\
\end{array}$ & $\begin{array}{l}2.94 \times 10^{1} \\
6.83 \times 10^{1} \\
1.58 \times 10^{1} \\
3.05 \times 10^{1} \\
\end{array}$ & $\begin{array}{r}-23.4 \\
-1.2 \\
3.9 \\
-21.6 \\
\end{array}$ & $\begin{array}{l}5.52 \times 10^{1} \\
1.01 \times 10^{2} \\
4.39 \times 10^{1} \\
5.59 \times 10^{1} \\
\end{array}$ & $\begin{array}{l}6.90 \times 10^{1} \\
9.48 \times 10^{1} \\
3.33 \times 10^{1} \\
6.90 \times 10^{1}\end{array}$ & $\begin{array}{r}-20.0 \\
7.0 \\
31.8 \\
-18.9\end{array}$ \\
\hline $\begin{array}{l}\text { Prodromal Vomiting } \\
\text { 100\% Evacuation } \\
\text { No Evacuation } \\
100 \% \text { Shelter } \\
\text { Variable Evacuation }\end{array}$ & $\begin{array}{l}9.18 \times 10^{1} \\
1.77 \times 10^{2} \\
6.71 \times 10^{1} \\
9.43 \times 10^{1}\end{array}$ & $\begin{array}{l}1.01 \times 10^{2} \\
1.81 \times 10^{2} \\
6.99 \times 10^{1} \\
1.03 \times 10^{2}\end{array}$ & $\begin{array}{l}-9.2 \\
-2.1 \\
-4.1 \\
-8.7\end{array}$ & $\begin{array}{l}1.42 \times 10^{2} \\
1.72 \times 10^{2} \\
1.02 \times 10^{2} \\
1.43 \times 10^{2}\end{array}$ & $\begin{array}{l}1.50 \times 10^{2} \\
1.68 \times 10^{2} \\
9.40 \times 10^{1} \\
1.50 \times 10^{2}\end{array}$ & $\begin{array}{r}-5.0 \\
2.3 \\
9.0 \\
-4.6\end{array}$ \\
\hline $\begin{array}{c}\text { Pop Dose (Sv), } 0 \text { - } 10 \mathrm{mi} \\
100 \% \text { Evacuation } \\
\text { No Evacuation } \\
100 \% \text { Shelter } \\
\text { Variable Evacuation }\end{array}$ & $\begin{array}{l}5.68 \times 10^{3} \\
6.74 \times 10^{3} \\
2.95 \times 10^{3} \\
5.72 \times 10^{3}\end{array}$ & $\begin{array}{l}5.92 \times 10^{3} \\
6.69 \times 10^{3} \\
2.93 \times 10^{3} \\
5.94 \times 10^{3}\end{array}$ & $\begin{array}{r}-3.9 \\
0.7 \\
0.8 \\
-3.7\end{array}$ & $\begin{array}{l}5.96 \times 10^{3} \\
2.86 \times 10^{3} \\
1.60 \times 10^{3} \\
5.86 \times 10^{3}\end{array}$ & $\begin{array}{l}6.22 \times 10^{3} \\
2.81 \times 10^{3} \\
1.56 \times 10^{3} \\
6.10 \times 10^{3}\end{array}$ & $\begin{array}{r}-4.2 \\
1.5 \\
2.7 \\
-3.9\end{array}$ \\
\hline $\begin{array}{c}\text { Pop Dose (Sv), } 0-1000 \mathrm{mi} \\
100 \% \text { Evacuation } \\
\text { No Evacuation } \\
100 \% \text { Shelter } \\
\text { Variable Evacuation }\end{array}$ & $\begin{array}{l}3.26 \times 10^{4} \\
3.37 \times 10^{4} \\
2.99 \times 10^{4} \\
3.27 \times 10^{4}\end{array}$ & $\begin{array}{l}3.27 \times 10^{4} \\
3.35 \times 10^{4} \\
2.97 \times 10^{4} \\
3.28 \times 10^{4}\end{array}$ & $\begin{array}{r}-0.3 \\
0.5 \\
0.5 \\
-0.3\end{array}$ & $\begin{array}{l}1.36 \times 10^{4} \\
1.31 \times 10^{4} \\
1.17 \times 10^{4} \\
1.36 \times 10^{4}\end{array}$ & $\begin{array}{l}1.32 \times 10^{4} \\
1.29 \times 10^{4} \\
1.16 \times 10^{4} \\
1.32 \times 10^{4}\end{array}$ & $\begin{array}{l}3.0 \\
1.7 \\
1.0 \\
3.0\end{array}$ \\
\hline $\begin{array}{c}\text { Early Fat Prob, } 0 \text { - } 1 \text { mi } \\
100 \% \text { Evacuation } \\
\text { No Evacuation } \\
100 \% \text { Shelter } \\
\text { Variable Evacuation }\end{array}$ & $\begin{array}{l}2.01 \times 10^{-2} \\
5.03 \times 10^{-2} \\
2.54 \times 10^{-2} \\
2.09 \times 10^{-2}\end{array}$ & $\begin{array}{l}2.05 \times 10^{-2} \\
4.99 \times 10^{-2} \\
2.58 \times 10^{-2} \\
2.13 \times 10^{-2}\end{array}$ & $\begin{array}{r}-1.9 \\
0.7 \\
-1.3 \\
-1.7\end{array}$ & $\begin{array}{l}8.88 \times 10^{-3} \\
2.28 \times 10^{-2} \\
1.22 \times 10^{-2} \\
8.91 \times 10^{-3}\end{array}$ & $\begin{array}{l}9.20 \times 10^{-3} \\
2.15 \times 10^{-2} \\
1.37 \times 10^{-2} \\
9.26 \times 10^{-3}\end{array}$ & $\begin{array}{r}-3.5 \\
6.1 \\
-10.6 \\
-3.8\end{array}$ \\
\hline $\begin{array}{c}\text { Max Early Fat Dist (km) } \\
\text { No Evacuation }\end{array}$ & $7.07 \times 10^{0}$ & $7.18 \times 10^{\circ}$ & -1.5 & $3.14 \times 10^{\circ}$ & $3.36 \times 10^{0}$ & -6.6 \\
\hline
\end{tabular}


Robustness of Analysis

Table 20. Comparison of Stepwise Regression Analyses with Rank-Transformed Data for Two Independent Latin Hypercube Samples for Mean Number of Early Fatalities for the

Following Cases:

$100 \%$ Evacuation, No Evacuation, 100\% Sheltering, and Variable Evacuation

\begin{tabular}{|c|c|c|c|c|c|c|}
\hline & \multicolumn{3}{|c|}{ Sample 1} & \multicolumn{3}{|c|}{ Sample 2} \\
\hline Step $^{\mathbf{2}}$ & Variable $^{\mathbf{b}}$ & $\mathrm{SRC}^{\mathbf{c}}$ & $\mathbf{R}^{2 d}$ & Variable $^{\mathbf{b}}$ & SRC $^{c}$ & $\mathbf{R}^{2 \mathbf{d}}$ \\
\hline \multicolumn{7}{|c|}{ Early Fatalities: $100 \%$ Evacuation } \\
\hline 1 & YSCALE & -0.68 & 0.65 & YSCALE & -0.68 & 0.68 \\
\hline 2 & ESPEED & -0.28 & 0.72 & EFFACA1 & -0.27 & 0.76 \\
\hline 3 & ZSCALE & -0.29 & 0.79 & ZSCALE & -0.28 & 0.81 \\
\hline 4 & EFFACA1 & -0.23 & 0.85 & ESPEED & -0.20 & 0.85 \\
\hline 5 & GSHFACN & 0.14 & 0.88 & VDEPOS & -0.17 & 0.88 \\
\hline 6 & VDEPOS & -0.12 & 0.90 & GSHFACN & 0.14 & 0.90 \\
\hline 7 & CSFACTN & 0.10 & 0.91 & TDELAY & 0.13 & 0.92 \\
\hline 8 & TDELAY & 0.08 & 0.92 & TIMHOT & 0.08 & 0.93 \\
\hline \multicolumn{7}{|c|}{ Early Fatalities: No Evacuation } \\
\hline 1 & YSCALE & -0.59 & 0.50 & YSCALE & -0.63 & 0.59 \\
\hline 2 & GSHFACN & 0.39 & 0.66 & TIMHOT & 0.35 & 0.72 \\
\hline 3 & EFFACA1 & -0.33 & 0.76 & EFFACA1 & -0.29 & 0.81 \\
\hline 4 & TIMHOT & 0.27 & 0.83 & GSHFACN & 0.22 & 0.88 \\
\hline 5 & ZSCALE & -0.28 & 0.89 & ZSCALE & -0.24 & 0.92 \\
\hline 6 & & & & VDEPOS & 0.09 & 0.93 \\
\hline 7 & & & & CSFACTN & 0.09 & 0.94 \\
\hline 8 & & & & BUILDW & -0.07 & 0.94 \\
\hline \multicolumn{7}{|c|}{ Early Fatalities: $100 \%$ Shelter } \\
\hline 1 & YSCALE & -0.64 & 0.57 & YSCALE & -0.63 & 0.63 \\
\hline 2 & EFFACA1 & -0.39 & 0.72 & EFFACA1 & -0.39 & 0.80 \\
\hline 3 & ZSCALE & -0.29 & 0.79 & ZSCALE & -0.29 & 0.86 \\
\hline 4 & GSHFACS & 0.22 & 0.84 & GSHFACS & 0.19 & 0.89 \\
\hline 5 & VDEPOS & 0.12 & 0.85 & VDEPOS & 0.10 & 0.90 \\
\hline 6 & PROTINS & 0.11 & 0.86 & TIMHOT & 0.09 & 0.91 \\
\hline
\end{tabular}


Table 20 (concluded)

\begin{tabular}{|c|c|c|c|c|c|c|}
\hline & \multicolumn{3}{|c|}{ Sample 1} & \multicolumn{3}{|c|}{ Sample 2} \\
\hline Step $^{2}$ & Variable $^{b}$ & $\mathbf{S R C}^{\mathrm{c}}$ & $\mathbf{R}^{2 d}$ & Variable $^{b}$ & $\mathbf{S R C}^{\mathbf{c}}$ & $\mathbf{R}^{2 \mathrm{~d}}$ \\
\hline \multicolumn{7}{|c|}{ Early Fatalities: Variable Evacuation } \\
\hline 1 & YSCALE & -0.68 & 0.63 & YSCALE & -0.68 & 0.69 \\
\hline 2 & ZSCALE & -0.29 & 0.70 & EFFACA1 & -0.29 & 0.78 \\
\hline 3 & EFFACA1 & -0.24 & 0.76 & ZSCALE & -0.28 & 0.83 \\
\hline 4 & ESPEED & -0.25 & 0.81 & ESPEED & -0.16 & 0.85 \\
\hline 5 & GSHFACN & 0.20 & 0.87 & GSHFACN & 0.15 & 0.88 \\
\hline 6 & EVFRAC & 0.14 & 0.89 & TIMHOT & 0.14 & 0.90 \\
\hline 7 & TIMHOT & 0.11 & 0.90 & VDEPOS & -0.13 & 0.91 \\
\hline 8 & CSFACTN & 0.09 & 0.91 & TDELAY & 0.11 & 0.92 \\
\hline 9 & SCLCRW & -0.08 & 0.92 & & & \\
\hline 10 & VDEPOS & -0.08 & 0.92 & & & \\
\hline
\end{tabular}

${ }^{\mathrm{a}} \mathrm{Steps}$ in stepwise regression analysis.

bVariables listed in order of selection in regression analysis.

'Standardized regression coefficients in final regression model.

${ }^{d}$ Cumulative $R^{2}$ value with entry of each variable into regression model. 
Table 21. Important Input Variables Identified in Sensitivity Analyses for Early Fatalities

\begin{tabular}{|c|c|c|}
\hline $\begin{array}{c}\text { First Four } \\
\text { Variables in } \\
\text { PRCC Analysis }\end{array}$ & $\begin{array}{c}\text { Additional } \\
\text { Variables in } \\
\text { PRCC Analysis }\end{array}$ & $\begin{array}{l}\text { Additional } \\
\text { Variables in } \\
\text { Stepwise } \\
\text { Regression } \\
\text { Analysis }\end{array}$ \\
\hline $\begin{array}{l}\text { ESPEED } \\
\text { GSHFACN } \\
\text { GSHFACS } \\
\text { TDELAY } \\
\text { VDEPOS } \\
\text { YSCALE } \\
\text { ZSCALE }\end{array}$ & $\begin{array}{l}\text { CSFACTN } \\
\text { EFFACA1 } \\
\text { EFFTHR1 } \\
\text { EVFRAC } \\
\text { SCLCRW } \\
\text { TIMHOT }\end{array}$ & PROTINS \\
\hline $\begin{array}{c}\text { First Four } \\
\text { Variables in } \\
\text { Stepwise } \\
\text { Regression } \\
\text { Analysis }\end{array}$ & $\begin{array}{l}\text { Additional } \\
\text { Variables in } \\
\text { Stepwise } \\
\text { Regression } \\
\text { Analysis }\end{array}$ & $\begin{array}{c}\text { Additional } \\
\text { Variables in } \\
\text { PRCC Analysis }\end{array}$ \\
\hline $\begin{array}{l}\text { EFFACA1 } \\
\text { ESPEED } \\
\text { GSHFACN } \\
\text { GSHFACS } \\
\text { TIMHOT } \\
\text { YSCALE } \\
\text { ZSCALE }\end{array}$ & $\begin{array}{l}\text { CSFACTN } \\
\text { EVFRAC } \\
\text { PROTINS } \\
\text { SCLCRW } \\
\text { TDELAY } \\
\text { VDEPOS }\end{array}$ & EFFTHR1 \\
\hline $\begin{array}{c}\text { First Four } \\
\text { Variables in } \\
\text { Either Analysis }\end{array}$ & $\begin{array}{l}\text { Additional } \\
\text { Variables }\end{array}$ & \\
\hline $\begin{array}{l}\text { EFFACA1 } \\
\text { ESPEED } \\
\text { GSHFACN } \\
\text { GSHFACS } \\
\text { TDELAY } \\
\text { TIMHOT } \\
\text { VDEPOS } \\
\text { YSCALE } \\
\text { ZSCALE }\end{array}$ & $\begin{array}{l}\text { CSFACTN } \\
\text { EFFTHR1 } \\
\text { EVFRAC } \\
\text { PROTINS } \\
\text { SCLCRW }\end{array}$ & \\
\hline
\end{tabular}


Robustness of Analysis
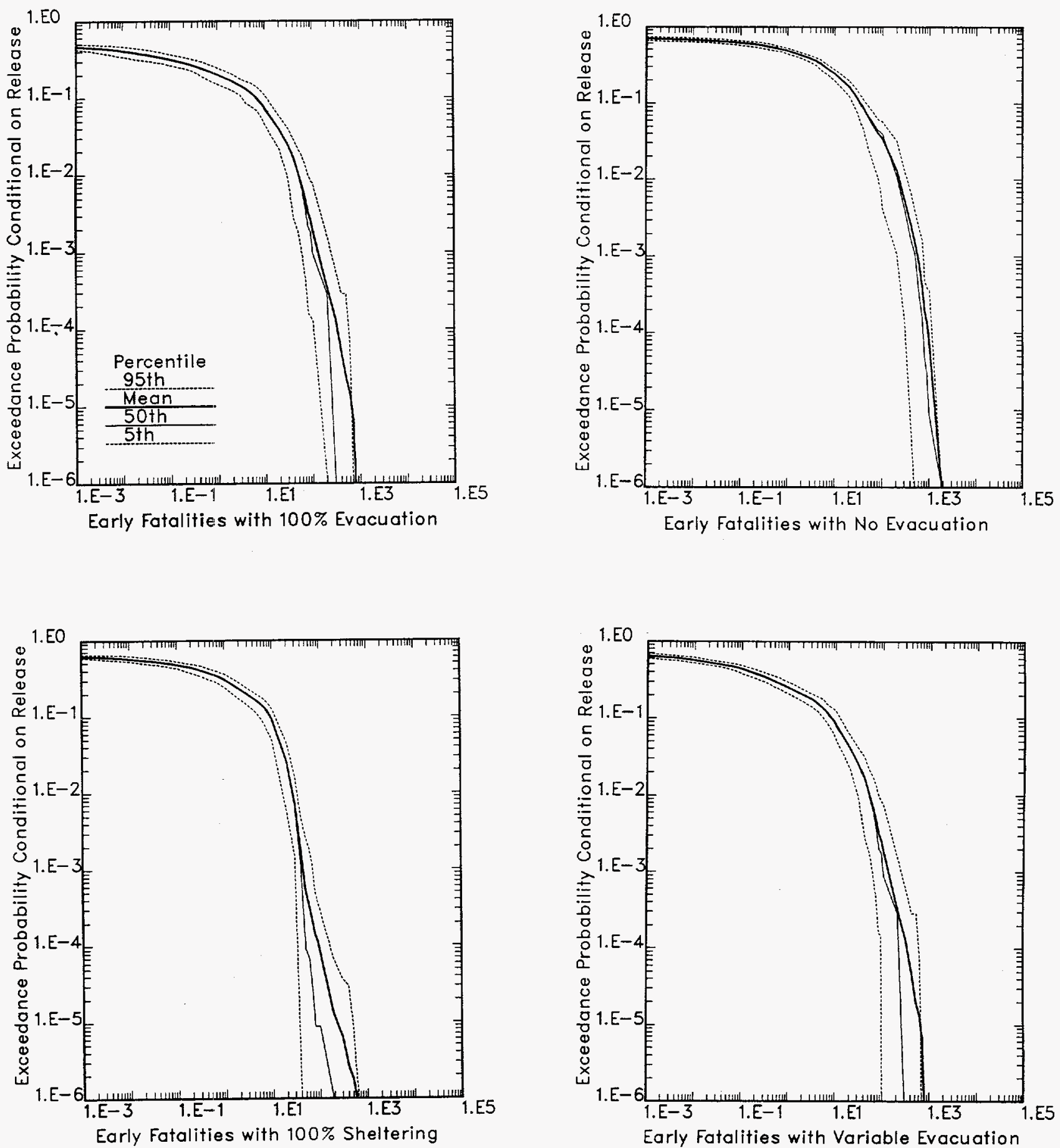

Figure 28. Mean and Percentile Curves for Number of Early Fatalities with Variables Listed in Table 21 Fixed at Best-Estimate Values for the Following Cases: $100 \%$ Evacuation, No Evacuation, $100 \%$ Sheltering, and Variable Evacuation. 
A similar comparison can also be made for the mean number of early fatalities, with the mean defined as shown in Eq. (28). The distributions for the mean number of early fatalities obtained with the variables in Table 21 held fixed at their best-estimate values are shown in Figure 29. As comparison of Figures 9 and 29 shows, holding the important variables at their best-estimate values again leads to a substantial reduction in uncertainty.

Once the calculations leading to Figures 28 and 29 have been completed, additional sensitivity analyses can be performed to determine the important variables when the variables in Table 21 are held fixed at their best-estimate values. For example, the PRCCs for the CCDFs summarized in Figure 28 are shown in Figure 30. Such analyses provide perspective on what would become the important variables if the uncertainty in the most important variables identified in the first analysis could be substantially reduced. For example, EFFACB1 (early fatality hazard function beta value for bone marrow exposure) is now identified as the most important variable in all four analyses presented in Figure 30, with the probability of exceeding a specified number of early fatalities tending to decrease as EFFACB1 increases. This negative effect results because increasing EFFACB1 decreases the probability of becoming an early fatality at doses below EFFACA1 (early fatality hazard function alpha value for bone marrow exposure)(See Eq. 25). After EFFACB1, the PRCC analyses presented in Figure 30 selected a number of additional variables with effects that are consistent with their implementation within MACCS.

An interesting pattern is displayed by SCLEFP (plume rise scaling factor for stability classes $\mathrm{E}$ through $\mathrm{F}$ ) in the analyses for no evacuation and $100 \%$ sheltering, with this variable having a negative effect on the probability of exceeding 1 or more early fatalities and a positive effect on the probability of exceeding 100 or more early fatalities. In contrast, only the negative effect is displayed in the analyses with evacuation. Increasing SCLEFP increases plume rise for stability classes $E$ through $F$, with the result that less radioactive material is deposited close to the reactor and correspondingly more is deposited farther away from the reactor. This reduces the number of early fatalities among evacuees by reducing the high-concentration deposits that are necessary to produce radiation exposures with the potential to cause an early fatality before evacuation precludes additional exposure. For analyses without evacuation, the spreading of the release due to increased plume rise results in more individuals receiving potentially lethal radiation exposures for some weather sequences owing to the longer time period for exposure in the absence of evacuation.

Stepwise regression analyses for mean number of early fatalities are presented in Table 22. The original analysis with all variables is given in Table 7. Again, the impact of variables whose effects were too small to be identified in the original analysis can now be seen. As already observed in the PRCC analysis in Figure 30, increasing EFFACB1 (early fatality hazard function beta value for bone marrow exposure) has a negative effect in all analyses. Also in accord with the results obtained in the PRCC analysis, SCLEFP (plume rise scaling factor for stability classes $E$ through $F$ ) has a positive effect for the no evacuation case and negative effects for the other three cases. The dominant variable in the analysis for $100 \%$ evacuation is EFFACA2 (early fatality hazard function alpha value for lung exposure), with the number of early fatalities tending to decrease as EFFACA2 increases. Interestingly, EFFACA2 does not appear in the analysis for either no evacuation or $100 \%$ sheltering, which suggests that lung exposure is more important in the evacuees than in the nonevacuees. A difference between the PRCC analyses in Figure 30 and the regression analyses in Table 22 is that the former indicates a small positive effect for BUILDH (reactor building height) while the latter indicates a small negative effect. However, the overall effect of BUILDH is small, and this difference probably results from BUILDH having both a positive and a negative effect for the probability of exceeding different numbers of early fatalities. 
Robustness of Analysis
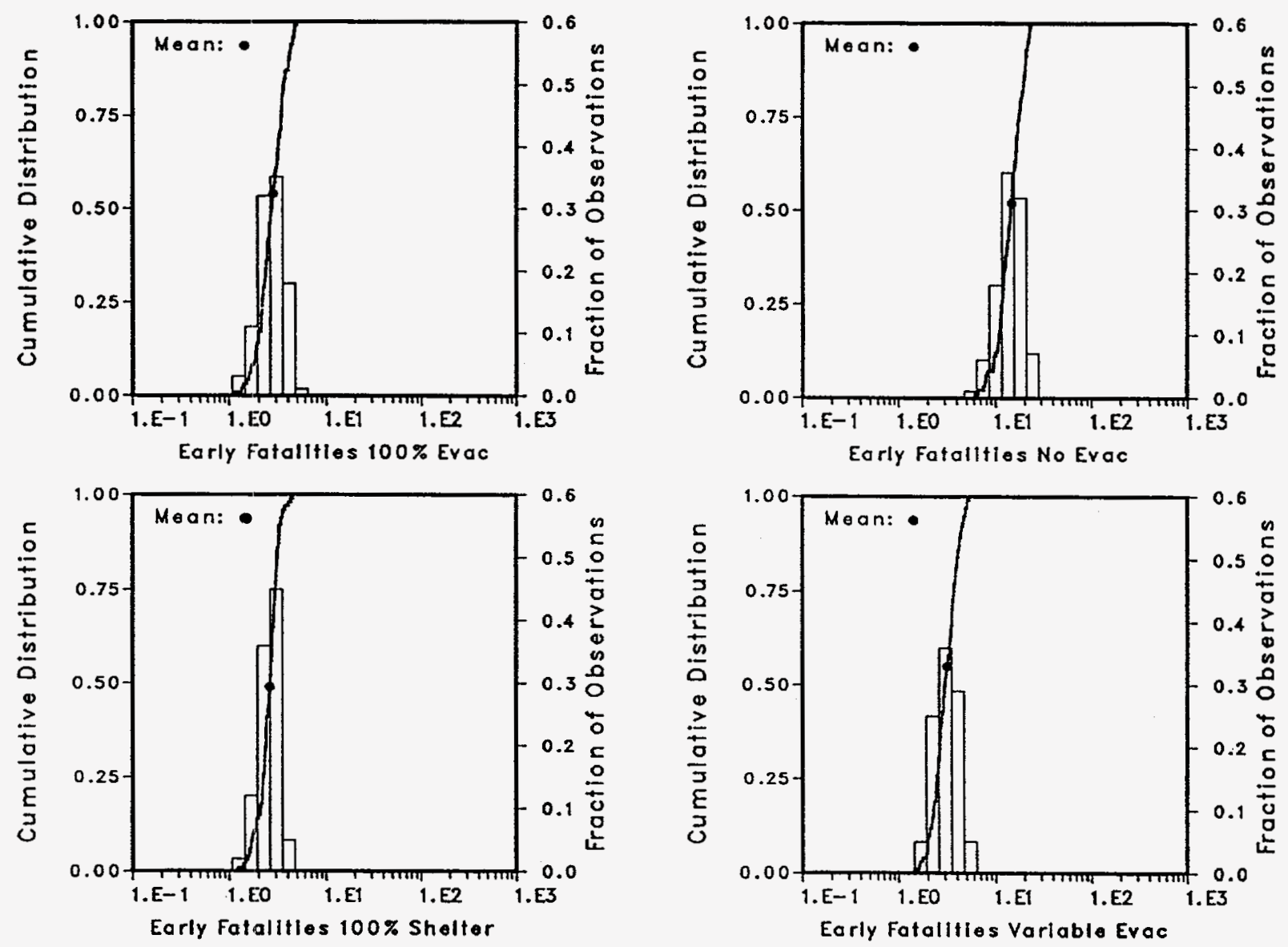

Figure 29. Distribution of Mean Number of Early Fatalities with Variables Listed in Table 21 Fixed at Best-Estimate Values for the Following Cases: $100 \%$ Evacuation, No Evacuation, 100\% Sheltering, and Variable Evacuation. 
Robustness of Analysis
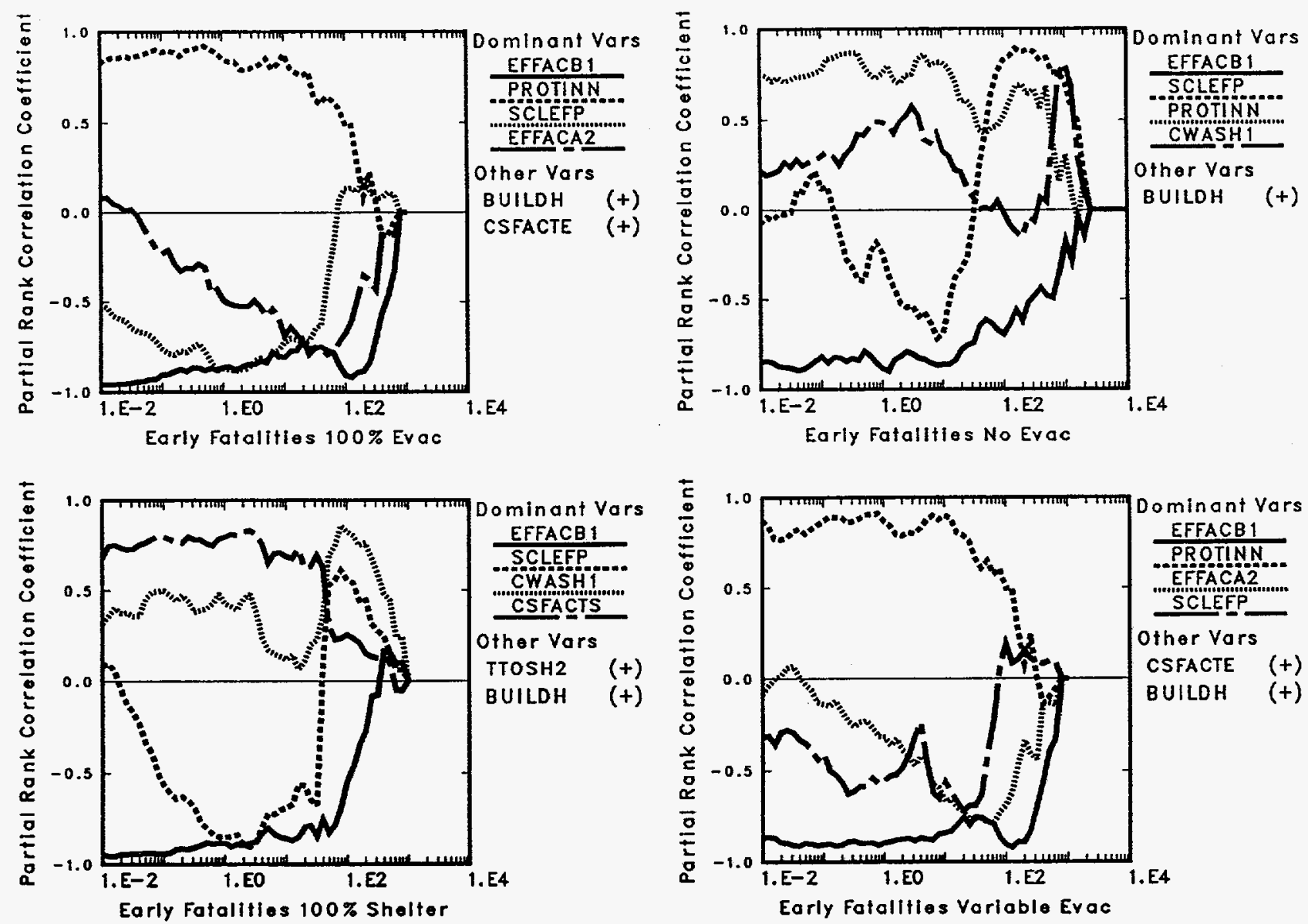

Figure 30. Partial Rank Correlation Coefficients for Probability that a Specified Number of Early Fatalities Will Be Exceeded with the Variables in Table 21 Fixed at Best Estimate Values for the Following Cases: 100\% Evacuation, No Evacuation, $100 \%$ Sheltering, and Variable Evacuation. 
Robustness of Analysis

Table 22. Stepwise Regression Analysis with Rank-Transformed Data for Mean Number of Early Fatalities with Variables in Table 21 Set to Best-Estimate Values for the Following Cases: $100 \%$ Evacuation, No Evacuation, 100\% Sheltering, and Variable Evacuation

\begin{tabular}{||c|l|c|c|l|l|l||}
\cline { 2 - 7 } \multicolumn{1}{c|}{} & \multicolumn{3}{c|}{$100 \%$ Evacuation } & \multicolumn{3}{c||}{ No Evacuation } \\
\hline Step $^{\mathbf{a}}$ & Variable $^{\mathrm{b}}$ & SRC $^{\mathbf{c}}$ & $\mathbf{R}^{\mathbf{2}}$ & Variable $^{\mathbf{b}}$ & SRC $^{\mathbf{c}}$ & $\mathbf{R}^{\mathbf{2}}$ \\
\hline 1 & EFFACA2 & -0.57 & 0.30 & SCLEFP & 0.65 & 0.42 \\
2 & EFFACB1 & -0.51 & 0.58 & EFFACB1 & -0.39 & 0.57 \\
3 & PROTINN & 0.36 & 0.70 & BUILDH & -0.33 & 0.68 \\
4 & SCLEFP & -0.32 & 0.79 & PROTINN & 0.33 & 0.78 \\
5 & CSFACTE & 0.25 & 0.85 & & & \\
6 & BUILDH & -0.15 & 0.88 & & & \\
\hline \hline
\end{tabular}

\begin{tabular}{||c|l|c|c|l|c|c||}
\cline { 2 - 7 } \multicolumn{1}{c|}{} & \multicolumn{3}{c|}{$100 \%$ Shelter } & \multicolumn{3}{c||}{ Variable Evacuation } \\
\hline Step $^{\mathbf{2}}$ & Variable $^{\mathrm{b}}$ & SRC $^{\mathrm{c}}$ & $\mathbf{R}^{2 \mathrm{~d}}$ & Variable $^{\mathrm{b}}$ & SRC $^{\mathrm{c}}$ & $\mathbf{R}^{\mathbf{2 d}}$ \\
\hline 1 & EFFACB1 & -0.67 & 0.44 & EFFACB1 & -0.54 & 0.29 \\
2 & SCLEFP & -0.43 & 0.63 & EFFACA2 & -0.55 & 0.58 \\
3 & CSFACTS & 0.40 & 0.79 & PROTINN & 0.40 & 0.73 \\
4 & TTOSH2 & 0.20 & 0.83 & CSFACTE & 0.24 & 0.79 \\
5 & & & & SCLEFP & -0.23 & 0.84 \\
6 & & & & BUILDH & -0.19 & 0.87 \\
\hline
\end{tabular}

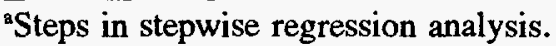

bVariables listed in order of selection in regression analysis.

'Standardized regression coefficients in final regression model.

${ }^{d}$ Cumulative $\mathbf{R}^{2}$ value with entry of each variable into regression model. 
This section has presented analyses for number of early fatalities with the important variables identified in Section 5.1 fixed at their best-estimate values. Similar analyses could be performed for each of the other dependent variables considered in Sections 5.2 through 5.6. For obvious reasons, this gets to be rather tedious. However, as comparison of the important variables listed in Tables $8,10,12,14$, 16 and 18 shows, the important input variables for the other dependent variables are essentially the same as those listed in Table 21 for number of early fatalities. Thus, the MACCS calculations with the variables in Table 21 held fixed also provides perspective on fixing the important input variables for the other dependent variables. The results of sensitivity analyses for these dependent variables with the variables in Table 21 fixed are summarized without discussion in Table 23. 
Robustness of Analysis

Table 23. Summary of Sensitivity Analysis Results Based on PRCCs and Stepwise Regression Analysis with the Variables in Table 21 Fixed at Best-Estimate Values

\begin{tabular}{|c|c|c|c|}
\hline $100 \%$ Evacuation & No Evacuation & $100 \%$ Shelter & Variable Evacuation \\
\hline \multicolumn{4}{|c|}{ Early Fatalities } \\
\hline $\begin{array}{l}\text { EFFACB1 }(1-, 2-)^{a} \\
\text { PROTINN }(2+, 3+) \\
\text { SCLEFP }(3-, 4-) \\
\text { EFFACA2 }(4-, 1-) \\
\text { BUILDH }(5+, 6-) \\
\text { CSFACTE }(6+, 5+)\end{array}$ & $\begin{array}{l}\text { EFFACB1 }(1-, 2-) \\
\text { SCLEFP }(2-+, 1+)^{\mathrm{b}} \\
\text { PROTINN }(3+, 4+) \\
\text { BUILDH }(5+, 4-) \\
\text { CWASH1 }(4+, *)^{\mathrm{c}}\end{array}$ & $\begin{array}{l}\text { EFFACB1 }(1-, 1-) \\
\text { SCLEFP }(2-+, 2-) \\
\text { CSFACTS }(4+, 3+) \\
\text { TTOSH2 }(5+, 4+) \\
\text { CWASH1 }(3+, *) \\
\text { BUILDH }(6+, *)\end{array}$ & $\begin{array}{l}\text { EFFACB1 }(1-, 1-) \\
\text { PROTINN }(2+, 3+) \\
\text { EFFACA2 }(3-, 2-) \\
\text { SCLEFP }(4-, 5-) \\
\text { CSFACTE }(5+, 4+) \\
\text { BUILDH }(6+, 6-)\end{array}$ \\
\hline \multicolumn{4}{|c|}{ Prodromal Vomiting } \\
\hline $\begin{array}{l}\text { EIFACA1 }(1-, 1-) \\
\text { PROTINN }(2+, 4+) \\
\text { CSFACTE }(3+, 2+) \\
\text { BUILDH }(4+, 3-) \\
\text { GSHFACE }(6+, 5+) \\
\text { SCLEFP }(5+, *)\end{array}$ & $\begin{array}{l}\text { EIFACA1 }(1-, 1-) \\
\text { PROTINN }(2+, 3+) \\
\text { SCLEFP }(3+, 2+) \\
\text { BUILDH }(4+, 4-) \\
\text { CWASH1 }(5+, *)\end{array}$ & $\begin{array}{l}\text { EIFACA1 }(1-, 1-) \\
\text { SCLEFP }(2+, 2+) \\
\text { CSFACTS }(3+, 3+) \\
\text { BUILDH }(4+, 4-) \\
\text { CWASH1 }(5+, 6+) \\
\text { TTOSH2 }(*, 5+)\end{array}$ & $\begin{array}{l}\text { EIFACA1 }(1-, 1-) \\
\text { PROTINN }(2+, 4+) \\
\text { SCLEFP }(3+, 6+) \\
\text { BUILDH }(4+, 3-) \\
\text { CSFACTE }(5+, 2+) \\
\text { GSHFACE }(6+, 5+)\end{array}$ \\
\hline \multicolumn{4}{|c|}{ Population Dose (Sv), 0-10 mi } \\
\hline $\begin{array}{l}\text { PROTINN }(1+, 1+) \\
\operatorname{SCLEFP~}(2-+, 3+) \\
\text { BUILDH }(5+-, 2-) \\
\text { SCLADP }(3-, *) \\
\text { CWASH1 }(4-, *) \\
\text { VDEPOS }(*, 4-) \\
\text { GSHFACE }(*, 5+)\end{array}$ & $\begin{array}{l}\text { PROTINN }(1+, 1+) \\
\text { SCLEFP }(3+, 2+) \\
\text { P2DOS1 }(4+, 3+) \\
\text { SCLADP }(2-, *) \\
\text { BUILDH }(5+, *) \\
\text { VDEPOS }(*, 4-)\end{array}$ & $\begin{array}{l}\operatorname{SCLEFP}(1+, 1+) \\
\text { BUILDH }(3+-, 2-) \\
\operatorname{CSFACTS}(4+, 3+) \\
\text { CWASH1 }(5+-, 4-) \\
\operatorname{SCLADP}\left(2-,{ }^{*}\right)\end{array}$ & $\begin{array}{l}\text { PROTINN }(1+, 1+) \\
\text { SCLEFP }(3+, 3+) \\
\text { BUILDH }(4+-, 2-) \\
\text { SCLADP }(2-, *) \\
\text { CWASH1 }\left(4-,{ }^{*}\right) \\
\text { P2DOS1 }(5+, *) \\
\text { VDEPOS }(*, 4-) \\
\text { GSHFACE }(*, 5+)\end{array}$ \\
\hline \multicolumn{4}{|c|}{ Population Dose (Sv), 0-1000 mi } \\
\hline $\begin{array}{l}\text { PROTINN }(1+, 1+) \\
\text { SCLEFP }(2+, 3+) \\
\text { CWASH1 }(3-, 4-) \\
\text { P2DOS1 }(4+, 2+) \\
\text { BUILDH }(5-, 5-) \\
\text { PHS2T2 }(*, 6+)\end{array}$ & $\begin{array}{l}\text { PROTINN }(1+, 1+) \\
\text { CWASH1 }(2-, 4-) \\
\text { SCLEFP }(3+, 2+) \\
\text { P2DOS1 }(4+, 3+) \\
\text { PHS2T2 }(*, 5+)\end{array}$ & $\begin{array}{l}\text { PROTINN }(1+, 1+) \\
\text { SCLEFP }(2+, 3+) \\
\text { CWASH1 }(3-, 4-) \\
\text { P2DOS1 }(4+, 2+)\end{array}$ & $\begin{array}{l}\text { PROTINN }(1+, 1+) \\
\text { SCLEFP }(2+, 3+) \\
\text { CWASH1 }(3-, 4-) \\
\text { P2DOS1 }(4+, 2+) \\
\text { BUILDH }(5-, *) \\
\text { BUILDW }(*, 5-) \\
\text { PHS2T2 }(*, 6+)\end{array}$ \\
\hline
\end{tabular}


Table 23 (concluded)

\begin{tabular}{|c|c|c|c|}
\hline $100 \%$ Evacuation & No Evacuation & $100 \%$ Shelter & Variable Evacuation \\
\hline \multicolumn{4}{|c|}{ Individual Early Fatality Probability, 0-1 mi } \\
\hline $\begin{array}{l}\text { SCLEFP }(1-, 1-) \\
\text { PROTINN }(2+, 2+) \\
\text { BUILDH }(4+, 3+) \\
\text { EFFACB1 }(3-, *) \\
\text { EFFACA2 }(*, 4-)\end{array}$ & $\begin{array}{l}\text { PROTINN }(3+, 2+) \\
\text { SCLEFP }(4-, 1-) \\
\text { BUILDH }(5+, 3+) \\
\text { BUILDW }(6+, 4+) \\
\text { CWASH1 }(1+, *) \\
\text { EFFACB1 }(2-, *) \\
\text { EFFACA2 }(*, 5-)\end{array}$ & $\begin{array}{l}\text { EFFACB1 }(1-, 5-) \\
\text { SCLEFP }(2-, 1-) \\
\text { CWASH1 }(3+, 4+) \\
\text { BUILDH }(4+, 2+) \\
\text { CSFACTS }(6+, 3+) \\
\text { BUILDW }(5+, *) \\
\text { TTOSH2 }(7+, *)\end{array}$ & $\begin{array}{l}\operatorname{SCLEFP}(1-, 1-) \\
\text { PROTINN }(2+, 2+) \\
\text { BUILDH }(4+, 3+) \\
\text { EFFACB1 }(3-, *) \\
\text { EFFACA2 }(*, 4-)\end{array}$ \\
\hline
\end{tabular}

a $\left(i+/-j+/\right.$ )indicates that the associated variable had the $i^{\text {th }}$ largest PRCC, in absolute value, with this coefficient being positive ( + ) or negative $(-)$ when its absolute value exceeds 0.5 and was the $j^{\text {th }}$ variable selected in the stepwise regression analysis, with the corresponding regression coefficient being positive $(+)$ or negative $(-)$.

${ }^{b}+-$ indicates that a PRCC is first positive and then negative when it exceeds 0.5 in absolute value; the opposite pattern is indicated by - + .

c* indicates variable not identified in analysis. 


\subsection{Important Variables Fixed at Different Best-Estimate Values}

As shown in Section 6.2, fixing the important variables at their best-estimate values leads to a substantial reduction in the uncertainty in predicted results. The effect of different best-estimate values is now considered.

The results presented in this section are based on two Latin hypercube samples from the variables in Table 4. The first sample, which is represented by

$$
x_{i}, i=1, \ldots, n S=20 \text {, }
$$

is of size 20 and is constructed from all variables in Table 4 (i.e., $n V=34$ ). The second sample, which is represented by

$$
y_{i}, i=1, \ldots, n S=5 \text {, }
$$

is of size 5 and is constructed from the variables in Table 4 that are not listed in Table 21 (i.e., $n V=$ $34-14=20$ ). Thus, the second sample contains the variables that were not identified as being important in the sensitivity analyses in Section 5.1 for number of early fatalities. Due to the small size of the samples in Eqs. (29) and (30), they were generated without use of the Iman/Conover restricted pairing technique. ${ }^{100}$

The two preceding samples can now be used to construct a new sample

$$
\left(x_{i}, y_{j}\right), i=1, \ldots, 20, j=1, \ldots, 5,
$$

from the variables in Table 4, with the convention that the variable values in $\boldsymbol{y}_{j}$ replace the corresponding variable values in $x_{i}$ for each pair $\left(x_{i}, y_{j}\right)$. The new sample is of size 100 with $n V=34$, but only five values are used for each of the variables not listed in Table 21. The sample indicated in Eq. (31) can also be viewed as 20 samples of size 5 , that is

$$
\left(x_{i}, y_{j}\right), j=1, \ldots, 5 \text {, }
$$

for $i=1, \ldots, 20$, and as 5 samples of size 20 , that is

$$
\left(x_{i}, y_{j}\right), i=1, \ldots, 20
$$

for $j=1, \ldots, 5$. For the 20 samples indicated in Eq. (32), values for the variables in Table 21 are fixed and the remaining variables from Table 4 are allowed to take on different values. The opposite occurs for the 5 samples indicated in Eq. (33), with the values for the variables in Table 21 changing and values for the remaining variables in Table 4 fixed.

If the analyses in Section 5.1 were successful in identifying the important variables influencing the number of early fatalities, then variability between results obtained with the different samples in Eq. (32) should be greater than the variability associated with the individual sample elements within a sample. In contrast, the opposite pattern should hold for the samples in Eq. (33). To test this, the associated 100 MACCS runs were made, and the indicated comparisons were performed. 
For the samples in Eq. (32), 20 sets of 5 CCDFs result for each dependent variable. Three of these sets are shown in Figure 31 for number of early fatalities with variable evacuation. As examination of this figure shows, the variation between the three sets of CCDFs is greater than the variation within each set. As suggested by Figure 28, the variation within each set would increase with a larger sample size (i.e., $>5$ ) for the variables not listed in Table 21 but not enough to equal the between set variation. For additional perspective, Figure 32 shows the median CCDF for each of the 20 samples in Eq. (32); the variation between these CCDFs is much greater than the variation within each set of CCDFs in Figure 31 or, for that matter, within the sets in Figure 28. The results in Figures 31 and 32 indicate that the position of the CCDF for number of early fatalities with variable evacuation is controlled by the uncertainty in the variables listed in Table 21 , with little influence due to the other 20 variables considered in the analysis (i.e., those variables listed in Table 4 but not in Table 21). In particular, the results in Figures 31 and 32 indicate that the substantial reduction of uncertainty shown in Figure 22 is not a function of the particular set of best-estimate values selected for the variables in Table 21, although this selection does determine where the resultant distribution of CCDFs is located.

For the samples in Eq. (33), 5 sets of $20 \mathrm{CCDFs}$ result for each dependent variable. The mean and selected percentile curves for number of early fatalities with variable evacuation are presented in Figure 33. As this figure shows, changing the values for the variables not contained in Table 21 has only a small effect on the distribution of CCDFs for early fatalities with variable evacuation. A similar pattern is also displayed by the other dependent variables under consideration. Thus, as indicated by the results in Figures 31, 32 and 33, the analysis has been successful in identifying the dominant variables that influence number of early fatalities. Similar comparisons also show that the variables in Table 21 are the dominant variables with respect to the other MACCS predictions under consideration.

\subsection{Effect of Different Distributions on Sensitivity Analysis Results}

The variables in Table 4 were assigned either uniform or loguniform distributions for the analyses presented in Section 5. These distributions were selected to provide sampled values across the full range of each variable. Although the distributions of predicted variables can be quite sensitive to the distributions assigned to input variables, the results of regression-based sensitivity analyses are often fairly insensitive to the actual distributions selected for use. To illustrate this point, the analyses in Section 5 were repeated with the variables in Table 4 first assigned left-triangular distributions and then assigned right-triangular distributions (i.e., distributions that have density functions that are triangular in shape, with the modes appearing at the left and right ends of the range of each variable, respectively). In this way, the original variable ranges were preserved but the selected distributions weighted the left and right ends of these ranges, respectively.

The use of left-triangular as opposed to right-triangular distributions for the variables in Table 4 caused observable, but not large, changes in the location of the mean and percentile curves for individual consequences. The exceedance probabilities for individual consequence values typically changed by a factor of 2 to 10 for these two distributional assumptions. A typical comparison is shown in Figure 34 for number of early fatalities with variable evacuation; the corresponding mean and percentile curves obtained with the original distributions are shown in Figure 7.

The box plots shown in Figure 35 for mean number of early fatalities obtained with each of the distributional assumptions provide another comparison of the effects of different distributional assumptions. As a reminder, the endpoints of the boxes in Fig. 35 are formed by the lower and upper quartiles of the data, that is $x_{.25}$ and $x_{.75}$. The vertical line within the box represents the median, $x_{.50}$. 
Robustness of Analysis

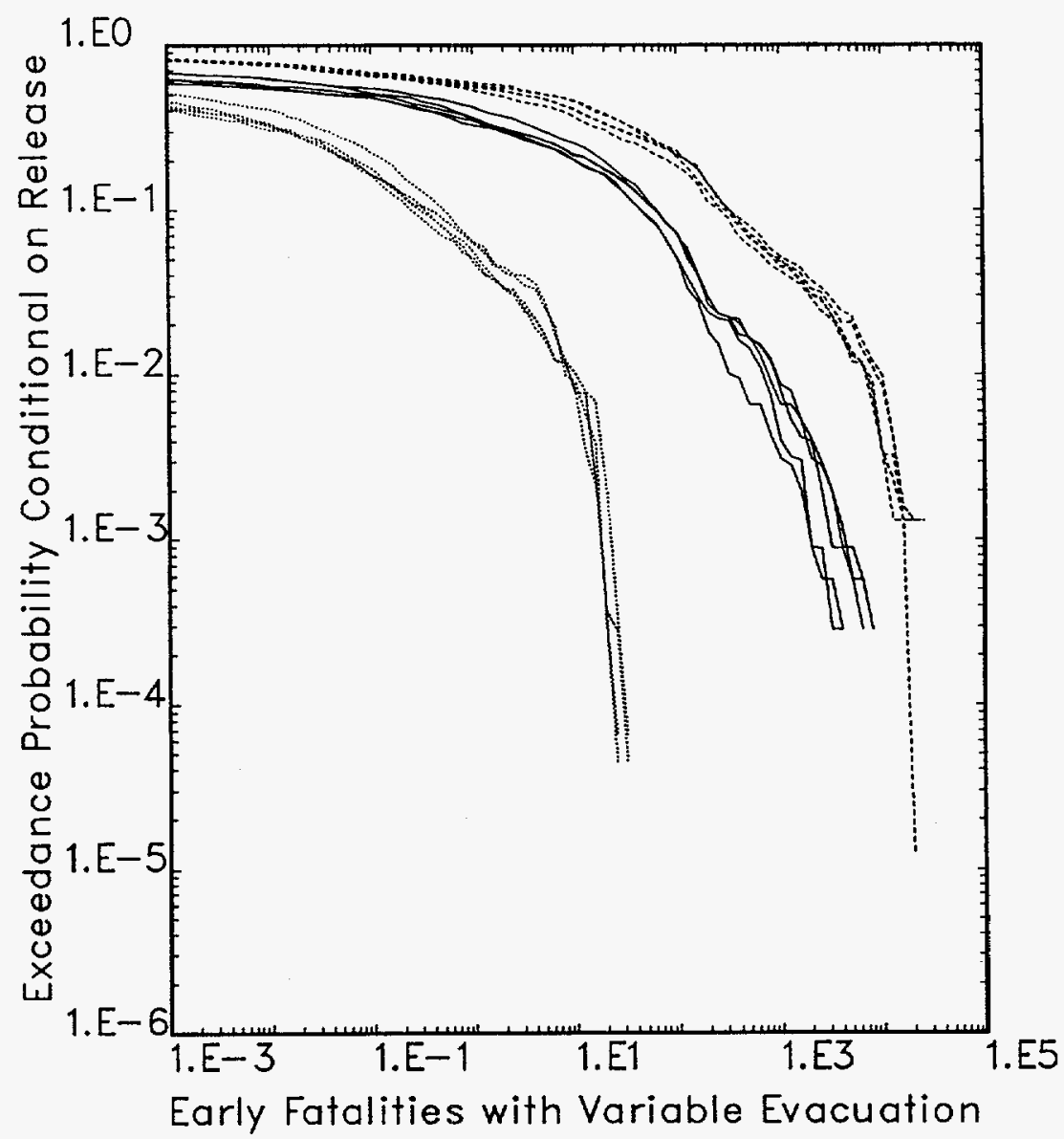

Figure 31. Three Sets of CCDFs for Number of Early Fatalities with Variable Evacuation with Variables in Table 21 Set to Different Best-Estimate Values. 




Figure 32. Median CCDFs for Number of Early Fatalities with Variable Evacuation for 20 Sets of CCDFs with Variables in Table 21 Set to Different Best-Estimate Values. 
Robustness of Analysis

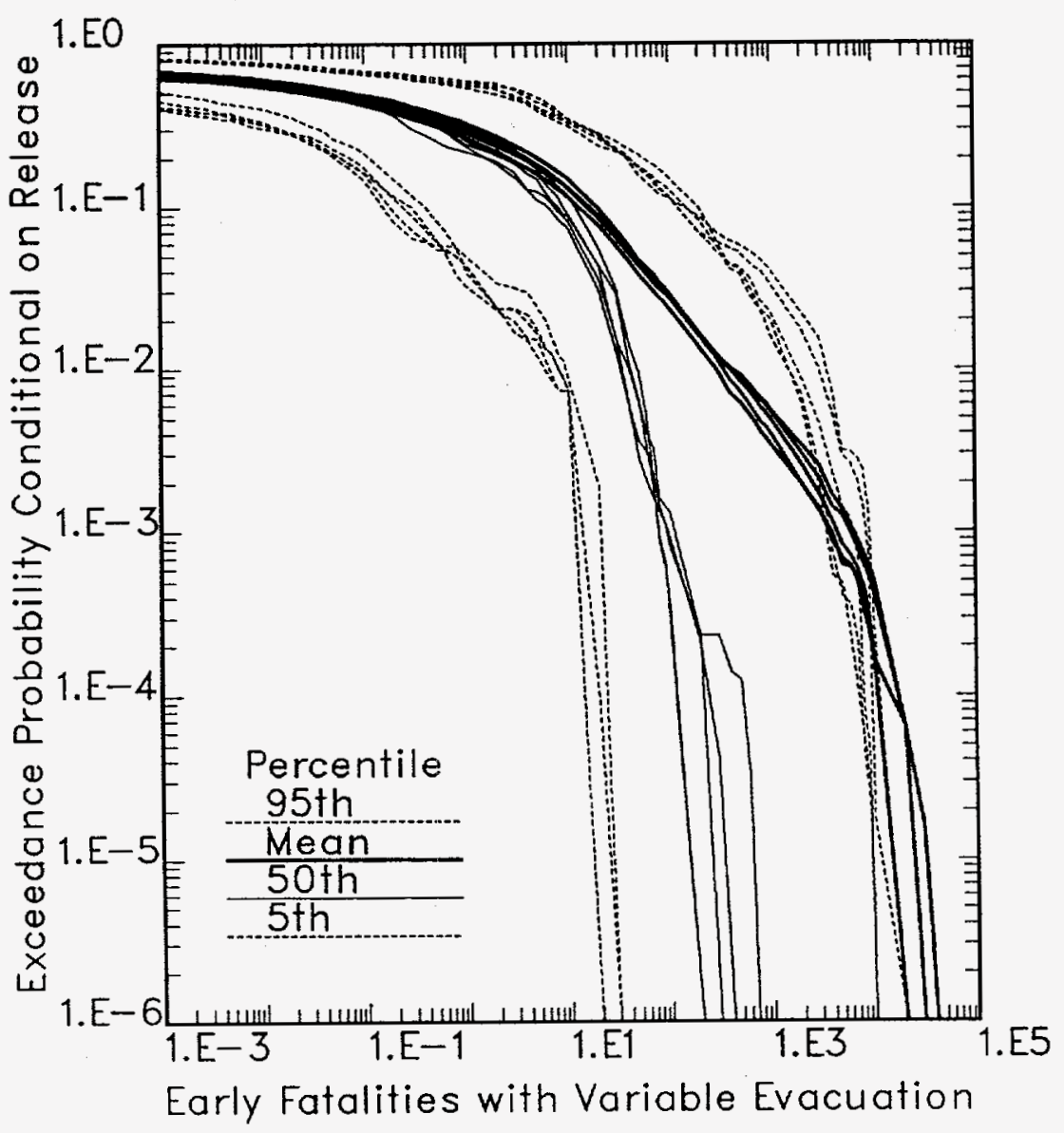

Figure 33. Mean and Percentile Curves for Number of Early Fatalities with Variable Evacuation for Variables Not Contained in Table 21 Set to Five Different Sets of Best-Estimate Values. 
Robustness of Analysis
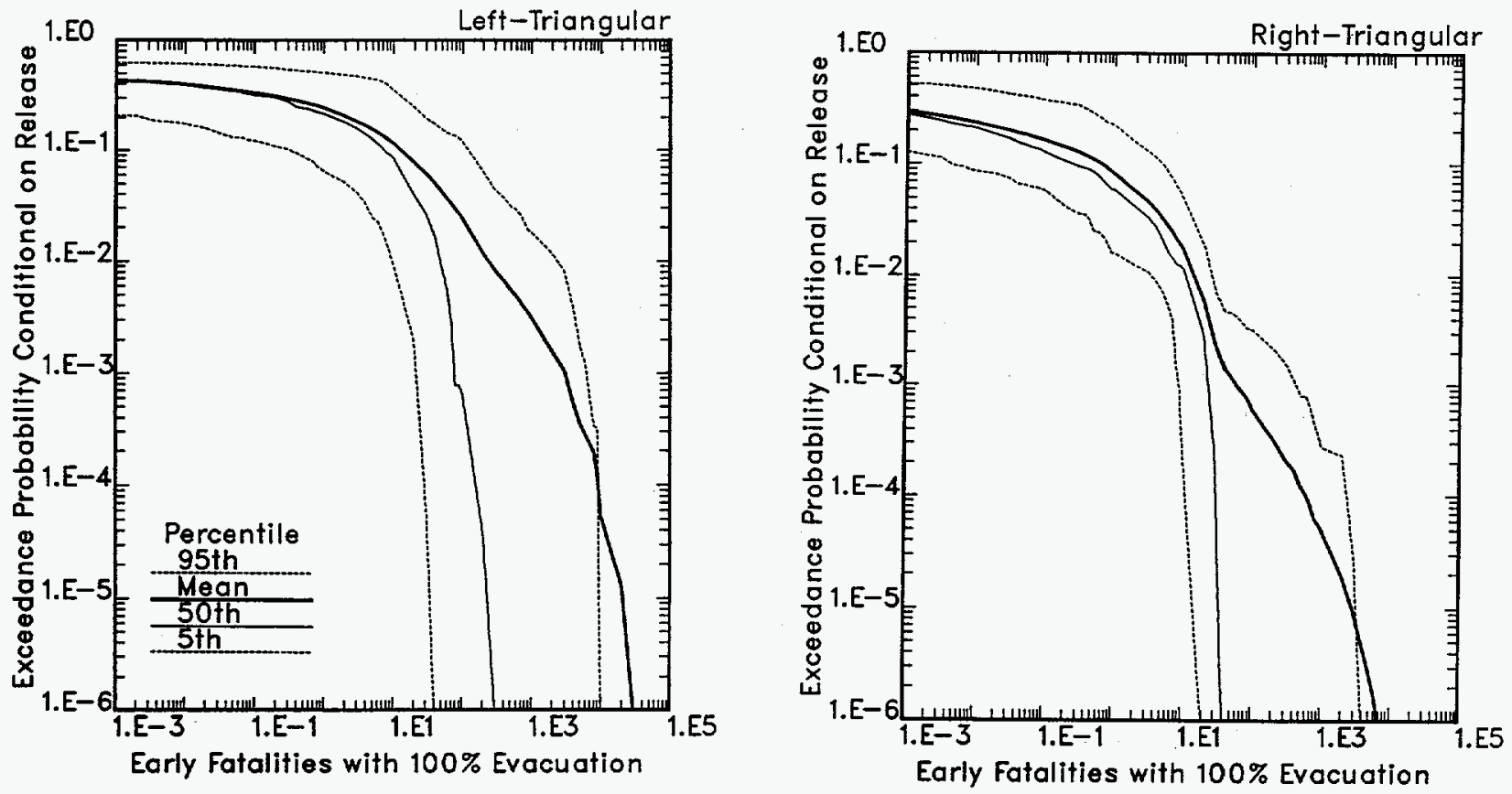

Figure 34. Mean and Percentile Curves for Number of Early Fatalities with Variable Evacuation for Left-Triangular Distributions (left frame) and Right-Triangular Distributions (right frame) Assigned to the Variables in Table 5. 
Robustness of Analysis
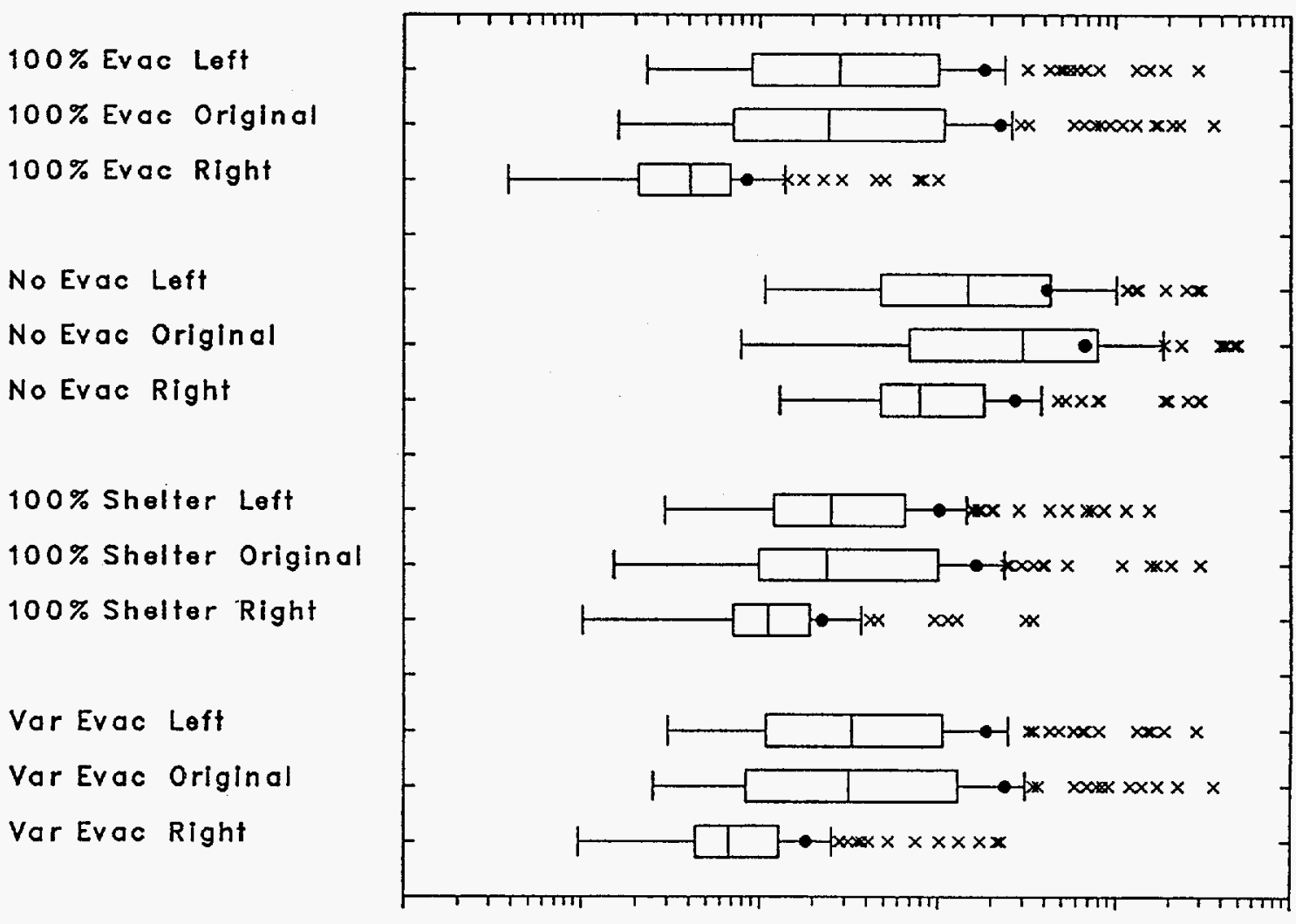
1. $E-2$
1. $E-1$
1. EO
1. E1
1.E2
1.E3

MEAN EARLY FATALITIES

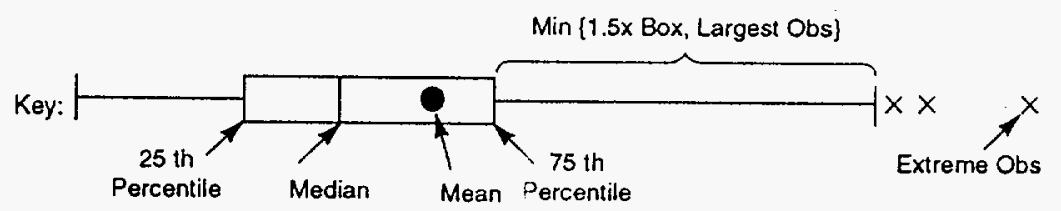

Figure 35. Box Plots for Mean Number of Early Fatalities for Left-Triangular Distributions, Original Distributions and Right-Triangular Distributions Assigned

to the Variables in Table 5 for the Following Cases:

$100 \%$ Evacuation, No Evacuation, 100\% Sheltering, and Variable Evacuation. 
The sample mean is identified by the large dot. The bar on the right of the box extends to the minimum of $x_{.75}+1.5\left(x_{.75}-x_{.25}\right)$ and the maximum observation. In a similar manner, the bar on the left of the box extends to the maximum of $x_{.25}-1.5\left(x_{.75}-x_{.25}\right)$ and the minimum observation. Observations falling outside of these bars are shown with $x$ 's.

The sensitivity analyses based on PRCCs appearing in Figures 8,11, 14, 17 and 20 were repeated with left-triangular and right-triangular distributions, respectively. The results of the analyses with the three distributional assumptions (i.e., left-triangular, original as defined in Table 4, and right-triangular) are summarized in Table 24. As examination of this table shows, a similar set of important variables is picked with each distributional assumption, although there is some variation in the order of variable importance.

The similarity of the sensitivity analysis results obtained with the three distributional assumptions is particularly apparent when the set of all variables identified in the analysis at a specific level of importance is considered. For example, the sets $\mathbf{L}_{P i}, \mathbf{O}_{P i}$ and $\mathbf{R}_{P i}$ defined in Table 25 contain the top $i$ variables identified in the analyses presented in Table 24 for left-triangular distributions, the original distributions and right-triangular distributions, respectively. Thus, $\mathbf{L}_{P i}$ contains all variables listed in Table 24 for which the first integer following the variable is less than or equal to $i$; the sets $\mathbf{O}_{P_{i}}$ and $\mathbf{R}_{P_{i}}$ are defined similarly for the second and third integers, respectively. As examination of Table 25 shows, the sets $\mathbf{L}_{P i}, \mathbf{O}_{P i}$ and $\mathbf{R}_{P i}$ tend to be similar. The changing membership of the sets $\mathbf{U}_{P i}-\mathbf{L}_{P i}, \mathbf{U}_{P_{i}}-\mathbf{O}_{P i}$ and $\mathbf{U}_{P i}-\mathbf{R}_{P i}$, where $\mathbf{U}_{P i}=\mathbf{L}_{P i} \cup \mathbf{O}_{P i} \cup \mathbf{R}_{P i}$, indicates that the differences between $\mathbf{L}_{P i}, \mathbf{O}_{P i}$ and $\mathbf{R}_{P i}$ are due primarily to order of variable selection rather than inherent differences between these sets as $i$ increases.

The sensitivity analyses based on stepwise regression analysis appearing in Tables $7,9,11,13$ and 15 were also repeated with left-triangular and right-triangular distributions. As shown in Table 26, the results of these analyses with the three distributional assumptions are quite similar. In particular, the different distributional assumptions tend to lead to the identification of the same variables, although the order of importance can be different.

As was the case for the sensitivity analysis results based on PRCCs in Table 24, the similarity of the sensitivity analysis results based on stepwise regression analysis in Table 26 is particularly apparent when the set of all variables identified in the analysis at a specific level of importance is considered. The sets $\mathbf{L}_{R i}, \mathbf{O}_{R i}$ and $\mathbf{R}_{R i}$ defined in Table 27 contain the top $i$ variables identified in the analyses presented in Table 26 for left-triangular distributions, the original distributions and right-triangular distributions, respectively, and are analogous to the sets $\mathbf{L}_{P i}, \mathbf{O}_{P_{i}}$ and $\mathbf{R}_{P i}$ used in Table 25 to summarize results based on PRCCs. The sets $\mathbf{L}_{R i}, \mathbf{O}_{R i}$ and $\mathbf{R}_{R i}$ shown in Table 27 tend to be similar. Further, as was the case for groupings based on PRCCs in Table 25, the changing membership of the sets $\mathbf{U}_{R i}-\mathbf{L}_{R i}, \mathbf{U}_{R i}-\mathbf{O}_{R i}$ and $\mathbf{U}_{R i}-\mathbf{R}_{R i}$ indicates that the differences between $\mathbf{L}_{R i}, \mathbf{O}_{R i}$ and $\mathbf{R}_{R i}$ are due primarily to order of variable selection rather than inherent differences between these sets as $i$ increases. 
Robustness of Analysis

Table 24. Comparison of Sensitivity Analysis Results Obtained with PRCCs for Left-Triangular Distributions, Original Distributions as Defined in Table 4 and Right-Triangular Distributions

\begin{tabular}{|c|c|c|c|}
\hline $100 \%$ Evacuation & No Evacuation & $100 \%$ Shelter & Variable Evacuation \\
\hline \multicolumn{4}{|c|}{ Early Fatalities } \\
\hline $\begin{array}{l}\text { YSCALE }(1-, 1-, 1-)^{\mathrm{a}} \\
\operatorname{ZSCALE}(2-, 2-, 5-) \\
\operatorname{TDELAY}(3+, 3+, 2+) \\
\operatorname{ESPEED}(4-, 4-, 7-) \\
\operatorname{SCLCRW}(5-, 5-, 6-) \\
\operatorname{VDEPOS}(6-, 7-, 4+) \\
\operatorname{CSFACTN}(8+, 8+, *) \\
\text { EFFACA1 }(*, 6-, *) \\
\text { EFFTHR1 }(7, *, *) \\
\operatorname{GSHFACN}(*, *, 3+) \\
\operatorname{SCLEFP}(*, *, 8-) \\
\end{array}$ & $\begin{array}{l}\operatorname{YSCALE}(1-, 1-, 3-) \\
\operatorname{GSHFACN}(2+, 2+, 1+) \\
\operatorname{ZSCALE}(3-, 3-, 6-) \\
\text { VDEPOS }(5+-, 4+-, 2+-) \\
\text { TIMHOT }(6+, 6+, 5+) \\
\left.\operatorname{SCLCRW}(4-, 5-,)^{*}\right) \\
\text { EFFTHR1 }(7-, *, *) \\
\operatorname{CWASH} 1(*, *, 4+) \\
\operatorname{EFFACA1}(*, *, 7-)\end{array}$ & $\begin{array}{l}\text { YSCALE }(1-, 1-, 2-) \\
\operatorname{ZSCALE}(2-, 2-, 4-) \\
\operatorname{VDEPOS}(3+, 3+, 1+) \\
\operatorname{GSHFACS}(5+, 4+, 3+) \\
\text { SCLCRW }(4-, 5-, 6-) \\
\operatorname{EFFACA1}(6-, 6-, 5-) \\
\text { EFFTHR1 }\left(7-, 7-,{ }^{*}\right)\end{array}$ & $\begin{array}{l}\text { YSCALE }(1-, 1-, 1-) \\
\text { ZSCALE }(2-, 2-, 6-) \\
\text { VDEPOS }(5+-, 3+, 3+)^{b} \\
\operatorname{GSHFACN}(6+, 4+, 2+) \\
\text { EVFRAC }(8+, 7+, 5+) \\
\text { TIMHOT }(7+, 9+, 7+) \\
\text { ESPEED }(3-, 5-, *) \\
\left.\operatorname{SCLCRW~}(4,, 6-,)^{*}\right) \\
\operatorname{EFFACA1}(*, 8-, 8-) \\
\operatorname{TDELAY}(*, *, 4)\end{array}$ \\
\hline \multicolumn{4}{|c|}{ Prodromal Vomiting } \\
\hline $\begin{array}{l}\text { YSCALE }(1-, 1-, 1-) \\
\text { ZSCALE }(2-, 2-, 5-) \\
\operatorname{TDELAY}(3+, 3+, 2+) \\
\operatorname{VDEPOS}(5-, 6-, 7-) \\
\text { EIFACA1 }(6-, 7-, 4-) \\
\operatorname{SCLCRW}\left(7-, 4-, 4^{*}\right) \\
\operatorname{ESPEED}\left(4-, 5^{-,},\right) \\
\operatorname{GSHFACN}(*, 8+, 3+) \\
\text { TIMHOT }(*, *, 6+)\end{array}$ & $\begin{array}{l}\text { YSCALE }(1-, 1-, 3-) \\
\operatorname{GSHFACN}(2+, 2+, 1+) \\
\text { ZSCALE }(3-, 3-, 5-) \\
\text { VDEPOS }(5+-, 4+, 2+) \\
\text { TIMHOT }(6+, 6+, 4+) \\
\text { SCLCRW }(4-, 5-, *) \\
\text { EIFACA1 }(*, 8-, 6-) \\
\text { CWASH1 }(*, 7+, *)\end{array}$ & $\begin{array}{l}\text { YSCALE }(1-,, 1-, 1-) \\
\text { ZSCALE }(2-, 2-, 4-) \\
\text { SCLCRW }(3-, 3-, 8-) \\
\operatorname{GSHFACS~}(4+, 4+, 5+) \\
\text { VDEPOS }(5+-, 5+-, 3+-) \\
\text { EIFACA1 }(6-, 6-, 6-) \\
\text { GSHFACN }(7+, 7+, 2+) \\
\text { TIMHOT }(*, *, 8+)\end{array}$ & $\begin{array}{l}\text { YSCALE }(1-, 1-, 2-) \\
\text { ZSCALE }(2-,, 2-, 3-) \\
\text { GSHFACN }(6+, 3+, 1+) \\
\text { VDEPOS }(5+-, 6+-, 4+-) \\
\text { EIFACA1 }(7-, 7-, 7-) \\
\text { TIMHOT }(9+, 8+, 5+) \\
\text { SCLCRW }\left(4-, 4-,{ }^{*}\right) \\
\left.\text { ESPEED }(3-, 5-,)^{*}\right) \\
\operatorname{EVFRAC}(*, 9+, 6+) \\
\operatorname{TDELAY}\left(8+,{ }^{*},{ }^{*}\right) \\
\end{array}$ \\
\hline \multicolumn{4}{|c|}{ Population Dose (Sv), 0-10 mi } \\
\hline $\begin{array}{l}\operatorname{TDELAY}(1+, 1+, 1+) \\
\text { YSCALE }(3-, 2-, 2-) \\
\text { ESPEED }(2-, 3-, 5-) \\
\text { VDEPOS }(4-, 4-, 4-) \\
\text { ZSCALE }(5-, 5-, 6-) \\
\text { PROTINN }(6+, 6+, 3+)\end{array}$ & $\begin{array}{l}\text { YSCALE }(1+, 1+, 1+) \\
\operatorname{VDEPOS}(2-, 2+-, 3+-) \\
\text { PROTINN }(3+, 3+, 2+) \\
\text { ZSCALE }(4-, 4-, 4+-) \\
\operatorname{GSHFACN}(5+, 5+, 5+) \\
\text { TIMHOT }(6+, *, 7+) \\
\text { SCLEFP }(7+, *, 6+) \\
\text { P2DOS1 }(8+, *, 8+)\end{array}$ & $\begin{array}{l}\operatorname{YSCALE}(1+, 1+, 2+) \\
\operatorname{PROTINS}(2+, 2+, 1+) \\
\operatorname{VDEPOS}(3-, 3-, 3-) \\
\operatorname{ZSCALE}(4-, 4-, 4-) \\
\operatorname{GSHFACS}(5+, 5+, 5+) \\
\operatorname{SCLEFP}(6+, *, 6+) \\
\operatorname{SCLCRW}\left(7-, *^{*},{ }^{*}\right)\end{array}$ & $\begin{array}{l}\text { YSCALE }(1-, 1-, 2+-) \\
\text { TDELAY }(3+, 2+, 1+) \\
\text { ESPEED }(2-, 3-, 7-) \\
\text { VDEPOS }(5-, 4-, 4-) \\
\text { EVFRAC }(4+, 5+, 5+) \\
\text { PROTINN }(6+, 6+, 3+) \\
\text { ZSCALE }(7-, 7-, 6+-) \\
\text { SCLEFP }(*, *, 8+) \\
\operatorname{SCLADP}(*, *, 9-)\end{array}$ \\
\hline
\end{tabular}


Table 24 (concluded)

\begin{tabular}{|c|c|c|c|}
\hline $100 \%$ Evacuation & No Evacuation & $100 \%$ Shelter & Variable Evacuation \\
\hline \multicolumn{4}{|c|}{ Population Dose (Sv), 0-1000 mi } \\
\hline $\begin{array}{l}\text { VDEPOS }(1-, 1-, 1-) \\
\text { GSHFACN }(2+, 2+, 2+) \\
\text { PROTINN }(3+, 3+, 4+) \\
\text { YSCALE }(4+-, 4+-, 5+) \\
\text { CWASH1 }(6-, 5-, 6-) \\
\text { ZSCALE }(5+, 6+, 3+) \\
\text { SCLEFP }(8+, *, 7+) \\
\operatorname{P} 2 \operatorname{DOS1}(9+, *, 8+) \\
\operatorname{ESPEED}(7-, *, *)\end{array}$ & $\begin{array}{l}\text { VDEPOS }(1-, 1-, 1-) \\
\text { PROTINN }(2+, 2+, 3+) \\
\operatorname{GSHFACN}(3+, 3+, 2+) \\
\text { YSCALE }(4+, 4+, 4+) \\
\text { ZSCALE }(5+, *, 5+) \\
\text { CWASH }(6-, *, *) \\
\text { SCLEFP }(*, *, 6+) \\
\text { P2DOS1 }(*, *, 7+)\end{array}$ & $\begin{array}{l}\text { VDEPOS }(1-, 1-, 1-) \\
\text { PROTINN }(3+, 2+, 4+) \\
\text { GSHFACN }(2+, 3+, 2+) \\
\text { YSCALE }(5+, 4+, 5+) \\
\text { ZSCALE }(4+, 5+, 3+) \\
\text { CWASH }(7-, 6-, 6-) \\
\text { PROTINS }(6+, *, *) \\
\text { SCLCRW }(8+, *, *) \\
\text { SCLEFP }(*, *, 7+) \\
\text { P2DOS1 }(*, *, 8+)\end{array}$ & $\begin{array}{l}\text { VDEPOS }(1-, 1-, 1-) \\
\text { GSHFACN }(2+, 2+, 2+) \\
\text { PROTINN }(3+, 3+, 4+) \\
\text { YSCALE }(4+-, 4+-, 5+) \\
\text { CWASH1 }(6-, 5-, 6-) \\
\text { ZSCALE }(5+, 6+, 3+) \\
\text { SCLEFP }(8+, *, 7+) \\
\text { P2DOS1 }(9+, *, 8+) \\
\text { ESPEED }(7-, *, *)\end{array}$ \\
\hline \multicolumn{4}{|c|}{ Individual Early Fatality Probability, 0-1 mi } \\
\hline $\begin{array}{l}\operatorname{SCLCRW}(1-, 1-, 2-) \\
\text { YSCALE }(2-, 2-, 3-) \\
\text { TDELAY }(4+-, 3+, 1+) \\
\text { ESPEED }(8-, 4-, 7-) \\
\text { EFFTHR1 }(5-, 6-, 9-) \\
\text { EFFACA1 }(7-, 8-, 8-) \\
\text { ZSCALE }(3-, 5-, *) \\
\text { VDEPOS }(*, 7+, 4+) \\
\text { PROTINN }(6+, *, *) \\
\text { GSHFACN }(*, *, 5+) \\
\operatorname{SCLEFP~}(*, *, 6-)\end{array}$ & $\begin{array}{l}\text { YSCALE }(1+, 1+, 3+) \\
\operatorname{VDEPOS}(2+, 2+, 1+) \\
\operatorname{SCLCRW}(5-, 3-, 5-) \\
\operatorname{GSHFACN}(6+, 5+, 2+) \\
\text { TIMHOT }(4+, 6+, 4+) \\
\operatorname{ZSCALE}(3-, 4-, *) \\
\text { CWASH1 }(7+, *, *)\end{array}$ & $\begin{array}{l}\text { VDEPOS }(1+, 1+, 1+) \\
\text { YSCALE }(2+-, 2+-, 3+-) \\
\text { SCLCRW }(3-, 3-, 2-) \\
\text { ZSCALE }(4-, 4-, 6-) \\
\text { GSHFACS }(5+, 5+, 4+) \\
\text { EFFACA1 }(6-, 7-, 7-) \\
\text { EFFTHR1 }(7-, *, 5-) \\
\text { SCLEFP }(*, 6-, *) \\
\text { PROTINS }(8+, *, *)\end{array}$ & $\begin{array}{l}\operatorname{SCLCRW}(1-, 1-, 1-) \\
\text { YSCALE }(2+-, 2+-, 2+-) \\
\operatorname{VDEPOS}(3+, 3+, 3+) \\
\text { ZSCALE }(4-, 4-, 11-) \\
\operatorname{TDELAY}(5-, 5-, 4+) \\
\text { EVFRAC }(6+, 6+, 5+) \\
\text { ESPEED }(11-, 7-, 9-) \\
\text { GSHFACN }(8+, 8+, 6+) \\
\text { TIMHOT }(7+, 9+, 10+) \\
\text { EFFACA1 }(9-, 10-, 8-) \\
\text { PROTINN }(10+, 11+, *) \\
\operatorname{SCLEFP~}(*, *, 7-)\end{array}$ \\
\hline
\end{tabular}

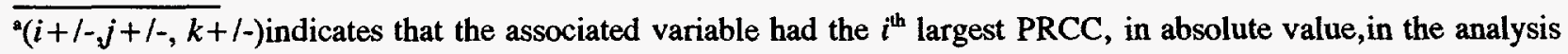
when left-triangular distributions are assumed for the variables in Table 4, with this coefficient being positive ( + ) or negative (-) when its absolute value exceeds $0.5 ; j+1$ - and $k+1$ - provide similar information when the original distributions and right-triangular distributions, respectively, are assumed for the variables in Table 4; * indicates that the variable was not selected in the associated analysis.

${ }^{b}+-$ indicates that a PRCC is first positive and then negative when it exceeds 0.5 in absolute value; the opposite pattern is indicated by -+ . 
Table 25. Comparison of Sets of Variables Identified in Sensitivity Analyses with PRCCs for Left-Triangular Distributions, Original Distributions as Defined in Table 4 and Right-Triangular Distributions

\begin{tabular}{|c|c|}
\hline & Notation \\
\hline $\mathbf{L}_{p_{i}}=\{V A R:$ & $\begin{array}{l}V A R \text { is one of the top } i \text { variables (i.e., rank } 1,2, \ldots, i \text { as defined by the maximum } \\
\text { value of the PRCC) for at least one of the predicted variables in Table } 24 \text { when } \\
\text { left-triangular distributions are assumed }\}\end{array}$ \\
\hline \multicolumn{2}{|c|}{$\begin{array}{l}\mathbf{O}_{P i}, \mathbf{R}_{P i} \text { are defined the same as } \mathbf{L}_{P i} \text { but for the original distributions in Table } 4 \text { and right-triangular } \\
\text { distributions, respectively. }\end{array}$} \\
\hline \multicolumn{2}{|c|}{$\mathbf{U}_{P i}=\mathbf{L}_{P i} \cup \mathbf{O}_{P_{i}} \cup \mathbf{R}_{P i}$} \\
\hline \multicolumn{2}{|c|}{$n U_{P_{i}}=$ number of variables in $\mathbf{U}_{P_{i}}$} \\
\hline \multicolumn{2}{|r|}{ First Variable in One or More Analyses } \\
\hline \multicolumn{2}{|c|}{$\begin{array}{l}\mathbf{U}_{P 1}-\mathbf{L}_{P 1}=\mathbf{U}_{P 1}-\mathbf{O}_{P I}=\{\text { GSHFACN, PROTINN }\} \\
\mathbf{U}_{P i}-\mathbf{R}_{P i}=\varnothing\end{array}$} \\
\hline \multicolumn{2}{|r|}{ Top 2 Variables in One or More Analyses } \\
\hline \multicolumn{2}{|c|}{$\begin{aligned} \mathbf{U}_{P 2}= & \mathbf{U}_{P 1} \cup\{\text { ESPEED, SCLCRW, ZSCALE }\} \\
= & \{\text { ESPEED, GSHFACN, PROTINN, PROTINS, SCLCRW, TDELAY, VDEPOS, } \\
& \text { YSCALE, ZSCALE }\}, n U_{P 2}=9\end{aligned}$} \\
\hline \multicolumn{2}{|c|}{$\begin{array}{l}\mathbf{U}_{P 2}-\mathbf{L}_{P 2}=\varnothing \\
\mathbf{U}_{P 2}-\mathbf{O}_{P 2}=\{\text { ESPEED }\} \\
\mathbf{U}_{P 2}-\mathbf{R}_{P 2}=\{\text { ESPEED, ZSCALE }\}\end{array}$} \\
\hline
\end{tabular}

Top 3 Variables in One or More Analyses

$$
\begin{aligned}
\mathbf{U}_{P 3}= & \mathbf{U}_{P 2} \cup\{\text { GSHFACS }\} \\
= & \text { } \text { ESPEED, GSHFACN, GSHFACS, PROTINN, PROTINS, SCLCRW, TDELAY, } \\
& \text { VDEPOS, YSCALE, ZSCALE }, n U_{P 3}=10 \\
\mathbf{U}_{P 3}-\mathbf{L}_{P 3}= & \mathbf{U}_{P 3}-\mathbf{O}_{P 3}=\{\text { GSHFACS }\} \\
\mathbf{U}_{P 3}-\mathbf{R}_{P 3}= & \{\text { ESPEED }\}
\end{aligned}
$$


Table 25 (concluded)

Top 4 Variables in One or More Analyses

$$
\begin{aligned}
\mathbf{U}_{P 4}= & \mathbf{U}_{P 3} \cup\{C W A S H 1, \text { EIFACA1, EVFRAC, TIMHOT }\} \\
= & \{\text { CWASH1, EIFACA1, ESPEED, EVFRAC, GSHFACN, GSHFACS, PROTINN, } \\
& \text { PROTINS, SCLCRW, TDELAY, TIMHOT, VDEPOS, YSCALE, ZSCALE }, \\
& n U_{P 4}=14 \\
\mathbf{U}_{P 4}-\mathbf{L}_{P 4}= & \text { \{CWASH1, EIFACA1 }\} \\
\mathbf{U}_{P 4}-\mathbf{O}_{P 4}= & \text { CWWASH1, EIFACA1, EVFRAC, TIMHOT }\} \\
\mathbf{U}_{P 4}-\mathbf{R}_{P 4}= & \text { \{ESPEED, EVFRAC }\}
\end{aligned}
$$

Top 5 Variables in One or More Analyses

$$
\begin{aligned}
\mathbf{U}_{P S}= & \mathbf{U}_{P 4} \cup \text { \{EFFACA1, EFFTHR1\} } \\
= & \{C W A S H 1, \text { EFFACA1, EFFTHR1, EIFACA1, ESPEED, EVFRAC, GSHFACN, } \\
& \text { GSHFACS, PROTINN, PROTINS, SCLCRW, TDELAY, TIMHOT, VDEPOS, } \\
& \text { YSCALE, ZSCALE }, n U_{P S}=16
\end{aligned}
$$

$\mathbf{U}_{P S}-\mathbf{L}_{P S}=\{$ CWASH1, EFFACA1, EIFACA1 $\}$

$\mathbf{U}_{P 5}-\mathbf{O}_{P 5}=\{$ EFFACA1, EFFTHR1, EIFACA1, TIMHOT $\}$

$\mathbf{U}_{P S}-\mathbf{R}_{P S}=\varnothing$

Top 6 Variables in One or More Analyses

$$
\begin{aligned}
\mathbf{U}_{P \sigma}= & \mathbf{U}_{P S} \cup\{\text { SCLEFP }\} \\
= & \{C W A S H 1, \text { EFFACA1, EFFTHR1, EIFACA1, ESPEED, EVFRAC, GSHFACN, } \\
& \text { GSHFACS, PROTINN, PROTINS, SCLCRW, SCLEFP, TDELAY, TIMHOT, } \\
& \text { VDEPOS, YSCALE, ZSCALE }, n U_{P \sigma}=17
\end{aligned}
$$

$\mathbf{U}_{P \sigma}-\mathbf{L}_{P \sigma}=\mathbf{U}_{P \sigma}-\mathbf{O}_{P \sigma}=\mathbf{U}_{P \sigma}-\mathbf{R}_{P \sigma}=\varnothing$ 
Robustness of Analysis

Table 26. Comparison of Sensitivity Analysis Results Obtained by Stepwise Regression Analysis with Rank-Transformed Data for Left-Triangular Distributions, Original Distributions as Defined in Table 4 and Right-Triangular Distributions

\begin{tabular}{|c|c|c|c|}
\hline $100 \%$ Evacuation & No Evacuation & $100 \%$ Shelter & Variable Evacuation \\
\hline \multicolumn{4}{|c|}{ Early Fatalities } \\
\hline $\begin{array}{l}\text { YSCALE }(1-, 1-, 1-)^{\mathrm{a}} \\
\text { ESPEED }(2-, 2-, 7-) \\
\text { EFFACA1 }(4-, 4-, 3-) \\
\operatorname{GSHFACN}(6+, 5+, 2+) \\
\operatorname{TDELAY}(7+, 8+, 4+) \\
\operatorname{ZSCALE}(3-, 3-, *) \\
\text { VDEPOS }\left(5-, 6-,{ }^{*}\right) \\
\operatorname{CSFACTN}(*, 7+, *) \\
\text { SCLEFP }(*, *, 5-) \\
\text { BUILDH }(*, *, 6+)\end{array}$ & $\begin{array}{l}\operatorname{YSCALE}(1-, 1-, 2-) \\
\operatorname{GSHFACN}(2+, 2+, 1+) \\
\text { EFFACA1 }(3-, 3-, 4) \\
\text { TIMHOT }(4+, 4+, 3+) \\
\operatorname{ZSCALE}(5-, 5-, 5-) \\
\operatorname{VDEPOS}(*, *, 6+)\end{array}$ & $\begin{array}{l}\text { YSCALE }(1-, 1-, 1-) \\
\text { EFFACA1 }(2-, 2-, 2-) \\
\text { ZSCALE }(4-, 3-, 5-) \\
\text { GSHFACS }(3+, 4+, 3+) \\
\text { VDEPOS }(*, 5+, 4+) \\
\text { PROTINS }(5+, 6+, *)\end{array}$ & $\begin{array}{l}\operatorname{YSCALE}(1-, 1-, 1-) \\
\operatorname{ZSCALE}(3-, 2-, 7-) \\
\operatorname{EFFACA1}(4-, 3-, 3-) \\
\operatorname{GSHFACN}(6+, 5+, 2+) \\
\operatorname{EVFRAC}(8+, 6+, 6+) \\
\text { ESPEED }(2-, 4-, *) \\
\operatorname{TIMHOT}(+, 7+, 4+) \\
\operatorname{VDEPOS}\left(5-, 10-,{ }^{*}\right) \\
\operatorname{TDELAY}(7+, *, 5+) \\
\operatorname{CSFACTN}(*, 8+, *) \\
\operatorname{SCLCRW}(*, 9-, *)\end{array}$ \\
\hline \multicolumn{4}{|c|}{ Prodromal Vomiting } \\
\hline $\begin{array}{l}\text { YSCALE }(1-, 1-,, 1-) \\
\text { ZSCALE }(2-, 2-, 8-) \\
\text { ESPEED }(3-, 3-, 6-) \\
\text { VDEPOS }(4-, 4-, 7-) \\
\text { GSHFACN }(7+, 5+, 2+) \\
\text { EIFACA1 }(6-, 6-, 3-) \\
\text { TDELAY }(5+, 7+, 5+) \\
\text { TIMHOT }(*, 8+, 4+) \\
\text { CSFACTE }(*, *, 9+)\end{array}$ & $\begin{array}{l}\operatorname{YSCALE}(1-, 1-, 2-) \\
\operatorname{GSHFACN}(2+, 2+, 1+) \\
\operatorname{ZSCALE}(3-, 3-, 5-) \\
\operatorname{TIMHOT}(4+, 4+, 3+) \\
\operatorname{EIFACA} 1(7-, 5-, 4-) \\
\operatorname{SCLEFP}(5+, *, 6+) \\
\operatorname{VDEPOS}(6-, *, *) \\
\operatorname{PROTINN}(8+, *, *)\end{array}$ & $\begin{array}{l}\text { YSCALE }(1-, 1-, 1-) \\
\operatorname{ZSCALE}(2-, 2-, 5-) \\
\text { EIFACA1 }(4-, 3-, 2-) \\
\operatorname{GSHFACS}(3+, 4+, 3+) \\
\text { TIMHOT }(6+, 7+, 6+) \\
\operatorname{GSHFACN}(*, 5+, 4+) \\
\text { VDEPOS }(5-, 6-, *) \\
\text { PROTINS }(7+, 8+, *) \\
\text { CWASH1 }(*, *, 7+)\end{array}$ & $\begin{array}{l}\text { YSCALE (1-, 1-, 1-) } \\
\text { ZSCALE }(2-, 2-, 5-) \\
\text { ESPEED }(3-, 3-, 8-) \\
\operatorname{GSHFACN}(7+, 4+, 2+) \\
\text { VDEPOS }(4-, 5-, 7-) \\
\text { EIFACA1 }(6-, 6-, 4-) \\
\text { TIMHOT }(*, 7+, 3+) \\
\text { TDELAY }(5+, 8+, *) \\
\text { EVFRAC }(*, *, 6+)\end{array}$ \\
\hline \multicolumn{4}{|c|}{ Population Dose (Sv), 0-10 mi } \\
\hline $\begin{array}{l}\text { YSCALE }(1-, 1-, 1-) \\
\text { ESPEED }(2-, 2-, 6-) \\
\operatorname{VDEPOS}(3-, 3-, 3-) \\
\operatorname{TDELAY}(4+, 4+, 2+) \\
\operatorname{ZSCALE}(5-, 5-, 5-) \\
\text { PROTINN }(*, *, 4+)\end{array}$ & $\begin{array}{l}\text { VDEPOS }(1-, 1-, 4-) \\
\text { PROTINN }(2+, 2+, 2+) \\
\text { ZSCALE }(3-, 3-, 5-) \\
\text { GSHFACN }(5+, 4+, 1+) \\
\text { TIMHOT }(4+, 5+, 3+) \\
\text { SCLEFP }(6+, 6+, 7+) \\
\text { P2DOS }(7+, *, 6+)\end{array}$ & $\begin{array}{l}\text { VDEPOS }(1-, 1-, 2-) \\
\operatorname{PROTINS}(2+, 2+, 1+) \\
\operatorname{ZSCALE}(3-, 3-, 3-) \\
\operatorname{SCLEFP}(4+, *, 4+) \\
\operatorname{GSHFACS}(5+, *, 5+) \\
\text { CWASH } 1(6+, *, *) \\
\operatorname{EFFACA} 1(7-, *, *)\end{array}$ & $\begin{array}{l}\text { YSCALE }(1-, 1-, 1-) \\
\text { VDEPOS }(3-, 2-, 3-) \\
\text { ESPEED }(2-, 3-, 6-) \\
\text { TDELAY }(4+, 4+, 2+) \\
\text { ZSCALE }(5-, 5-, 5-) \\
\text { PROTINN }(*, *, 4+)\end{array}$ \\
\hline
\end{tabular}


Table 26 (concluded)

\begin{tabular}{|c|c|c|c|}
\hline $100 \%$ Evacuation & No Evacuation & $100 \%$ Shelter & Variable Evacuation \\
\hline \multicolumn{4}{|c|}{ Population Dose (Sv), 0-1000mi } \\
\hline $\begin{array}{l}\operatorname{VDEPOS}(1-, 1-, 2-) \\
\text { GSHFACN }(2+, 2+, 1+) \\
\text { PROTINN }(3+, 3+, 4+) \\
\text { P2DOS1 }(4+, 4+, 5+) \\
\text { ESPEED }(5-, 5-, *) \\
\text { ZSCALE }(*, *, 3+) \\
\text { CWASH1 }(*, *, 6-)\end{array}$ & $\begin{array}{l}\operatorname{VDEPOS}(1-, 1-, 2-) \\
\operatorname{PROTINN}(3+, 2+, 4+) \\
\operatorname{GSHFACN}(2+, 3+, 1+) \\
\operatorname{ZSCALE}(7+, 4+, 3+) \\
\text { P2DOS1 }(5+, 5+, 5+) \\
\text { YSCALE }(4+, *, 6+) \\
\text { PHS2T2 }(6+, *, *) \\
\operatorname{SCLCRW~}(8+, *, *) \\
\operatorname{CWASH}(9-, *, *) \\
\text { CWASH1 }(*, *, 7-) \\
\operatorname{SCLEFP}(*, *, 8+)\end{array}$ & $\begin{array}{l}\text { VDEPOS }(1-, 1-, 2-) \\
\text { GSHFACN }(2+, 2+, 1+) \\
\text { PROTINN }(3+, 3+, 4+) \\
\text { ZSCALE }(4+, 4+, 3+) \\
\text { P2DOS1 }(5+, 5+, 5+) \\
\text { YSCALE }(7+, 7+, 6+) \\
\text { PROTINS }(6+, 6+, *) \\
\text { SCLCRW }(8+, 8+, *) \\
\text { CWASH1 }(9-, *, 7-)\end{array}$ & $\begin{array}{l}\operatorname{VDEPOS}(1-, 1-, 2-) \\
\operatorname{GSHFACN}(2+, 2+, 1+) \\
\text { PROTINN }(3+, 3+, 4+) \\
\text { P2DOS1 }(4+, 4+, 5+) \\
\text { ESPEED }(5-, 5-, *) \\
\text { ZSCALE }(*, *, 3+) \\
\operatorname{CWASH} 1(*, *, 6-)\end{array}$ \\
\hline \multicolumn{4}{|c|}{ Individual Early Fatality Probability, 0-1 mi } \\
\hline $\begin{array}{l}\text { SCLCRW }(2-, 1-, 7-) \\
\text { YSCALE }(4-,, 2-, 2-) \\
\text { EFFACA1 }(3-,, 3-, 1-) \\
\text { SCLEFP }(9-, 4-, 4-) \\
\text { PROTINN }(5+, 6+, 9+) \\
\text { BUILDH }(7+, 7+, 11+) \\
\text { ESPEED }(8-, 9-, 10-) \\
\text { ZSCALE }(1-, 5-, *) \\
\text { CSFACTN }(6+, 8+, *) \\
\text { EFFACA2 }(*, 10-, *) \\
\text { TDELAY }(*, *, 3+) \\
\text { GSHFACN }(*, *, 5+) \\
\text { VDEPOS }(*, *, 6+) \\
\text { TIMHOT }(*, *, 8-)\end{array}$ & $\begin{array}{l}\operatorname{VDEPOS}(2+, 1+, 1+) \\
\text { GSHFACN }(3+, 2+, 2+) \\
\text { TIMHOT }(1+, 3+, 3+) \\
\text { SCLCRW }(5-, 4-, 5-) \\
\text { EFFACA1 }(4-, 5-, 4-) \\
\text { BUILDH }(9+, 6+, *) \\
\text { YSCALE }(7+, 8+, *) \\
\text { ZSCALE }(6-, 9-, *) \\
\text { PROTINN }\left(8+, 10+,{ }^{*}\right) \\
\operatorname{SCLEFP~}(*, 7-, *)\end{array}$ & $\begin{array}{l}\operatorname{VDEPOS}(1+, 1+, 1+) \\
\operatorname{SCLCRW}(4-, 2-, 4-) \\
\text { EFFACA1 }(2-, 3-, 2-) \\
\operatorname{GSHFACS}(3+, 4+, 3+) \\
\text { ZSCALE }(5-, 5-, 6-) \\
\text { SCLEFP }(8-, 6-, 5-) \\
\text { BUILDH }(7+, 7+, *) \\
\text { PROTINS }(6+, 8+, *) \\
\text { CSFACTE }(*, *, 7-) \\
\text { YSCALE }(*, *, 8-)\end{array}$ & $\begin{array}{l}\operatorname{SCLCRW}(2-, 1-, 7-) \\
\text { YSCALE }(4-, 2-, 2-) \\
\text { EFFACA1 }(3-,, 3-, 1-) \\
\text { SCLEFP }(7-, 5-, 3-) \\
\text { ZSCALE }\left(1-, 4-,{ }^{*}\right) \\
\text { PROTINN }(5+, 6+, *) \\
\left.\text { CSFACTN }(6+, 7+,)^{*}\right) \\
\text { ESPEED }(9-, 8-, *) \\
\text { BUILDH }(8+, 9+, *) \\
\text { VDEPOS }(*, 11+, 6+) \\
\text { EFFACA2 }(*, 10-, *) \\
\text { TDELAY }(*, *, 4+) \\
\text { GSHFACN }(*, *, 5+)\end{array}$ \\
\hline
\end{tabular}

a $(i+/-, j+/-, k+/-)$ indicates that the associated variable was the $i^{\text {th }}$ variable selected in the stepwise regression analysis when left-triangular distributions are assumed for the variables in Table 4, with the corresponding regression coefficient being positive $(+)$ or negative $(-) ; j+1$ - and $k+1$ - provide similar information when the original distributions and right-triangular distributions, respectively, are assumed for the variables in Table 4; * indicates that the variable was not selected in the associated analysis. 
Robustness of Analysis

Table 27. Comparison of Sets of Variables Identified in Sensitivity Analyses Based on Stepwise Regression Analysis with Rank-Transformed Data for Left-Triangular Distributions, Original Distributions as Defined in Table 4 and Right-Triangular Distributions

\begin{tabular}{l} 
Notation \\
\hline $\mathbf{L}_{R i}=\left\{V A R: \quad \begin{array}{l}V A R \text { is one of the top } i \text { variables (i.e., rank } 1,2, \ldots, i \text { as defined by the order of } \\
\text { entry into a stepwise regression analysis) for at least one of the predicted variables } \\
\text { in Table } 26 \text { when left-triangular distributions are assumed }\}\end{array}\right.$ \\
$\begin{array}{l}\mathbf{O}_{R i}, \mathbf{R}_{R i} \text { are defined the same as } \mathbf{L}_{R i} \text { but for the original distributions in Table } 4 \text { and right-triangular } \\
\text { distributions, respectively. }\end{array}$ \\
$\mathbf{U}_{R i}=\mathbf{L}_{R i} \cup \mathbf{O}_{R i} \cup \mathbf{R}_{R i}$ \\
$n U_{R i}=$ number of variables in $\mathbf{U}_{R i}$
\end{tabular}

First Variable in One or More Analyses

$\mathbf{U}_{R l}=\{$ EFFACA1, GSHFACN, PROTINS, SCLCRW, TIMHOT, VDEPOS, YSCALE, ZSCALE $\}, n U_{R I}=8$

$\mathbf{U}_{R I}-\mathbf{L}_{R I}=$ \{EFFACA1, GSHFACN, PROTINS, SCLCRW $\}$

$\mathbf{U}_{R I}-\mathbf{O}_{R I}=$ EFFACA1, GSHFACN, PROTINS, TIMHOT, ZSCALE $\}$

$\mathbf{U}_{R I}-\mathbf{R}_{R I}=\{$ SCLCRW, TIMHOT, ZSCALE $\}$

Top 2 Variables in One or More Analyses

$$
\begin{aligned}
\mathbf{U}_{R 2}= & \left.\mathbf{U}_{R I} \cup \text { \{EIFACA1, ESPEED, PROTINN, TDELAY }\right\} \\
= & \{\text { EFFACA1, EIFACA1, ESPEED, GSHFACN, PROTINN, PROTINS, SCLCRW, } \\
& \text { TDELAY, TIMHOT, VDEPOS, YSCALE, ZSCALE }, n U_{R 2}=12 \\
\mathbf{U}_{R 2}-\mathbf{L}_{R 2}= & \text { \{EIFACA1, TDELAY }\} \\
\mathbf{U}_{R 2}-\mathbf{O}_{R 2}= & \text { EIFACA1, TDELAY, TIMHOT }\} \\
\mathbf{U}_{R 2}-\mathbf{R}_{R 2}= & \text { ESSPEED, SCLCRW, TIMHOT, ZSCALE }\}
\end{aligned}
$$$$
\text { TDELAY, TIMHOT, VDEPOS, YSCALE, ZSCALE }\}, n U_{R 2}=12
$$

Top 3 Variables in One or More Analyses

$$
\begin{aligned}
\mathbf{U}_{R 3}= & \mathbf{U}_{R 2} \cup\{\text { GSHFACS, SCLEFP }\} \\
= & \text { \{EFFACA1, EIFACA1, ESPEED, GSHFACN, GSHFACS, PROTINN, PROTINS, } \\
& \text { SCLCRW, SCLEFP, TDELAY, TIMHOT, VDEPOS, YSCALE, ZSCALE }, \\
& n U_{R 3}=14 \\
\mathbf{U}_{R 3}- & \left.\mathbf{L}_{R 3}=\text { \{EIFACA1, SCLEFP, TDELAY }\right\} \\
\mathbf{U}_{R 3}-\mathbf{O}_{R 3}= & \text { \{GSHFACS, SCLEFP, TDELAY }\} \\
\mathbf{U}_{R 3}- & \mathbf{R}_{R 3}=\{\text { ESPEED, GSHFACS, SCLCRW }\}
\end{aligned}
$$$$
\text { SCLCRW, SCLEFP, TDELAY, TIMHOT, VDEPOS, YSCALE, ZSCALE\}, }
$$ 
Table 27 (concluded)

Top 4 Variables in One or More Analyses

$$
\begin{aligned}
& \mathbf{U}_{R 4}=\mathbf{U}_{R 3} \cup\{\mathrm{P} 2 \mathrm{DOS} 1\} \\
& =\text { EFFACA1, EIFACA1, ESPEED, GSHFACN, GSHFACS, PROTINN, PROTINS, } \\
& \text { ZSCALE }\}, n U_{R 4}=15 \\
& \mathbf{U}_{R 4}-\mathbf{L}_{R 4}=\mathbf{U}_{R 4}-\mathbf{O}_{R 4}=\varnothing \\
& \mathbf{U}_{R 4}-\mathbf{R}_{R 4}=\{\text { ESPEED, P2DOS1 }\} \\
& \mathbf{U}_{R S}=\mathbf{U}_{R 4} \cup \varnothing=\mathbf{U}_{R 4}, n U_{R S}=15 \\
& \mathbf{U}_{R S}-\mathbf{L}_{R S}=\mathbf{U}_{R S}-\mathbf{O}_{R S}=\varnothing \\
& \mathbf{U}_{R S}-\mathbf{R}_{R S}=\{\mathrm{P} 2 \mathrm{DOS} 1\}
\end{aligned}
$$$$
\text { P2DOS1, SCLCRW, SCLEFP, TDELAY, TIMHOT, VDEPOS, YSCALE, }
$$

Top 5 Variables in One or More Analyses

Top 6 Variables in One or More Analyses

$\mathbf{U}_{R \sigma}=\mathbf{U}_{R S} \cup\{$ BUILDH, CSFACTN, CWASH1, EVFRAC, PHS2T2\}

$=\{$ BUILDH, CSFACTN, CWASH1, EFFACA1, EIFACA1, ESPEED, EVFRAC, GSHFACN, GSHFACS, PROTINN, PROTINS, PHS2T2, P2DOS1, SCLCRW, SCLEFP, TDELAY, TIMHOT, VDEPOS, YSCALE, ZSCALE $\}, n U_{R 6}=20$

$\mathbf{U}_{R \sigma}-\mathbf{L}_{R \sigma}=\{$ BUILDH, EVFRAC $\}$

$\mathbf{U}_{R \sigma}-\mathbf{O}_{R \sigma}=\{$ CSFACTN, CWASH1, PHS2T2\}

$\mathbf{U}_{R \sigma}-\mathbf{R}_{R \sigma}=\{$ CSFACTN, PHS2T2 $\}$ 


\subsection{Effect of Logarithmic Transformations}

The analyses presented to this point have used rank-transformed data. As indicated in Section 5.1 , the use of rank-transformed data led to better sensitivity analysis results than use of the original untransformed (i.e., raw) data. Other transformations are also possible. For example, the logarithmic (i.e., $\log _{10}$ ) transformation is often effective. The logarithmic transformation is difficult to use in the analysis of distributions of CCDFs of the form shown in Figure 2 owing to the occurrence of zero exceedance probabilities as the consequence values increase. However, all of the mean results analyzed in Section 5 are nonzero and so use of the logarithmic transform presents no problems. As shown in Table 28 for mean number of early fatalities, use of rank-transformed data and logarithmically transformed data lead to similar sensitivity analysis results. Similar comparisons between sensitivity analysis results with rank-transformed data and logarithmically transformed data were obtained for all the mean consequence values considered in Section 5. 
Table 28. Comparison of Stepwise Regression Analysis Results with Rank-Transformed Data and Logarithmically Transformed Data for Mean Number of Early Fatalities for the Following Cases:

100\% Evacuation, No Evacuation, 100\% Sheltering, and Variable Evacuation

\begin{tabular}{|c|c|c|c|c|}
\hline & \multicolumn{2}{|c|}{ Rank-Transformed } & \multicolumn{2}{|c|}{ Log-Transformed } \\
\hline Step" & Variable $^{\mathbf{b}}$ & $\mathbf{R}^{2 \mathbf{c}}$ & Variable $^{b}$ & $\mathbf{R}^{2 c}$ \\
\hline \multicolumn{5}{|c|}{ Early Fatalities: $100 \%$ Evacuation } \\
\hline 1 & YSCALE & $0.65(-)$ & YSCALE & $0.64(-)$ \\
\hline 2 & ESPEED & $0.72(-)$ & ZSCALE & $0.72(-)$ \\
\hline 3 & ZSCALE & $0.79(-)$ & ESPEED & $0.78(-)$ \\
\hline 4 & EFFACA1 & $0.85(-)$ & EFFACA1 & $0.84(-)$ \\
\hline 5 & GSHFACN & $0.88(+)$ & GSHFACN & $0.88(+)$ \\
\hline 6 & VDEPOS & $0.90(-)$ & VDEPOS & $0.90(-)$ \\
\hline 7 & CSFACTN & $0.91(+)$ & & \\
\hline \multicolumn{5}{|c|}{ Early Fatalities: No Evacuation } \\
\hline 1 & YSCALE & $0.50(-)$ & YSCALE & $0.51(-)$ \\
\hline 2 & GSHFACN & $0.66(+)$ & GSHFACN & $0.66(+)$ \\
\hline 3 & EFFACA1 & $0.76(-)$ & EFFACA1 & $0.77(-)$ \\
\hline 4 & TIMHOT & $0.83(t)$ & TIMHOT & $0.85(+)$ \\
\hline 5 & ZSCALE & $0.89(-)$ & ZSCALE & $0.91(-)$ \\
\hline \multicolumn{5}{|c|}{ Early Fatalities: $100 \%$ Shelter } \\
\hline 1 & YSCALE & $0.57(-)$ & YSCALE & $0.57(-)$ \\
\hline 2 & EFFACA1 & $0.72(-)$ & EFFACA1 & $0.74(-)$ \\
\hline 3 & ZSCALE & $0.79(-)$ & ZSCALE & $0.80(-)$ \\
\hline 4 & GSHFACS & $0.84(+)$ & GSHFACS & $0.85(+)$ \\
\hline 5 & VDEPOS & $0.85(+)$ & GSHFACN & $0.87(+)$ \\
\hline 6 & PROTINS & $0.86(+)$ & VDEPOS & $0.88(+)$ \\
\hline 7 & & & TIMHOT & $0.89(+)$ \\
\hline
\end{tabular}


Table 28 (concluded)

\begin{tabular}{|c|c|c|c|c|}
\hline & \multicolumn{2}{|c|}{ Rank-Transformed } & \multicolumn{2}{|c|}{ Log-Transformed } \\
\hline Step $^{\mathbf{a}}$ & Variable $^{b}$ & $\mathbf{R}^{2 \mathrm{c}}$ & Variable $^{b}$ & $\mathbf{R}^{2 \mathbf{c}}$ \\
\hline \multicolumn{5}{|c|}{ Early Fatalities: Variable Evacuation } \\
\hline 1 & YSCALE & $0.63(-)$ & YSCALE & $0.64(-)$ \\
\hline 2 & ZSCALE & $0.70(-)$ & ZSCALE & $0.71(-)$ \\
\hline 3 & EFFACA 1 & $0.76(-)$ & EFFACA1 & $0.76(-)$ \\
\hline 4 & ESPEED & $0.81(-)$ & ESPEED & $0.82(-)$ \\
\hline 5 & GSHFACN & $0.87(+)$ & GSHFACN & $0.87(+)$ \\
\hline 6 & EVFRAC & $0.89(+)$ & TIMHOT & $0.89(+)$ \\
\hline 7 & TIMHOT & $0.90(+)$ & EVFRAC & $0.90(+)$ \\
\hline 8 & CSFACTN & $0.91(t)$ & VDEPOS & $0.91(-)$ \\
\hline 9 & SCLCRW & $0.92(-)$ & SCLCRW & $0.92(-)$ \\
\hline 10 & VDEPOS & $0.92(-)$ & & \\
\hline
\end{tabular}

"Steps in stepwise regression analysis.

bVariables listed in order of selection in stepwise regression analysis.

"Cumulative $R^{2}$ value with entry of each variable into regression model, with the "+/-" in parentheses after the $R^{2}$ value indicating whether the variable selected at that step has a positive $(+)$ or negative $(-)$ regression coefficient. 


\section{DISCUSSION}

An uncertainty/sensitivity analysis for the early health effects associated with a severe accident at a nuclear power station has been performed with the MACCS reactor accident consequence model. The primary purpose of this study is to identify important variables for further review to improve the quality of results obtained in future uncertainty analyses. To facilitate the identification of important variables, a source term that involves a large release and results in large exposures to evacuees was selected for use in the analysis.

In the presented analyses, care is taken to distinguish between stochastic uncertainty, which leads to a single CCDF, and subjective uncertainty, which leads to a distribution of CCDFs. Stochastic uncertainty enters the analysis through weather sequence probabilities and thus is a property of the system under study. Subjective uncertainty enters the analysis because of lack of knowledge about quantities that are assumed to be fixed within the computational implementation of the analysis and thus is a property of both how the system is modeled and the analysts performing the analysis.

Thirty-four imprecisely known variables are considered in this study and used in the calculation of the following predicted variables: number of fatalities occurring within $1 \mathrm{yr}$ of the accident, number of individuals experiencing prodromal vomiting, population dose (Sv) from exposure received by individuals initially within $10 \mathrm{mi}$ of the reactor, population dose (Sv) from exposure received by individuals within $1000 \mathrm{mi}$ of the reactor, probability that an individual initially within $1 \mathrm{mi}$ of the reactor will become an early fatality, and maximum distance from the reactor at which an individual has a nonzero probability of becoming an early fatality. Conditional on the characterizations of subjective uncertainty in use, the corresponding uncertainty in the preceding reactor accident consequences typically spanned several orders of magnitude for both the exceedance probabilities associated with CCDFs and mean values derived from CCDFs. However, excessive emphasis should not be placed on the observed uncertainty ranges until after additional review can be performed for the dominant variables identified in the sensitivity analyses.

Of the 34 variables treated as being uncertain, a relatively small number had substantial effects on the predicted variables under consideration. When the predicted variables are considered collectively, the following input variables were found to be the dominant contributors to uncertainty: YSCALE (scaling factor for horizontal dispersion), VDEPOS (dry deposition velocity), PROTINN (inhalation protection factor for nonevacuees), GSHFACN (groundshine shielding factor for nonevacuees), EFFACA1 (early fatality hazard function alpha value for bone marrow exposure), and ZSCALE (scaling factor for vertical dispersion).

Several tests were conducted to provide a check on the robustness of the results obtained in this study. Concern is often expressed that a different sample from the input variables will lead to different uncertainty and sensitivity analysis results. To provide a check, the analyses were repeated with a second independent Latin hypercube sample. Both samples were of size 100 and produced similar results.

The dominant variables were identified with procedures based on PRCCs and stepwise regression analysis. Several checks were then performed to provide further verification of the importance of these variables. Setting the dominant variables to best-estimate values led to a substantial reduction in uncertainty. Further, with the dominant variables set to best-estimate values, sensitivity analyses were performed to provide an indication of what would become the new set of dominant variables if the uncertainty in the initial set of dominant variables could be substantially reduced or eliminated. 
In addition, the effects of different choices for best-estimate values were investigated. When the best-estimate values for the dominant variables were changed, the uncertainty in the predicted variables remained small but the actual location of the uncertainty distributions showed considerable variability. In contrast, when the dominant variables were allowed to vary and the less important variables were set to best-estimate values, little effect on the uncertainty in the predicted variables resulted.

Concern is often expressed about the distributions assigned to input (i.e., independent) variables in sampling-based sensitivity analyses because of the possibility that the resultant variable rankings will be highly dependent on these distributions. As a check, the analyses presented in this report were repeated with the variables assigned first left-triangular distributions and then right-triangular distributions. The sensitivity analysis results obtained with these two distributions were quite similar to the results obtained with the original uniform and loguniform distributions. Thus, maintaining the ranges in use and switching between emphasizing the left and right ends of these ranges does not have a large effect on the sensitivity analysis results in this presentation. However, it should be recognized that extreme changes in distributions may cause substantial changes in sensitivity analysis results. For example, the results given in this report of the effects of assigning the dominant variables their bestestimate values can be viewed as a redefinition of their distributions in which the density functions become Dirac delta (i.e., impulse) functions.

This analysis used rank-transformed data, which were found to yield better sensitivity analysis results than raw (i.e., untransformed) data. The logarithmic transformation is another possible transformation. Logarithmic transformations are not very convenient for the analysis of CCDFs owing to the large number of zeros present in the analysis. However, the mean consequence results obtained from CCDFs were always nonzero in this analysis. Sensitivity analyses of these mean results with ranktransformed data and logarithmically transformed data yielded similar rankings of variable importance. 


\section{References}

1. U. S. Nuclear Regulatory Commission, Severe Accident Risks: An Assessment For Five U.S. Nuclear Power Plants, USNRC, Washington, DC, NUREG-1150, final summary report, December, 1990.

2. Bertucio, R. C. and Julius, J. A., Analysis of Core Damage Frequency From Internal Events, Surry Unit 1, Sandia National Laboratories, Albuquerque, NM, NUREG/CR-4550, SAND862084, Volume 3, Rev. 1, Parts 1 and 2, 1990.

3. Bohn, M. P., et al., NUREG-1150 External Event Risk Analyses: Surry Power Station, Sandia National Laboratories, Albuquerque, NM, NUREG/CR-4550, SAND86-2084, Volume 3, Rev. 1, Part 3, 1990.

4. Breeding, R. J., et al., Evaluation of Severe Accident Risks: Surry Unit 1, Sandia National Laboratories, Albuquerque, NM, NUREG/CR-4551, SAND86-1309, Volume 3, Rev. 1, 1990.

5. Breeding, R. J., et al., "The NUREG-1150 Probabilistic Risk Assessment for the Surry Nuclear Power Station," Nuclear Engineering and Design, 135:29-59, 1992.

6. Kolaczkowki, A. M., et al., Analysis of Core Damage Frequency From Internal Events, Peach Bottom, Unit 2, Sandia National Laboratories, Albuquerque, NM, NUREG/CR-4550, SAND862084, Volume 4, Rev. 1, Parts 1 and 2, 1990.

7. Bohn, M. P., et al., NUREG-1150 External Event Risk Analyses, Peach Bottom Power Station, Sandia National Laboratories, Albuquerque, NM, NUREG/CR-4550, SAND86-2084, Volume 4, Rev. 1, Part 3, 1990.

8. Payne, A. C., Jr., et al., Evaluation of Severe Accident Risks: Peach Bottom. Unit 2, Sandia National Laboratories, Albuquerque, NM, NUREG/CR-4551, SAND86-1309, Volume 4, Rev. $1,1990$.

9. Payne, A. C., Jr., et al., "The NUREG-1150 Probabilistic Risk Assessment for the Peach Bottom Atomic Power Station," Nuclear Engineering and Design, 135:61-94, 1992.

10. Bertucio, R. C. and Brown, S. R., Analysis of Core Damage Frequency From Internal Events, Sequoyah Unit 1, Sandia National Laboratories, Albuquerque, NM, NUREG/CR-4550, SAND 86-2084, Volume 5, Rev. 1, Parts 1 and 2, 1990.

11. Gregory, J. J., et al., Evaluation of Severe Accident Risks: Sequoyah Unit 1, Sandia National Laboratories, Albuquerque, NM, NUREG/CR-4551, SAND86-1309, Volume 5, Rev. 1, 1990.

12. Gregory, J. J., et al., "The NUREG-1150 Probabilistic Risk Assessment for the Sequoyah Nuclear Plant," Nuclear Engineering and Design, 135:95-115, 1992.

13. Drouin, M. T., et al., Analysis of Core Damage Frequency from Internal Events, Grand Gulf, Sandia National Laboratories, Albuquerque, NM, NUREG/CR-4551, SAND86-2084, Volume 5, Rev. 1, Parts 1 and 2, 1990. 
References

14. Brown, T. D., et al., Evaluation of Severe Accident Risks: Grand Gulf, Sandia National Laboratories, Albuquerque, NM, NUREG/CR-4551, SAND86-1309, Volume 6, Rev. 1, 1990.

15. Brown, T. D., et al., "The NUREG-1150 Probabilistic Risk Assessment for the Grand Gulf Nuclear Station," Nuclear Engineering and Design, 135:117-137, 1992.

16. Sattison, M. B. and Hall, K. W., Analysis of Core Damage Frequency: Zion, Unit 1, Internal Events, Idaho National Engineering Laboratory, Idaho Falls, ID, NUREG/CR-4550, EEG-2554, Vol. 7, Rev. 1, 1990.

17. Park, C. K., et al., Evaluation of Severe Accident Risks: Zion, Unit 1, Brookhaven National Laboratory, Upton, NY, NUREG/CR-4551, Volume 1, Rev. 1, BNL/NUREG-5209, 1993.

18. U.S. Nuclear Regulatory Commission, Reactor Safety Study -- An Assessment of Accident Risks in U.S. Commercial Nuclear Power Plants, USNRC, Washington, DC, WASH-1400 (NUREG75/014), 1975.

19. Lewis, H. W., et al., Risk Assessment Review Group Report to the U.S. Nuclear Regulatory Commission, USNRC, Washington, DC, NUREG/CR-0400, 1978.

20. Ericson, D. M., et al., Analysis of Core Damage Frequency: Methodology Guidelines, Sandia National Laboratories, Albuquerque, NM, NUREG/CR-4550, SAND86-2084, Volume 1, Rev. $1,1990$.

21. Gorham, E. D., et al., Evaluation of Severe Accident Risks: Methodology for Accident Progression, Source Term, Consequence, Risk Integration, and Uncertainty Analyses, Sandia National Laboratories, Albuquerque, NM, NUREG/CR-4551, SAND86-1309, Volume 1, Rev. $1,1993$.

22. Breeding, R. J., et al., "Summary Description of the Methods Used in the Probabilistic Risk Assessments for NUREG-1150," Nuclear Engineering and Design, 135:1-27, 1992.

23. Helton, J. C. and Breeding, R. J., "Calculation of Reactor Accident Safety Goals," Reliability Engineering and System Safety, 39:129-158, 1993.

24. Ortiz, N. R., et al., "Use of Expert Judgment in NUREG-1150," Nuclear Engineering and Design, 126:313-331, 1991.

25. Hora, S. C. and Iman, R. L., "Expert Opinion in Risk Analysis: the NUREG-1150 Methodology," Nuclear Science and Engineering, 102:323-331, 1989.

26. Wheeler, T. A., et al., Analysis of Core Damage Frequency From Internal Events: Expert Judgment Elicitation, Sandia National Laboratories, Albuquerque, NM, NUREG/CR-4550, SAND86-2084, Volume 2, Rev. 1, 1990.

27. Harper, F. T., et al., Evaluation of Severe Accident Risks: Quantification of Major Input Parameters, Experts' Determination of In-vessel Issues, Sandia National Laboratories, Albuquerque, NM, NUREG/CR-4551, SAND86-1309, Volume 2, Rev. 1., Part 1, 1990. 
28. Harper, F. T., et al., Evaluation of Severe Accident Risks: Quantification of Major Input Parameters, Experts' Determination of Containment Loads and Molten Core-Containment Interaction Issues, Sandia National Laboratories, Albuquerque, NM, NUREG/CR-4551, SAND86-1309, Volume 2, Rev. 1, Part 2, 1991.

29. Breeding, R. J., et al., Evaluation of Severe Accident Risks: Quantification of Major Input Parameters, Experts' Determination of Structural Issues, Sandia National Laboratories, Albuquerque, NM, NUREG/CR-4551, SAND86-1309, Volume 2, Rev. 1, Part 3, 1992.

30. Harper, F. T., et al., Evaluation of Severe Accident Risks: Quantification of Major Input Parameters, Experts' Determination of Source Term Issues, Sandia National Laboratories, Albuquerque, NM, NUREG/CR-4551, SAND86-1309, Volume 2, Rev. 1, Part 4, 1992.

31. Harper, F. T., et al., Evaluation of Severe Accident Risks: Quantification of Major Input Parameters; Supporting Material, Sandia National Laboratories, Albuquerque, NM, NUREG/CR4551, SAND86-1309, Volume 2, Rev. 2, Part 5, available at USNRC Public Document Room.

32. Harper, F. T., et al., Evaluation of Severe Accident Risks: Quantification of Major Input Parameters, Determination of Parameter Values not Quantified by Expert Panels, Sandia National Laboratories, Albuquerque, NM, NUREG/CR-4551, SAND86-1309, Volume 2, Rev. 1, Part 6, available at USNRC Public Document Room.

33. Chanin, D. I., et al., MELCOR Accident Consequence Code System (MACCS): User's Guide, Sandia National Laboratories, Albuquerque, NM, NUREG/CR-4691, SAND 86-1562, Volume $1,1990$.

34. Jow, H.-N., et al., MELCOR Accident Consequence Code System (MACCS): Model Description, Sandia National Laboratories, Albuquerque, NM, NUREG/CR-4691, SAND861562, Volume 2, 1990.

35. Rollstin, J. A., et al., MELCOR Accident Consequence Code System (MACCS): Programmer's Reference Manual, Sandia National Laboratories, Albuquerque, NM, NUREG/CR-4691, SAND86-1562, Volume 3, 1990.

36. Sprung, J. L., et al., Evaluation of Severe Accident Risks: Quantification of Major Input Parameters, MACCS Inputs, Sandia National Laboratories, Albuquerque, NM, NUREG/CR4551, SAND86-1309, Volume 2, Rev. 1, Part 7, 1990.

37. Helton, J. C., et al., "An Exploratory Sensitivity Study With the MACCS Reactor Accident Consequence Model," Reliability Engineering and System Safety, 36:137-164, 1992.

38. Madni, I. K., et al., "Assessment of Uncertainties in Early Off-Site Consequences From Nuclear Reactor Accidents," Nuclear Technology, 90:63-77, 1990.

39. Kastenberg, W. E., et al., Findings of the Peer Review Panel on the Draft Reactor Risk Reference Document, NUREG-1150, Lawrence Livermore National Laboratory, Livermore, CA, NUREG/CR-5113, 1988. 
40. Kocher, D. C., et al., "Sensitivity and Uncertainty Studies of the CRAC2 Computer Code," Risk Analysis, 7:497-507, 1987.

41. Alpert, D. J., et al., A Demonstration Uncertainty/Sensitivity Analysis Using the Health and Economic Consequence Model CRAC2, Sandia National Laboratories, Albuquerque, NM, NUREG/CR-4199, SAND84-1824, 1985.

42. Rountree, S. L. K. and Hatch, S. W., "Evaluation of the Sensitivity of Reactor Risks to Uncertainties," In Proceedings of International Meeting on Light Water Reactor Severe Accident Evaluation, Cambridge, MA, 28 August - 1 September 1983, pp. 17.6-1 to 17.6-7, American Nuclear Society, La Grange Park, IL, 1983.

43. Miller, C. W. and Little, C. A., Review of Uncertainty Estimates Associated with Models for Assessing the Impact of Breeder Reactor Radioactivity Releases, Oak Ridge National Laboratory, Oak Ridge, TN, ORNL-5832, 1982.

44. Slinn, W. G. N., "Meteorological Aspects of the Reactor Safety Study Requiring Further Study," in Symposium on Intermediate-Range Atmospheric-Transport Processes and Technology Assessment, pp. 215-220, Oak Ridge National Laboratory, Oak Ridge, TN, 1981.

45. Jones, J. A., et al., "An Uncertainty Analysis Using the NRPB Accident Consequence Code MARC," In Proceedings of Seminar on Methods and Codes for Assessing the Off-Site Consequences of Nuclear Accidents, Athens, May 1990, pp. 929-948, edited by G. N. Kelly and F. Luykx, Commission of the European Communities, 1991.

46. Crick, M. J., et al., Uncertainty Analysis of the Foodchain and Atmospheric Dispersion Models of MARC, National Radiological Protection Board, Chilton, UK, NRPB-R184, 1988.

47. Crick, M. J. and Jones, J. A., "Uncertainty Analysis of Selected Modules of the MARC Code," in Proceedings of CEC Workshop on Methods for Assessing the Off-Site Radiological Consequences of Nuclear Accidents, Luxembourg, 15-19 April 1985, pp. 851-868, ed. F. Luykx and J. Sinnaeve, Commission of the European Communities, Luxembourg, 1986.

48. Fischer, F., et al., Uncertainty and Sensitivity Analyses of the Complete Program System UFOMOD and of Selected Submodels, Kernforschungszentrum Karlsruhe, Karlsruhe, Federal Republic of Germany, KfK 4627, 1990.

49. Fischer, F., et al., Uncertainty Analyses of the Countermeasures Module of the Program System UFOMOD, Kernforschungszentrum Karlsruhe, Karlsruhe, Federal Republic of Germany, KfK 4472, 1989.

50. Fischer, F., et al., Uncertainty Analyses for the Atmospheric Submodel of UFOMOD with Emphasis on Parameter Correlations, Kernforschungszentrum Karlsruhe, Karlsruhe, Federal Republic of Germany, KfK 4447, 1989.

51. Fischer, F., et al., Analysis of Uncertainties Caused by the Atmospheric Dispersion Model in Accident Consequence Assessments with UFOMOD, Kernforschungszentrum Karlsruhe, Karlsruhe, Federal Republic of Germany, KfK 4262, 1988. 
52. Fischer, F. and Erhardt, J., Uncertainty Analysis with a View Towards Applications in Accident Consequence Assessments, Kernforschungszentrum Karlsruhe, Karlsruhe, Federal Republic of Germany, KfK 3906, 1985.

53. Hofer, E. and Krzykacz, B., Uncertainty Analysis of the Computational Assessment of the Radiological Consequences of Nuclear Accidents, Part 2, Gesellschaft fuer Reaktorsicherheit, Garching, Federal Republic of Germany, 1985.

54. Hofer, E. and Krzykacz, B., Uncertainty Analysis of the Computational Assessment of the Radiological Consequences of Nuclear Accidents, Part 1, Gesellschaft fuer Reaktorsicherheit, Garching, Federal Republic of Germany, 1984.

55. Jones, J. A., et al., MARC-2A. The 1989-90 Version of the MARC Program, Chilton, UK, NRPB-M222, 1990.

56. Ehrhardt, J., et al., "Structure, Important Features and Illustrative Results of the New UFOMOD Program System for Assessing the Radiological Consequences of Nuclear Accidents," Nuclear Technology, 95:177-195, 1991.

57. Ehrhardt, J., et al., The Program System UFOMOD for Assessing the Consequences of Nuclear Accidents, Kernforschungszenstrum Karlsruhe, Karlsruhe, Federal Republic of Germany, KfK 4330, October, 1988.

58. Kelly, G. N., COSYMA, A New Programme Package for Accident Consequence Assessment, CEC, Luxembourg, EUR 13028 EN, 1991.

59. Hasemann, I. and Jones, J., compilers, COSYMA: User's Guide, CEC, Brussels, EUR 13045, KfK 4331B, 1990.

60. Harper, F. T., et al., Joint USNRC/CEC Consequence Uncertainty Study: Summary of Objectives, Approach, Application, and Results for the Dispersion and Deposition Uncertainty Assessment, Sandia National Laboratories, Albuquerque, NM, NUREG/CR-6244, SAND941453, December 1994.

61. Cooke, R., Expert Judgement Study on Atmospheric Dispersion and Deposition, Delft University of Technology, Delft, Reports of the Faculty of Technical Mathematics and Informatics No. 91$81,1991$.

62. Helton, J. C., " Risk, Uncertainty in Risk, and the EPA Release Limits for Radioactive Waste Disposal," Nuclear Technology, 101:18-39, 1993.

63. International Atomic Energy Agency, Evaluating the Reliability of Predictions Made Using Environmental Transfer Models, Vienna, Austria, Safety Series Report No. 100, 1989.

64. Parry, G. W., "On the Meaning of Probability in Probabilistic Safety Assessment," Reliability Engineering and System Safety, 23:309-314, 1988.

65. Paté-Cornel1, M. E., "Probability and Uncertainty in Nuclear Safety Decisions," Nuclear Engineering and Design, 93:319-327, 1986. 
66. Stern, E. and Tadmor, J., "Uncertainty Bands in CCDF Risk Curves; Their Importance in Decision Making Processes," Proceedings of ANS/ENS International Topical Meeting on Probabilistic Safety Methods and Applications, pp. 22.1-22.9, American Nuclear Society, LaGrange Park, IL, 1985.

67. Vessely, W. E. and Rasmussen, D. M., "Uncertainties in Nuclear Probabilistic Risk Analyses," Risk Analysis , 4:313-322, 1984.

68. Kaplan, S. and Garrick, B. J., "On the Quantitative Definition of Risk," Risk Analysis, 1:11-27, 1981.

69. Hammersley, J. M. and Handscomb, D. C., Monte Carlo Methods, Metheun, London, 1964.

70. McKay, M. D., et al., "A Comparison of Three Methods for Selecting Values of Input Variables in the Analysis of Output From a Computer Code," Technometrics, 21:239-245, 1979.

71. Helton, J. C., et al., Sensitivity Analysis Techniques and Results for Performance Assessment at the Waste Isolation Pilot Plant, Sandia National Laboratories, Albuquerque, NM, SAND90$7103,1991$.

72. Helton, J. C., "Uncertainty and Sensitivity Analysis Techniques for Use in Performance Assessment for Radioactive Waste Disposal, " Reliability Engineering and System Safety, 42:327$367,1993$.

73. Ritchie, L. T., et al., CRAC2 Model Description, Sandia National Laboratories, Albuquerque, NM, NUREG/CR-2552, SAND82-0342, 1984.

74. Hall, D. J. and Waters, R. A., Further Experiments on a Buoyant Emission from a Building, Warren Spring Laboratory, Stevenage, England, LR 567 (PA), 1986.

75. Briggs, G. A., Plume Rise Predictions, Environmental Research Laboratories, U. S. Department of Commerce, National Oceanic and Atmospheric Administration, 1975.

76. Hanna, S. R., et al., Handbook on Atmospheric Diffusion, U. S. Department of Energy, Washington, DC, DOE/TIC-11223, 1982.

77. USNRC, "Environmental Transport and Consequence Analysis," PRA Procedures Guide, Vol. II, Chapter 9, NUREG/CR-2300, 1983.

78. CEC, Radiation Protection: Methods for Assessing the Off-Site Radiological Consequences of Nuclear Accidents, Commission of the European Communities, Luxembourg, EUR 10243 EN, 1986.

79. Kao, S. K., "Theories of Atmospheric Transport and Diffusion," Atmospheric Sciences and Power Production, edited by D. Randerson, U. S. Department of Energy, Washington, DC, DOE/TIC-27601, pp. 189-239, 1984. 
80. Holzworth, G. C., Mixing Heights, Wind Speeds, and Potential for Urban Air Pollution Throughout the Contiguous United States, U. S. Environmental Protection Agency, Office of Air Programs, Research Triangle Park, NC, AP-101, 1972.

81. Turner, D. B., Workbook of Atmoshperic Dispersion Estimates, U. S. Department of Health, Education and Welfare, Washington, DC, PSH-999-AP-26, 1970.

82. Brenk, H. D. and Vogt, K. J., "The Calculation of Wet Deposition from Radioactive Plumes," Nuclear Safety, 22:362-371, 1981.

83. Sehmel, G. A., "Deposition and Resuspension," Atmospheric Sciences and Power Production, edited by D. Randerson, U. S. Department of Energy, Washington, DC, DOE/TIC-27601, pp. 533-583, 1984.

84. Gale, H. J., et al., "Weathering of Caesium-137 in Soil," Nature, 201:257-261, 1964.

85. Helton, J. C., et al., "Contamination of Surface-Water Bodies After Reactor Accidents by the Erosion of Atmospherically Deposited Radionuclides," Health Physics, 48:757-771, 1985.

86. Healy, J. W., "Radioactive Cloud Dose Calculations," Atmospheric Sciences and Power Production, edited by D. Randerson, U.S. Department of Energy, Washington, DC, DOE/TIC27601, pp. 685-745, 1984.

87. Runkle, G. E. and Ostmeyer, R. M., An Assessment of Dosimetry Data for Accidental Radionuclide Releases from Nuclear Reactors, Sandia National Laboratories, Albuquerque, NM, NUREG/CR-4185, SAND85-0283, 1985.

88. Kocher, D. C., "Dose Rate Conversion Factors for External Exposure to Photons and Electron Radiation from Radionuclides Occuring in Routine Releases from Nuclear Fuel Cycle Facilities," Health Physics, 38:543-621, 1980.

89. Evans, J. S., Health Effects Models for Nuclear Power Plant Accident Consequence Analysis, Part I, Introduction, Integration, and Summary, Sandia National Laboratories, Albuquerque, NM, NUREG/CR-4214, Rev. 1, SAND85-7185, 1989.

90. Abrahamson, S., et al., Health Effects Models for Nuclear Power Plant Accident Consequence Analysis, Modifications of Models Resulting from Recent Reports on Health Effects of Ionizing Radiation, Low LET Radiation, Part II: Scientific Basis for Health Effects Models, Lovelace Biomedical and Environmental Research Institute, Albuquerque, NM, NUREG/CR-4214, Rev. 1, Part II, Addendum 1, LMF-132, 1991.

91. BEIR, The Effects on Populations of Exposure to Low Levels of Ionizing Radiation, Report of the Advisory Committee on the Biological Effects of Ionizing Radiation, National Academy of Sciences, Washington, DC, 1980.

92. NCRP, Influence of Dose and Its Distribution in Time on Dose-Response Relationships for LowLET Radiations, National Council on Radiation Protection and Measurements, Washington, DC, NCRP Report 64, 1980. 
93. UNSCEAR, Sources and Effects of Ionizing Radiation, United Nations Scientific Committee on Atomic Radiation, United Nations, NY, 1977.

94. Burke, R. P., et al., Economic Risks of Nuclear Power Reactor Accidents, Sandia National Laboratories, Albuquerque, NM, NUREG/CR-3673, SAND84-0178, 1984.

95. Iman, R. L., et al., "A Methodology for Grouping Source Terms for Consequence Calculations in Probabilistic Risk Assessments," Risk Analysis, 10:507-520, 1990.

96. Iman, R. L., et al., PARTITION: A Program for Defining the Source Term/Consequence Analysis Interface in the NUREG-1150 Probabilistic Risk Assessments, Sandia National Laboratories, Albuquerque, NM, NUREG/CR-5253, SAND88-2940, 1990.

97. Helton, J. C., et al., "Probability of Containment Failure Mode for Fast Pressure Rise," Reliability Engineering and System Safety, 35:91-106, 1992.

98. Iman, R. L. and Helton, J. C., "The Repeatability of Uncertainty and Sensitivity Analyses for Complex Probabilistic Risk Assessments," Risk Analysis, 11:591-606, 1991.

99. Bennet, D., SANDIA-ORIGEN User's Manual, Sandia National Laboratories, Albuquerque, NM, NUREG/CR-0987, SAND79-0299, 1979.

100. Iman, R. L. and Conover, W. J., "A Distribution-Free Approach to Inducing Rank Correlation Among Input Variables," Communications in Statistics: Part B--Simulation and Computation, B11:311-334, 1982.

101. Iman, R. L. and Davenport, J. M., "Rank Correlation Plots for Use with Correlated Input Variables," Communications in Statistics: Part B--Simulation and Computation, B11:335-360, 1982.

102. Slinn, W. G. N., "Precipitation Scavenging," Atmospheric Science and Power Production, edited by D. Randerson, U.S. Department of Energy, Washington, DC, DOE/TIC-27601, pp 466-532, 1984.

103. Briggs, G. A., "Plume Rise and Buoyancy Effects," Atmospheric Science and Power Production, edited by D. Randerson, U.S. Department of Energy, Washington, DC, DOE/TIC-27601, pp. 327-366, 1984.

104. Barr, S. and Clements, W. E., "Diffusion Modeling: Principles of Application," Atmospheric Science and Power Production, edited by D. Randerson, U.S. Department of Energy, Washington, DC, DOE/TIC-27601, pp. 584-619, 1984.

105. Gifford, F. A., "Turbulent Diffusion-Typing Schemes: A Review," Nuclear Safety, 17:68-86, 1976.

106. Iman, R. L. and Shortencarier, M. J., A FORTRAN 77 Program and User's Guide for the Generation of Latin Hypercube and Random Samples For Use With Computer Models, Sandia National Laboratories, Albuquerque, NM, NUREG/CR-3624, SAND83-2365, 1984. 
107. Iman, R. L., et al., A FORTRAN 77 Program and User's Guide for the Calculation of Partial Correlation and Standardized Regression Coefficients, Sandia National Laboratories, Albuquerque, NM, NUREG/CR-4122, SAND85-0044, 1985.

108. Iman, R. L., et al., Stepwise Regression With PRESS and Rank Regression (Program user's Guide), Sandia National Laboratories, Albuquerque, NM, SAND79-1472, 1980.

109. Allen, D. M., The Prediction Sum of Squares as a Criterion for Selecting Predictor Variables, Report No. 23, Department of Statistics, University of Kentucky, Lexington, KY, 1971.

110. Iman, R. L. and Conover, W. J., "The Use of the Rank Transform in Regression," Technometrics, 21:499-509, 1979.

111. Iman, R. L. and Conover, W. J., "A Measure of Top-Down Correlation," Technometrics, 29:351-357, 1987.

112. Helton, J. C. and Iman, R. L., "Sensitivity Analysis of a Model for the Environmental Movement of Radionuclides," Health Physics, 42:565-584, 1982.

113. Helton, J. C., et al., "Sensitivity Analysis of the Asymptotic Behavior for a Model of the Environmental Movement of Radionuclides," Ecological Modelling, 28:243-278, 1985.

114. Helton, J. C., et al., "Uncertainty and Sensitivity Analysis of a Model for Multicomponent Aerosol Dynamics," Nuclear Technology, 73:320-342, 1986.

115. Helton, J. C., et al., "Uncertainty and Sensitivity Analysis of a Dry Containment Test Problem for the MAEROS Aerosol Model," Nuclear Science and Engineering, 102:22-42, 1989.

116. Helton, J. C. and Johnson, J. D., "An Uncertainty/Sensitivity Study for the Station Blackout Sequence at a Mark I Boiling Water Reactor," Reliability Engineering and System Safety, 26:293$328,1989$.

117. Helton, J. C., et al., "Uncertainty and Sensitivity Analysis Results Obtained in a Preliminary Performance Assessment for the Waste Isolation Pilot Plant," Nuclear Science and Engineering, 114:286-331, 1993.

118. McKay, M. D., et al., "An Alternative View of Sensitivity in the Analysis of Computer Codes," 1992 Proceedings of the Section on Physical and Engineering Sciences of the American Statistical Association, American Statistical Association, Washington, DC, pp. 87-92, 1992.

119. McKay, M. D. and Beckman, R. J., "A Procedure for Assessing Uncertainty in Models," Proceedings of PSAM II, An International Conference Devoted to the Advancement of Systembased Methods for the Design and Operation of Technological Systems and Processes, San Diego, CA, March 20-25, 1994, edited by G. E. Apostolakis and J. S. Wu, Vol. 1, pp. 9-13 to 9-18, 1994. 


\section{Distribution}

U.S. Nuclear Regulatory Commission (10)

Attn: C. Lui

Mail Stop T9 F31

U.S. Nuclear Regulatory Commission

Washington, DC 20555

U.S. Nuclear Regulatory Commission

Attn: A. Buslik

Mail Stop T9 F31

U.S. Nuclear Regulatory Commission

Washington, DC 20555

B. John Garrick

4590 MacArthur Blvd., \#400

Newport Beach, CA 92660-2027

Clement International Corp.

Attn: Christopher Whipple

160 Spear St.

Suite 1380

San Francisco, CA 94105-1535

Future Resources

Associates, Inc.

Attn: Robert J. Budnitz

2000 Center Street

Suite 418

Berkeley, CA 94704

Battelle Columbus Laboratories (3)

Attn: Paul Baybutt

R. S. Denning

Steve Unwin

505 King Avenue

Columbus, OH 43201

Battelle Northwest

Attn: Pamela Doctor

P.O. Box 999

Richland, WA 99352
Los Alamos National Laboratory (2) Analysis and Assessment Division, A-1, MS F600

Attn: M. D. McKay M. A. Meyer

P.O. Box 1663

Los Alamos, NM 87544

Oak Ridge National Laboratory

Computer Sciences

Attn: Darryl Downing

Building 2029, P.O. Box X

Oak Ridge, TN 37830

Oak Ridge National Laboratory (3)

Engineering Physics and Mathematics

Division

Attn: E. M. Oblow Francois G. Pin

P.O. Box X

Brian A. Worley

Oak Ridge, TN 37820

Oak Ridge National Laboratory (2)

Environmental Sciences Division

Attn: Steve Bartell

P.O. Box X

R. H. Gardner

Oak Ridge, TN 37830

Oak Ridge National Laboratory (2)

Health and Safety Research Division

Attn: David G. Kocher

P.O. Box X

F. O. Hoffman

Oak Ridge, TN 37830

Science Applications International

Corporation (2)

Attn: John Young

Dave Lester

18706 North Creek Parkway

Suite 110

Bothell, WA 98011 
Science Applications International Coporation

Attn: David C. Aldrich

1710 Goodridge Drive

P.O. Box 1303

McLean, VA 22102

Science Applications International Corporation

Attn: Mark D. Otis

P.O. Box 50697

101 S. Park Ave.

Idaho Falls, ID 83405

D. G. Cacuci

Dept. of Nuclear Engineering

University of Illinois

103 South Goodwin Avenue

Urbana, IL 61801-2984

W. J. Conover

College of Business Administration

Texas Tech University

Lubbock, TX 79409

John Evans

Harvard School of Public Health

665 Huntington Avenue

Boston, MA 02115

F. E. Haskin

Dept. of Chemical \& Nuclear Engr.

University of New Mexico

Albuquerque, NM 87131

Max Henrion

Dept. of Engineering and Public

Policy

Carnegie-Mellon University

Pittsburgh, PA 15213

Stan Kaplan

Pickard, Lowe and Garrick, Inc.

2260 University Drive

Newport Beach, CA 92660

Thomas B. Kirchner

Natural Resource Ecology Lab

Colorado State University

Fort Collins, CO 85023
Greg McRae

Dept. Of Chemical Engineering

Carnegie-Mellon University

Pittsburgh, PA 15213

M. Granger Morgan

Dept. of Engineering and Public

Policy

Carnegie-Mellon University

Pittsburgh, PA 15213

H. Rabitz

Department of Chemistry

Princeton University

Princeton, NJ 08544

K. H. Reckhow

School of Forestry and Environmental

Studies

Duke University

Durham, NC 27706

S. K. Seaholm

University of Minnesota

Div. of Health Computer Science

Box 511 UMHC

420 Delaware St., SE

Minneapolis, MN 55455

F. Ward Whicker

Dept. of Radiology and Radiation

Biology

Colorado State University

Fort Collins, Co 80523

Timothy M. Barry

Office of Policy, Planning, and Evaluation

PM 223X U.S. EPA

Washington, DC 20460

SENES Oak Ridge, Inc. (2)

Attn: Steve M. Bartell

F. O. Hoffman

Center for Risk Analysis

677 Emory Valley Road, Suite C

Oak Ridge, TN 37830 
Kenneth T. Bogen

Environmental Sciences Division

Lawrence Livermore National Laboratory

Livermore, CA 94550

David Burmaster, President

Alceon Corporation

P.O. Box 2669

Harvard Square Station

Cambridge, MA 02239

Adam Finkel

Center for Risk Management

Resources for the Future

1616 P Street, NW

Washington, DC 20036

Yacov Y. Haimes

Center for Risk Management of Engineering

Systems

D111 Thornton Hall

University of Virginia

Charlottsville, VA. 22901

Nicholas Matalas

Water Resources Division

Geological Survey

U.S. Department of the Interior

Reston, VA 22092

Elisabeth Pate-Cornell

Industrial Engineering \& Engineering Mgmt.

Stanford University

Stanford, CA 94305

Robert L. Sielken

Sielken, Inc.

Suite 410

3833 Texas Avenue

Bryan, TX 77802

Alison Taylor

Dept. of Environmental Health

Harvard School of Public Health

Bldg. 1 Room 1308

664 Huntington Ave.

Boston, MA 02115
University of California (2)

Mechanical, Aerospace, and

Nuclear Engineering Dept.

Attn: W. Kastenberg

G. Apostolakis

5532 Boelter Hall

Los Angeles, CA 90024

University of Hawaii at Hilo

Attn:. S. Hora

Business Administration

Hilo, HI 96720-4091

Gordon S. Linsley

Division of Nuclear Fuel Cycle and

Waste Management

International Atomic Energy Agency

P.O. Box 100

A-1400 Vienna

AUSTRIA

J. Marivoet

Centre d'Etudes de l'Energie

Nucleaire

CEN/SCK

Boeretang 200

B-2400 Mol

BELGIUM

Eduard Hofer

Gesellschaft fur Reaktorsicherheit

(GRS) MBH

Forschungsgelande

D-8046 Garching

GERMANY

Oak Ridge National Laboratory (2)

Attn: Steve Fisher

MS-8057

Sherrel Greene

P.O. Box 2009

Oak Ridge, TN 37831

Westinghouse Savannah River Company (2)

Attn: Kevin O'Kula

Jackie East

Safety Technology Section

1991 S. Centennial Ave., Bldg. 1

Aiken, SC 29803 
Vern Peterson

Building T886B

EG \& G Rocky Flats

P.O. Box 464

Golden, CO 80402

Brookhaven National Laboratory (3)

Attn: Lev Neymotin Arthur Tingle Trevor Pratt

Building 130

Upton, NY 11973

EG \& G Idaho, Inc. (2)

Attn: Doug Brownson

Darrel Knudson

MS-2508

P.O. Box 1625

Idaho Falls, ID 83415

EG \& G, Idaho Inc. (2)

Attn: Art Rood

Mike Abbott

MS-2110

P.O. Box 1625

Idaho Falls, ID 83415

Los Alamos National Laboratory (2)

Attn: Desmond Stack Kent Sasser

$\mathrm{N}-6, \mathrm{~K}-557$

Los Alamos, NM 87545

Technadyne Engineering Consultants (3)

Attn: David Chanin Jeffery Foster

Walt Murfin

Suite A225

8500 Menual Blvd. NE

Albuquerque, NM 87112

David M. Brown

Paul C. Rizzo Associates, Inc.

300 Oxford Drive

Monroeville, PA 15146-2347
Westinghouse Electric Company (2)

Attn: John Iacovino

Burt Morris

Energy Center East, Bldg. 371

P.O. Box 355

Pittsburgh, PA 15230

Marc Rothschild

Halliburton NUS

1303 S. Central Ave.

Suite 202

Kent, WA 98032

Knolls Atomic Power Labortory (2)

Attn: Ken McDonough

Dominic Sciaudone

Box 1072

Schenectady, NY 12301

Mr. Dennis Strenge

Pacific Northwest Laboratory

RTO/125

P.O. Box 999

Richland, WA 99352

Mr. Fred Mann

Westinghouse Hanford Co.

W/A-53

P.O. Box 1970

Richland, WA 99352

Lawrence Livermore National Lab.

Attn: George Greenly

Marvin Dickerson

Rolf Lange

Livermore, CA 94550

Mr. Terry Foppe

Safety Analysis Engineering

Rocky Flats Plant

Energy Systems Group

Rockwell International Corp

P.O. Box 464

Golden, CO 80401 
Distribution

U.S. Environmental Protection Agency (2)

Attn: Allen Richardson Joe Logsdon

Office of Radiation Programs

Environmental Analysis Division

Washington, DC 20460

U.S. Department of Energy (2)

Attn: Ken Murphy (EH351)

Ed Branagan (EH332)

Washington, DC 20545

Mr. Robert Ostmeyer

U.S. Department of Energy

Rocky Flats Area Office

P.O. Box 928

Golden, CO 80402

Mr. Bruce Burnett:

CDRH (HFZ-60)

U.S. Department of Health and Human Services

Food and Drug Administration

5600 Fishers Lane

Rockville, MD 20857

Mr. Scott Bigelow

S-CUBED

2501 Yale SE, Suite 300

Albuquerque, NM 87106

David Black

American Electric Power

1 Riverside Plaza

Columbus, OH 43215

Gerald Davidson

Fauske and Associates, Inc.

16 W 070 West 83rd Street

Burr Ridge, IL 60521

Keith Woodard

Pickard, Lowe, and Garrick

Suite 730

1615 M. Street

Washington, DC 20056

Jim Mayberry

Ebasco Services

160 Chubb Ave.

Lyndhurst, NJ 07071
Mr. Mike Cheok

NUS

910 Clopper Road

Gaithersburg, MD 20878

Ken O'Brien

University of Wisconsin

Nuclear Engineering Dept.

153 Engineering Research Blvd.

Madison, WI 53706

Mr. Harold Careway

General Electric Co., M/C 754

175 Curtner Ave.

San Jose, CA 95129

Zen Mendoza

SAIC

5150 El Camino Real

Suite C31

Los Altos, CA 94022

Roger Blond

SAIC

20030 Century Blvd.

Suite 201

Germantown, MD 20874

John Luke

Florida Power \& Light

P.O. Box 14000

Juno Beach, FL 33408

Duke Power Co. (2)

Attn: Duncan Brewer Steve Deskevich

422 South Church Street

Charlotte, NC 28242

Mr. Griff Holmes

Westinghouse Electric Co.

Energy Center East

Bldg. 371

P.O. Box 355

Pittsburgh, PA 15230

Mr. Edward Warman

Stone \& Webster Engineering Corp.

P.O. Box 2325

Boston, MA 02107 
Distribution

Mr. William Hopkins

Bechtel Power Corporation

15740 Shady Grove Road

Gaithersburg, MD 20877

R. Toossi

Physical Research, Inc. 25500 Hawthorn Blvd.

Torrance, CA 90505

Bill Eakin

Northeast Utilities

Box 270

Hartford, CT 06141

Ian Wall

Electric Power Research Institute

3412 Hillview Avenue

Palo Alto, CA 94304

Jim Meyer

Scientech

11821 Parklawn Dr.

Suite 100

Rockville, MD 20852

Ray Ng

NUMARC

1776 Eye St. NW

Suite 300

Washington, DC 20006-2496

Robert Gobel

Clark University

Center for Technology, Environment and Development

950 Main St.

Worcester, MA 01610-1477

Ken Keith

TVA

W 20 D 201

400 West Summit Hill

Knoxville, TN 37092

Shengdar Lee

Yankee Atmoic Electric Company

580 Main St.

Bolton, MA 01740
Paul Govaerts

Studiecentrum voor Kernenergie

(SCK/CEN)

Boeretang, 200

B-2400 Mol

BELGIUM

S. Daggupaty

Environment Canada

4905 Dufferin Street

Downsview

Ontario, M3H 5T4

CANADA

Soren Thykier-Nielsen

Riso National Laboratory

Postbox 49

DK-4000 Roskile

DENMARK

Seppo Vuori

Technical Research Centre of Finland

Nuclear Engineering Laboratory

Lonnrotinkatu 37

P.O. Box 169

Sf-00181 Helsinki 18

FINLAND

Daniel Manesse

IPSN

Voite Postale 6

F-92265 Fontenay-auz-Roses CEDEX

FRANCE

John G. Kollas

Institute of Nuclear Technology and

Radiation Protection

N.R.C.P.S. "Domokritos"

P.O. Box 60228

GR-153 10 Aghia Paraskevi

Attiki

GREECE

ENEA/DISP (2)

Attn: Alvaro Valeri

Alfredo Bottino

Via Vitaliano Brancati, 48

00144 Roma EUR

ITALY 
Distribution

Mr. Hideo Matsuzuru

Tokai Research Establishment

Tokai-mur

Maka-gun

Ibaraki-ken, 319-11

JAPAN

Mr. Jan Van de Steen

KEMA Laboratories

Utrechtseweg, 310

Postbus 9035

NL-6800 ET Arnhem

NETHERLANDS

D. Eugenio Gil Lopez

Consejo de Seguridad Nuclear

Calle Justo Dorado, 11

E-28040 Madrid

SPAIN

Lennart Devell

Studsvik Nuclear

Studsvik Energiteknik AB

S-611 82 Nykoping

SWEDEN

Hanspeter Isaak

Abteilung Strahlenschutz

Hauptabteilung fur die Dicherheit

der Kernanlagen (HSK)

CH-5303 Wurenlingen

SWITZERLAND

Ephraim Asculai

Division of Nuclear Safety

Wagramestrasse, 5

P.O. Box 100

A-1400 Wien

AUSTRIA

Ulf Tveten

Enviornmental Physics Section

Institutt for Energiteknikk

Postboks 40

N-2007 Kjeller

NORWAY
M. K. Yeung

University of Hong Kong

Mechanical Engineering Dept.

Polfulam

HONG KONG

Leonel Canelas

New University of Lisbon

Quinta de Torre

2825 Monte de Caparica

PORTUGAL

Stephen Boult

Electrowatt Engineering Services (UK) Ltd.

Grandford House

16 Carfax, Horsham

West. Sussex RH12 1UP

ENGLAND

Nadia Soido Falcao Martins

Comissao Nacional de Energia Nuclear

R General Severianao 90 S/408-1

Rio de Janeiro

BRAZIL

Eli Stern

Israel AEC Licensing Div.

P.O. Box 7061

Tel-Aviv 61070

ISRAEL

Der-Yu Hsia

Atomic Energy Council

67, Lane 144

Keelung Road, Section 4

Taipei, Taiwan 10772

TAIWAN

Shankaran Nair

Central Electricity Generating Board

Berkeley Nuclear Laboratories

Berkeley

Gloucestershire CL13 9PB

UNITED KINGDOM

Paul Kayser

Division de la Radioprotection

1, Avenue des Archiducs

L-1135 Luxembourg-Belair

Luxembourg 
U.S. Nuclear Regulatory Commission

Attn: Richard Codell

Mail Stop 4-H-3

Washington, D.C. 20555

Andrea Saltelli

Commission of the European Communities

Joint Research Centre od Ispra

I-21020 Ispra (Varese)

ITALY

Radiation Protection Program CEC

Attn: G. Neale Kelly

Rue de al Loi, 200

B-1049 Bruxelles

BELGIUM

National Water Research Institute

Attn: E. Halfon

Canada Centre for Inland Waters

Burlington, Ontario

CANADA

BGA/ISH/ZBD

Attn: Anton Bayer

P.O. Box 1108

D-8042 Neuherberg

GERMANY

Gesellschaft fur Reaktorsicherheit

Attn: Bernard Krzykacz

D-8046 Garching

GERMANY

Kernforschungszentrum Karlsruhe/INR (2)

Attn: Joachim Ehrhardt

Friedmar Fischer

Postfach 3640

D-7500 Karlsruhe 1

GERMANY

Catholic University Brabant

Attn: J. P. C. Kleijnen

Tilburg

THE NETHERLANDS
Delft University of Technology

Dept. of Mathematics

Attn: Roger Cooke

Julianalaan 132

Delft

THE NETHERLANDS

Abtielung fur die Sicherheit der

Kernanlagen

Attn: S. Chakraborty

Eidgenossisches Amt fur

Energiewirtschaft

CH-5303

Wurenlingen

SWITZERLAND

The University of Reading

Department of Statistics

Attn: Derek J. Pike

Whiteknights

Reading RG6 2AN

UNITED KINGDOM

National Radiological Protection Board (3)

Attn: M. Crick

Marion Hill

J. A. Jones

Chilton, Didcot

Oxon OX11 ORQ

UNITED KINGDOM

United Kingdom Atomic Energy Authority

Attn: William Nixon

Safety \& Reliability Directorate

Wigshaw Lane

Culcheth

Warrington WA3 4NE

UNITED KINGDOM 